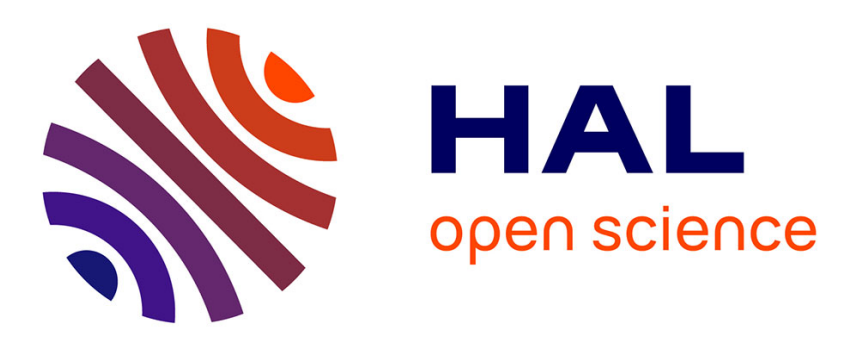

\title{
Control of an ultrahigh speed centrifugal compressor for the air management of fuel cell systems
}

Dongdong Zhao

\section{To cite this version:}

Dongdong Zhao. Control of an ultrahigh speed centrifugal compressor for the air management of fuel cell systems. Other. Université de Technologie de Belfort-Montbeliard, 2013. English. NNT: 2013BELF0220 . tel-01002037

\section{HAL Id: tel-01002037 https://theses.hal.science/tel-01002037}

Submitted on 5 Jun 2014

HAL is a multi-disciplinary open access archive for the deposit and dissemination of scientific research documents, whether they are published or not. The documents may come from teaching and research institutions in France or abroad, or from public or private research centers.
L'archive ouverte pluridisciplinaire HAL, est destinée au dépôt et à la diffusion de documents scientifiques de niveau recherche, publiés ou non, émanant des établissements d'enseignement et de recherche français ou étrangers, des laboratoires publics ou privés. 


\section{THESIS}

Presented at

The University of Technology of Belfort-Montbéliard for the degree of

DOCTOR OF PHILOSOPHY

By

Dongdong ZHAO

Control of an Ultra-high Speed Centrifugal Compressor for the Air Management of Fuel Cell Systems

\section{THESIS COMMITTEE:}

M. Mohamed Benbouzid - Professeur, LBMS, Uniersité de Brest, Brest

M. Demba Diallo — - Professeur, Université Paris Sud-IUT de Cachan, Paris

M. Bernard Davat - Professeur, GREEN, Université de Lorraine, Nancy.

M. Manfeng Dou - Professeur, Northwestern Polytechnical University, Chine

M. Mahesh Krishnamurthy - Assistant professor, Illinois Institute of Technology, USA

M. Abdellatif Miraoui - Professeur, UTBM

M. Fei Gao $\quad$ - Maître de conférences, UTBM

M. David Bouquain atre de conférences, UTBM

10th January 2014 



\begin{abstract}
Fuel cell is a power supply system, which takes advantage of the electro-chemical reaction between oxygen and hydrogen to produce electricity with water as its byproduct. Due to their lower pollution and high efficiency compared with fossil fuels, fuel cell systems are under extensive development for many power applications. Compared with high temperature fuel cells (such as molten carbonate fuel cells or solid oxide fuel cells), the proton exchange membrane fuel cell (PEMFC) is more suitable for automotive applications because of its low temperature working condition, thereby a fast startup.

Air compressor supplying the oxygen to the stack is an important component in the fuel cell systems. The compressor can consumes up to $20 \%$ of the generated power in the most severe cases. The selecting of the compressor and corresponding control are directly related to the performance of the fuel cell. The size and weight of the air compressor has to be reduced to make them more feasible for automotive applications. Moreover, the control of the air compression system is also an important issue, which affects the efficiency and the safety of the fuel cell. To avoid oxygen starvation of the stack, the mass flow of the supplied air has to be controlled appropriately according to the load demand. Meanwhile, the pressure should not have large deviations or ripples which may damage the stack membrane.

In this thesis, the requirements to the compressor for fuel cell applications are discussed. And several kinds of compressor are compared, including positive displacement types and dynamic superchargers. In the view of compactness, an ultra-high speed, up to $280,000 \mathrm{rpm}$, centrifugal compressor is adopted. The centrifugal compressor which is a kind of dynamics superchargers converts the kinetic energy of the air to the pressure. Compared with positive displacement compressors, it has the advantages of compactness, high efficiency and low noise, making it more suitable for automotive applications. However, the difficulty of the control as well as the surge
\end{abstract}


constraint obstructs its industrial implementation for fuel cells.

In this dissertation, The model of the air compression system is developed and the coupling between the model inputs and outputs are analyzed. The compressor map is measured and then fitted by a two hidden layer neural network model. The relative gain array (RGA) method is used for the coupling analysis. It shows that the coupling degree varies as the operation point changes because of the nonlinearity of the system.

The second part of this work focuses on solving the control problems to adapt the centrifugal compressor to the fuel cell system. The objective is to control the mass flow and pressure simultaneously according to the fuel cell load demand. The problem lies in the coupling between the mass flow control and pressure control because the variations of one variable will also lead to the deviation of the other one. The interaction between the two control loops declines the performance of the fuel cell system. Decoupling controllers which aim to eliminate the interaction between the inputs and outputs are more feasible for the centrifugal compression system control. A recently proposed disturbance decoupling control (DDC) is used for the centrifugal compression system. DDC treats the internal interactions as a disturbance and then eliminates them in the control. The performance of the DDC is compared with a decentralized sliding mode controller. Through the comparison of those two controllers, the results show that the proposed DDC performs better in both the steady state and dynamic conditions, making the centrifugal compressor is capable of applying to the fuel cell in automotive applications. On a hardware-in-the-loop (HIL) testbench, the proposed controller is validated with a $10 \mathrm{~kW}$ fuel cell model under varied load demands. Moreover, a surge avoidance method, namely reference limiter, is proposed to prevent the compressor from surging. The experimental results show that the operation is restricted to the right of the surge line. 


\section{RÉSUMÉ}

La pile à combustible est un système de production d'énergie, qui tire profit de la réaction chimique entre l'oxygène et l'hydrogène pour produire de l'électricité et de la chaleur tout en rejetant que de l'eau. En raison de leur pollution moindre par rapport aux carburants fossiles, les systèmes pile à combustible connaissent un développement important pour de nombreuses applications de puissance. Par rapport aux piles à combustible à haute température (comme les piles à combustible à carbonates fondus et les piles à combustible à oxydes solides), la pile à combustible à membrane échangeuse de protons (PEMFC) est plus appropriée pour les applications automobiles en raison de sa température de fonctionnement plus faible et de son temps de démarrage plus rapide.

Le compresseur d'air alimentant en oxygène la pile est un élément important dans les systèmes pile à combustible. Le compresseur peut consommer jusqu'à $20 \%$ de l'électricité produite dans les cas les plus défavorables. Le choix et le dimensionnement du compresseur, ainsi que son système de contrôle associé, sont directement liés à la performance du système global. La taille et le poids du système de compression d'air doivent être réduits pour le rendre plus adapté aux applications automobiles. En outre, le contrôle du système de compression d'air est également une problématique importante car il affecte l'efficacité et la sécurité de fonctionnement de la pile à combustible. Pour éviter une sous-alimentation en oxygène de la pile, le débit massique d'air fourni doit être géré de façon appropriée en fonction de la demande de la charge électrique. Pendant ce temps, la pression ne doit pas montrer de trop grandes variations ou ondulations qui peuvent endommager la membrane de la pile.

Dans ce mémoire, les exigences pour le compresseur d'air pour des applications automobiles sont présentées et plusieurs types de compresseurs sont comparés, y compris les compresseurs à déplacement positif et dynamique. Le compresseur centrifuge ultra-rapide (280 $000 \mathrm{tr} / \mathrm{min}$ ), compte tenu de sa compacité et de ses performances, 
a été retenu pour ces travaux. Le compresseur centrifuge, qui peut rentrer la famille des compresseurs dynamiques, convertit l'énergie cinétique de l'air en pression. Par rapport aux compresseurs volumétriques, il a les avantages de la compacité, une haute efficacité et un faible bruit. Cela le rend le plus adapté pour les applications automobiles. Cependant, la complexité du contrôle, due notamment à la contrainte de la ligne de pompage, gêne sa mise enœuvre industrielle dans les systèmes pile à combustible.

Dans cette thèse, un modèle du système de compression d'air est développéet le couplage entre les entrées et les sorties est analysé. Le compresseur est caractérisé puis sa cartographie est ajustée par un réseau de neurones à deux couches cachées. La méthode de la matrice de gain relatif (RGA) est utilisée pour l'analyse du couplage. Elle montre que le degré de couplage varie avec le point de fonctionnement, en raison de la non linéarité du système.

Ce travail se concentre enfin sur la résolution des problèmes de contrôle pour adapter ce compresseur centrifuge au système pile à combustible. L'objectif est de contrôler le débit massique et la pression simultanément, en fonction des variations de la charge électrique. Le problème réside dans le couplage entre la rgulation de débit massique et la régulation de la pression. La variation de l'une des deux variables entraine une variation de l'autre variable. L'interaction entre les deux boucles de contrôle diminue la performance du système. Comparativement aux contrôleurs décentralisés, les contrôleurs à découplage qui visent à éliminer l'interaction entre les entrées et les sorties sont plus adaptés pour les systèmes de compression centrifuges. Un contrôle découplage proposé récemment dans la littérature, nommé contrôle à découplage de perturbation (DDC), est utilisé pour le système de compression centrifuge. Le DDC traite les interactions internes comme une perturbation, puis les éliminent dans le contrôle. Les performances du DDC sont comparées à un dispositif de commande en mode glissant décentralisé. Grâce à la comparaison de ces deux contrôleurs, les résultats montrent que le DDC proposé est performant tant pour des cas stables que dynamiques. Le compresseur centrifuge est donc utilisable pour les systèmes pile à combustible automobiles. Sur un banc d'essai hardware-in-the-loop (HIL), le contrôleur proposé est validé avec un modèle de pile à combustible de $10 \mathrm{~kW}$ avec des demandes de charge variables. En outre, une méthode d'évitement d'instabilité, à savoir un limiteur de référence, est proposé pour empêcher le dépassement de la ligne de pompage du compresseur. Les résultats expérimentaux montrent que, dans tous les cas, la zone d'utilisation du com- 
presseur est bien cantonnée droite de la ligne de pompage. 
1. Introduction $\ldots \ldots \ldots \ldots \ldots \ldots \ldots \ldots \ldots \ldots \ldots$

1.1 Proton exchange membrane fuel cell $\ldots \ldots \ldots \ldots \ldots$

1.2 PEMFCs auxiliary components . . . . . . . . . . . . . . . 4

1.2.1 Fuel supply subsystem . . . . . . . . . . . . . . . 4

1.2.2 Humidification subsystem _ . . . . . . . . . . . . 5

1.2.3 Cooling subsystem $\ldots \ldots \ldots \ldots \ldots \ldots$

1.2.4 Power management subsystem . . . . . . . . . . . . . . 6

1.2.5 Air management subsystem _ . . . . . . . . . . . 7

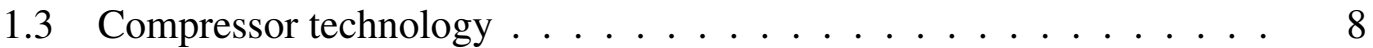

1.3.1 Positive displacement compressors . . . . . . . . . . . . 9

1.3.2 Dynamic compressors . . . . . . . . . . . . . . 10

1.3.3 Choice for PEM fuel cell system . . . . . . . . . . . . . . 13

1.4 Research objective and scope . . . . . . . . . . . . . . . . . . . 18

1.4.1 Control problem overview . . . . . . . . . . . . 18

1.4.2 Objectives and methods . . . . . . . . . . . . . . . . 21

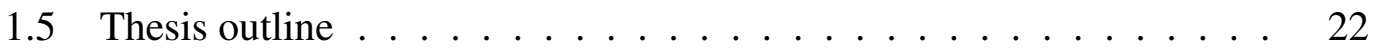

2. Air compression system modeling for PEMFC systems . . . . . . . . . 25

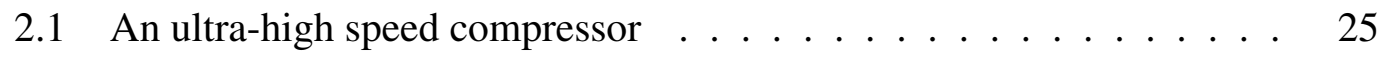

2.2 Compressor modeling . . . . . . . . . . . . . . . . 30

2.2.1 Compressor map modeling overview . . . . . . . . . . . 30

2.2.2 Compressor map measurement . . . . . . . . . . . . . . . . . 31

2.2.3 Neural network modeling _. . . . . . . . . . . 33

2.3 Manifold modeling . . . . . . . . . . . . . . . . . . . . . 36

2.4 Actuators modeling . . . . . . . . . . . . . . . . . . 39

2.5 Fuel cell stack model . . . . . . . . . . . . . . . . . . . . . . . . . 42

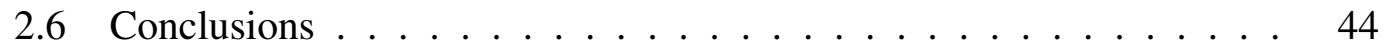


3. Controller design and simulation . . . . . . . . . . . . . . . . . . . 47

3.1 Introduction . . . . . . . . . . . . . . . . . . 47

3.2 Compressor coupling analysis . . . . . . . . . . . . . . 49

3.3 Choice of the controller . . . . . . . . . . . . . . 52

3.4 Disturbance decoupling control . . . . . . . . . . . . . 53

3.4.1 ADRC framework .................. 53

3.4 .2 DDC approach ....................... 54

3.4.3 ESO design for the air management system . . . . . . . . 57

3.4 .4 Control algorithm . . . . . . . . . . . . . . . 61

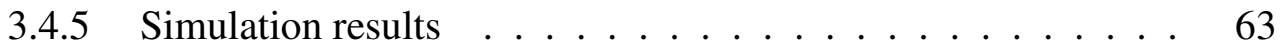

3.5 Sliding mode control . . . . . . . . . . . . . . . 67

3.5.1 Pressure control . . . . . . . . . . . . . . 68

3.5.2 Mass flow control . . . . . . . . . . . . . 70

3.6 Comparison by Simulations . . . . . . . . . . . . . . . . . . 71

3.6.1 Test with mass flow variations . . . . . . . . . . 72

3.6.2 Test with pressure variations . . . . . . . . . 75

3.6.3 Simulation with the parameter deviations . . . . . . . 77

3.7 Simulation for a $10 \mathrm{~kW}$ fuel cell model . . . . . . . . . . . . . . 81

3.8 Conclusions . . . . . . . . . . . . . . . . . 86

4. Experimental results . . . . . . . . . . . . . . . . . . 87

4.1 Experimental setup . . . . . . . . . . . . . . . . 87

$4.1 .1 \quad$ Signals measurement . . . . . . . . . . . . . 88

4.1.2 Real-time controller . . . . . . . . . . . . . . 90

4.2 Surge prevention $\ldots \ldots \ldots$. . . . . . . . . . . . 90

4.3 Disturbance decoupling control vs Sliding mode control . . . . . . . . 97 
4.4 Applied to a $10 \mathrm{~kW}$ fuel cell model . . . . . . . . . . . . . . . . . . 104

4.4 .1 Oxygen excess ratio $\ldots \ldots \ldots \ldots$

4.4 .2 Pressure ...................... 109

4.5 Conclusions . . . . . . . . . . . . . . . . . . . . 111

5. Conclusions and future work . . . . . . . . . . . . . . . 113

5.1 Conclusions . . . . . . . . . . . . . . . . 113

5.1.1 Compressor selection . . . . . . . . . . . . . . 113

5.1.2 Proposed control approaches . . . . . . . . . . . . . . . 114

5.1 .3 Applications ................... . . 115

5.2 Future work . . . . . . . . . . . . . . . . 115

5.2.1 Active surge control . . . . . . . . . . . . . . . 115

5.2.2 Applied to an actual $10 \mathrm{~kW}$ fuel cell system . . . . . . . . . 116

5.2.3 Humidification control . . . . . . . . . . . . . . . 117

5.2.4 Cathode partial pressure observation . . . . . . . . . . . . 119

Bibliography . . . . . . . . . . . . . . . . . . 127 


\section{LIST OF FIGURES}

$1 \quad$ Fuel cell model. . . . . . . . . . . . . . . . . . . . . 3

2 A $5 \mathrm{~kW}$ commercial fuel cell stack consisting of 90 cells. . . . . . . 3

3 Fuel supply stream. . . . . . . . . . . . . . . . . . 4

4 Schematic of fuel cell stack with internal humidifier [7]. . . . . . . 5

5 Air management system in the fuel cell system. . . . . . . . . . . 7

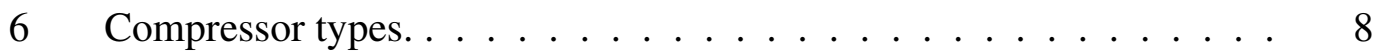

7 Reciprocating compressors. . . . . . . . . . . . . . 9

8 Reciprocating working characteristics. . . . . . . . . . . 10

9 Single rotor of an axial compressor [17] . . . . . . . . . . 11

10 Dynamic compressor blades $[22] . \ldots \ldots \ldots$

11 Centrifugal compressor map. . . . . . . . . . . . . . . 12

12 Comparison between several kinds of compressor [16]. . . . . . . 13

13 Honeywell's motorized compressor module [29]. . . . . . . . . . . . 16

14 A $12 \mathrm{~kW}$ centrifugal compressor with maximum speed of 120,000 rpm [30]. 16

15 The prototype of an ultra-high speed centrifugal compressor for fuel cell systems. . . . . . . . . . . . . . . . . . . . . 17

16 Cross section view of the compressor. . . . . . . . . . . 26

17 Assembled rotor including impeller and high-speed ball bearings. . . 27

18 Critical speeds of the centrifugal compressor rotor. (Blue) No displacement. (Red) Maximal displacement. . . . . . . . . . . . . . . . . 28 
19 Compressor maps. . . . . . . . . . . . . . . . . . . . . . . . . . . . 29

20 Compressor efficiency map. . . . . . . . . . . . . . . 30

21 Measured compressor power. . . . . . . . . . . . . . 32

22 Measured compressor map. . . . . . . . . . . . . . . . 32

23 Neural network model of the centrifugal compressor. . . . . . . . . . 34

24 Neural network layers. . . . . . . . . . . . . . . . . . 35

25 The trained neural network model . . . . . . . . . . . . 36

26 butterfly valve. . . . . . . . . . . . . . . . 37

27 Pulse amplitude modulation (PAM) power electronics and control system for driving an ultra-high-speed PMSM. . . . . . . . . . . . 39

28 Comparison of the speed dynamics between the measurement and the simulation with $T_{m}=0.2 \ldots \ldots \ldots \ldots \ldots$

29 Valve controller. . . . . . . . . . . . . . . . . . . 41

30 Valve position dynamics under the PI control. . . . . . . . . . . . . . 41

31 Simulation and experimental results of the system. . . . . . . . . 45

32 Controllers for MIMO system. . . . . . . . . . . . . . . . 48

33 Block diagram of the centrifugal compressor. . . . . . . . . 50

34 Compressor coupling analysis. . . . . . . . . . . . 52

35 The $i$-th loop of the system. . . . . . . . . . . . . . . 55

36 Structure of the proposed ESO . . . . . . . . . . . . . 58

37 The relation of the mass flow and speed at different pressure ratio. . . 59

38 Mass flow estimation. . . . . . . . . . . . . . . . 60

39 Pressure estimation. . . . . . . . . . . . . . . . . 60

40 The relationship of $b_{1}$ with the pressure and temperature. . . . . . . 62

41 Diagram of the DDC implemented on the air compression system. . . 63 
42 Simulation model in the Simulink. . . . . . . . . . . . . . . . 64

43 Responses of the system under a mass flow step command. . . . . . . 65

44 Responses of the output variable under a pressure step command. . . . 66

45 Simulink model of the twisting algorithm. . . . . . . . . . . . . . 69

46 Simulink model of the super-twisting algorithm. . . . . . . . . . . 70

47 Comparison of the DDC with the sliding mode controller with the mass flow variations. . . . . . . . . . . . . . . . . 73

48 Responses of the actuator under the mass flow variations. . . . . . . . 74

49 Comparison of the DDC with the sliding mode controller with the pressure variations. . . . . . . . . . . . . . . . . 75

50 Responses of the compressor and valve. . . . . . . . . . . . 76

51 Mass flow variations. (a) Mass flow dynamics (b) Zoom in of the mass flow deviation at $38 \mathrm{~s} \ldots \ldots \ldots \ldots 78$

52 Pressure variations. (a) pressure dynamics (b) Zoom in of the pressure deviations at 31 and $33 \mathrm{~s} \ldots \ldots \ldots 79$

53 Speed variations. . . . . . . . . . . . . . . 80

54 Valve position variations. . . . . . . . . . . . . 80

55 Fuel cell polarization curve $(\mathrm{U}-\mathrm{I})$ property. . . . . . . . . . . . . 81

56 Block diagram of the simulation. . . . . . . . . . . . . 82

57 Fuel cell current. . . . . . . . . . . . . . . 82

58 Mass flow. . . . . . . . . . . . . . . . 83

59 Oxygen excess ratio $\ldots \ldots \ldots \ldots$. . . . . . . . . . . 83

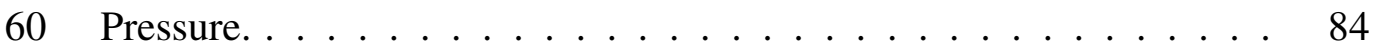

61 Compressor speed. . . . . . . . . . . . . . . . . . 84

62 Valve position. ...................... 85

63 Stack voltage. . . . . . . . . . . . . . . 85 
64 Hardware-in-the-loop air management test bench. . . . . . . . . . . . 87

65 Temperature sensor (right) and pressure sensor (left) . . . . . . . . 88

66 Valve position measurement. . . . . . . . . . . . . . 89

67 Mass flow sensor. . . . . . . . . . . . . . . . . . 89

68 DS1104 controller board layout. . . . . . . . . . . . . . . 91

69 Testbench block diagram and connections. . . . . . . . . . . . . . . 91

70 The trajectory of the compressor operation. . . . . . . . . 93

71 Oscillations caused by the reference limiter in terms of equation (4.1) and $(4.2) \ldots \ldots \ldots \ldots$. . . . . . . . . . . . . . . . . . . . . . . . . . . .

72 Surge prevention as the results of the improved reference limiter. . . 96

73 Comparison by hard-ware-in-the-loop test. . . . . . . . . . . . . 97

74 The responses of the mass flow and pressure under a mass flow step command. . . . . . . . . . . . . . . . . 98

75 Measurement at steady state (zoom-in of Figure 74). . . . . . . . . 99

76 The actuator responses under a mass flow step-up. . . . . . . . . . . 100

77 The responses of the mass flow and pressure under a pressure step command. . . . . . . . . . . . . . . . . . 101

78 Zoom in of Figure 77. . . . . . . . . . . . . . . . . . . 102

79 The actuator responses. . . . . . . . . . . . . . . . . 103

80 Block diagram of the fuel cell stack model. . . . . . . . . . . . 105

81 Current drawn from the fuel cell stack. . . . . . . . . . . . . . . 105

82 Calculated mass flow reference and the measurement in real time. . . 107

83 Oxygen excess ratio. . . . . . . . . . . . . . . 107

84 Compressor speed dynamics during the operation. . . . . . . . . . 108

85 Valve position dynamics during the operation. . . . . . . . . . 108 
86 Supplied air pressure. . . . . . . . . . . . . . . . . 109

87 Realtime simulated fuel cell stack output voltage. . . . . . . . . . . . 110

88 Realtime simulated fuel cell stack output power. . . . . . . . . . . . . 110

89 Operating range of surge avoidance and active control. . . . . . . . 116

90 A $10 \mathrm{~kW}$ fuel cell system testbench. . . . . . . . . . . . . 117

91 Membrane specific resistance vs. average water content at $80^{\circ} \mathrm{C}$ and with the same water activity at the anode and cathode side [10] . . . . 118

92 Saturated vapor pressure at different temperature. . . . . . . . . . . 118

93 Fuel cell current variations. . . . . . . . . . . . . . . . . . 122

94 Compressor mass flow variations. . . . . . . . . . . . . . . 122

95 (a) Cathode pressure estimation, (b) Zoom of the startup. . . . . . . . 123

96 (a) Supply manifold pressure estimation, (b) Zoom of the startup. . . . 124

97 (a) Oxygen partial pressure estimation, (b) Nitrogen partial pressure estimation. . . . . . . . . . . . . . . . . 125 


\section{LIST OF TABLES}

1 Specifications of the PMSM. . . . . . . . . . . . . . 27

2 Thermodynamic constants and manifold parameters. . . . . . . 38

3 Fuel cell stack parameters. . . . . . . . . . . . . . . . 43

4 The RGA of the centrifugal compressor at different operating points. . 51

5 Parameter deviation range. . . . . . . . . . . . . . 77

6 Characters of the sensors. . . . . . . . . . . . . . . 90

$7 \quad$ Operating conditions of the PEM fuel cell stack. . . . . . . . . . . . . 104 


\section{INTRODUCTION}

\subsection{Proton exchange membrane fuel cell}

Nowadays, the research on alternative/renewable energy sources have received more and more attention resulting from the increasing energy consumption. Fuel cell systems, which take advantage of the electro-chemical reaction of fuel gases to produce electricity with water and heat as the byproduct, are promising power supply equipments because of their high efficiencies and low pollutions. Nowadays fuel cell systems are under intensive development in terms of the cell material and auxiliary devices, which promote both the stationary and automotive applications. Compared with traditional heat engines, fuel cells have high power density and greater efficiency, as high as $60 \%$ in electrical energy conversion and overall $80 \%$ in co-generation of electrical and thermal energies [1]. Unlike batteries with the reactants stored internally, the reactants of fuel cell are stored externally, which can make it operate continuously as fuel is available.

Five categories of fuel cells have received major efforts of research [2]:

1. Proton exchange membrane fuel cells (PEMFCs): The PEMFCs use solid polymer electrolytes to exchange the ions between two porous electrodes, which is a conductor of protons and an insulator for electrons. Low temperature PEMFCs operate around $70^{\circ} \mathrm{C}$. Whereas, the working condition is up to $180^{\circ} \mathrm{C}$ for high temperature PEMFCs. The advantages of PEMFC are their high power density and fast star-up which make it suitable for automotive applications.

2. Alkaline fuel cells (AFCs): The AFC uses an aqueous solution of the potassim hydroxide as an electrolyte. AFCs operate at a low temperature around $100^{\circ} \mathrm{C}$ and it has the high efficiency up to 60-70\%. However, they are sensitive to $\mathrm{CO}_{2}$ 
because it consumes the alkaline in the electrolyte thereby reducing the concentration of hydroxide ion during chemical reactions. Therefore, they need a separate system to remove the $\mathrm{CO}_{2}$ from the air. The use of a corrosive electrolyte is also a disadvantage because it has shorter life span [2].

3. Phosphoric acid fuel cells (PAFCs): PAFCs are a type of fuel cell that uses liquid phosphoric acid as an electrolyte. They are the first commercialized fuel cells. Unlike PEMFCs and AFCs, they are very tolerant to impurities in the reformed hydrocarbon fuels. They operate about $175-200^{\circ} \mathrm{C}$. And their efficiency could be up to $70 \%$. They are typically used for stationary power generation.

4. Solid oxide fuel cells (SOFCs): The SOFCs which operate around $1000^{\circ} \mathrm{C}$ with an electrical efficiency of around 50\%. They use dense yttria stabilized zirconia, which is a solid ceramic material, as the electrolyte. SOFCs have high efficiency of 50-60\%. Whereas, they need a long start-up time because of the high temperature. SOFCs are mainly used for stationary applications in medium and large power capacity.

5. Molten carbonate fuel cells (MCFCs): MCFCs working around $650^{\circ} \mathrm{C}$ is a kind of high temperature fuel cell. Unlike low temperature fuel cells, MCFCs do not need expensive metal as the fuel catalyst. It has two porous electrodes with good conductivity are in contact with a molten carbonate electrolyte. Like SOFCs, MCFCs also has the disadvantage of slow star-up.

Among different types of fuel cells, the PEMFCs show more advantages for transportation applications because of their low temperature working conditions, fast start-up and good dynamic characteristics. Interests in fuel cell can be traced back to the late 1970s and received a major boost in recent years. Many motor corporations have been developed even released their fuel-cell vehicles based on PEMFC, e.g. GM Hydrogen 1, Honda FCX-V3, Toyota FCHV, etc [1].

The basic working principle of a PEMFC is shown in Figure 1. A single cell consists of seven elementary layers: The cathode gas channel which is used to circulate the air, the cathode gas diffusion layer where water and oxygen diffuse, the cathode catalyst layer where the oxygen is consumed and the water is produced, the membrane where allowing protons to pass through while blocking electrons, the anode catalyst 
layer where hydrogen is consumed, the anode gas diffusion layer where hydrogen and water diffuse, and the anode gas channel which is used to circulate the hydrogen. A commercial fuel cell (Figure 2) consists of a number of single cells depending on the power capacity.

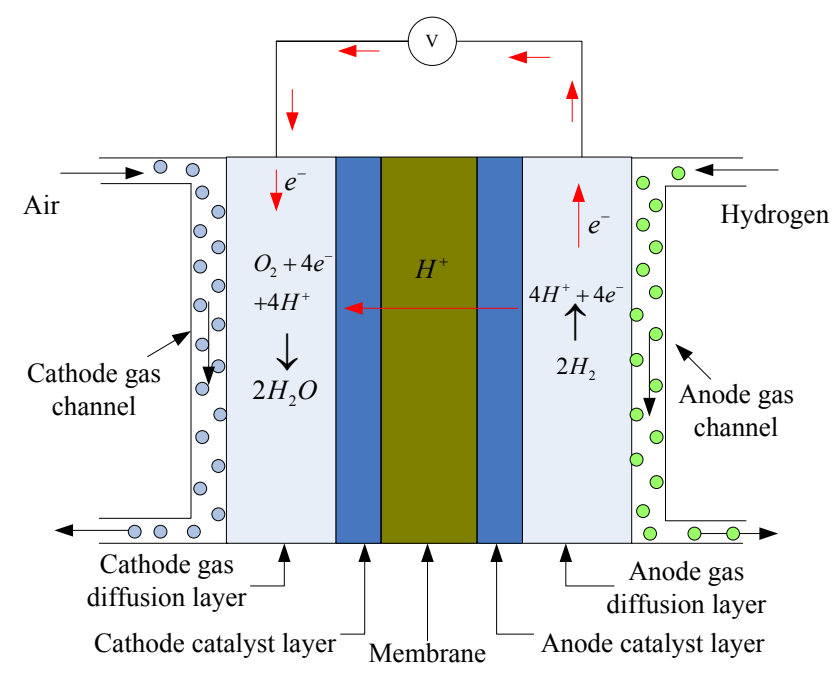

Fig. 1. Fuel cell model.

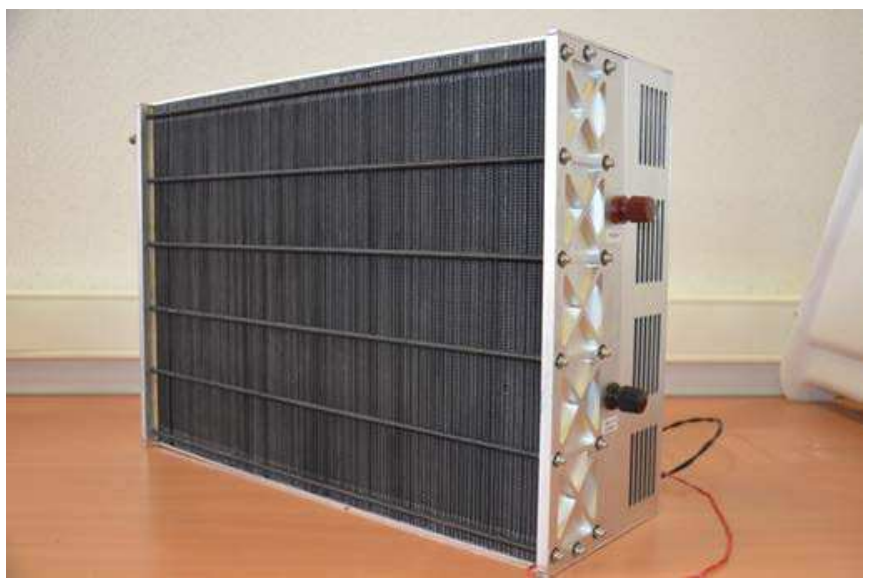

Fig. 2. A $5 \mathrm{~kW}$ commercial fuel cell stack consisting of 90 cells. 


\subsection{PEMFCs auxiliary components}

\subsubsection{Fuel supply subsystem}

In the operation of a fuel cell, the fuel (hydrogen) has to be provided continuously to the anode side. Normally, there are two kinds of fuel supply methods as shown in Figure 3: One is that store the pressurized pure hydrogen in a tank and transport it directly to the fuel cell stack; The other way is by reforming available fuels such as methanol, gasoline, natural gas, etc., to produce hydrogen on site, and then supply it to the fuel cell. For most of vehicular applications, the first method is adopted because of its high purity and reliability. Whereas, the second method has been used for many stationary power units.

Several kinds of fuel generation strategy have been studied over the past few years [35]. The presence of $\mathrm{CO}$ in the reformate are well known contributors to the failure of the PEM stack, and thus its need to be constrained to very low concentrations. For example, the maximum allowable $\mathrm{CO}$ concentration in the reformate is typically as low as $50 \mathrm{ppm}$ by volume or less $[4,5]$. To remove (reduce) the $\mathrm{CO}$, the air is needed to injected to the reformer, and then reacts with $\mathrm{CO}$.

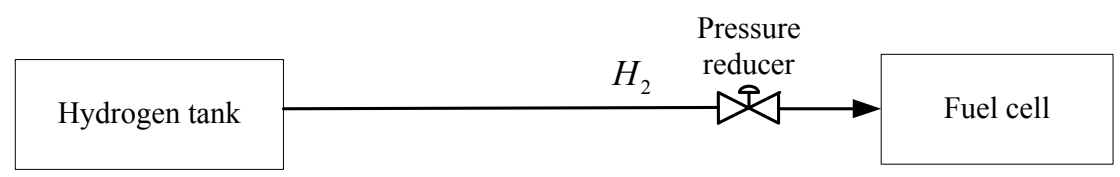

a. Hydrogen is stored in a high pressure tank

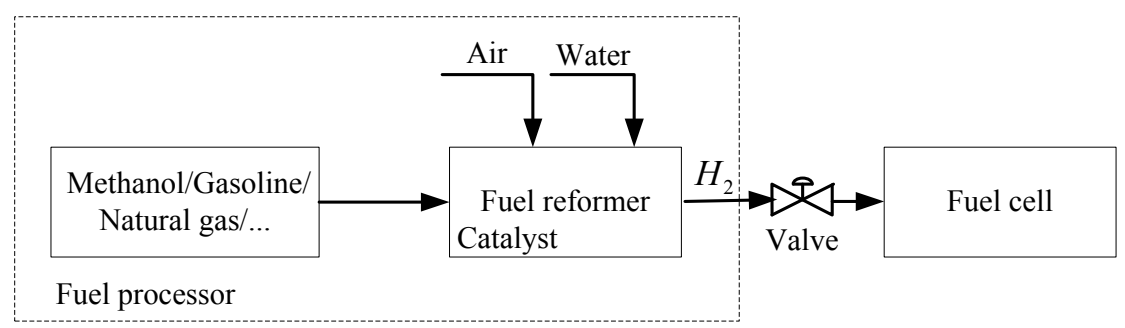

b. Hydrogen is produced on site

Fig. 3. Fuel supply stream. 


\subsubsection{Humidification subsystem}

Maintaining proper membrane humidity is one of the key requirements for the fuel cell to reach its optimum performance. The intention of humidification of the gases entering the fuel cell is to maintain proton conductivity of the electrolyte in the membrane. Without humidification, the membrane becomes too dry and thus prohibits the proton transport. Therefore it results in poor fuel cell function or even failure.

Two kinds of humidifying methods exist, namely, external humidification and internal humidification. The internal humidification, shown in Figure 4, is based on the principle that the electrolyte absorbs and retains water under the operating conditions by introducing a special membrane [6]. Porous membrane located between the gas channel and the water channel is used to transfer the water vapor [7]. Water droplets permeate through the membrane from the water side to the gas side. The heat produced in the stack could be used as an energy source for vaporizing water in this method.

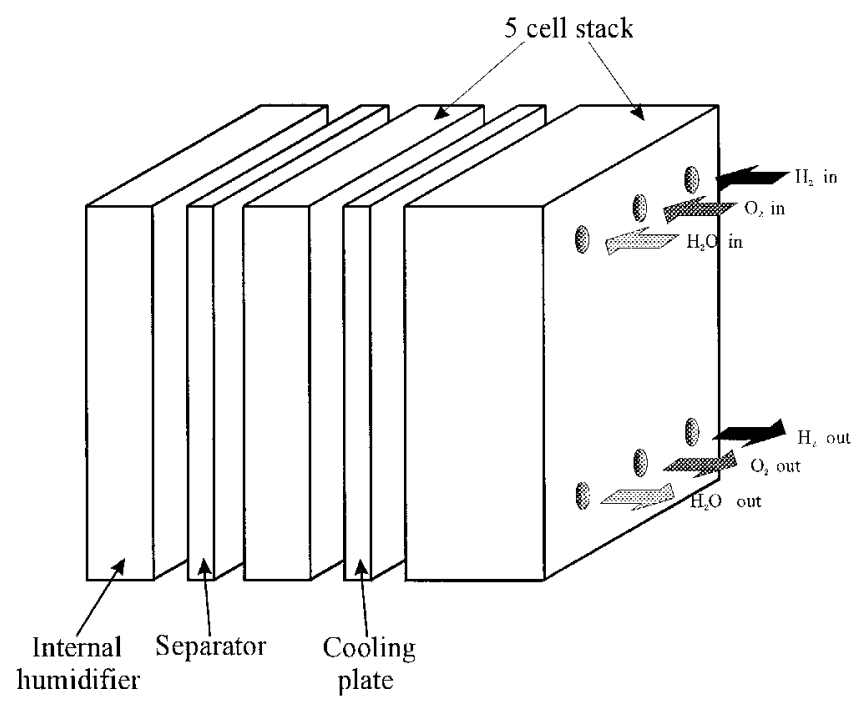

Fig. 4. Schematic of fuel cell stack with internal humidifier [7].

The external humidification methods such as bubble humidifiers, enthalpy wheel exchanger, direct water vapor injection into the reactant gases, lead to additional energy consumption [8]. In this way, an auxiliary component, humidifier, is needed. Humidifiers provide heat and humidity to the incoming oxidant or hydrogen fuel stream of fuel cells and are critical to overall system performance and reliability. The external 
humidification method is widely used in small scale laboratory fuel cell experiments due to its simplicity [9].

\subsubsection{Cooling subsystem}

During the operation of PEMFCs, large amount of heat is generated which should be effectively removed to avoid overheating of the membrane and other components. The favorable working temperature of PEMFCs is usually between $60^{\circ} \mathrm{C}$ and $80^{\circ} \mathrm{C}$. A high temperature can significantly exacerbate the degradation of the membrane and the catalyst, and reduce the stack performance, while a lower temperature is not favorable for the reaction kinetics and may also cause flooding due to lower water saturation pressures at low temperatures [10].

Several cooling methods have been studied, such as using highly thermal conductive material as heat spreaders, air flow cooling, liquid cooling, etc. Both increased supply of cathode air and additional air channels have been studied as the air cooling. The liquid cooling method, in which additional devices are needed, has been widely employed for automotive applications because of its strong cooling capability.

\subsubsection{Power management subsystem}

For hybrid vehicles, where the fuel cell combines with energy storage devices, such as batteries and ultra-capacitors to output energy, power management strategy affects the vehicle performance and efficiency significantly. Several topology connections and control strategies have been developed to optimize the energy consumption [11-15]. The energy flow which is determined by the power management method is controlled by DC/DC converters. Because of the dynamics of the load, the fuel cell alone might cannot satisfy the load demand resulting from its slow response. A energy storage devices such as batteries and ultra-capacitors can be used to absorb the fast transient. The fuel cell output power is delivered to the load through a uni-directional converter. Whereas, a bi-directional converter is used to transfer the energy to/from of the storage devices, e.i. charge or discharge. 


\subsubsection{Air management subsystem}

Air management subsystem (AMS) is used to supply the compressed air to the fuel cell cathode, where the electro-chemical reaction takes place, producing the electricity with the water and heat as byproducts. The block diagram of the AMS is shown in Figure 5.

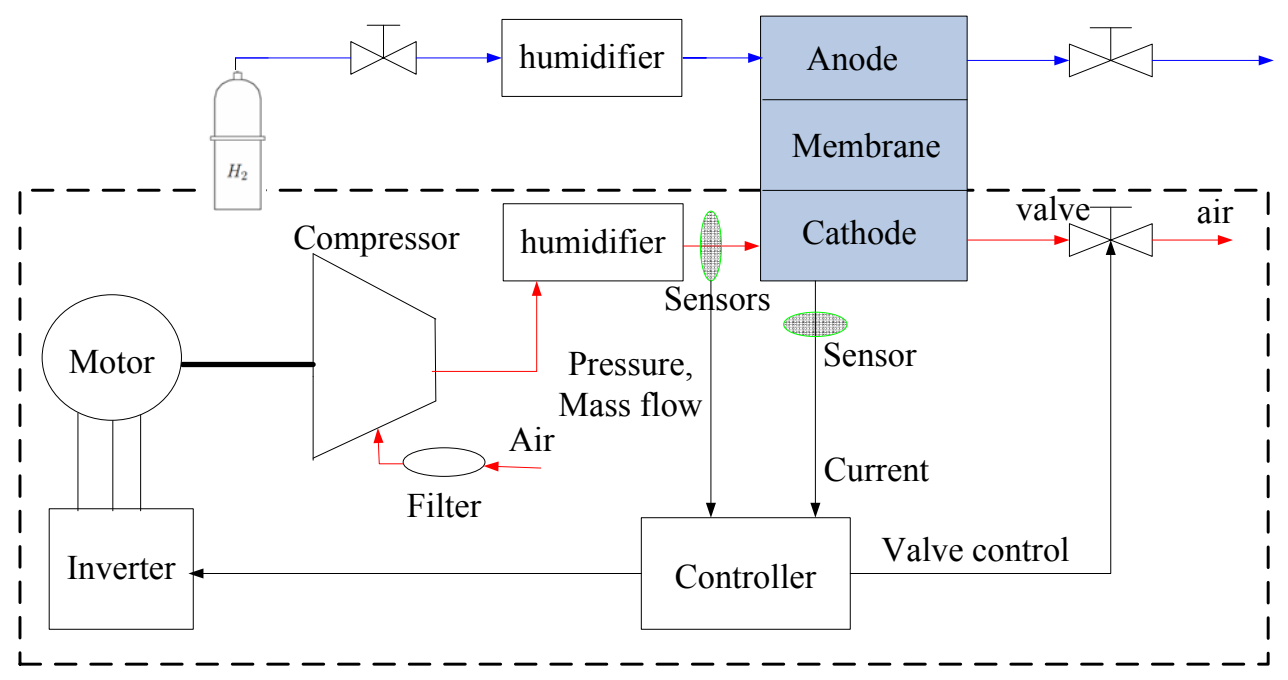

Fig. 5. Air management system in the fuel cell system.

The major tasks of the air management subsystem are as follows [16]

- Air supply. The air management system has to supply sufficient reactant flow to keep the desired oxygen excess ratio over the full power range. Insufficient air flow may damage the stack in severe cases. The air is normally circulated by a air compressor or blower.

- Air cleaning. Any particle or chemical substance, such as carbon monoxide, can be harmful for the catalyst and the membrane. Therefore, the air has to be filtered before going into the stack.

- Air pressurization. The air supplied to the fuel cell is generally pressurized from slightly above atmospheric pressure to 2.5 bar, depending on the stack requirement. Pressurizing the air to the fuel cell implies a high efficiency and gives better water balance characteristics. Higher air pressure implies a more compact 
stack and higher power density. Whereas, compared with low pressure fuel cells, more parasitic power losses are produced by the air compressor.

- Air humidification. The polymer membrane has to be maintained in a fully hydrated state to have optimal working conditions. The air management subsystem usually combines the humidification subsystem to fulfill this target.

In order to fulfill these tasks, many components are needed. For the cleaning of air, filters are needed to remove particles before the air going into the fuel cell. The air transportation and pressurization could be realized by an air compressor or blower. Meanwhile, a control system with sensors is needed to control the mass flow and pressure properly to ensure good transient responses of the fuel cell.

\subsection{Compressor technology}

The air compressor, the key component of the AMS, is the largest parasitic power consumption device in the fuel cell system. In the most severe cases, it consumes up to $20 \%$ of the generated power. The compressor efficiency including motor, power converter, and controller depends on the compressor type, the pressure level, and the speed. According to the working principle, a general classification of the compressor is depicted in Figure 6.

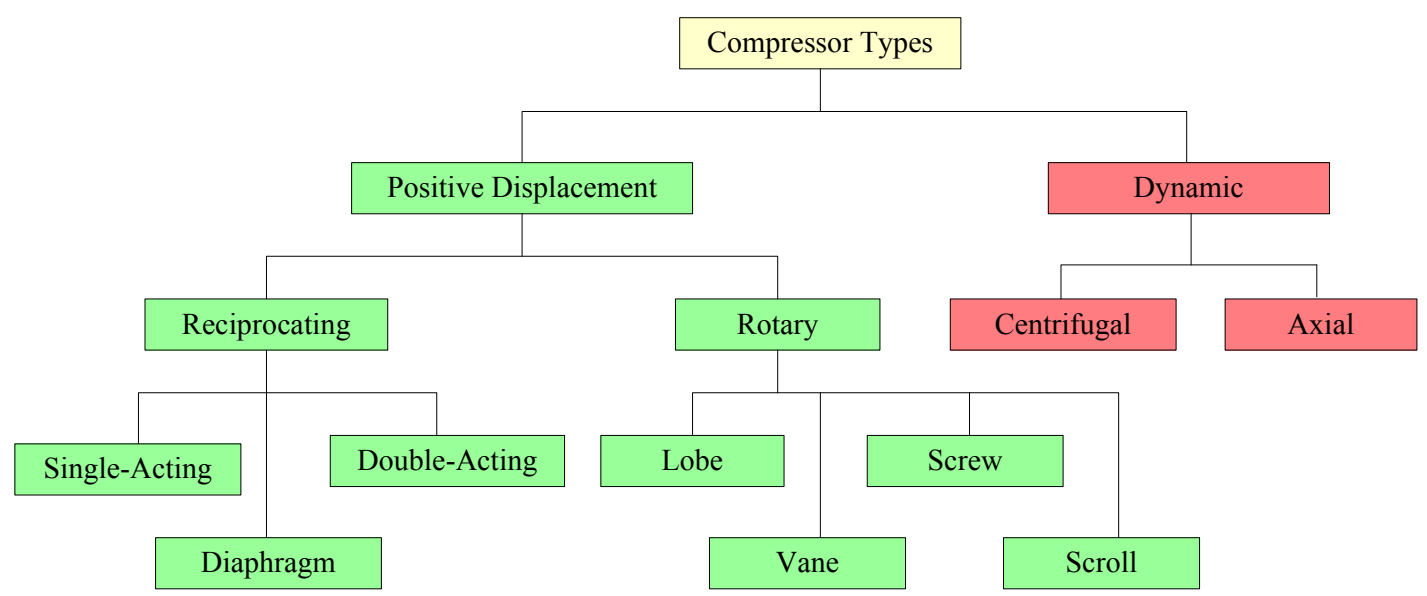

Fig. 6. Compressor types. 
Several kinds of compressor, including positive displacement compressors (scroll, screw, lobe, centrifugal, etc,) and dynamic compressors like centrifugal type, have been studied for fuel cell applications in the literature.

\subsubsection{Positive displacement compressors}

Positive displacement machines (Figure 7) work on the principle that: changing the pressure by mechanically changing the volume of the working fluid. They typically operate in two different ways: reciprocating and rotary.
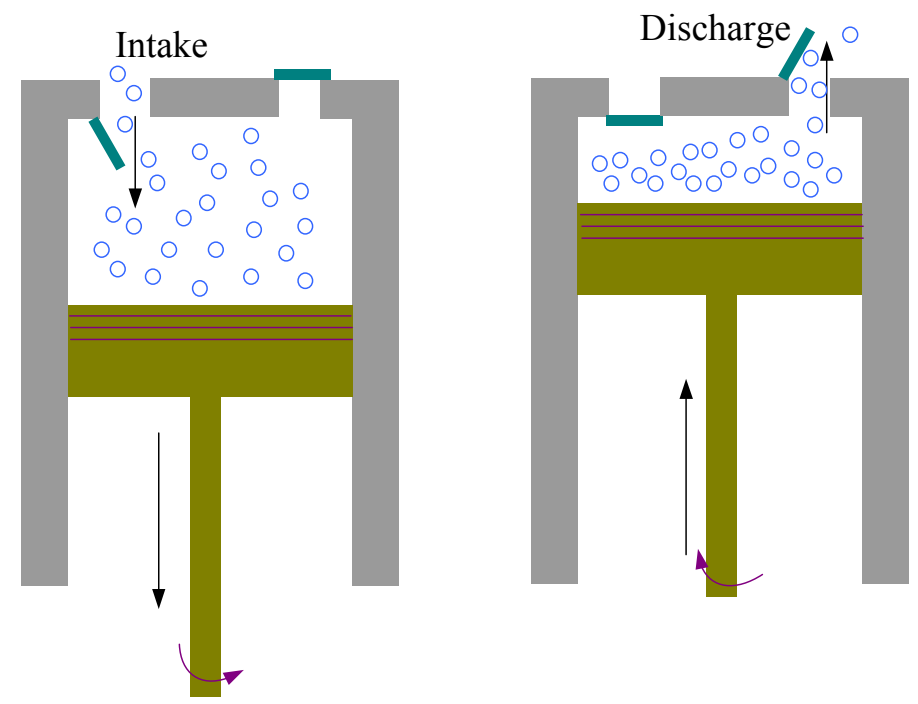

Fig. 7. Reciprocating compressors.

- Reciprocating. Reciprocating compressors, also known as piston compressors, compress the fluid by reciprocating motion of a piston within a cylinder. The overall cycle is charactered by four typical phases of intake, compression, discharge, and expansion shown in Figure 8. As the piston moves downward, a vacuum created, the intake valve is forced open and fluid is sucked into the cylinder. After the piston reaches its bottom position it begins to move upward. The intake valve closes and the pressure increases inside the cylinder. At a certain point the pressure exerted by the fluid forces the exhaust valve to open and the compressed fluid flows out of the cylinder. Once the piston reaches it top-most position, it starts moving downward again and the cycle is repeated. These pumps can be 
single-acting, meaning they operate via single or independent discharge and suction strokes. They can also be double-acting, meaning they create discharge and suction in both directions.

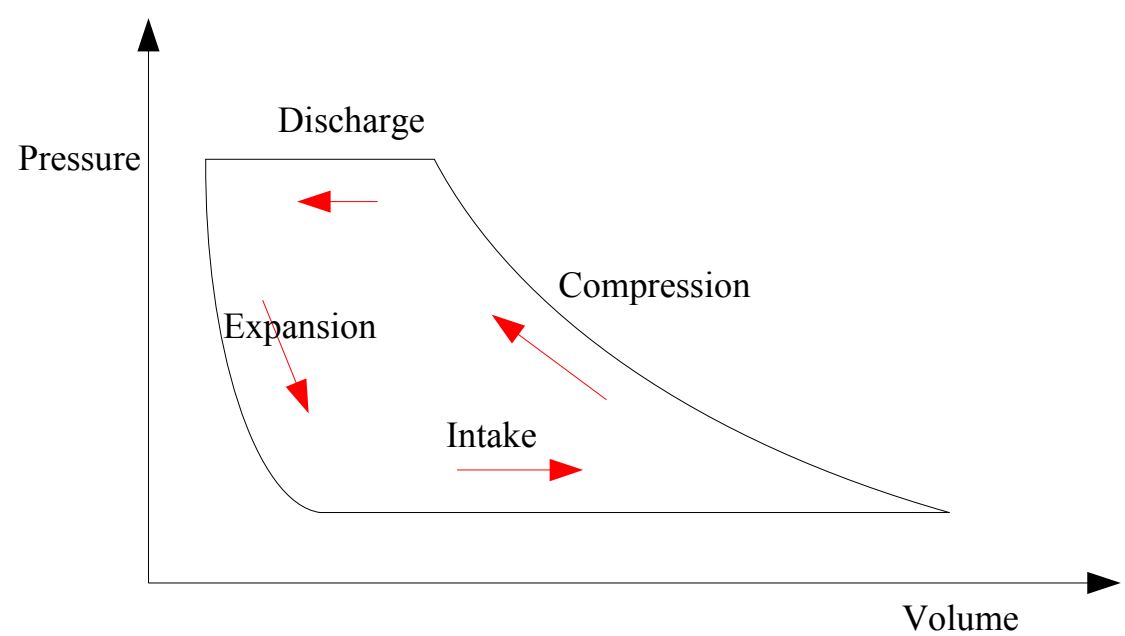

Fig. 8. Reciprocating working characteristics.

- Rotary. Rotary compressors work by changing the fluid volume by the rotating action. A rotary compressor consists of a rotor inside a cylinder, spring-mounted blades and a stator. The rotor rotes around a shaft with a variable volume of fluid. At a certain point in the rotation, a quantity of fluid is sucked into the cylinder and kept in a sealed area. The pressure increases as the volume becomes smaller by the rotating action. When reaching sufficient-high point, the gas pressure forces the exhaust valve to open and then the fluid is released. With the rotating going on anther operation of compressing begins. Rotary compressors have the same working principle with the reciprocating machines: having four operation stages: expansion, intake, compression and intake.

\subsubsection{Dynamic compressors}

Dynamic compressors compress air work by mechanically changing the velocity of the working fluid. Unlike positive displacement compressors, they can supply continues air flow. According to the flow direction they are divided into axial and centrifugal types. 
- Axial. An axial compressors has a rotor with rows of blades which accelerate the velocity of the flow. Figure 9 shows the single rotor of an axial compressor [17]. The stator is composed of many fixed blades which is used to guide the direction of flow and increase the pressure. The flow both enters and exits the compressor in an axial direction, parallel with the axis of rotation. In an axial flow compressor, multi-stage, successive rotor-stator pairs, are generally used to raise the pressure.

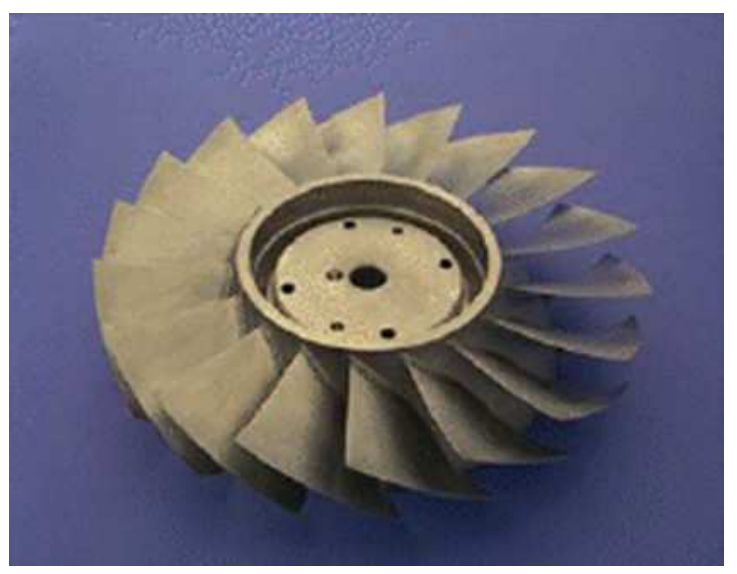

Fig. 9. Single rotor of an axial compressor [17].

- Centrifugal. Like axial compressors, centrifugal compressors realize compression by transferring momentum to the fluid and the subsequent diffusion to convert the kinetic energy into pressure. The momentum transfer takes place at the doubly curved blades of the impeller that is mounted on a rotating shaft. Diffusion takes place in the annular channel of increasing radius around the impeller, usually referred as the diffuser [18]. Whereas, unlike axial compressors, centrifugal compressors change the direction of the fluid from parallel to vertical orientation of the rotor as shown in Figure 10. Mechanical and thermodynamic modeling of the centrifugal compressor are available in [19-22]. External characteristics of a centrifugal compressor can be described by its speed, mass flow, pressure and efficiency. A typical centrifugal compressor map is shown in Figure 11, which depicts the relation of the speed, mass flow and pressure.

Dynamic compressors usually require high speed to increase the momentum of the fluid. Therefore, they are more compact than positive displacement compressors. Dynamic compressors are more efficient, especially operating at full 
power. The working principle makes that positive displacement compressors, unlike dynamic compressors, cannot supply continue flow. An comprehensive comparison of these compressors are depicted by radar diagrams in Figure 12.

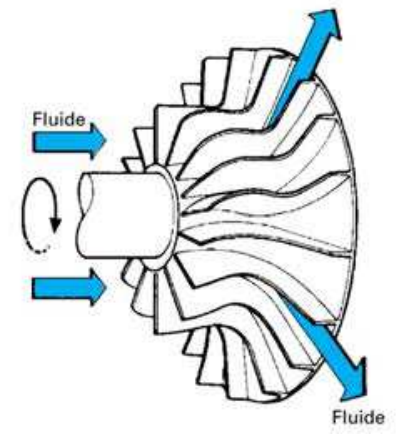

(a) Centrifugal compressor

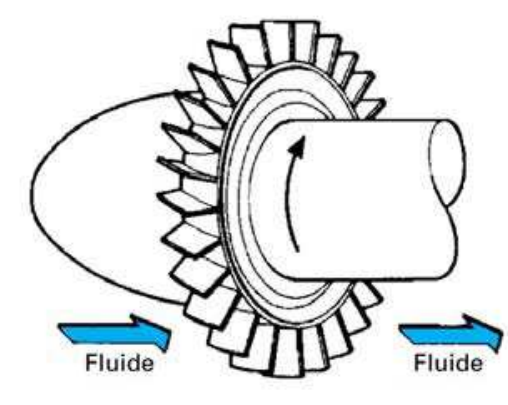

(b) Axial compressor

Fig. 10. Dynamic compressor blades [22].

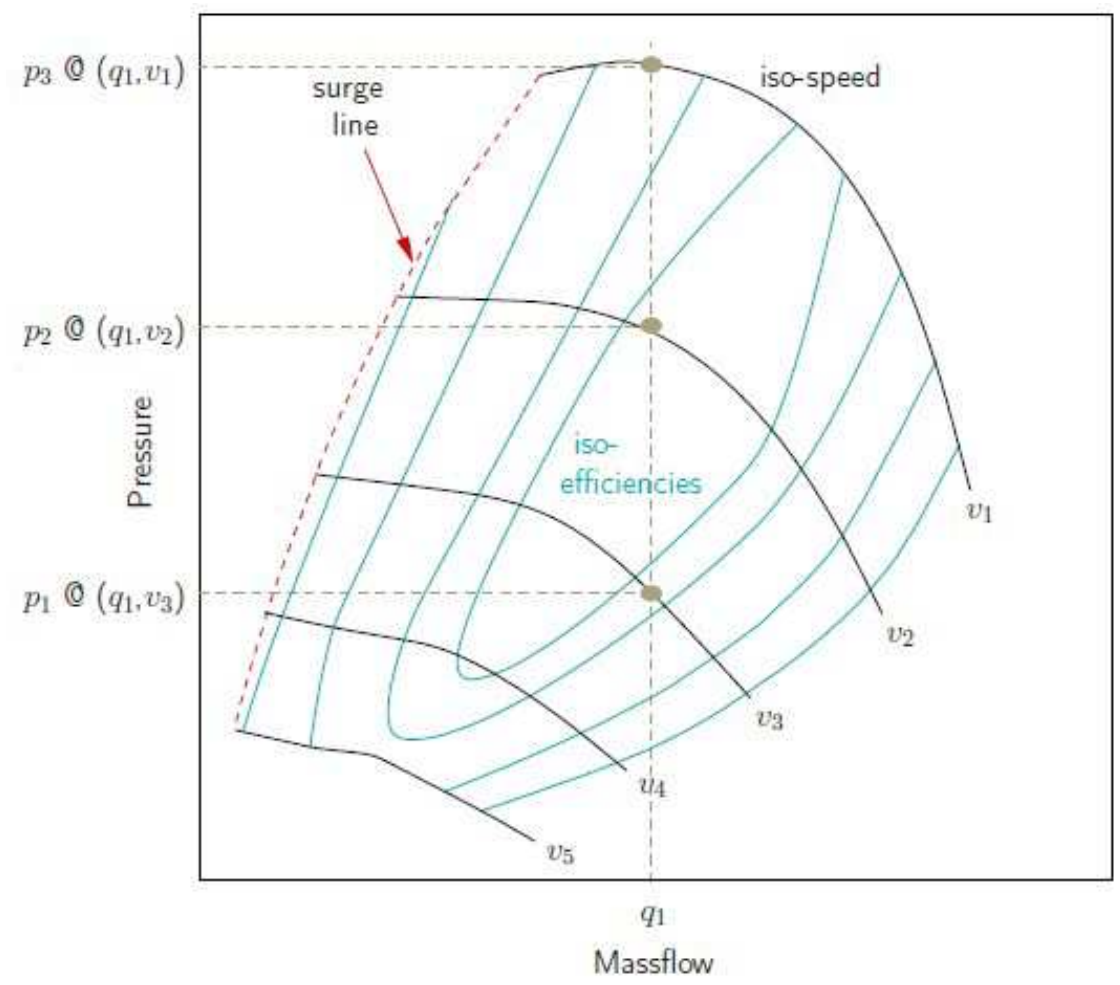

Fig. 11. Centrifugal compressor map. 


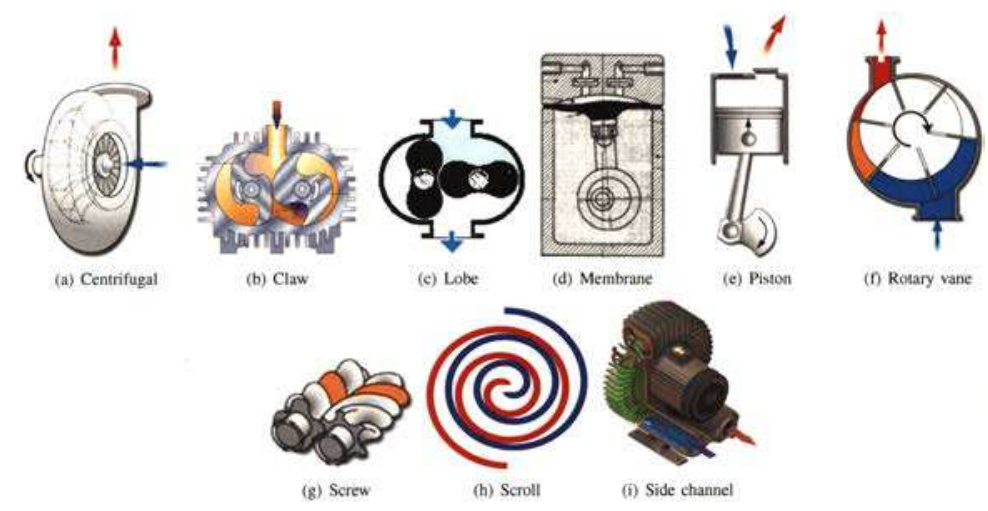

(a) Compressor types

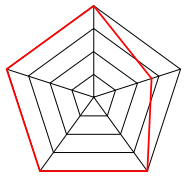

(a)Centrifugal

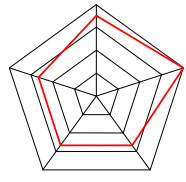

(b)Claw

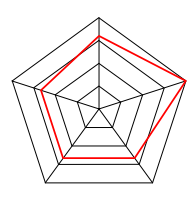

(c)Lobe

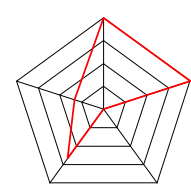

(d)Membrane

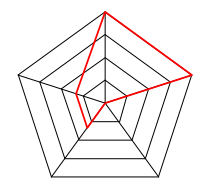

(e)Piston

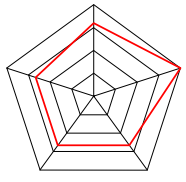

(f)Rotary vane
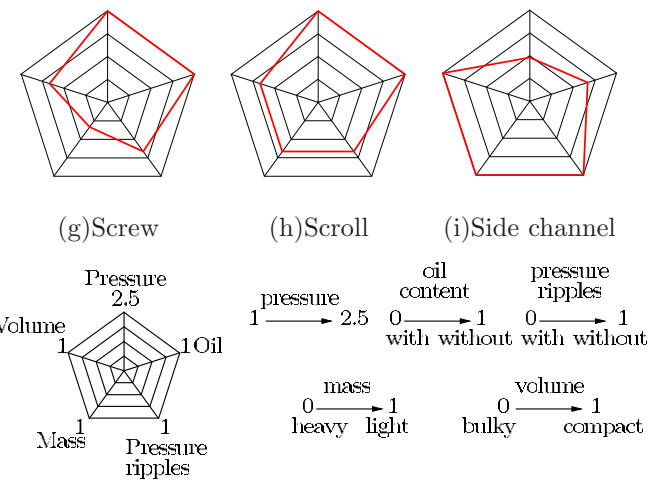

(b) Comparisions

Fig. 12. Comparison between several kinds of compressor [16].

\subsubsection{Choice for PEM fuel cell system}

Fuel cell performances greatly relate to the compressor behavior. The compressor needs to be appropriately chosen according to the requirement of the fuel cell system. For automotive applications, following requirements need to be considered [16].

- Oil free. Oil which is pernicious for the fuel cell membrane is not allowed in the air flow. The oil-free air compressor should be used for fuel cell applications. For positive displacement compression technology, even so called "oil- 
free" machines use oil lubricants that migrate into and contaminate the gas path. In contrast centrifugal compressors have distinct advantage of being an oil-free air compressing system.

- Low parasitic consumption (high efficiency). Air compression system which can consumes up to $15 \%$ of the fuel cell generated power is the biggest parasitic losses. A high efficiency compressor reduces the parasitic power losses and therefore increases the overall system efficiency. Centrifugal compressors could achieve higher efficiency since less friction losses are produced.

- Compactness. For automotive applications, the volume and weight of the fuel cell system have to be reduced. It also applies to the air compressor. In terms of compactness, the centrifugal compressor which usually operates at high speed is superior to positive displacement compressors.

- Flexible flow operation. Fuel cell vehicles need the fuel cell to work around an optimized operating range according to the load demand. Therefore, varied current drawn from the fuel cell requires the compressor to supply a flexible flow rate. Therefore, a fast mass flow controller is necessary in order to make the fuel cell work efficiently. The mass flow of positive displacement compressors is directly related to the compressor speed. Whereas, the centrifugal compressor's flow is affected by not only the speed but also the pressure. In other words, more efforts has to be made to control a centrifugal compressor for fuel cell applications.

- Low noise. In automotive applications, especially for vehicles, the noise is also a performance index. Generally, rotary compressors have lower noise than the reciprocating compressors.

- Small pressure ripple. For the stack, large pressure ripples may damage the thin polymer-membrane and produce voltage pulsation, which should be avoided. Positive displacement compressors normally work on an constant pressure. Therefore the cathode pressure changes when the mass flow changes. Centrifugal compressor can work on different pressure point controlled by the speed and mass flow. 
Many research and development efforts are aimed at different compressor technologies and their possible implementation in fuel cell systems [23]. In 1999, Air Squared designed the first scroll fuel cell compressor with the maximum pressure of $1.38 \mathrm{barg}$, and maximum mass flow of $28 \mathrm{~g} / \mathrm{s}$ [24]. It can be driven by a $2.5 \mathrm{~kW}$ brushless DC motor or an induction motor. For automotive applications, a $2.2 \mathrm{~kW}$ scroll compressor driven by a induction motor using senorless technology has been studied in [25]. The nominal pressure is kept at 2.0 bars. And a simplified fuel cell model is used to validate the proposed method under Classic European Driving Cycles. In [26], a three-lobe compressor driven by an induction motor was modeled and analyzed for the possible application in the fuel cell system. This compressor has the maximum mass flow of $20 \mathrm{~g} / \mathrm{s}$ with the maximum pressure of 2.0 bars. However no fuel cell character was described in the literature. A three-order fuel cell model driven by a twin-screw compressor has been developed in [27] and it is controlled by a sliding mode controller. The proposed air supply system is used to feed in parallel two PEM fuel cell stacks of $20 \mathrm{~kW}$ each. However, in the system the pressure issue which is an important variable was not discussed. A $860 \mathrm{~W}$ rotary vane compressor driven by a brushless DC motor has been used in Fclab, France [28]. The maximum mass flow is $15 \mathrm{~g} / \mathrm{s}$ and maximum absolute outlet pressure 1.5 bars. This compressor is validated on a $5 \mathrm{~kW}$ PEM fuel cell plant.

All the compressors mentioned above are positive displacement machines.The United States department of Energy (DOE) gave the technical challenges and objectives of air compression system for a $80 \mathrm{~kW}$ transportation fuel cell systems. The technical plan, according to the 2017 target, shows that the weight has to be reduced from 22 to $15 \mathrm{~kg}$. Meanwhile the durability is planed to $5000 \mathrm{~h}$ and efficiency to $75 \%$. The motor and controller efficiency at full flow is $90 \%$. It is $80 \%$ at $25 \%$ flow. It is well known that compared with other displacement compressors, centrifugal compressors have the advantages of compactness and high efficiency. They are more suitable to fulfill those targets. Under contract to the DOE, Honeywell has designed the motor-driven centrifugal compressor/expander and evaluated data on its performance, weight, and projected cost. Fulfilling the 2010 target of DOE, a Honeywell's compressor for a $80 \mathrm{~kW}$ fuel cell is shown in Figure 13 [29]. It has the maximum shaft speed of 110,000 rpm, with a minimum idling speed of $36,000 \mathrm{rpm}$ required by the bearings. To fulfill compactness requirement, Miti Ltd also developed a centrifugal compressor (Figure 14) driven by permanent magnet motor, for fuel cell applications [30]. This compressor can operate 
from 20,000 to $120,000 \mathrm{rpm}$ to meet pressure and flow demands.

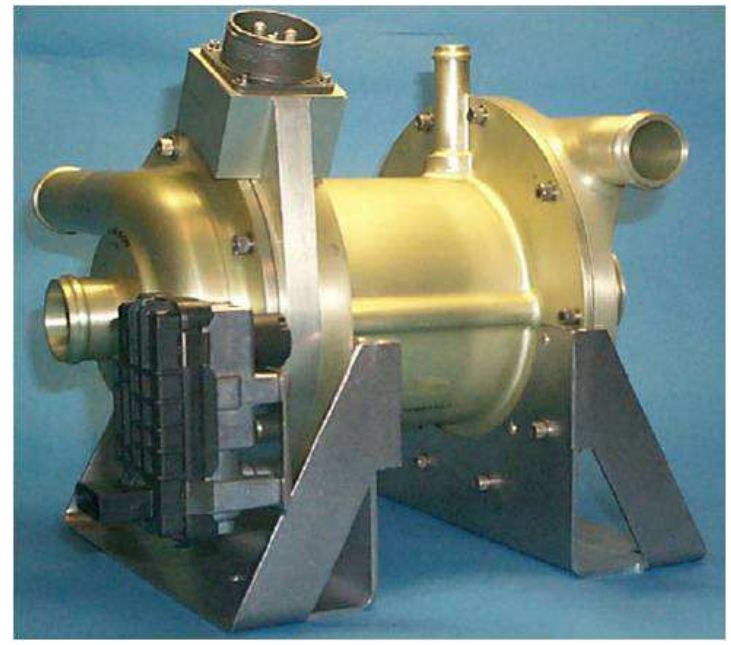

Fig. 13. Honeywell's motorized compressor module [29].

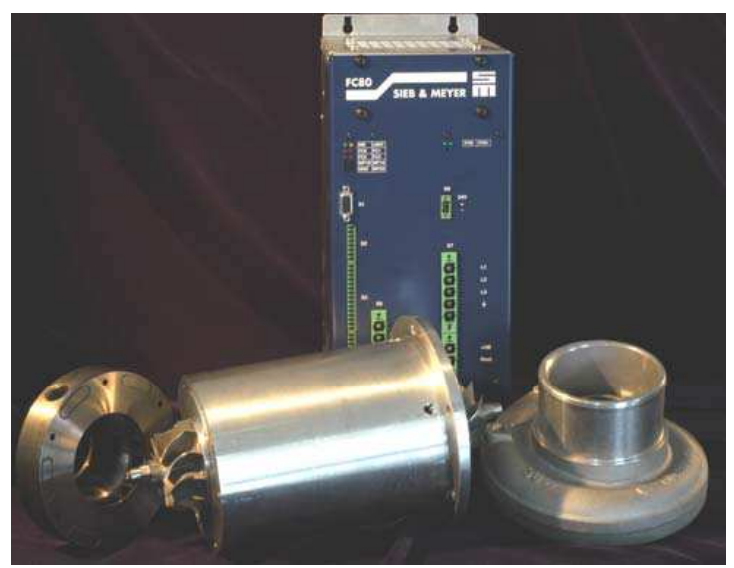

Fig. 14. A $12 \mathrm{~kW}$ centrifugal compressor with maximum speed of 120,000 rpm [30].

In general, positive displacement compressors which has a fixed internal pressure ratio, on the other hand, offer more flexible pressure ratio at low mass flow rate because they don't suffer surge phenomenon. Therefore, they can operate at the expected pressure ratio which is desired by the fuel cell. Moreover, the air flow and pressure can be controlled decoupled, and thereby it simplifies the controller design. However, the bulkiness and discrete output flow of the positive displacement compressors are the crucial disadvantages for automotive applications. The centrifugal technology has major advantages of compactness, low noise and high efficiency, which make it more suitable 
for automotive applications. For automotive compactness requirement, in this dissertation, an ultra-high speed centrifugal compressor (maximum speed 280,000 rpm) is adopted. The prototype of the compressor is shown in Figure 15. In addition to the merits of a centrifugal compressor, the adoption of ultra-high speed technology in compressor design results in the ultra-compactness. The advantage of this high rotational speed is the decrease of the impeller radius and therefore an increase in power density in turbo machinery [31]. Also the electrical motor power density is roughly proportional to the speed.

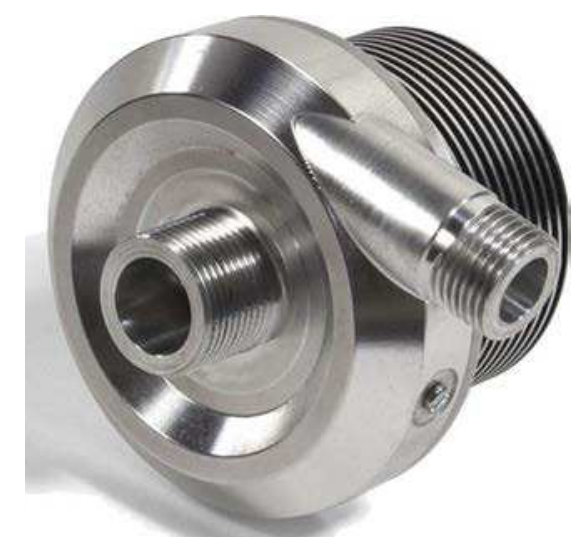

Fig. 15. The prototype of an ultra-high speed centrifugal compressor for fuel cell systems.

In summary, the centrifugal compressor exhibits more benefits for automotive fuel cell applications. However, the control problems, such as pressure control and surge control, introduced by the centrifugal compressor have to be solved. Moreover, the fuel cell characteristics and load situations have also to be considered in the controller development. Therefore, new control technologies are needed to cope with the control problems to satisfy the demands from both the compressor and the fuel cell. In fact, recently many control methods have been proposed to deal with the air management problem of fuel cell systems. More details are discussed in the following section. 


\subsection{Research objective and scope}

\subsubsection{Control problem overview}

In transportation applications, because of the dynamic load characteristic, the fuel cell needs to work at different operating points. During transients, current is instantaneously drawn from the load source connected to the fuel cell stack. An air management system is needed to provide sufficient oxygen for the fuel cell and regulate the pressure to a proper value to make fuel cell work at its optimal efficiency. A great deal of equipments (see Figure 5) are needed to fulfill these tasks. Explicit descriptions of the AMS and the tasks of each component were presented in [16].

Both the supplied air flow rate and pressure ratio need to be controlled appropriately in the operation of a fuel cell system. Insufficient air flow will probably lead to the oxygen starvation, which is a dangerous situation for the fuel cell stack. Whereas excessive parasitic power will be consumed if over flow rate is supplied. The supplied air pressure has a significant influence to the output voltage and efficiency of the fuel cell system. Moreover, the safety of the fuel cell stack depends much on a stable air pressure delivery. No pressure ripple greater than 100-200 mbars is allowed for automotive applications. A greater pressure ripple would damage the membrane.

Fuel cell oxygen starvation, which indicates insufficient oxygen is supplied to the fuel cell, is an undesirable phenomenon. In order to avoid oxygen starvation a fast response of mass flow rate is necessary. In [32], a PI controller with feedforward method was used to control the fuel cell breathing. It shows that an appropriate feedforward component can effectively improve the mass flow response. Both static feedforward and dynamic feedforward are studied. The oxygen excess ratio was maintained at 2 . This control is realized by linearizing the fuel cell at nominal operating point. However, because of the highly nonlinearity of the fuel cell system, the traditional PI control is not qualified. Some advanced control approaches have been proposed for the air circuit control in the past few years [33-36]. In [37-39], model predictive control (MPC) methods, including nonlinear MPC, explicit MPC and constraint MPC, were studied for the air feed of a fuel cell. Those paper are focused only on maintaining the oxygen excess ratio in a desired value by controlling the compressor voltage. [35] use the MPC to fulfill multi control targets including the pressure, excess ratio and current. 
However, it did not dig into the air flow control. Both the mass flow controller and electrical load are modeled as a first-order lag element. The advantage of MPC is that it can deal with the system constraints, such as the oxygen excess ratio and input voltage. However, MPC needs an accurate system model which is very difficult to obtain for fuel cell system. Moreover, it is very sensitive to system parameters and external disturbances, therefore is has a reduced robustness. And the heavy computation load is also a disadvantage of MPC.

Sliding mode control was also studied for the air flow control in fuel cell systems [27, 40-42]. In [40], a sliding model control with feedforward is used to track the reference of oxygen excess ratio. And variable setting of the reference was proposed according to the load current in order to obtain the maximum efficiency. A rate limiter in the slop of the compressor signal was implemented to avoid the compressor stalling. A reduced-order fuel cell model and a sliding model controlled motor-compressor was experimentally validated in [27]. In this reference, a four-order and three-order fuel cell model was developed respectively. And the compressor is modeled as a first-order system, controlled by the quadratic current component. Based on this model, sub-optimal second order sliding model control and super-twisting sliding mode control were developed in [43]. For those literature mentioned above, the sliding mode controllers were developed based on single input single output controlled strategy. They are focused only on the flow rate control or oxygen excess ratio control. The air pressure which is very a crucial variable in the fuel cell system was not taken into consideration. Moreover, sliding mode controller development also needs an explicit model.

Fuzzy logic was also studied to control the mass flow and pressure using the compressor speed and valve position respectively in [44]. A three-lobe compressor was used and all the control parameters were obtained by experimental tests. Some other advance controllers, such as adaptive method, robust approach and flatness-based control were also proposed by recent research $[34,45,46]$ for fuel cell air breathing management. However, the compressor parameters and corresponding control were not detailed. In this research, we focus on the air compressor control to supply appropriately the flow rate and pressure into the fuel cell.

This work realize the air management of a fuel cell system by controlling a centrifugal compressor. The control of a centrifugal compressor is challenging because of the strong coupling between its pressure and mass flow. The main difficulties for cen- 
trifugal compressor applications are pressure control and surge avoidance. Unlike displacement compressors, pressure control is challenging for centrifugal compressor as it is strongly coupled with the mass flow control. The mass flow has to be promptly regulated according to the load situations, which greatly varies the pressure ratio if it is not adjusted in time. In severe cases, the pressure may be dragged out of the normal operating region, which will paralyze the whole system. The highly nonlinear characteristic of mass flow, pressure, and speed also adds to the difficulty of pressure control. For the stack, large pressure ripples may damage the membrane and produce voltage pulsation, which should be avoided. In this work, a discharge valve is employed to control the pressure ratio.

For transportation applications of a fuel cell system, because of the load variations, the supplied mass flow has to be regulated accordingly to avoid fuel cell starvation [32]. Meanwhile, the air pressure also need to be controlled in order to achieve optimal power output. Large pressure ripples may shorten the stack life time and damage the fuel cell membrane in severe cases. Therefore, the pressure and mass flow control are crucial in operating of a fuel cell system. The control of a centrifugal compressor for fuel cell applications has been studied in $[41,47,48]$, where the only control variable is the motor input voltage, which cannot control the pressure and mass flow simultaneously. In [49,50], A PI controller and a sliding mode controller have been developed respectively to control the mass flow and pressure simultaneously. However, the coupling problem, which is a significant problem in the control of a centrifugal compressor, was not addressed. Therefore, the interaction between the air flow and pressure can reduce the control performance, therefore degrade the fuel cell performance.

For the implementation of a centrifugal compressor in a fuel cell system, surge constraint has to be considered to avoided the compressor surge. In [47, 48, 51, 52], reference/load governor approaches were proposed to restrict the current drawn from the fuel cell. Therefore the mass flow reference is changed according to the load governor. Then the compressor constraints, such as the surge and chock constraints, are fulfilled. This approach depends much on the power management system and the hybrid fuel cell configuration. In those literature, they supposed that the fuel cell current can be ideally distributed. Those reference governor were based on different control laws, such as robust and MPC approaches. But the computation is time consuming. 


\subsubsection{Objectives and methods}

1. Mass flow and pressure control. The air flow and pressure directly decide the output power of the fuel cell and have a great influence to the fuel cell safety. To control the mass flow and pressure simultaneously according to the load demand is the main research of this dissertation. The coupling degree of the centrifugal air compression system is analyzed by relative gain array (RGA) method. And the proper control pairs are determined for the two-input two-output system becoming a two-control-loop system. Two controllers, sliding mode controller and disturbance decoupling controller (DDC), are developed. The sliding mode controller regulates the mass flow and pressure independently through two decoupled control loops. However, because of the interaction the mass flow and pressure influence each other greatly especially during transient. Therefore a decoupling controller is necessary for this multivariable system.

Traditional model-based decoupling control technologies are not feasible for the centrifugal compression system because of the system's highly nonlinearity as well as the complexity of its mathematical model. In this paper, the dynamic disturbance decoupling control, which is derived from active disturbance rejection control (ADRC), is first implemented for the centrifugal compression system. ADRC, which is a drastic departure from both the PID and the model-based multivariable control paradigms, is a relatively new control design concept and a natural fit for strong coupling system [53-57]. The idea is that, the couplings among various channels are estimated and canceled in real time based on the measured input-output data, reducing the complicated multivariable control problem to a set of independent control loops [58]. Consequently, the control system can react promptly to the changes either in the internal dynamics of the plant, or its external disturbances. Such materialization of ADRC in multivariable control setting is denoted as dynamic disturbance decoupling control (DDC) in $[59,60]$. In this dissertation, a recently proposed dynamic DDC approach [59] is applied to the centrifugal compression system. Unlike many existing decoupling methods, the new method requires very little information of the plant dynamic. The essential information needed for the controller design is obtained not from a mathematical model but through the input-output data of the plant in real time.

2. Surge control. Surge is defined as the operating point at which the compressor 
peak head capability and minimum flow limit are reached. The compressor loses the ability to maintain the peak head when surge occurs and the entire system becomes unstable [61]. Surge is an unstable state, which gives rise to oscillations of mass flow and pressure ratio, and severely reduces compressor efficiency. Moreover, it can possibly damage the compressor in the most severe cases [62]. An effective and direct way to deal with the surge constraint is to make the compressor operate to the right of the surge line. In this dissertation, a reference limiter is designed to cope with the surge constraint. This reference limiter is a simple method to suppress the fast increase of the pressure by reconstructing its references. Then, the trajectory of the operation is controlled to the right of the surge line, thereby avoidance of the surge phenomenon.

\subsection{Thesis outline}

This dissertation is divided into five chapters. The current chapter has presented the compressor technologies for the air management of fuel cell systems. The requirements to the compressor for automotive applications has been discussed, such as compactness, low noise, oil free, etc.. Based on those requirements, an ultra-high speed, resulting in ultra-compactness, centrifugal compressor is adopted. The control challenges of the centrifugal compressor for fuel cell applications have been described. The control objectives and corresponding methods have been generally presented.

The model of the air management system, including the air compressor, valves and manifolds, is given in chapter 2. A fuel cell model is developed as well for the validation of the proposed controllers. The accuracy of the model depend much on the compressor map fitting. A neural network is used to fit the compressor map and it shows a good agreement with the experimental data. In Chapter 3, the system coupling is analysis and a DDC is developed to realize decoupling control of the compressor. The simulation results are compared with a decentralized sliding mode controller. Chapter 4 gives the experimental implementation of the proposed controller. And a reference limiter is used to prohibit the compressor surge. A hardware-in-the-loop (HIL) platform base on dSPACE1104 is adopted for the controller validation. Chapter 5 summarizes this research work and proposes the future work. The compressor selection, system modeling and controller development are summarized. And the future 
work is the implementation the proposed air management system on an actual fuel cell system. 


\section{AIR COMPRESSION SYSTEM MODELING FOR PEMFC SYSTEMS}

An ultra-high speed (maximum 280,000 rpm) centrifugal compressor is studied for the air management of PEM fuel cell systems. This motorized-compressor is designed by Celeroton Ltd, Switzerland. In this chapter, the characteristics of the compressor is described, including the structure, compressor map, efficiency, etc. Then the compression system is modeled, including the compressor, manifolds, the control valve, motor drives, etc. At last, a simple fuel cell stack model is developed for the validation of the proposed control method, i.e., disturbance decoupling control (DDC) in the following chapter.

\subsection{An ultra-high speed compressor}

The air compressor is designed for fuel cell applications, with the rated mass flow of $12 \mathrm{~g} / \mathrm{s}$ and a rated pressure of 1.4 bars. The inlet conditions are ambient pressure ( $1 \mathrm{bar}$ ) and $25^{\circ} \mathrm{C}$. The centrifugal compressor system consists of a radial impeller with splitter blades but no shroud, a vaneless diffuser and a spiral casing. The flow coefficient is a dimensionless parameter described relationship of the suction gas flow rate to impeller diameter and tip speed. Retaining an ideal flow coefficient of 0.085 , results in a centrifugal compressor with an impeller diameter of $21 \mathrm{~mm}$ and a rotational speed of $250,000 \mathrm{rpm}$. The assumed isentropic total-total efficiency is $74 \%$ [63] while the rated compressor power is $580 \mathrm{~W}$. The impeller optimization has been carried out with a $2 \mathrm{D}$ computational fluid dynamics (CFD) model [64] and verified with 3D-CFD simulations. The compressor and power map data for different rotational speeds and variable mass flow are calculated with a 1D-analytical design tool including correction factors based on empirical data from similar small high-speed compressors [65]. 


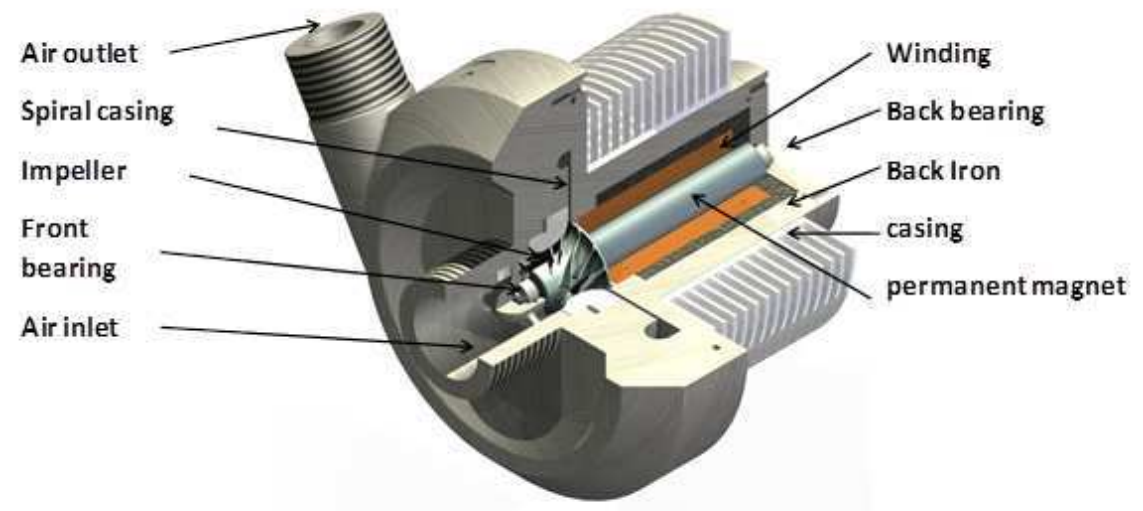

Fig. 16. Cross section view of the compressor.

A permanent magnet (PM) motor is employed for driving the compressor for the reason of very high power density with low losses. The electrical machine is designed for the rated specifications defined by the centrifugal compressor design: a rated rotational speed of 250,000 rpm and a shaft power of $580 \mathrm{~W}$. The peaks of speed and power are up to $280,000 \mathrm{rpm}$ and $1100 \mathrm{~W}$, respectively. The electrical machine design comprises several challenges such as the mechanical rotor design, particularly the stresses in the PM and the retaining titanium sleeve. Additionally, high rotational speeds increase the losses, mainly due to eddy current effects in winding, stator iron and the entire rotor (magnet, iron, sleeves), but also in higher air friction losses. For this reason, an optimization method has been developed, which takes air-friction losses, iron losses, copper losses, and eddy-current losses into account and minimizes the overall losses [66]. The rotor losses due to armature reaction is not part of the optimization process, but is calculated after optimization process. The stator magnetic field rotates with a high frequency (up to $4.66 \mathrm{kHz}$ ); it is therefore necessary to minimize the losses in the stator core by using amorphous iron and the eddy-current losses in the skewed air-gap winding by using litz wire. Specification of the PM motor is given in Table 1.

The rotor of the PM motor consists of a diametrically magnetized, cylindrical, SmCo $\mathrm{PM}$ encased in a retaining titanium sleeve ensuring sufficiently low mechanical stresses on the magnet (see Figure 17). The eccentricity is minimized by shrink-fitting the sleeve onto the PM and grinding the rotor. The two high-speed ball bearings are assembled at each end of the rotor in order to be able to change them without the need for disassembling the impeller. 
Table 1. Specifications of the PMSM.

\begin{tabular}{l|l}
\hline Number of pole pairs & 1 \\
Moment of inertia & $5.5 \times 10^{-7} \mathrm{~kg} \cdot \mathrm{m}^{2}$ \\
Rated/max power & $580 \mathrm{~W} / 1100 \mathrm{~W}$ \\
Rated/max torque & $22.9 \times 10^{-3} \mathrm{~N} \cdot \mathrm{m} / 37.5 \times 10^{-3} \mathrm{~N} \cdot \mathrm{m}$ \\
Rated/max frequency & $4.167 \mathrm{kHz} / 4.667 \mathrm{kHz}$ \\
Stator resistance & $0.9 \Omega$ \\
Stator inductance & $160 \mu \mathrm{H}$ \\
\hline
\end{tabular}

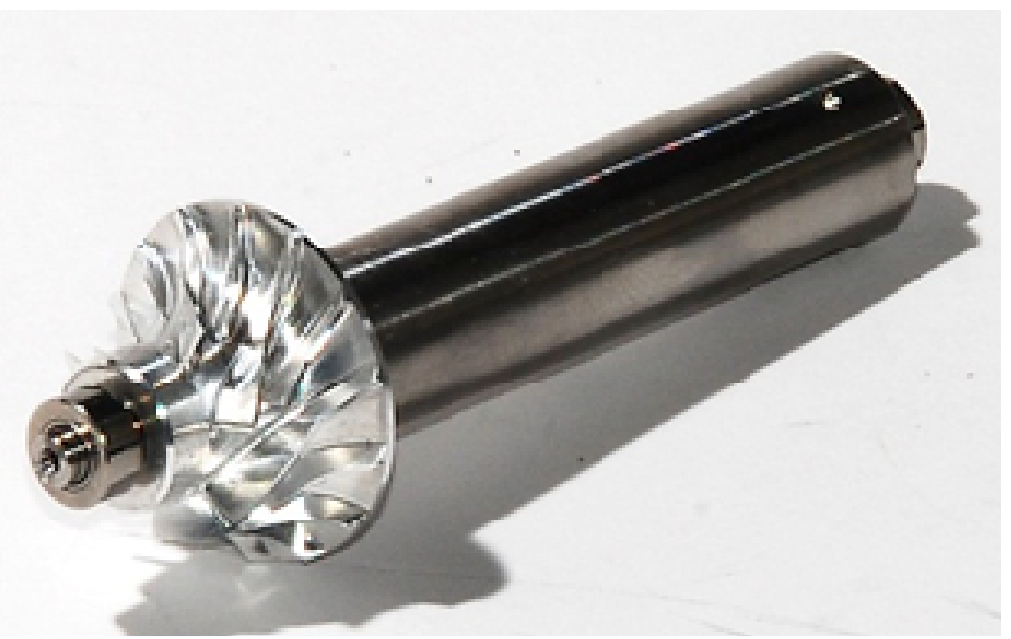

Fig. 17. Assembled rotor including impeller and high-speed ball bearings.

Besides the design of the individual components, rotor dynamics of the common rotor of the electrical machine and the centrifugal machine is required. The critical speeds of the rotor are depicted in Figure 18. In the field of rotordynamics, the critical speed is the theoretical angular velocity that excites the natural frequency of the rotor. As the speed of rotation approaches the object's natural frequency, the object begins to resonate, which dramatically increases system vibration. The critical speed calculations have been made during the electrical machine optimization process with an analytical approach in order to define geometric constraints for the machine. The final rotor dynamic design has been verified with 3D finite-element (FE) simulations. The rotor is designed such that the nominal speed of $250,000 \mathrm{rpm}$ is below the first bending mode (third critical speed), but above the two bearing modes (two first critical speeds). 


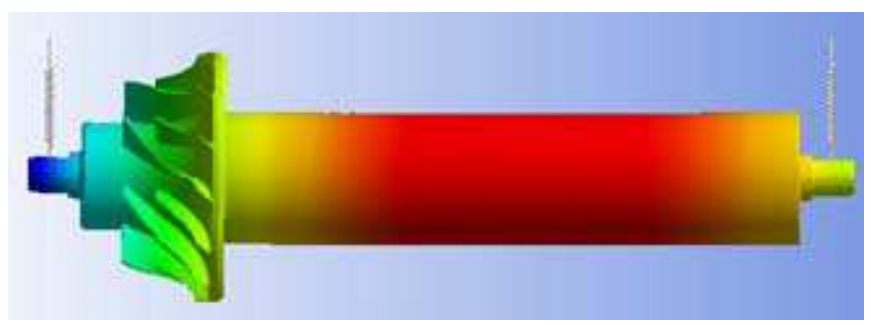

(a) First critical speed at $1.1 \mathrm{kHz}, 66000 \mathrm{r} / \mathrm{min}$.

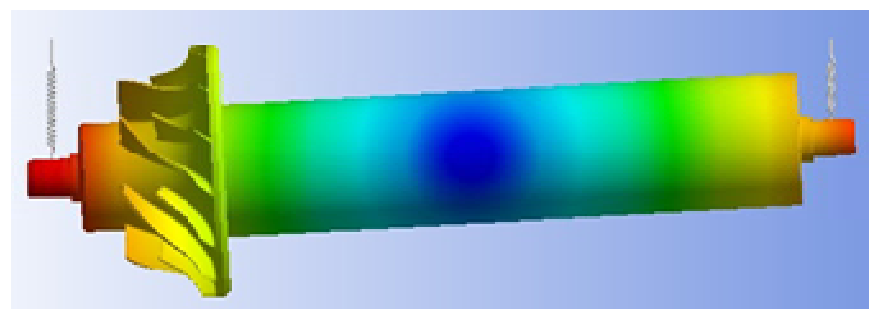

(b) second critical speed at $2.6 \mathrm{kHz}, 156000 \mathrm{r} / \mathrm{min}$.

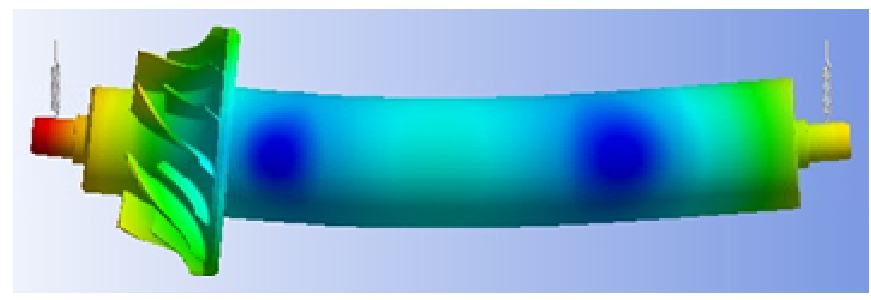

(c) third critical speed at $8 \mathrm{kHz}, 480000 \mathrm{r} / \mathrm{min}$.

Fig. 18. Critical speeds of the centrifugal compressor rotor. (Blue) No displacement. (Red) Maximal displacement.

The realized compressor prototype has a weight of $0.6 \mathrm{~kg}$ which is fifty times lower than a comparable scroll compressor. The compressor has been evaluated on a test bench. The measurement of the compressor and power map data is in very good agreement with the calculations as can be seen in Figure 19. The measured compressor efficiency in the rated operating point is $74.8 \%$ which is also very close to the designed efficiency. The motor and converter efficiency in the rated operating point is $92 \%$ and $90.6 \%$ respectively. This results in a total system efficiency of $62.3 \%$.

The centrifugal compression system is characterized by the compressor map, the actuator dynamics, and the manifold model. The compressor map gives the relation of speed, pressure, and mass flow. A speed motor controller and valve position controller, which are treated as embedded devices, have been developed and described. The manifold model describes the dynamics of the pressure and mass flow. 


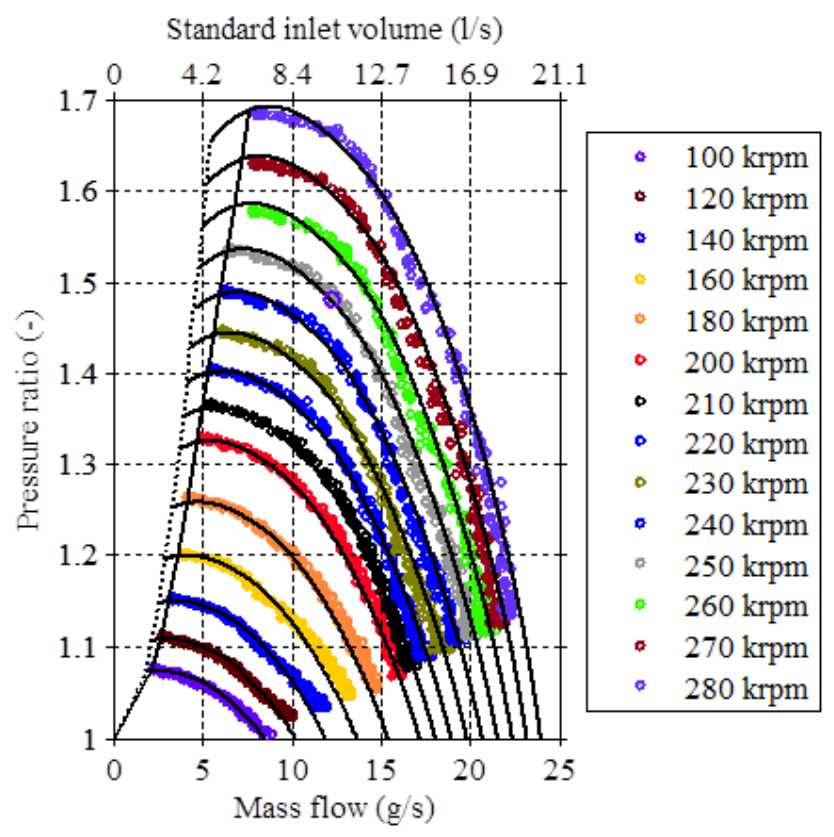

(a) Calculated and measured compressor map.

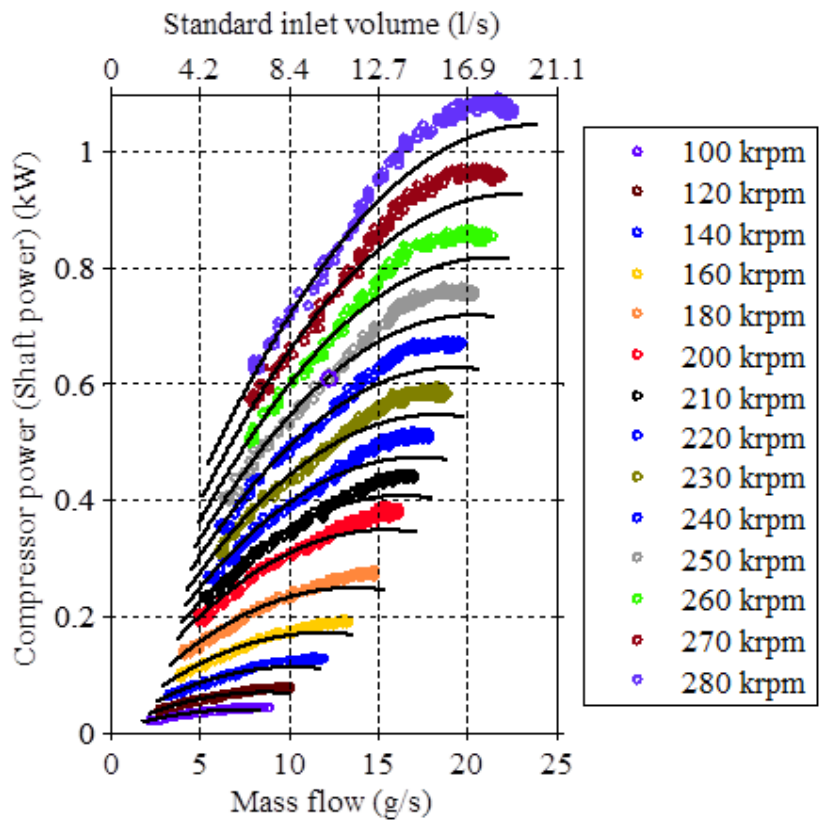

(b) Calculated and measured power map.

Fig. 19. Compressor maps. 


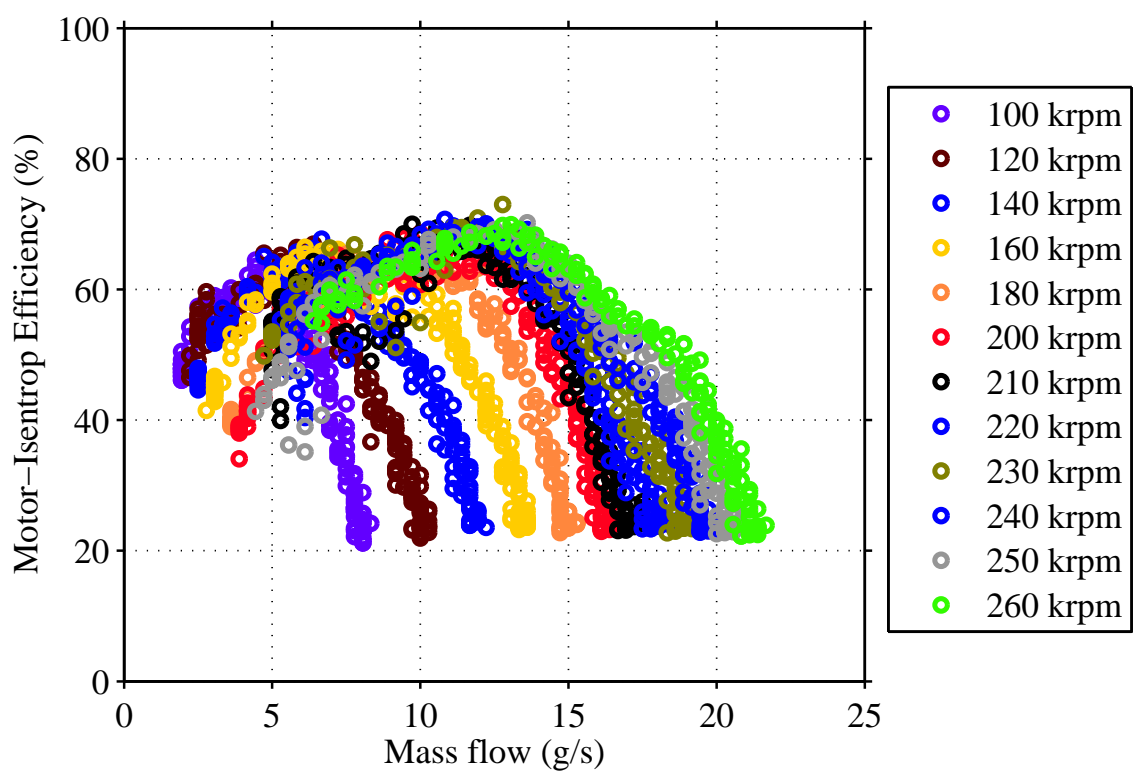

Fig. 20. Compressor efficiency map.

\subsection{Compressor modeling}

\subsubsection{Compressor map modeling overview}

The compressor map which gives the relationship of the speed $\omega$, mass flow $q$, and pressure ratio $p$ is one information we can get from the manufacturer. However, to find the mathematical relationship of the three variables is not an easy task. An accurate model of the compressor map can help us to analyze its characteristic and further adapt it to the air management system. Several methods have been described about the compressor map modeling in the literature.

J.Gravdahl et al. [67] described the compressor characteristic with a third order polynomial approximation which is obtained by the curve fitting using the measured data. The first step is to find the relation between the mass flow and pressure, fixing the speed constant. The second step is to fit the speed behavior through a third order polynomial equation with the coefficients to be determined.

In [68], auxiliary coordinates (lines $\beta$ ) which have no physical meaning, are introduced to describe the characteristic curves . In [69], with measured compressor characteris- 
tics, the coefficients of the theoretical implicit relations, Jensen \& Kristensen method, are determined by the curve fitting through least square methods. Many parameters, such as the compressor diameter, air density, air gas constant, etc., are needed in the theoretical equation.

R.Tirnovan et al. proposed and presented a moving least squares (MLS) algorithm for obtaining a surrogate model of the centrifugal compressor [70]. The use of MLS is justified by the fact that it is a powerful method for approximating a function when few data available.

Neural network based method was employed in [71-73] to develop the compressor map. A.Lazzaretto and A.Toffolo use the output power to predict the compressor performance (pressure, mass flow, efficiency, etc) through constructing a neural network [72].

A generalized compressor map was developed by Saravanamuttoo and MacIssac [74] using four different methods, including neural networks, and tested on three different compressors. And the fitting accuracies, model complexities, genericities and extrapolation capabilities are compared.

Compare with other fitting methods, the neural network technology is superior in terms of the fitting accuracy. Moreover little parameter information about the compressor is needed. Nevertheless, because of the complexity of the neural network model its computation is time consuming. However, for our applications, the compressor model is only used for the system analysis off-line, such as the coupling characteristics between the mass flow and pressure. Therefore, the complexity of the model dose not influence the control in real time. In this thesis, the neural network method is used for the map fitting.

\subsubsection{Compressor map measurement}

The measured compressor map normally has a great relation with the circumstances, such as the ambient temperature, the ambient pressure, and the accuracy of the sensors. Therefore, the compressor map is remeasured on our testbench instead of using the manufacture provided map. 


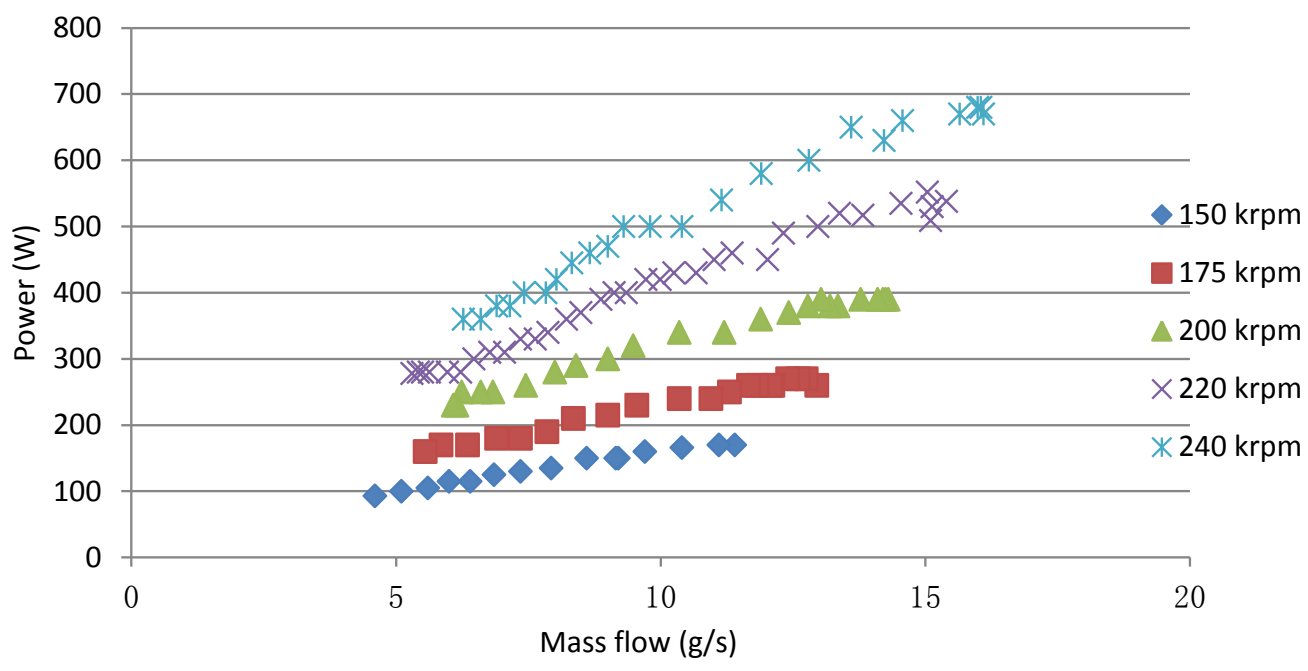

Fig. 21. Measured compressor power.

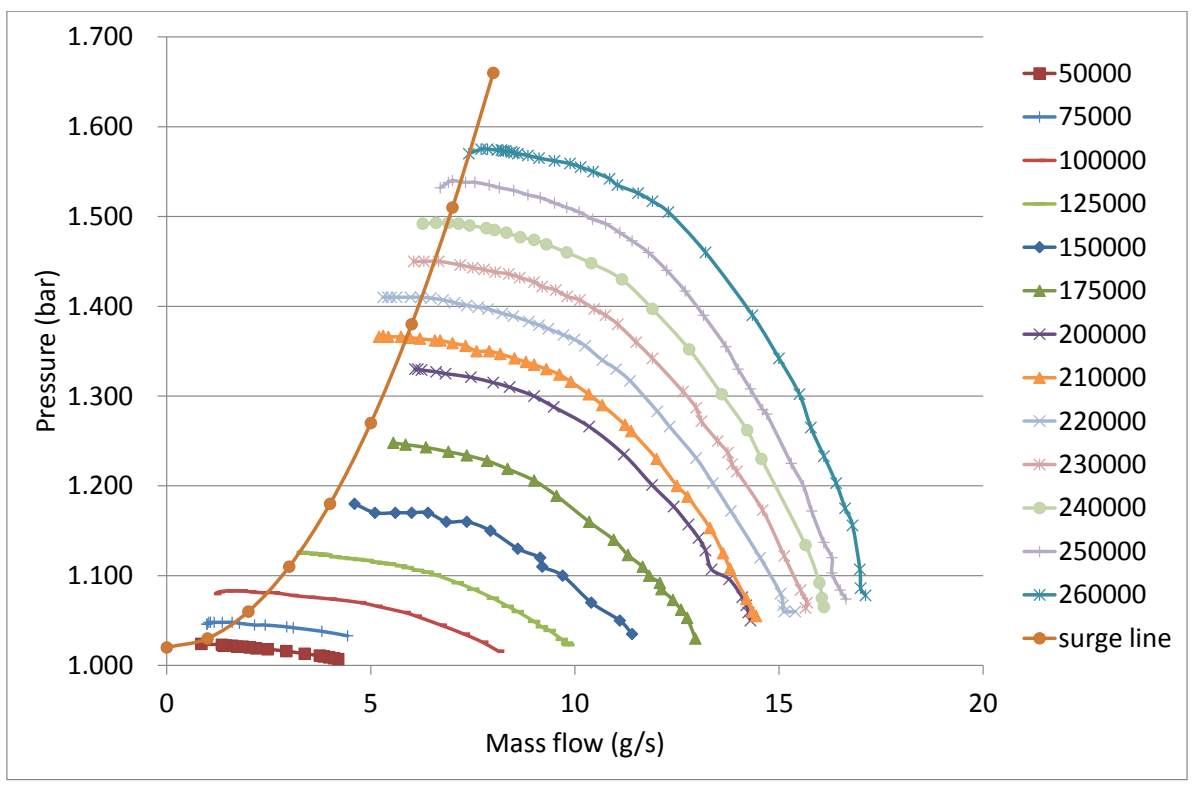

Fig. 22. Measured compressor map. 
By throttling down the compressor towards the surge line, the mass flow and pressure are measured while keeping the speed constant. The surge phenomenon is characterized by the large noise of the compressor with the oscillations of the mass flow and pressure. While measuring, at each point sufficient time is needed to wait the system operate at steady-state. The power at different speed is shown in Figure 21. The steadystate compressor map and the approximation of the surge line are measured as shown in Figure 22. As the measuring going close to the surge line, the pressure becomes nonsensitive to the mass flow variation. The system is not stable when operating to the left of the surge line.

\subsubsection{Neural network modeling}

A neural network is composed of groups of connected neurons, simple processing units, which has the ability of learning and storing knowledge obtained during the training. Normally, it consists of three components: input layer, hidden layers and output layer. In theory, a neural network can approximate an arbitrary mathematical function as long as the hidden layer has adequate number of neurons. In this thesis, a static BP based neural network with two hidden-layers is developed based on the measurement. The BP learning process works in iterative steps: The error between the network output and the known-good output is backwards each step to verify the weights in each layer reducing the error.

The structure of the trained network model is shown in Figure 23. This model is decided by training and evaluating different structures, from a simple one to the more complex structures. Maybe the selected one is not the most optimal approach having the minimum neurons. However, it will not influence the system analysis by the Simulink. The developed model involves two hidden layers and uses the speed and pressure to determine the mass flow. In the first hidden layer, tan-sigmoid is selected as the transfer-function. Whereas, purelin is the adopted transfer-function in the second hidden layer as well as the output layer. 


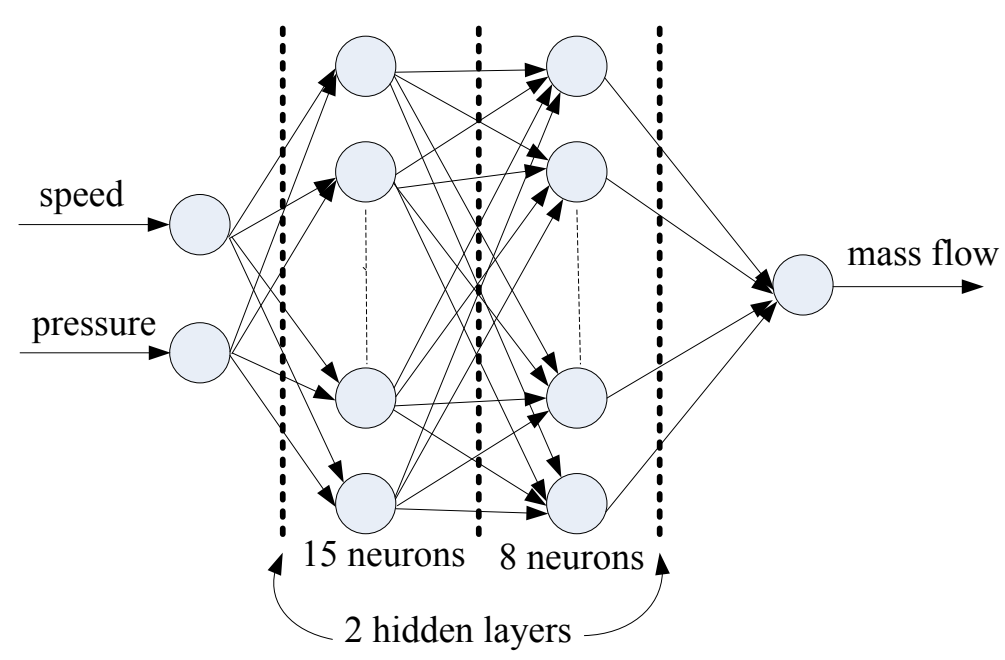

Fig. 23. Neural network model of the centrifugal compressor.

The equations used in this model are detailed as follows:

The output of the neural network model:

$$
q=\operatorname{purelin}\left(w_{1} \beta_{1}+w_{2} \beta_{2} \cdots w_{8} \beta_{8}+d\right)
$$

The second hidden layer outputs:

$$
\beta_{j}=\operatorname{purelin}\left(l_{1, j} \alpha_{1}+l_{2, j} \alpha_{2} \cdots l_{15, j} \alpha_{15}+e_{j}\right), j=1,2 \cdots, 8
$$

The first hidden layer outputs:

$$
\alpha_{i}=\operatorname{tansig}\left(a_{i} p+b_{i} \omega+c_{i}\right), i=1,2 \cdots, 15
$$

where $q, p, \omega$ are the mass flow, pressure and speed respectively. $w_{j}, l_{i, j}, a_{i}, b_{i}$ are the weight coefficients. $d, e_{j}, c_{i}$ are the biases. purelin $(\cdot)$ and tansig $(\cdot)$ are linear transfer function and hyperbolic tangent sigmoid transfer function respectively. The mathematical expressions of these two functions are purelin $(x)=x$ and $\operatorname{tansig}(x)=\frac{2}{1+e^{-2 x}}-1$ respectively. Summarizing (2.1)(2.2)(2.3), the final expression of $q$ can be expressed 


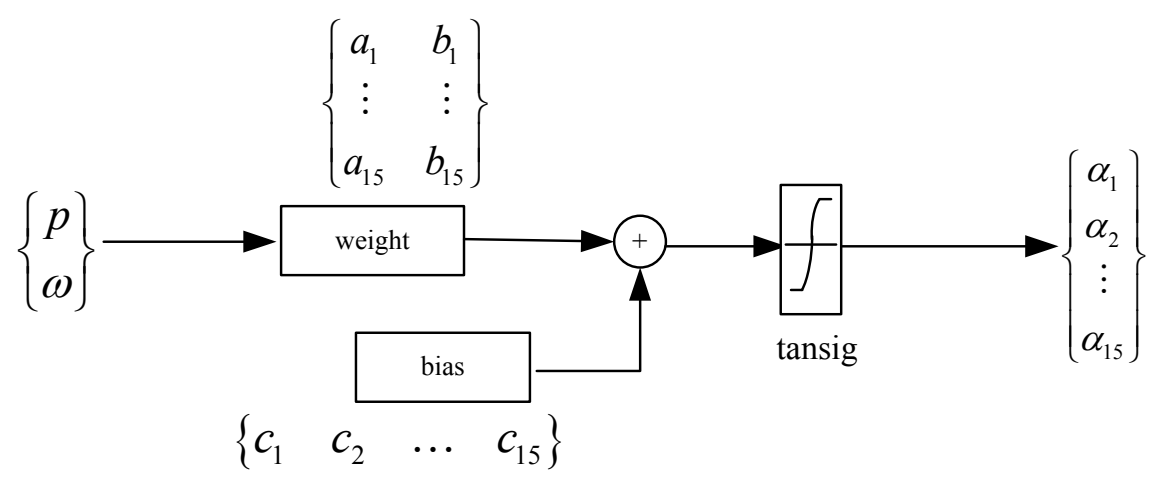

(a) The first hidden layer

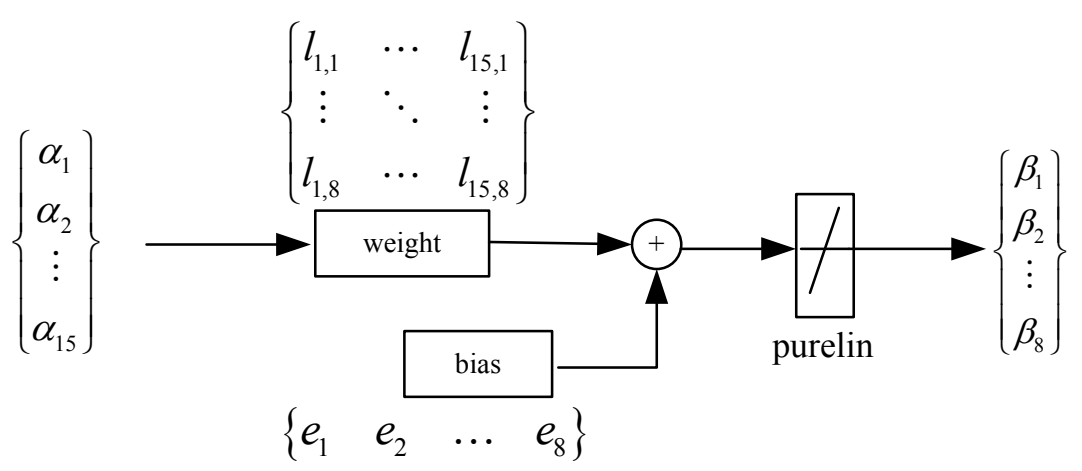

(b) The second hidden layer

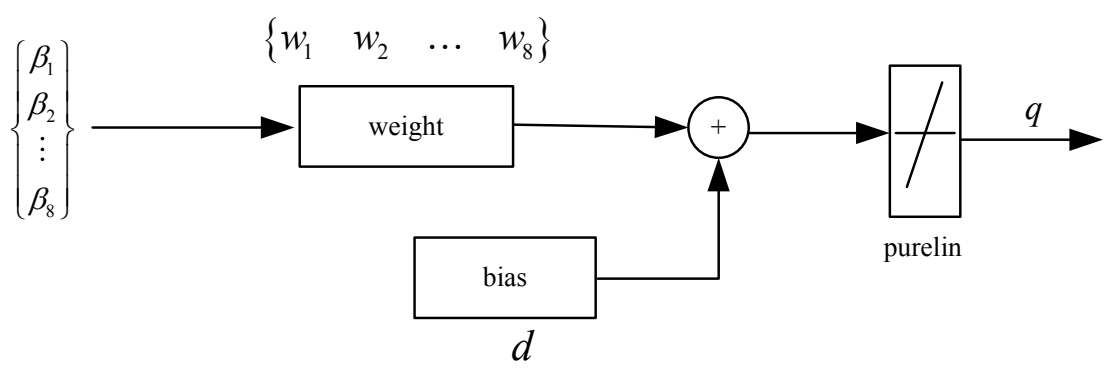

(c) Output layer

Fig. 24. Neural network layers.

as a function of $\omega$ and $p$ :

$$
\begin{aligned}
q=h(\omega, p)= & w_{1}\left(l_{1,1} \alpha_{1}+l_{2,1} \alpha_{2} \cdots l_{15,1} \alpha_{15}+e_{1}\right)+w_{2}\left(l_{1,2} \alpha_{1}+l_{2,2} \alpha_{2} \cdots l_{15,2} \alpha_{15}+e_{2}\right)+\cdots \\
& +w_{8}\left(l_{1,8} \alpha_{1}+l_{2,8} \alpha_{2} \cdots l_{15,8} \alpha_{15}+e_{8}\right)+d
\end{aligned}
$$


where

$$
\alpha_{i}=\frac{2}{1+e^{-2\left(a_{i} p+b_{i} \omega+c_{i}\right)}}-1, i=1,2, \cdots, 15 .
$$

In (2.4)(2.5), 182 parameters exist, which are obtained by the BP training algorithm. The structure of each layer are shown in Figure 24.

Figure 25 exhibits the map of the developed model, in accompany with the measured data. It shows that this model is in good agreement with the measurement.

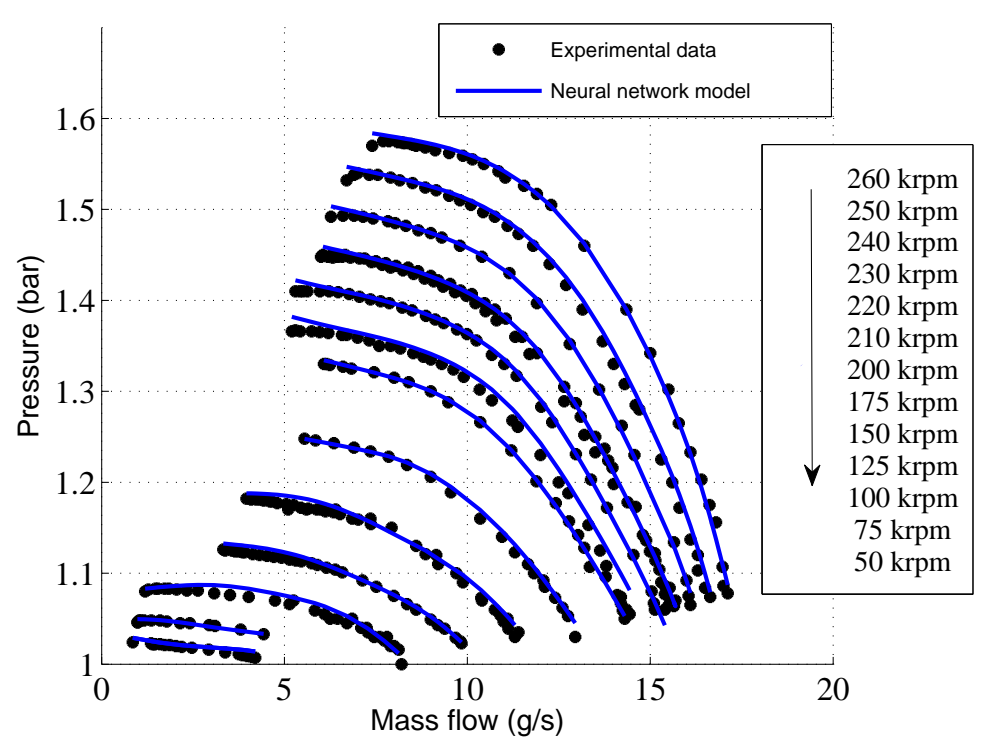

Fig. 25. The trained neural network model.

\subsection{Manifold modeling}

The manifold represents the lumped volume of the pipes between the compressor and the discharge valve. In fuel cell systems, it represents the cathode manifold. The dynamic of the air pressure in the manifolds is directly related to the compressor characteristic. According to the mass conservation principle, the dynamics of the air mass $m$ accumulated in the manifold volume and air pressure $p$ can be expressed by following equations $[47,69,75]$ :

$$
\frac{\mathrm{d} m}{\mathrm{~d} t}=q-q_{\text {out }}
$$




$$
\frac{\mathrm{d} p}{\mathrm{~d} t}=\frac{\gamma R}{M_{\text {air }} V}\left(q T_{\text {in }}-q_{\text {out }} T_{\text {out }}\right)
$$

where $q_{\text {out }}$ is the outflow rate. $T_{\text {in }}, T_{\text {out }}$ are temperatures of the gas going into and out of the manifold respectively. $M_{\text {air }}=0.029 \mathrm{~kg} / \mathrm{mol}$ is the molar mass of atmospheric air. $\gamma=1.4$ is the thermal ratio coefficient of the air and $R=8.31 \mathrm{~J} /(\mathrm{mol} \cdot \mathrm{K})$ is the universal gas constant. $V$ is the manifold volume. Thermal management subsystem normally exists in the fuel cell system. Therefore, we assume that the air temperature in the manifold is kept constant. That is $T_{\text {in }}=T_{\text {out }}=T$. Thus, the pressure dynamic can be expressed as follows:

$$
\frac{\mathrm{d} p}{\mathrm{~d} t}=\frac{R_{a} T}{V}\left(q-q_{\text {out }}\right)
$$

where $R_{a}=R / M_{a i r}$ is the air gas constant.

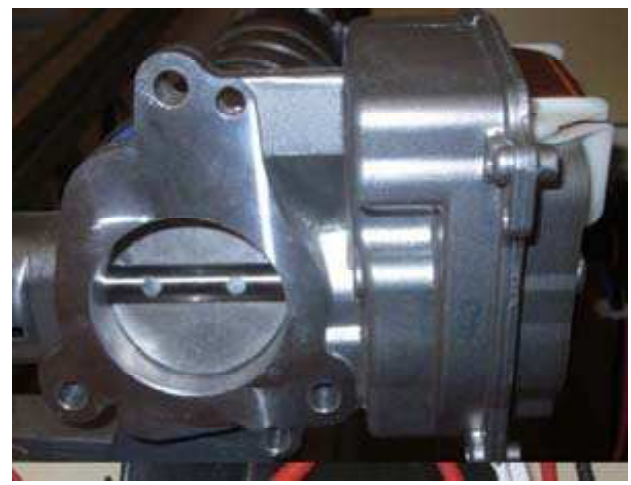

Fig. 26. butterfly valve.

A butterfly valve, as shown in Figure 26, is used to control the outlet flow. General nozzle flow equations are used to calculate $q_{\text {out }}$, which is divided into two regions by the critical pressure ratio $\xi$.

$$
\xi=\left(\frac{p_{a t m}}{p}\right)_{c r i t}=\left(\frac{2}{\gamma+1}\right)^{\frac{\gamma}{\gamma-1}}
$$

For $\frac{p_{a t m}}{p}>\xi$,

$$
q_{\text {out }}=C_{d} p A_{o} \sqrt{\frac{2 \gamma M_{\text {air }}}{(\gamma-1) R T}\left[\left(\frac{p_{\text {atm }}}{p}\right)^{\frac{2}{\gamma}}-\left(\frac{p_{\text {atm }}}{p}\right)^{\frac{\gamma+1}{\gamma}}\right]}
$$


Table 2. Thermodynamic constants and manifold parameters.

\begin{tabular}{l|l|l}
$M_{\text {air }}$ & $2.9 \times 10^{-2}$ & $\mathrm{~kg} / \mathrm{mol}$ \\
$\gamma$ & 1.4 & - \\
$R$ & 8.31 & $\mathrm{~J} /(\mathrm{mol} \cdot \mathrm{K})$ \\
$r_{v}$ & $2.18 \times 10^{-2}$ & $\mathrm{~m}$ \\
$V$ & $1.52 \times 10^{-3}$ & $\mathrm{~m}^{3}$ \\
\hline
\end{tabular}

For $\frac{p_{a t m}}{p} \leq \xi$

$$
q_{\text {out }}=C_{d} p A_{o} \sqrt{\frac{\gamma M_{\text {air }}}{R T}\left(\frac{2}{\gamma-1}\right)^{\frac{1+\gamma}{1-\gamma}}}
$$

$p_{a t m}$ is the atmosphere pressure, $C_{d}$ is the discharge coefficient of the Nozzle and $A_{o}$ is the opening area of the valve. Define the valve position (valve angle) $\theta$, let:

$$
\sin (\theta)=\frac{A_{o}}{A_{v}}
$$

where $\theta \in[0 \pi / 2] . A_{v}$ is the area of the valve. Note that $\theta$ is not the real valve opening angle. This substitution not only simplifies the controller development but also reserves the intuitive concept of the position. According to (2.12), $A_{o}$ can be expressed as [44]:

$$
A_{o}=\pi \cdot r_{v}^{2} \cdot \sin (\theta)
$$

where $r_{v}$ is the radius of the valve. In the applications, $\theta$ normally operates at a small value, $\theta<\pi / 10$, to keep the pressure at the nominal operating point. Therefore, $\sin (\theta) \approx \theta$.

The critical pressure ratio $\xi$ is equal to 0.528 according to the equation (2.9). In our test conditions, the pressure $p$ is below $1.6 \mathrm{bar}$. Assuming $p_{\text {atm }}=1 \mathrm{bar}$, gives $p_{\text {atm }} / p>$ $1 / 1.6>\xi$. Therefore, only (2.10) is used for the mathematical model development. The parameters of the manifold are given in Table 2 . 


\subsection{Actuators modeling}

The motorized compressor is driven by a pulse amplitude modulation (PAM) converter, shown in Figure 27, which consists of a standard 3-phase inverter, an additional buck converter and a DSP-based control system. Compared with PWM, PAM is more suitable for high frequency converter. The inverter part is controlled in six-step or block commutation mode, i.e. each switch is conducting for $120^{\circ}$ electrical degrees, and therefore, switched with the fundamental frequency of the electrical machine. The DC/DC buck converter controls the phase currents and therefore the torque of the machine. Therefore no high switching frequencies occur in the inverter leading to low switching losses. Furthermore, the PAM generates currents with low high-frequency harmonics, which also results in low losses in the slotless motor topology applied in the compressor. Further loss analysis in converter and motor is presented in [76].

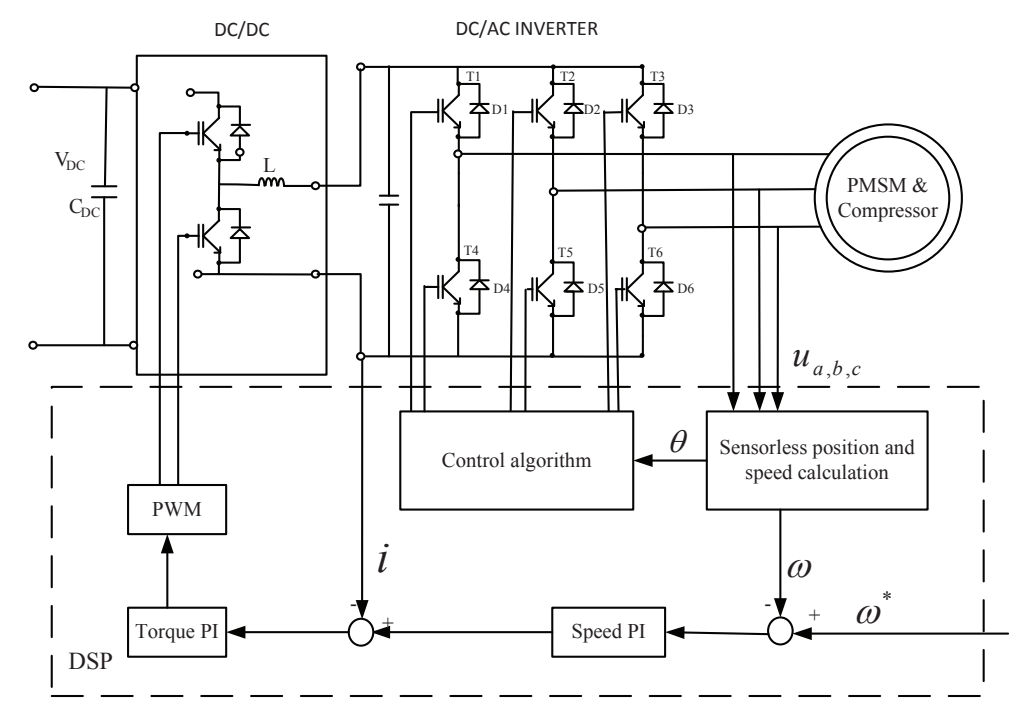

Fig. 27. Pulse amplitude modulation (PAM) power electronics and control system for driving an ultra-high-speed PMSM.

A sensorless rotor positioning technique eliminates the disadvantages of the present of rotor position sensors. For an inverter with $120^{\circ}$ block commutation, the motor back EMF (electro-motive force) containing the position information can directly be measured during the $60^{\circ}$ electrical degrees off intervals in each phase. The rotor position directly sets the state of the inverter. The speed information is passed over to the speed controller, which sets the required torque which is proportional to the required 
phase current. Since the low back EMF at low speeds leads to low amplitudes of the sensorless control signals, the starting of the machine can be achieved with impressed currents and a speed ramp. Further information to the sensorless control technique and the power electronics have been presented in [77-79].

Since a well tuned speed controller, which is not in the scope of this dissertation, is developed, for simplicity, the speed dynamic is deemed as an inertia element:

$$
\frac{d \omega}{d t}=\frac{1}{T_{m}}\left(\omega^{*}-\omega\right)
$$

where $T_{m}$ is the time constant which relates to the motor inertia and load situations.

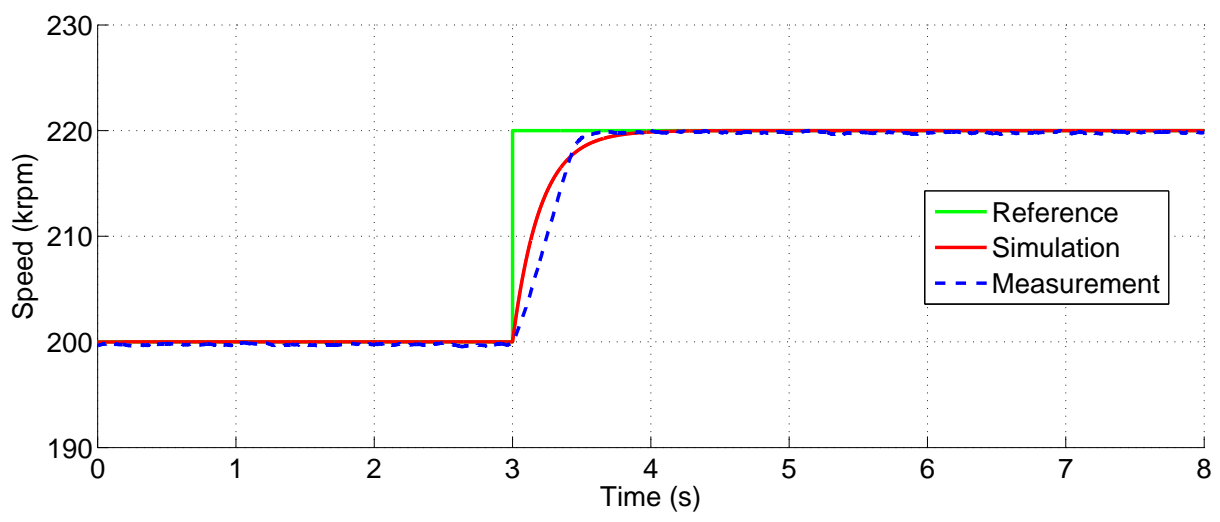

(a)

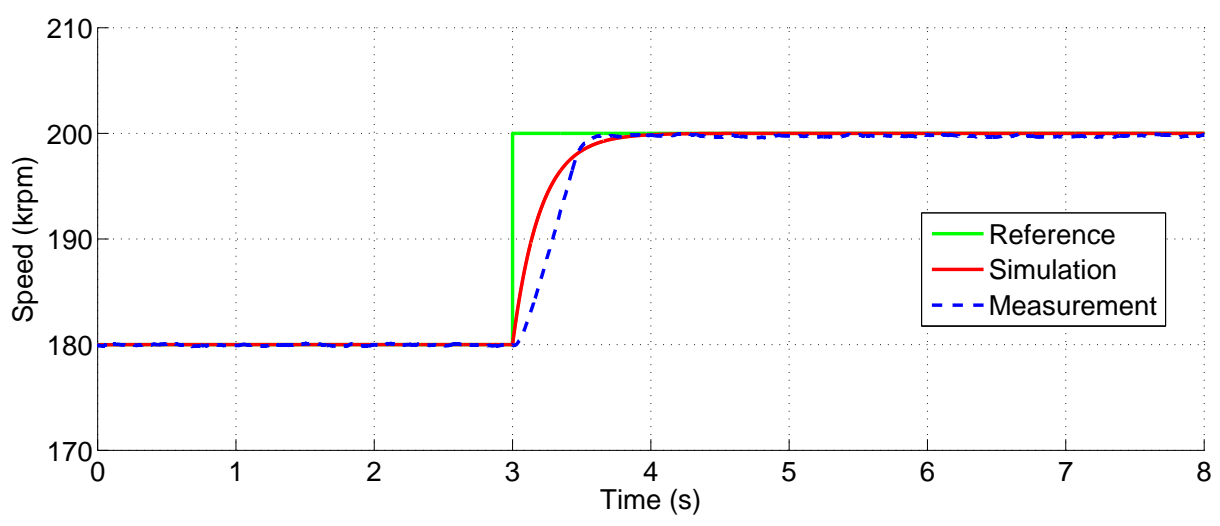

(b)

Fig. 28. Comparison of the speed dynamics between the measurement and the simulation with $T_{m}=0.2$. 
With $T_{m}=0.2$, speed dynamics of the simulation and experimental measurements are shown in Figure 28. The inaccuracy introduced from this assumption is treated as an external disturbance $w_{m}$ in this dissertation, that is $T_{m}=0.2+w_{m}$.

In the system, a fast butterfly valve is implemented to control the pressure ratio. A valve controller based on PI control algorithm is designed to control the valve position as shown in Figure 29. The valve position $\theta$ is proportional to the current $i_{v l}$ flowing through the converter, $\theta \propto i_{v l}$. As the valve has a very small inertia, compared with compressor speed, mass flow and pressure, the valve position has a much faster response time. In this case, the valve position $\theta$ can be deemed as input directly instead of $i_{v l}$. Figure 30 shows the valve position dynamics which have a good reference tracking performance as well as a fast response.

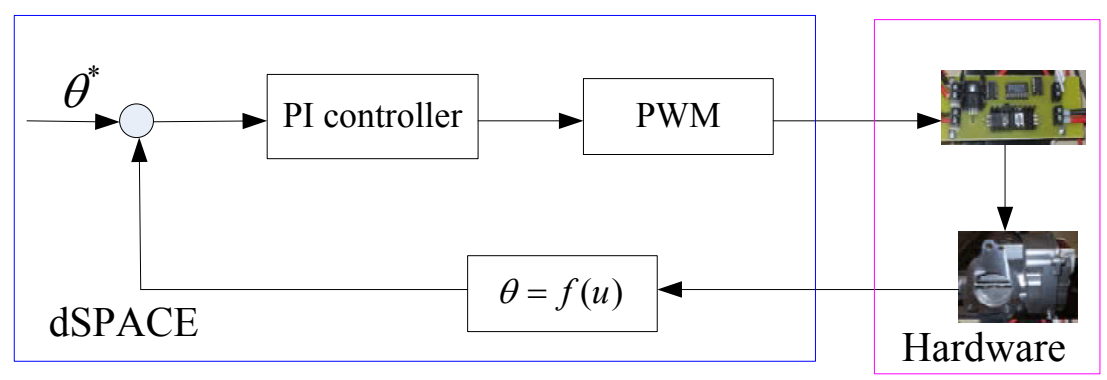

Fig. 29. Valve controller.

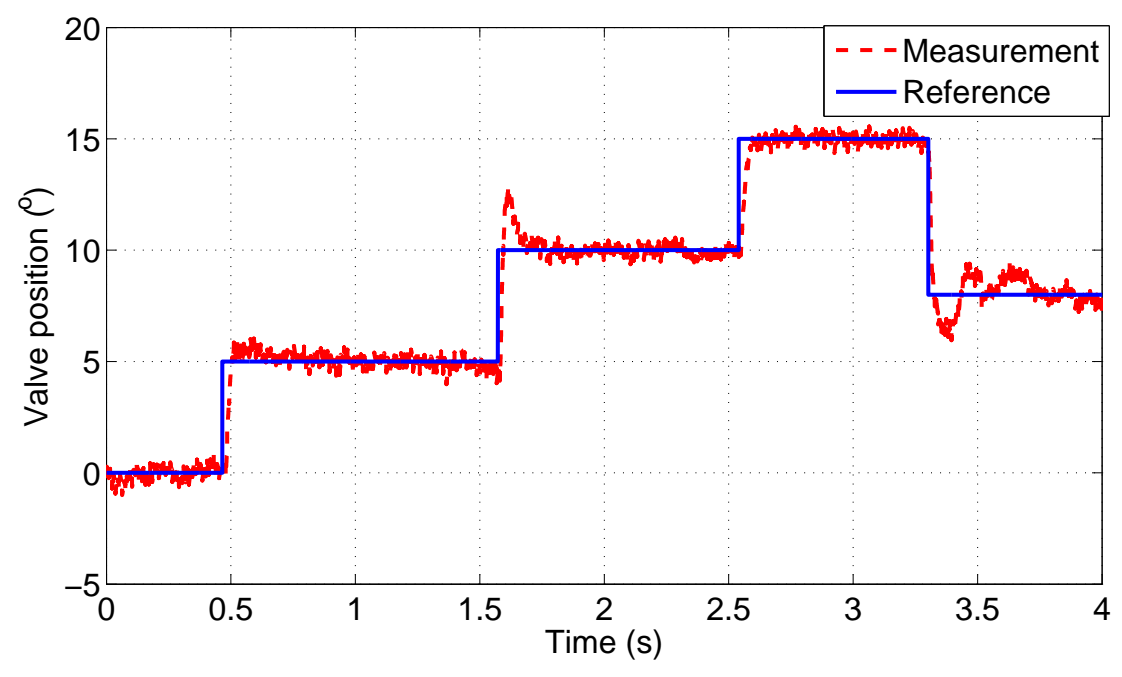

Fig. 30. Valve position dynamics under the PI control. 


\subsection{Fuel cell stack model}

An comprehensive fuel cell stack model reported in [69] is adopted for the validation of the control methodology. The mass flow rate of oxygen entering the cathode $q_{o_{2}, \text { in }}$, and that of consumed in the cathode $q_{o_{2}}$,reacted are calculated as follows:

$$
\begin{gathered}
q_{o_{2}, \text { reacted }}=M_{o_{2}} \frac{N_{c e l l} I_{s t}}{4 F} \\
q_{o_{2}, \text { in }}=\chi_{o_{2}} \cdot q_{c a, i n}
\end{gathered}
$$

where $M_{O_{2}}$ is the molar mass of the oxygen, $N_{\text {cell }}$ is the number of cells, $F$ is the Faraday constant, $\chi_{\mathrm{O}_{2}}$ is the oxygen molar fraction in the air. According to (2.15),(2.16), and taking the relative humidity of the air, $\phi_{a t m}$, into account, the final expression of the air mass flow reference $q^{*}$ results in [41]:

$$
q_{\text {ref }}=\left(1+\phi_{a t m}\right) \frac{1}{\chi_{o_{2}}} \lambda_{o_{2}, r e f} M_{o_{2}} \frac{N_{\text {cell }} I_{s t}}{4 F}
$$

where $\lambda_{o_{2}, \text { ref }}$ is the reference of oxygen excess ratio. The oxygen excess ratio, $\lambda_{o_{2}}$, is defined as

$$
\lambda_{o_{2}}=\frac{q_{o_{\text {in }}}}{q_{o_{\text {reacted }}}}
$$

The stack output voltage $V_{\text {stack }}$ is modeled from a single-cell static characteristic [25, 69]:

$$
V_{\text {stack }}=\left(E_{o c}-V_{\text {ohmic }}-V_{\text {act }}-V_{\text {trans }}\right) \times N_{\text {cell }}
$$

where $N_{\text {cell }}$ is the number of cells. $E_{o c}$ is the open circuit voltage which relates to the partial pressures of hydrogen and oxygen inside the stack $[25,69,80]$.

$$
\begin{gathered}
E_{o c}=1.229-0.85 * 10^{-3}\left(T_{f c}-298.15\right)+4.3085 * 10^{-5} \\
* T_{f c} *\left[\ln \left(p_{H_{2}}\right)+0.5 \ln \left(p_{o_{2}}\right)\right]
\end{gathered}
$$

where $T_{f c}$ is the temperature of the stack expressed in Kelvin. $p_{H_{2}}$ and $p_{o_{2}}$ are the partial pressures (in atm) of hydrogen and oxygen, respectively.

Denote current density by $i$. Then, ohmic losses $V_{\text {ohmic }}$, activation losses $V_{\text {act }}$ and transport losses $V_{\text {trans }}$ are explained as follows $[69,81]$ : 
1. $V_{\text {ohmic }}=i r$ is due to the electrical resistance of the electrodes, and the resistance to the flow of ions in the electrolyte. $r\left(\Omega \cdot \mathrm{m}^{2}\right)$ represents the fuel cell internal electrical resistance [82].

2. $V_{a c t}=A \ln \left(\frac{i}{i_{0}}\right)$ is due to the electrochemical irreversible reactions. Both $\mathrm{A}$ and $i_{0}$ are constants, which can be determined empirically. This equation is only valid for $i>i_{0}$. A more general equation is given in [69], valid for the entire range of $i$ : $V_{a c t}=v_{o}+c_{1}\left(1-e^{-c_{2} i}\right)$. $v_{o}$ is the voltage drop at zero current density. $c_{1}$ and $c_{2}$ are constants related to the temperature and partial pressure.

3. $V_{\text {trans }}=i\left(c_{3} \frac{i}{i_{\max }}\right)^{c_{4}}$ results from the variation of the reactant concentration at fuel cell catalyst interface as the fuel is consumed. $c_{3}$ and $c_{4}$ are constants that depend on the temperature and the reactant partial pressure and can be determined empirically.

The relation of the current density $i\left(\mathrm{~A} / \mathrm{m}^{2}\right)$, the stack current $I_{s t}(\mathrm{~A})$, the number of cells $N_{\text {cell }}$, and the total active surface area $S_{\text {tot }}\left(\mathrm{m}^{2}\right)$ is given by [25]:

$$
i=\frac{I_{s t} N_{\text {cell }}}{S_{\text {tot }}}
$$

Thus, the fuel cell power is calculated as follows:

$$
P_{s t}=I_{s t} \cdot V_{\text {stack }}=N_{\text {cell }} \cdot V_{\text {cell }} \cdot I_{s t}
$$

where $V_{\text {cell }}$ is the single cell voltage.

In this model, we assume that cooling system, fuel supply system are appropriately controlled. Therefore, the fuel cell stack temperature, hydrogen pressure can be kept at constant. And the fuel cell stack is ideally conditioned by a humidifier to certain humidity [33].

\subsection{Conclusions}

This chapter has presented the modeling of the air compression system based on an ultra-high speed centrifugal compressor. The compressor map is firstly measured, and then based on which a neural network model has been developed. The dynamics of the 
air in the manifold has been modeled. Moreover, the properties of the actuators i.e., motor and valve have also been analyzed. A fuel cell system model is developed for the controller validation, assuming that other subsystems, such as humidifier, cooling subsystem, fuel supplied subsystem, etc., are well controlled.

For the model validation, we give the same inputs (compressor speed and valve position) to the developed model and actual system and then compare their outputs (pressure and mass flow).

With the developed model, the dynamics of the pressure and mass flow are shown in Figure 31. The output differences between the model and the actual system are mainly because of the inaccuracies of the measurement, such as valve position, compressor speed, mass flow, and pressure, etc. At the same time, the discrepancies of the system parameters, manifold volume for instance, also lead to the mismatch. The experimental results have shown that the simulation model shows a good accuracy with the actual system. 


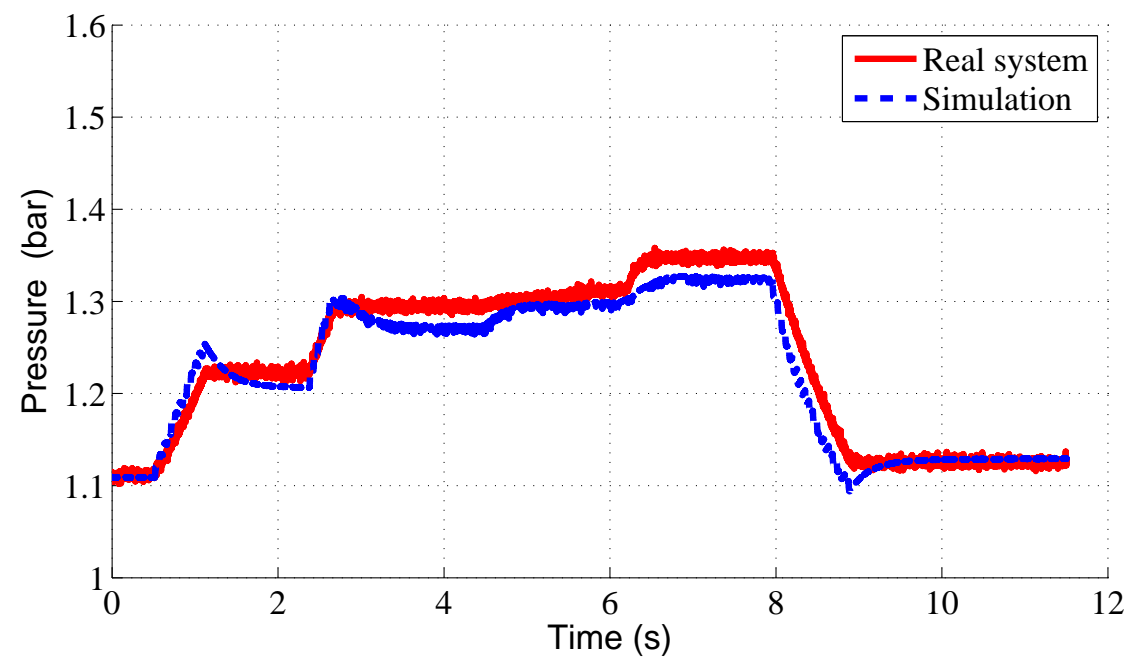

(a) pressure ratio response

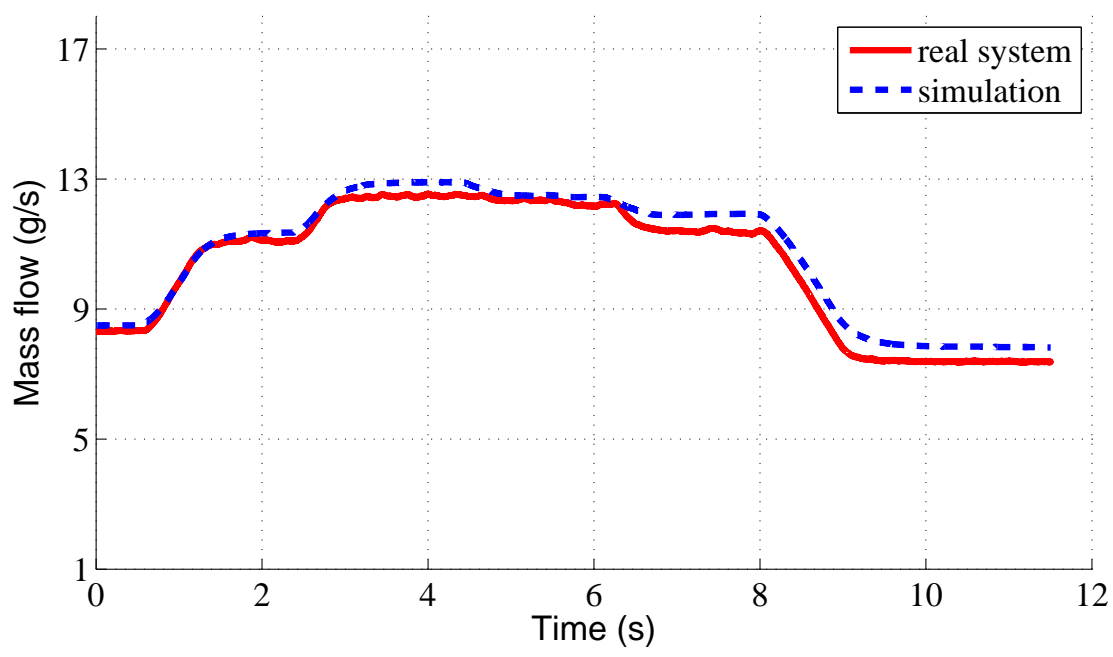

(b) mass flow response

Fig. 31. Simulation and experimental results of the system. 


\section{CONTROLLER DESIGN AND SIMULATION}

\subsection{Introduction}

Centrifugal air compression system is a highly nonlinear and multivariable device. Both of the mass flow and pressure need to be controlled in time for fuel cell applications. One the one hand, the mass flow has to be adjusted according to the load requirement. On the other hand, the pressure should be controlled at the desired value to make the fuel cell operate efficiently. Fast response of the mass flow is a fundamental requirement of fuel cell to avoid stack starvation. To protect the membrane, large variations of the pressure and pressure ripples are not allowed.

For centrifugal compressor, the control challenge lies in the coupling between the mass flow and pressure both of which are affected by the compressor speed. With a fixed area of the outlet orifice, both the mass flow and pressure increase (decrease) as the speed increases (decreases). It means that they cannot be independently controlled by the only one control variable, i.e.,compressor speed. A discharge valve, located after the compressor, is normally used to control the pressure. In this situation, the air compression device becomes a two-input two-output, as well as input-output coupled, system. The abrupt mass flow variation may greatly change the pressure, which is not allowed in the operation of fuel cell systems. Therefore, the fast response time of the pressure control is very important. It could be realized by utilizing a fast-response discharge valve. In this dissertation, a fast butterfly valve is employed. In this case, the pressure can be controlled in time to avoid deviations caused by the mass flow changes.

For a multi-input multi-output (MIMO) system, the appropriate input-output pairing is very important for the controlling. Inappropriate pairing may degrade the control performance or even lead to failure. The coupling among those control loops also deteriorates the control performance. Normally two control methods can be considered 


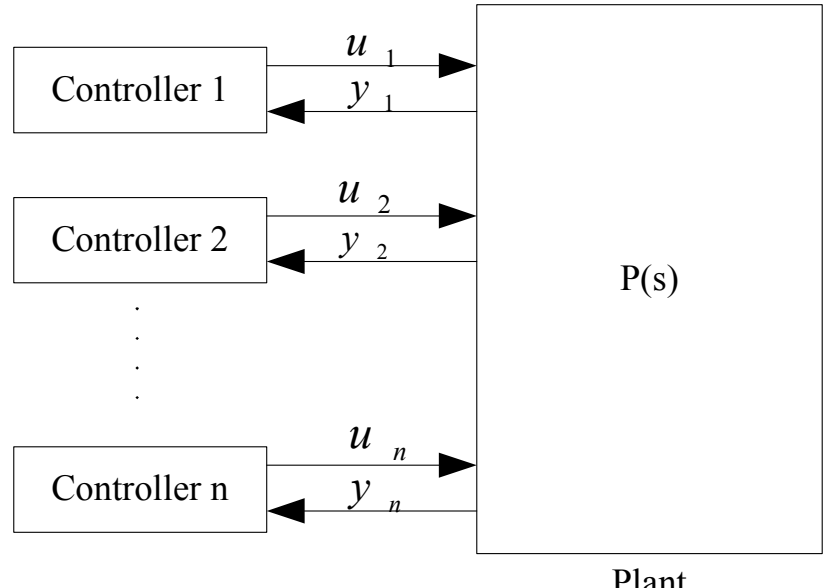

(a) A decentralized controller

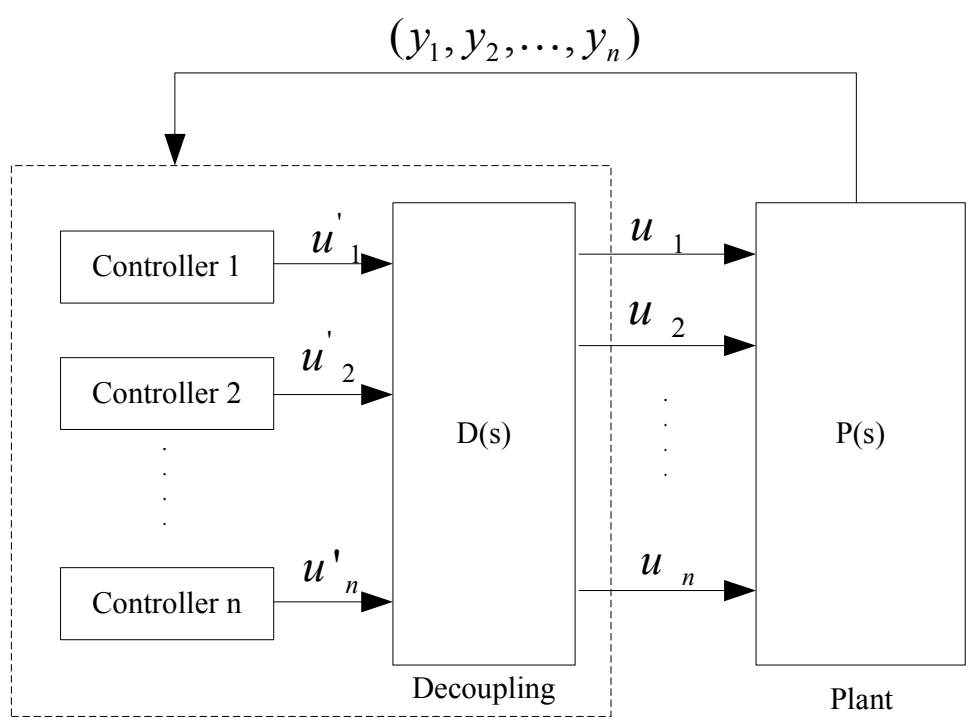

(b) A decoupling controller.

Fig. 32. Controllers for MIMO system. 
for MIMO system: decentralized (independent) control and decoupling (centralized) control, as shown in Figure 32. Because the decentralized approach does not consider the interaction between the multi control loops it need little information about the linkage among those independent loops. Decentralized controller is capable of dealing with MIMO control problem if only weak couplings exit. In contrast, the decoupling control which aims to cancel the interaction between different control loops is more suitable for MIMO system. At the same time, more effort is needed to analysis the system coupling.

In this chapter, the coupling degree between the mass flow control and pressure control is firstly analyzed by relative gain array (RGA) method. And the proper control pairs is then determined. A dynamic decoupling controller, namely disturbance decoupling control (DDC) is developed to eliminate/weaken the interaction between the mass flow control and pressure control. To verify the effectiveness of the decoupling, a decentralized controller based on sliding mode method is also designed for comparison purpose. And finally, the performances of those two controllers are compared by simulations.

\subsection{Compressor coupling analysis}

A centrifugal compressor is characterized by the speed, mass flow and pressure. The highly nonlinearity and interactions among those variables lead to the difficulty in the controller design. As an actuator, a butterfly valve is installed at the outlet of the compressor. The valve position, $\theta$, influences both the pressure and mass flow. The structure of centrifugal compressor system is shown in Figure 33. The coupling between the inputs and outputs has to be analyzed to get the appropriate control pairing. The speed of the compressor is obtained through a motor drive. And the valve position is controlled by a PI controller.

The centrifugal compressor system can be expressed as following:

$$
\left[\begin{array}{c}
q(s) \\
p(s)
\end{array}\right]=\left[\begin{array}{ll}
G_{p 11}(s) & G_{p 12}(s) \\
G_{p 21}(s) & G_{p 22}(s)
\end{array}\right]\left[\begin{array}{c}
\omega(s) \\
\theta(s)
\end{array}\right]
$$

Here, we define:

$$
G_{p}(s)=\left[\begin{array}{cc}
G_{p 11}(s) & G_{p 12}(s) \\
G_{p 21}(s) & G_{p 22}(s)
\end{array}\right]
$$




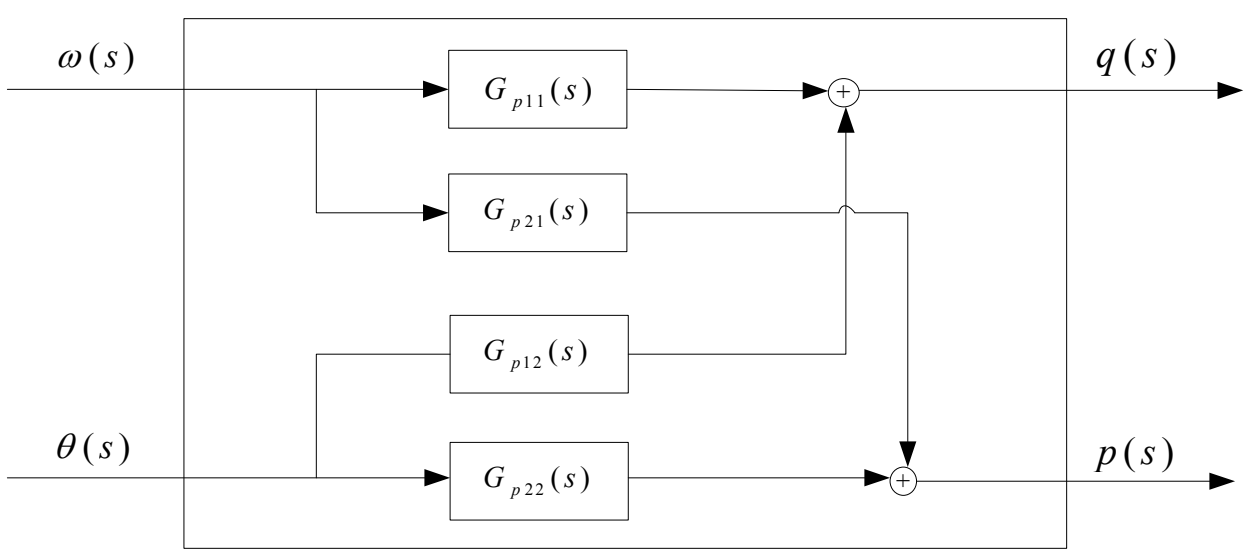

Fig. 33. Block diagram of the centrifugal compressor.

Since the system is highly nonlinear, the $G_{p}(s)$ is a variable quantity, changing as the operating point changing. Hence, the coupling degrees at varied operating points are also different. Relative gain array (RGA) method is used to analysis the coupling degree of the system. RGA method is a theory developed by Bristol in 1966 to quantify the degree of interaction and get the proper pairings of input and output signals. The RGA is a complex non-singular square matrix. For this two-input two-output system, the RGA is a $2 \times 2$ matrix:

$$
R G A=\left[\begin{array}{ll}
\lambda_{11} & \lambda_{12} \\
\lambda_{21} & \lambda_{22}
\end{array}\right]
$$

Let $u_{j}$ and $y_{i}$ denote a particular input-output pair for the multivariable system. $u_{j}$ is the $j$ th input and $y_{i}$ is the $i$ th output. Then, two extreme cases are studied:

Case 1 , keeping other inputs constant (open loop), $u_{r}=$ cont,$r \neq j$, calculate

$$
g_{i j}=\left.\frac{\partial y_{i}}{\partial u_{j}}\right|_{u_{r}=\text { cont },(r \neq j)}
$$

Case 2, keeping other outputs constant (closed loop), $y_{r}=$ cont,$r \neq i$, calculate

$$
g_{i j}^{*}=\left.\frac{\partial y_{i}}{\partial u_{j}}\right|_{y_{r}=c o n t,(r \neq i)}
$$

Then $\lambda_{i j}$ in (3.3) is defined as

$$
\lambda_{i j}=\frac{g_{i j}}{g_{i j}^{*}}
$$


Assuming that the system's zero frequency transfer matrix is $G_{p}(0)$, its RGA is given by:

$$
R G A=G_{p}(0) \times\left(G_{p}^{-1}(0)\right)^{T}
$$

where $G_{p}^{-1}(0)$ is the inverse of transfer matrix at zero frequency. $T$ denotes the transpose of the matrix. $\times$ denotes element-by-element multiplication. For square systems, the RGA has the unique property that all the elements in a row or column sum to unity. Relative gains in the range 0 to 1 indicate moderate interaction, with values of 0.5 being the worst. To minimize interaction, variables with relative gains closest to 1 should be paired. Variables with negative gains should not be paired for control, and relative gains of greater than 5 usually imply severe loop interaction [83].

For the centrifugal compressor system, the degree of the coupling is not an constant because of its nonlinearity. In order to get the transfer function at different operating points, the system is linearized at a wide range of different operating points by linear analysis tool in Simulink. The first step is to specify the input and output signals. Then, run the simulation to the desired operating point until it is stable. At last linearize the model at this point. Using the analysis tool the transfer matrix can then be obtained. Hence, the RGA at the specified operating point can be obtained by equation (3.6). Using MATLAB code, this process is executed in multiple loops with different specified operating points. Then, the RGA of the system is obtained, as shown in Table 4.

Table 3. The RGA of the centrifugal compressor at different operating points.

\begin{tabular}{|c|c|c|c|c|c|}
\hline \multicolumn{2}{|c|}{$\mathrm{p}=1.40$ bar } & \multicolumn{2}{|c|}{$\mathrm{p}=1.30 \mathrm{bar}$} & \multicolumn{2}{|c|}{$\mathrm{p}=1.20$ bar } \\
\hline$q(g / s)$ & RGA & $q(g / s)$ & RGA & $\mathrm{q}(\mathrm{g} / \mathrm{s})$ & RGA \\
\hline \multirow{2}{*}{15.85} & $0.6959 \quad 0.3041$ & \multirow{2}{*}{15.89} & $0.7279 \quad 0.2721$ & \multirow{2}{*}{15.12} & $0.7842 \quad 0.2158$ \\
\hline & 0.3041 & & 0.2721 & & 0.2158 \\
\hline \multirow{2}{*}{14.86} & 0.6679 & \multirow{2}{*}{14.96} & 0.7008 & \multirow{2}{*}{14.00} & 0.7592 \\
\hline & $\begin{array}{ll}0.3321 & 0.6679\end{array}$ & & 0.2992 & & 0.2408 \\
\hline \multirow{2}{*}{13.87} & 0.6361 & \multirow{2}{*}{13.89} & 0.6716 & \multirow{2}{*}{10.05} & 0.6284 \\
\hline & 0.3639 & & 0.3284 & & 0.3716 \\
\hline \multirow{2}{*}{9.88} & 0.5655 & \multirow{2}{*}{9.98} & 0.5641 & \multirow{2}{*}{5.00} & 0.4072 \\
\hline & 0.4345 & & 0.4359 & & 0.5928 \\
\hline
\end{tabular}




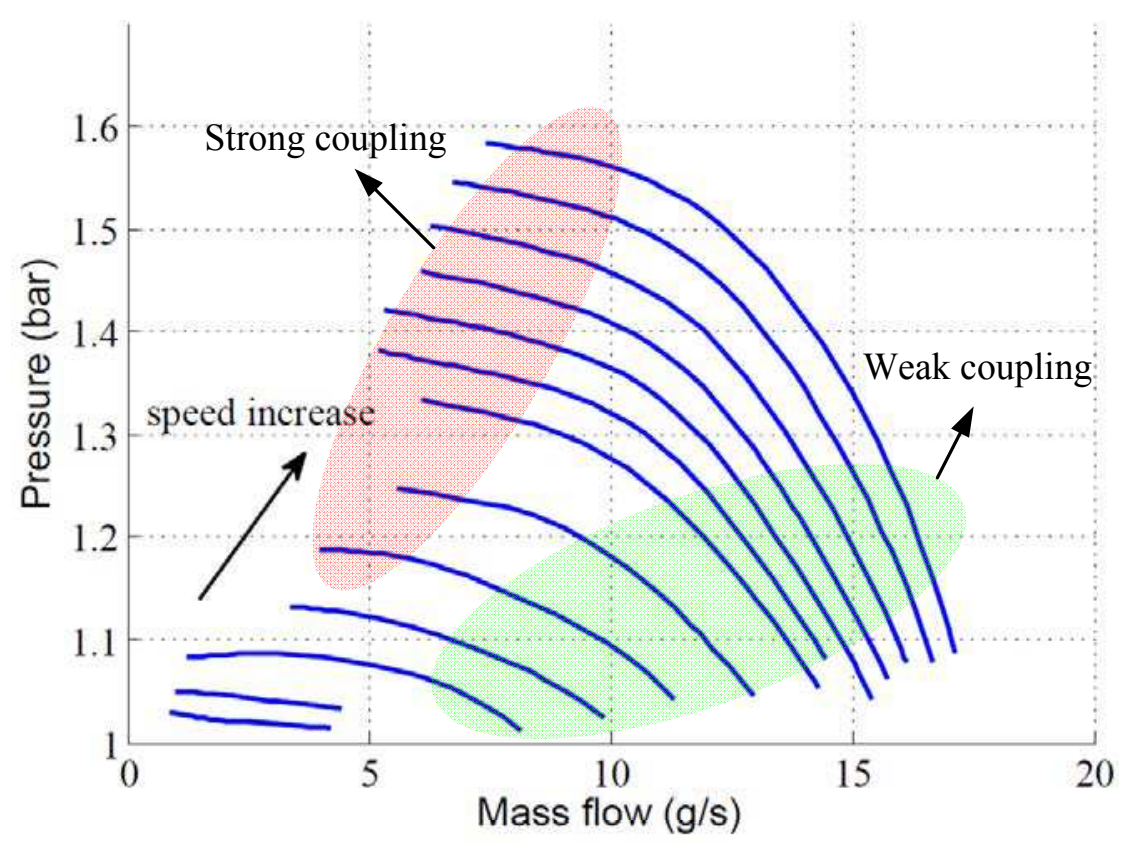

Fig. 34. Compressor coupling analysis.

From Table 4 we can see that coupling degree increases as the mass flow decreases or pressure increases. The strong coupling region is at the low mass flow and high pressure, where $\lambda_{11}$ and $\lambda_{22}$ are very close to 0.5 . As shown in Figure 34, the nearer to the surge line the stronger couping exists. In the strong coupling region, the mass flow and pressure cannot be controlled simultaneously by decentralized controller no matter what the input-output pairs are. The strong coupling region is a very unstable area for the two-input two-output control system. Small disturbances can possibly drag the system into the surge region. In the weak coupling region, decentralized controllers are possible to control the mass flow and pressure, with appropriate input-output pairings, i.e., speed/mass-flow and valve-position/pressure.

\subsection{Choice of the controller}

Since the interaction exists, no matter how strong it is, a well designed decoupling controller is superior to a decentralized controller. Through the analysis of the RGA, it shows that static decoupling is not feasible because of the nonlinear property. There are mainly two classical decoupling approaches [84]. One is the state-space approach 
centered on Morgan's problem. It is a completely decoupling method based on accurate cancellation. The other is frequency domain approach. This method eliminates the input-output coupling through the diagonalization. However, both of the two approach require accurate model. They are sensitive to the perturbation and the variation of parameters. Dynamic decoupling control (DDC) which is based on active disturbance rejection control (ADRC) achieve the decoupling by observing the interaction in real time. Extended state observer (ESO) can be used for disturbance observation which is based on the measured input-output data. Therefore, DDC requires little information of the system model making it have a good reliability and is practical for industry applications.

In order to demonstrate the performance of the decoupling, a decentralized sliding mode control is designed to compare with the developed DDC. In view of its good robustness, sliding mode control has been wildly used in the air flow management of the fuel cell $[27,41,43,85]$. In this dissertation, super twisting and twisting methodologies are used to control the mass flow and pressure respectively through a PM motor and a discharge valve.

\subsection{Disturbance decoupling control}

\subsubsection{ADRC framework}

Uncertainties are widely exist in the realistic systems, which leads to the difficulty in the controller designing. Uncertainties are mainly from the external disturbances and internal uncertainties including the parameter mismatches and the unmodeled dynamics. Model based controllers, such as MPC and sliding mode controller, are always uncapable to deal with the internal uncertainties, since they need complete plant model. Whereas, the PID controller is inadequate to deal with the external disturbances.

In ADRC framework, the lumped uncertainties are deemed as the disturbance which is observed on-line by extended state observer (ESO) and then rejected [55,56,60,86,87]. Take a single input single output system for example:

$$
y^{n}(t)=f(\cdot)+b_{e} u(t)
$$


where $y(t)$ is the output, $u(t)$ is the input, $n$ is the system order, $f(\cdot)$ is the lumped uncertainty, $b_{e}$ is the coefficient.

In the ideal case, $f(\cdot)$ is estimated in real time, and then $-f(\cdot)$ could be settled in the controller to cancel the disturbance. Moreover, the derivatives of $y(t)$ from the first to the $n-1$ order are also could be estimated. Therefore, by appropriate combination of the estimation the closed loop system could be formulated as a linear system. For example, the control low is designed as

$$
u=\frac{1}{b_{e}}\left(-\hat{f}(\cdot)+\sum_{i=1}^{n} p_{i}\left(r^{(i-1)}-\hat{y}^{(i-1)}\right)\right)
$$

where ${ }^{\wedge}$ means the estimation of the variables, $r$ is the reference, $p_{i}$ is the controller parameters to be determined. Thus, the disturbance $f(\cdot)$ is removed from the closed loop system.

For the MIMO system the interaction among multi loops could also be deems as part of the internal disturbance. The DDC is a method based on ADRC to deal with the MIMO control problems including the coupling issue. In the next section, the DDC approach is discussed. And details of the ESO development and controller design are given.

\subsubsection{DDC approach}

Multi-input multi-output systems, also known as multivariable systems, permeate industry. The interactions or cross-couplings among various inputs and outputs of a system make design technologies in multivariable control systems fundamentally different from single-input single-output control systems [59]. The popular way to deal with the MIMO control is to reduce a multivariable system into a number of independent SISO systems. However, the interactions among those variables in a multivariable system put a challenge problem to the controller design. Traditional PI controller, which still dominates in the industry, is not suitable. Decoupling control is a effective method to deal with the interactions among coupled input-output loops. In this dissertation, adaptive disturbance rejection control (ADRC) based DDC approach is used to address the decoupling problem for centrifugal compression system. As a dynamic decoupling 
method, DDC extends the ADRC to deal with the control problem of MIMO system with squared input-output coupling [59], having the following formulation:

$$
\left\{\begin{array}{c}
y_{1}^{n_{1}}=f_{1}\left(x, w_{1}, u\right)+b_{1} u_{1} \\
y_{2}^{n_{2}}=f_{2}\left(x, w_{2}, u\right)+b_{2} u_{2} \\
\vdots \\
y_{m}^{n_{m}}=f_{m}\left(x, w_{m}, u\right)+b_{m} u_{m}
\end{array}\right.
$$

where $y=\left[y_{1}, y_{2}, \cdots, y_{m}\right]$ is the output, $u=\left[u_{1}, u_{2}, \cdots, u_{m}\right]$ the input. $u_{i}$ and $y_{i}$, $i=1,2, \cdots, m$, are the dominate pairs. $x$ is the internal states, $w_{i}$ the external disturbances of the $i$ th loop. $y_{i}^{n_{i}}$ denotes the $n_{i}$ th order derivative of $y_{i} . f_{i}$ represents the combined effect of internal dynamics and external disturbances in the $i$ th loop. It is assumed that the numbers of inputs and output are the same. In the ADRC theory, the combined effect $f_{i}$, which includes the cross interaction, model uncertainties, and external disturbances, is estimated in real time through a ESO ant then eliminated in the controller design. Therefore, for a square m-loop system, the controller can be independently developed based on SISO control algorithm. Take the $i$ th loop in (3.9), (Figure 35), for example,

$$
y_{i}^{n_{i}}=f_{i}\left(x, w_{m}, u\right)+b_{i} u_{i}
$$

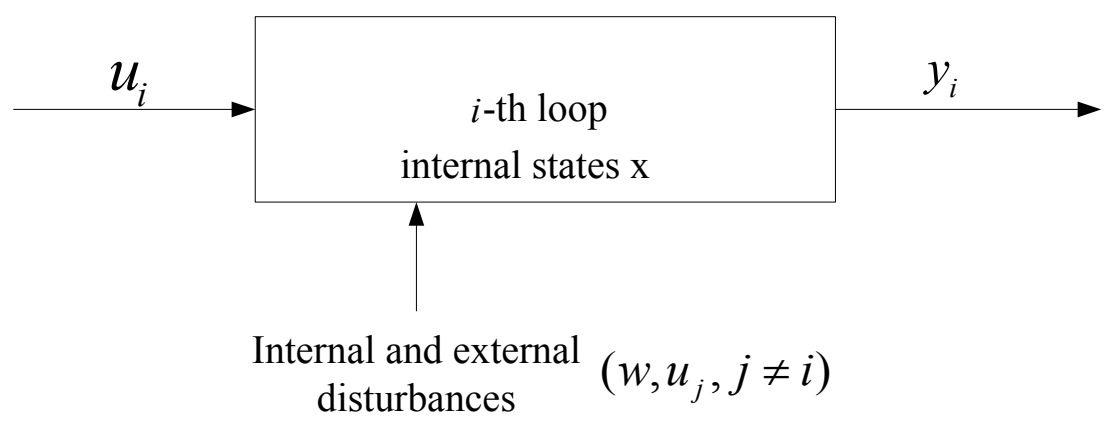

Fig. 35. The i-th loop of the system.

Let $x_{1, i}=y_{i}, x_{2, i}=\dot{y}_{i}, \cdots, x_{n_{i}, i}=y_{i}^{n_{i}-1}$. And define an extended sate $x_{n_{i}+1, i}=f_{i}$. Assuming $f_{i}$ is differentiable, define

$$
h_{i}=\dot{f}_{i}
$$


Denote $x_{i}=\left[x_{1, i}, x_{2, i}, \cdots, x_{n_{i}+1, i}\right]^{T}$ as the system state. Hence, (3.10) can be represented in state-space form as

$$
\left\{\begin{array}{l}
\dot{x}_{1, i}=x_{2, i} \\
\dot{x}_{2, i}=x_{3, i} \\
\vdots \\
\dot{x}_{n_{i}, i}=x_{n_{n+1}, i}+b_{i} u_{i} \\
\dot{x}_{n_{i}+1, i}=h_{i} \\
y_{i}=x_{1, i}
\end{array}\right.
$$

An ESO for (3.12) is designed as

$$
\left\{\begin{array}{l}
\dot{\hat{x}}_{1, i}=x_{2, i}+l_{1, i}\left(x_{1, i}-\hat{x}_{1, i}\right) \\
\dot{\hat{x}}_{2, i}=x_{3, i}+l_{2, i}\left(x_{1, i}-\hat{x}_{1, i}\right) \\
\vdots \\
\dot{\hat{x}}_{n_{i}, i}=x_{n_{n+1}, i}+b_{i} u_{i}+l_{n_{i}, i}\left(x_{1, i}-\hat{x}_{1, i}\right) \\
\dot{\hat{x}}_{n_{i}+1, i}=l_{n_{i}+1, i}\left(x_{1, i}-\hat{x}_{1, i}\right)
\end{array}\right.
$$

where $\hat{x}_{i}=\left[\hat{x}_{1, i}, \hat{x}_{2, i}, \cdots, \hat{x}_{n_{i}+1, i}\right]^{T}$ is the estimated state. And $l_{i}=\left[l_{1, i}, l_{2, i}, \cdots, l_{n_{i}+1, i}\right]^{T}$ is the observer gain to be chosen. The observer gain can be designed as following to guaranty the stability and convergency [59].

$$
l_{i}=\left[\mathrm{l}_{o, i} \alpha_{1, i}, \mathrm{l}_{o, i}^{2} \alpha_{2, i}, \cdots, \mathrm{l}_{o, i}^{n_{i}+1} \alpha_{n_{i}+1, i}\right]^{T}
$$

with $\mathrm{t}_{o, i}>0$. And $\alpha_{j, i}, j=1,2, \cdots, n_{i}+1$ are chosen such that $s^{n_{i}+1}+\alpha_{1, i} s^{n_{i}}+\cdots+$ $\alpha_{n_{i}, i} s+\alpha_{n_{i}+1, i}$ is Hurwitz, which means all the roots have negative real parts. For simplicity, let

$$
\alpha_{j, i}=\frac{\left(n_{i}+1\right) !}{j !\left(n_{i}+1-j\right) !}, j=1,2, \cdots, n_{i}+1
$$

It results in the characteristic polynomial of (3.13) to be

$$
\lambda_{o, i}(s)=\left(s+\mathbf{v}_{o, i}\right)^{n_{i}+1}
$$

Hence, $\mathrm{l}_{o, i}$ will be the observer bandwidth of the $i$ th loop. In this situation, compared with other observers the parameter chosen will be much simplified. It should be noted 
that a proper observer bandwidth should be selected in a compromise between tracking performance and tolerance.

With a well-tuned observer, the combined effect $f_{i}$ can be closely approximated by $\hat{x}_{n_{i}+1, i}$. In the controller design $f_{i}$ is actively eliminated. The controller is designed as

$$
u_{i}=\frac{k_{1, i}\left(r_{i}-\hat{x}_{1, i}\right)+k_{2, i}\left(\dot{r}_{i}-\hat{x}_{2, i}\right)+\cdots+k_{n, i}\left(r_{i}^{n_{i}-1}-\hat{x}_{n_{i}, i}\right)-\hat{x}_{n_{i}+1, i}+r_{i}^{n_{i}}}{b_{i}}
$$

where $r_{i}$ is the desired trajectory, $k_{j, i}$ is the controller gain. The closed loop system becomes

$$
y_{i}^{n_{i}}=\left(f_{i}-\hat{x}_{n_{i}+1, i}\right)+k_{1, i}\left(r_{i}-\hat{x}_{1, i}\right)+\cdots+k_{n_{i}, i}\left(r_{i}^{n_{i}-1}-\hat{x}_{n_{i}, i}\right)+r_{i}^{n_{i}}
$$

With a well-tuned observer, the first term, $\left(f_{i}-\hat{x}_{n_{i}+1, i}\right)$, in the right hand is equal to 0 . The controller gains are selected as

$$
k_{j, i}=\frac{\left(n_{i}\right) !}{(j-1) !\left(n_{i}+1-j\right) !} c_{c, i}^{n_{i}+1-j}, j=1,2, \cdots, n_{i}
$$

Then, the characteristic polynomial of the closed loop system becomes

$$
\lambda_{c, i}(s)=s^{n_{i}}+k_{n_{i}, i} s^{n_{i}-1}+\cdots+k_{1, i}=\left(s+\mathbf{u}_{c, i}\right)^{n_{i}}
$$

where $\boldsymbol{t}_{c, i}$ is the controller bandwidth to be chosen.

DDC is practical for industry applications because only few parameters, i.e., the observer and control gains, need to be tuned. The following subsections give the ESO and corresponding controller development for the air compression system.

\subsubsection{ESO design for the air management system}

The air compression system is divided into two control loops: speed to control mass flow and valve position to control pressure. In the DDC strategy, the cross-couplings between the two control loops as well as external disturbances are treated as the total disturbance estimated in real time and then rejected in the control laws. With the predetermined input-output paring, the decoupling problem is reformulated as that of disturbance rejection, where disturbance is defined as the cross channel interference. 
The effect of one input to all other outputs that it is not paired with is viewed as a disturbance to be rejected. In the ADRC framework, such disturbance is actively estimated using extended state observer (ESO) and canceled in the control law, in the absence of an accurate mathematical model of the plant $[55,60]$.

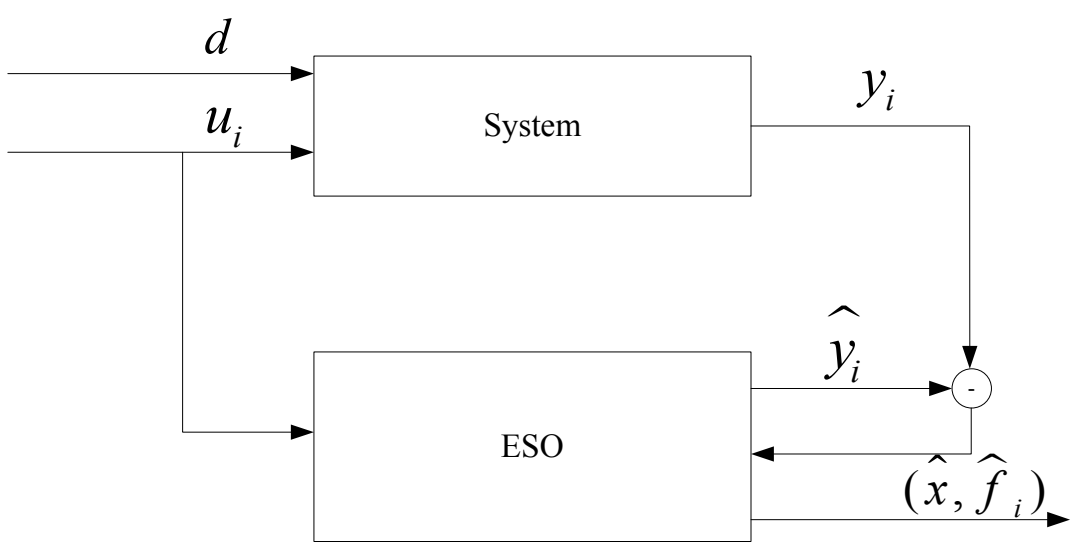

Fig. 36. Structure of the proposed ESO.

Instead of identifying the plant dynamics off-line, ESO is proposed to estimate the combined effect of plant dynamics and external disturbance in real time. The structure of the proposed ESO is shown in Figure 36.

Let $y_{1}=p, y_{2}=q$ and $u_{1}=\theta, u_{2}=\omega^{*}$.

$$
\dot{y}_{i}=f_{i}+b_{i} u_{i}, \quad i=1,2 \text {. }
$$

According to the system model given in the last chapter, the derivation of $p$ is obtained as follows:

$$
\begin{aligned}
& f_{1}=\frac{R_{a} T}{V} \cdot q_{c p}, \\
& b_{1}=-C_{d} p \pi r_{v}^{2} \frac{R_{a} T}{V} \sqrt{\frac{2 \gamma M_{a i r}}{(\gamma-1) R T}\left[\left(\frac{p_{a t m}}{p}\right)^{\frac{2}{\gamma}}-\left(\frac{p_{a t m}}{p}\right)^{\frac{\gamma+1}{\gamma}}\right]}
\end{aligned}
$$

Whereas, $f_{2}$ and $b_{2}$ are obtained according to the derivation of the compressor map, 


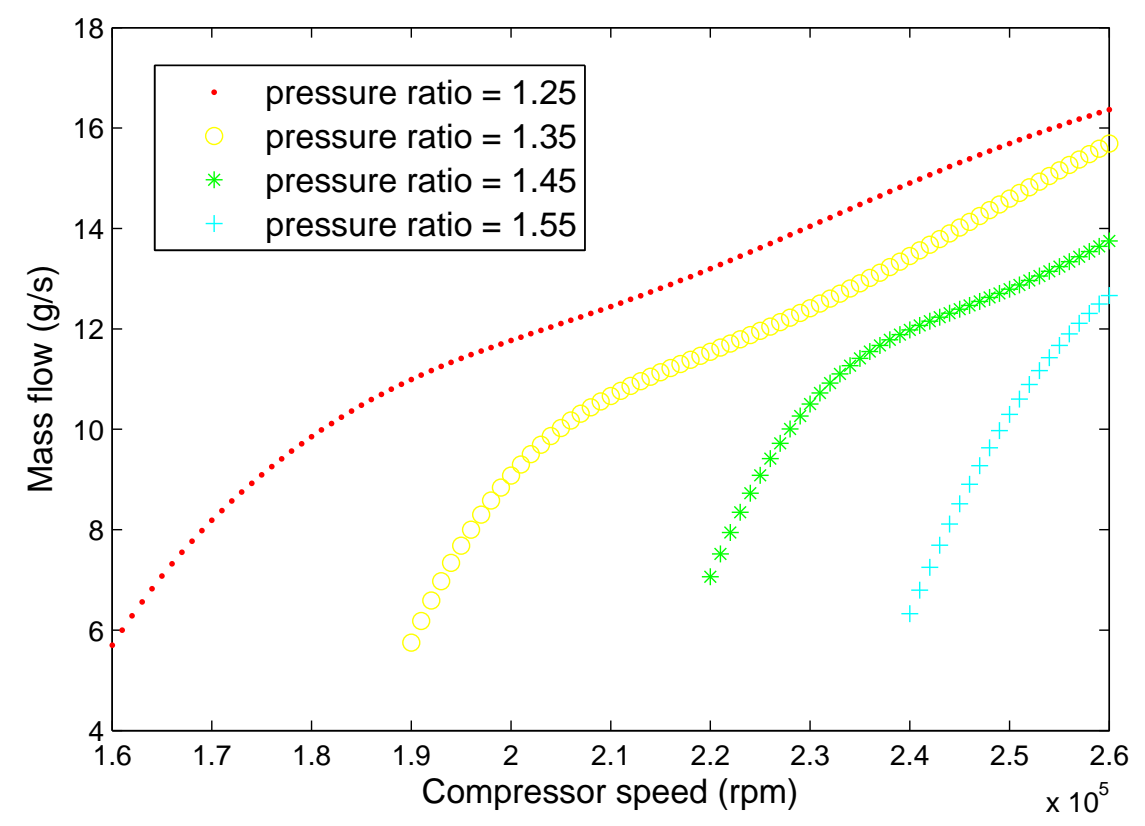

Fig. 37. The relation of the mass flow and speed at different pressure ratio.

$q=h(\omega, p)$

$$
\begin{aligned}
& f_{2}=\frac{\partial h(\omega, p)}{\partial p} \dot{p}-\frac{\partial h(\omega, p)}{\partial \omega} \frac{\omega}{T_{m}} \\
& b_{2}=\frac{1}{T_{m}} \frac{\partial h(\omega, p)}{\partial \omega}
\end{aligned}
$$

Figure 37 shows the relation between the mass flow and compressor speed at different pressure ratio. The value of $\partial h(\omega, p) / \partial \omega$ at different point can then be obtained. $T_{m}$ has the approximation value of 0.2 .

Let $x_{1, i}=y_{i}, x_{2, i}=f_{i}$. Assuming $f_{i}$ is differentiable, define

$$
h_{i}=\dot{f}_{i}
$$

Then (3.21) can also be represented in state space form as

$$
\left\{\begin{array}{l}
\dot{x}_{1, i}=x_{2, i}+b_{i} u_{i} \\
\dot{x}_{2, i}=h_{i} \\
y=x_{1, i}
\end{array}\right.
$$


where $x_{i}=\left[x_{1, i}, x_{2, i}\right]^{T} \in R^{2}$. An ESO for (3.27) is designed as

$$
\left\{\begin{array}{l}
\dot{\hat{x}}_{1, i}=\hat{x}_{2, i}+l_{1, i}\left(x_{1, i}-\hat{x}_{1, i}\right)+b_{i} u_{i} \\
\dot{x}_{2, i}=l_{2, i}\left(x_{1, i}-\hat{x}_{1, i}\right)
\end{array}\right.
$$

where $\hat{x}_{i}=\left[\hat{x}_{1, i}, \hat{x}_{2, i}\right]^{T} \in R^{2}$ and $L_{i}=\left[l_{1, i}, l_{2, i}\right]^{T}$ are the observer gain parameters to be chosen. According to the analysis of DDC [59] [60], the value of $L_{i}$ is chosen as follows:

$$
\left[l_{1, i}, l_{2, i}\right]^{T}=\left[\mathbf{l}_{o, i} \alpha_{1, i}, \mathbf{l}_{o, i}^{2} \alpha_{2, i}\right]^{T}
$$

with $\omega_{o, i}>0$. Here $\alpha_{j, i}, j=1,2$ are chosen such that $s^{2}+\alpha_{1, i} s+\alpha_{2, i}$ is Hurwitz to ensure the convergency of the observer. For simplicity, we just let $s^{2}+\alpha_{1, i} s+\alpha_{2, i}=$ $(s+1)^{2}$, where $\alpha_{1, i}=2, \alpha_{2, i}=1$.

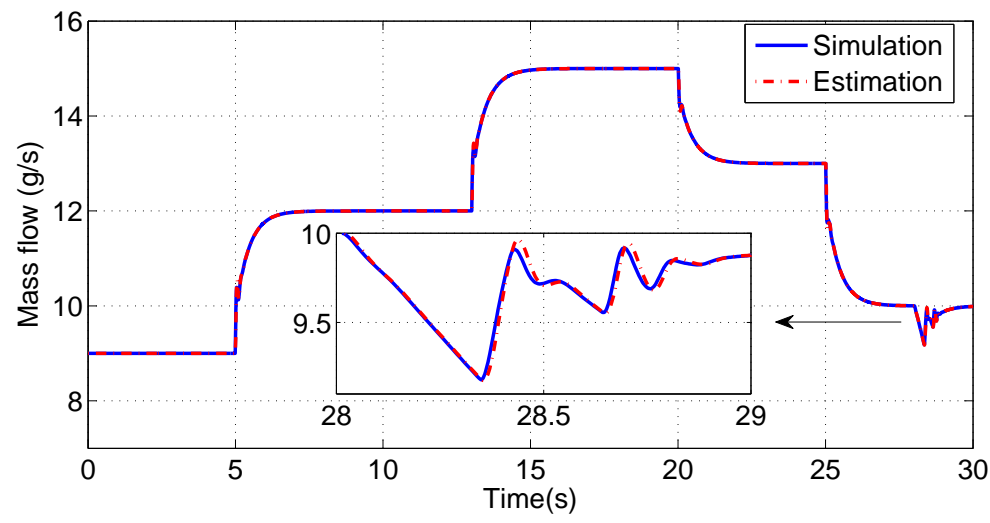

Fig. 38. Mass flow estimation.

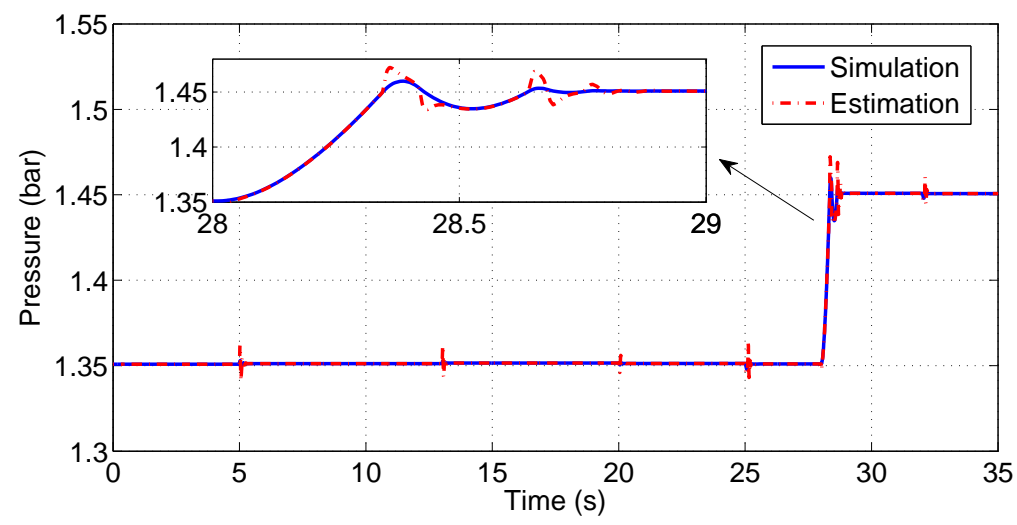

Fig. 39. Pressure estimation. 
Based on the ESO design, only two parameters, $\boldsymbol{t}_{o 1}$ and $\mathrm{t}_{o 2}$, need to be determined. Those two variables decide the bandwidth of the pressure estimation and mass flow estimation, respectively. Generally, the larger of the bandwidth, the more accurate of the estimation, but also increasing the noise sensitivity. Therefore, the proper values of $l_{o 1}$ and $t_{o 2}$ should balance the estimation performance and the noise tolerance. In this dissertation, we set those two parameters big enough, until the estimation performance is achieved. With the determined parameters, $\mathrm{t}_{o 1}=300$ and $\mathrm{t}_{o 2}=400$, Figure 38 and Figure 39 exhibit the mass flow estimation and pressure estimation, respectively. We can see that with the well tuned observer, the estimations can quickly follow the real values, which means the internal states and the disturbance are well estimated.

\subsubsection{Control algorithm}

With a well-tuned observer, the observer states will closely track the states of the augmented plant. By canceling the effect of $f_{i}$ using $\hat{f}_{i}$, i.e. $\hat{x}_{2, i}$. ADRC actively compensates for $f_{i}$ in real time. The controller is designed as follows:

$$
u_{i}=\frac{k_{i}\left(r_{i}-\hat{x}_{1, i}\right)-\hat{x}_{2, i}+\dot{r}_{i}}{b_{i}}
$$

where $r_{i}$ is the desired trajectory, and $k_{i}$ is the controller gain parameter. The closedloop system becomes

$$
\dot{y}_{i}=\left(f_{i}-\hat{x}_{2, i}\right)+k_{i}\left(r_{i}-\hat{x}_{1, i}\right)+\dot{r}_{i}
$$

Note that with a well-designed ESO, the first term in the right hand side, i.e. $f_{i}-\hat{x}_{2, i}$, is negligible and the rest part constitutes a proportional control with a feedforward term. According to the DDC control law, $k_{i}$ is selected as a positive number, which is the controller bandwidth. The controller bandwidth is selected based on how fast and steady we want the output to track the setpoint. A large controller bandwidth generally increases the response speed but, pushed to the limit, it also could make the system oscillatory, or even unstable. Thus the controller bandwidth is tuned based on the competing requirements of performance and stability margin, together with noise sensitivity as well. In addition, a large controller bandwidth usually increases the magnitude and rate of change in control signal, and therefore the operation cost. The following describes the parameter adjusting method for the air management system. 
According to the control law, equation (3.30), $b_{1}$ and $b_{2}$ are the parameters need to be determined. Generally, $b_{1}$ and $b_{2}$ which represent the system property can be calculated according to (3.23) and (3.25), respectively. However, because of the nonlinear property of the system, they are not constant. Therefore, the approximation around the operating point are necessary. For the fuel cell applications, the nominal pressure is determined by the fuel cell stack requirement, and it is normally a constant. Based on the compressor operating range, the pressure is assumed around 1.4 bar. It should be noted that the centrifugal compressor cannot operate to a low mass flow while keeping at a high pressure because of the surge constraint. Reducing the pressure is a method to avoid the compressor surge making the compressor run to a lower mass flow. But it also indicates a low compressor efficiency. Moreover, the fuel cell has a low efficiency when the load current is small. Therefore, the nominal mass flow is settled between 8 to $15 \mathrm{~g} / \mathrm{s}$ varying with the load demand.

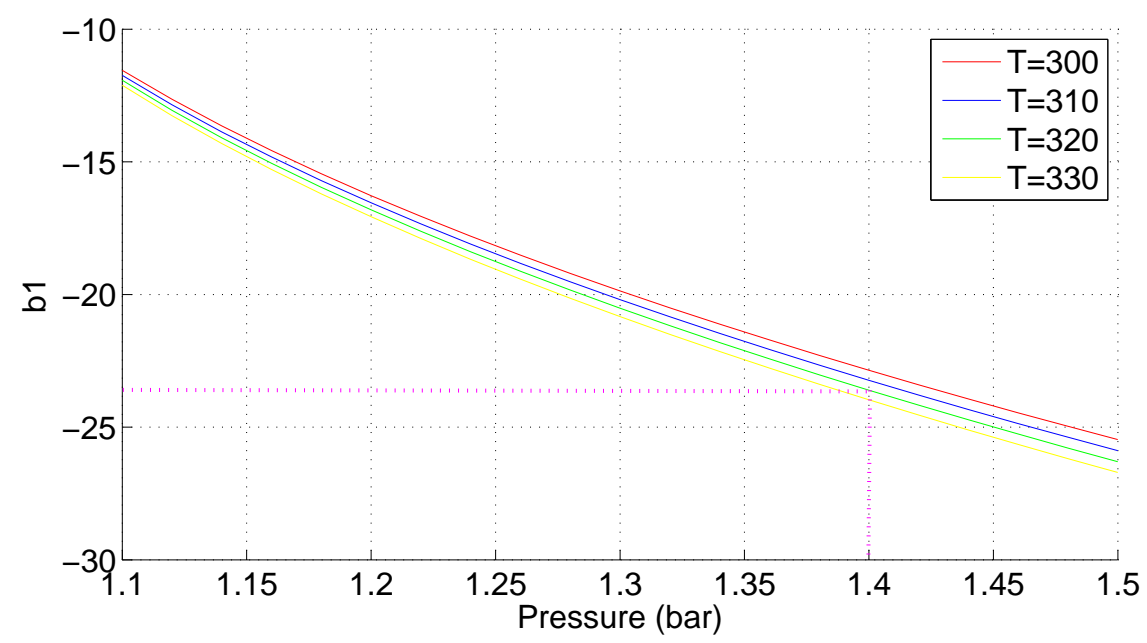

Fig. 40. The relationship of $b_{1}$ with the pressure and temperature.

According to (3.23), $b_{1}$ is only related to the temperature and pressure, which is depicted in Figure 40. It shows that the variation of air temperature has a very small influence to $b_{1}$. As the pressure changes from 1.35 to 1.45 bar, $b_{1}$ varies from -22 to -25 . We select the pressure at 1.4 bar, corresponding to $b_{1}=-24$. According to (3.25), $b_{2}$ is related to motor speed constant $T_{m}$ and the derivation of mass flow to the compressor speed. $T_{m}$ is settled at 0.2 based on the compressor speed tests. The value of $\partial h(\omega, p) / \partial \omega$ can be approximated around 0.001 when the mass flow from $8 \mathrm{~g} / \mathrm{s}$ to 15 $\mathrm{g} / \mathrm{s}$ and pressure from 1.35 to 1.45 bar. Then the approximation of $b_{2}$ is determined at 
0.005 according to $(3.25)$.

Summarizing the disturbance observer and the control algorithm, the block diagram of the proposed DDC is shown in Figure 41. The control system is divided into two control loops, i.e., the mass flow control loop and the pressure control loop. The interactions (coupling) between the two control loops are estimated by the ESO based on the input-output data. And then the interactions are eliminated in each control loops. In this way, the linear control method could be used in each loop to regulate the mass flow and pressure independently, meaning the decoupling control is achieved.

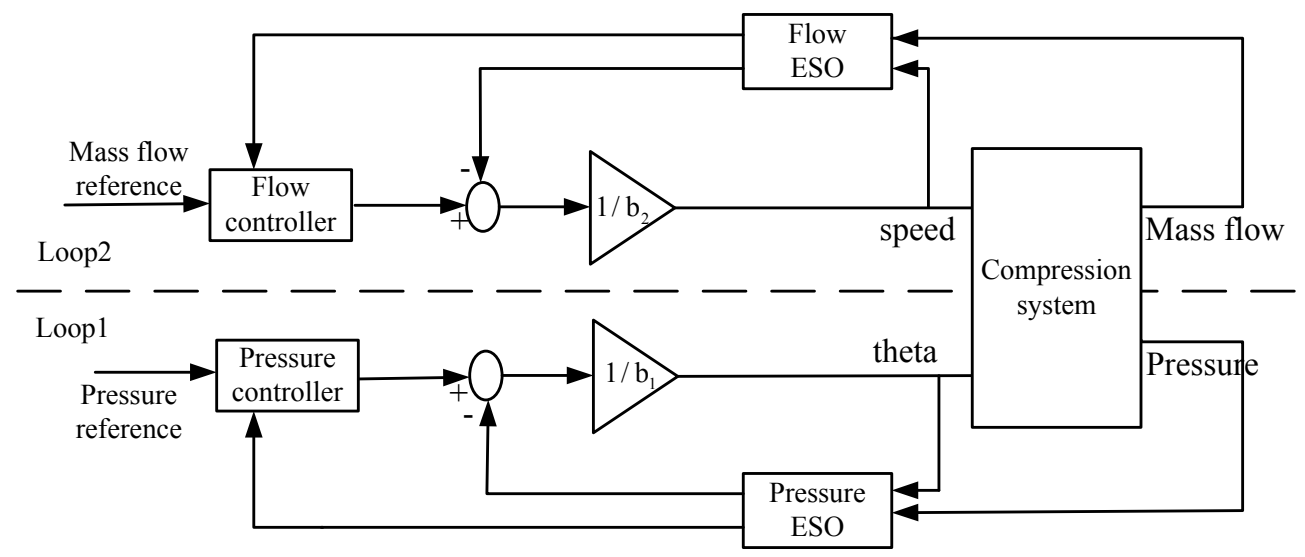

Fig. 41. Diagram of the DDC implemented on the air compression system.

\subsubsection{Simulation results}

The DDC approach used in the centrifugal air compression system is validated in MATLAB/Simulink. The block diagram of the simulation is shown in Figure 42. The decoupling controller is validated by testing the performance of the step responses of the mass flow and pressure, respectively. The interaction between the two control loops can then be observed. Figure 43 shows the system responses with a step change of the mass flow command at $2 \mathrm{~s}$. Figure 43(a) and Figure 43(b) exhibit the dynamics of mass flow and pressure, respectively. They demonstrate that the pressure is hardly influenced by the sudden change of the mass flow. Figure 43(c) and Figure 43(d) shows the variations of the compressor speed and valve position, respectively. The compressor speed increased from 220 to $240 \mathrm{krpm}$ which results in the raise of mass flow. Meanwhile, 
to maintained the pressure at 1.4 bar the valve position increases from $7.3^{\circ}$ to $10.2^{\circ}$ as the mass flow increases.

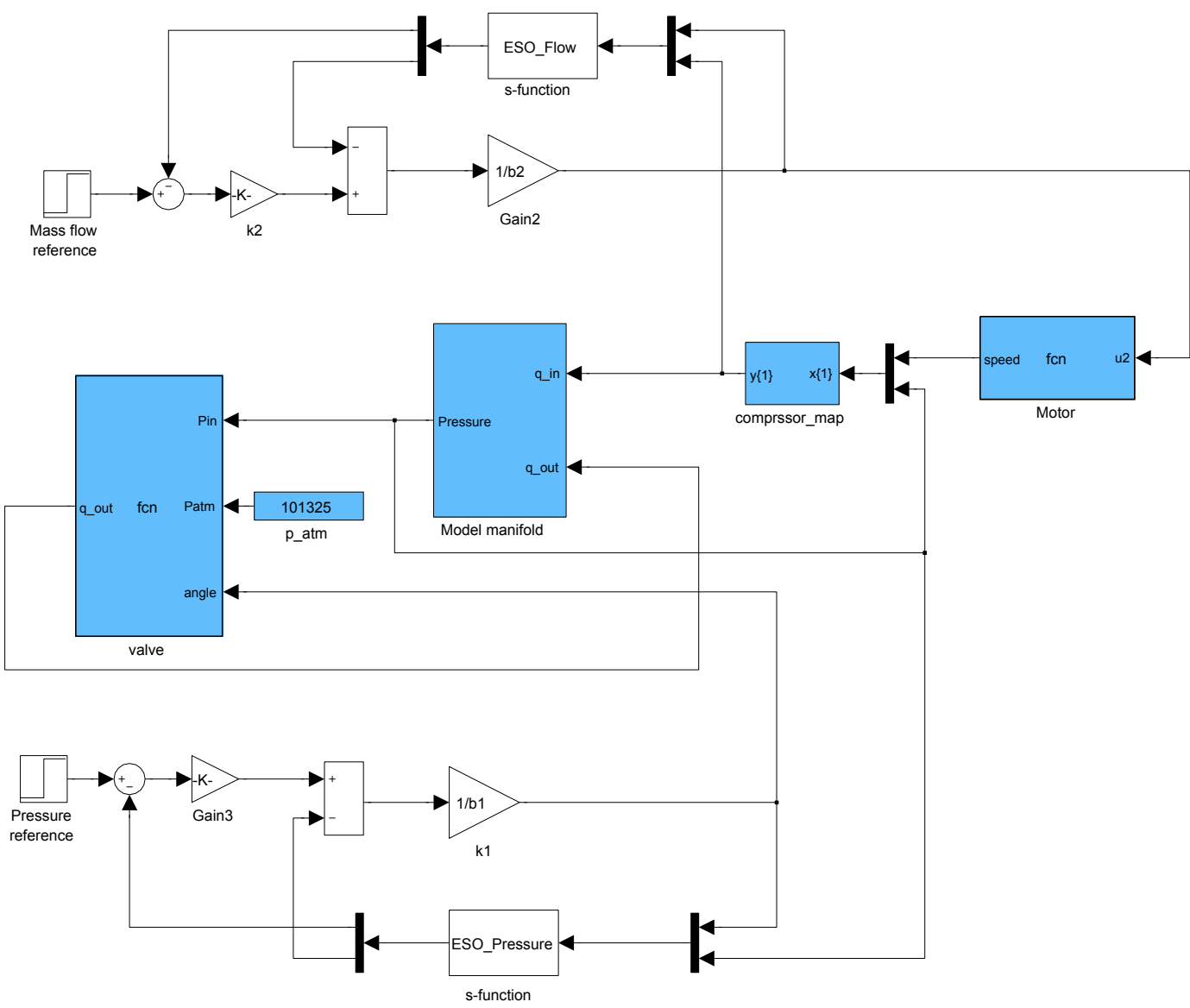

Fig. 42. Simulation model in the Simulink.

Figure 44 demonstrates the system responses with a step change of the pressure command, from 1.4 to 1.5 bar. This operation is used to test how much the mass flow is affected by the pressure change. Although abrupt pressure variations hardly happens in the fuel cell operation, the pressure fluctuations cannot be avoided in practical applications because of unexpected disturbances . Figure 44(b) shows that the mass flow is decreased from 11 to $10 \mathrm{~g} / \mathrm{s}$ by the sudden change of the pressure. Figure 44(c) and Figure 44(d) show the responses the compressor speed and valve position. The fast shutdown of the valve position leads to the raise of the pressure and the decline of the mass flow, as shown at $2 \mathrm{~s}$. In the other word, the pressure control loop has an impact to the mass flow control loop. This means that the system is not completely decoupled 


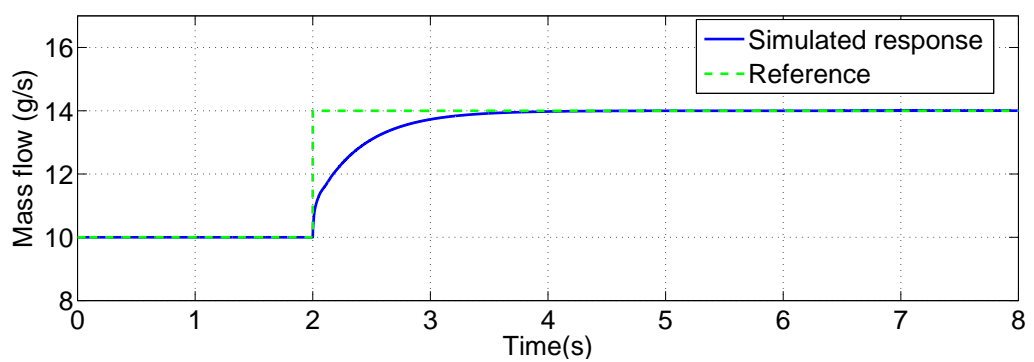

(a) Mass flow response with a step command

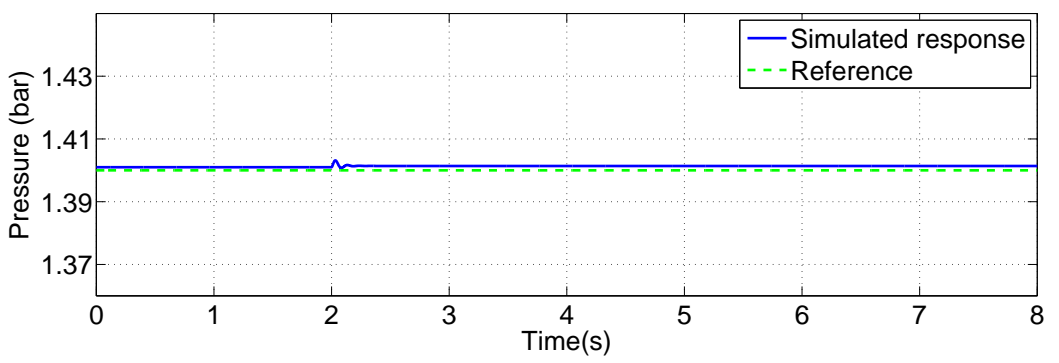

(b) Pressure dynamics

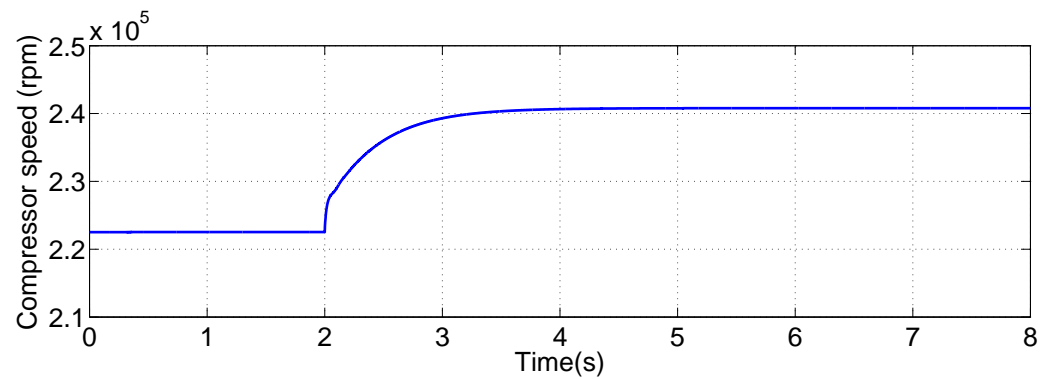

(c) Compressor speed dynamics

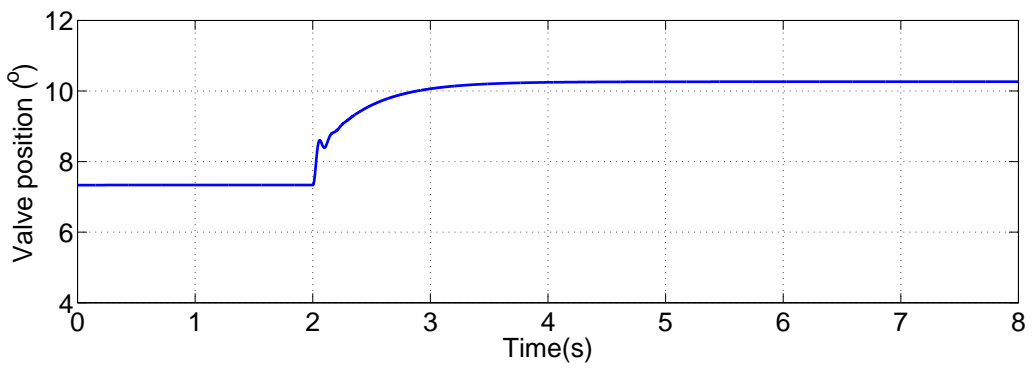

(d) Valve posistion dynamics

Fig. 43. Responses of the system under a mass flow step command. 


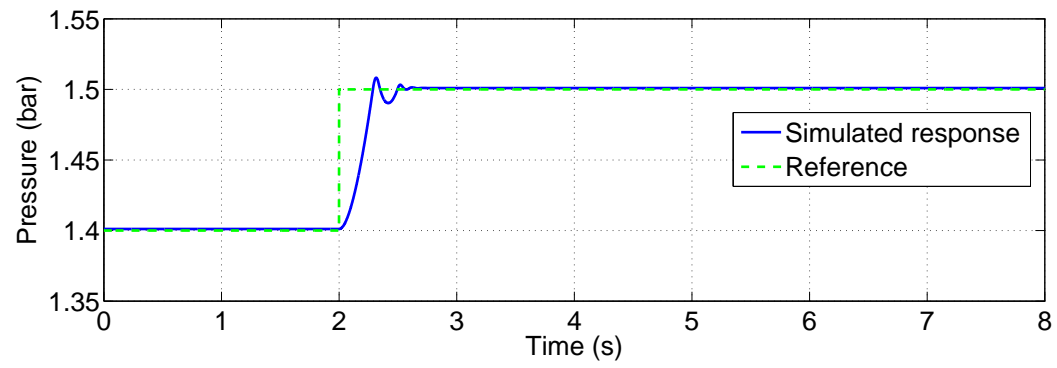

(a)

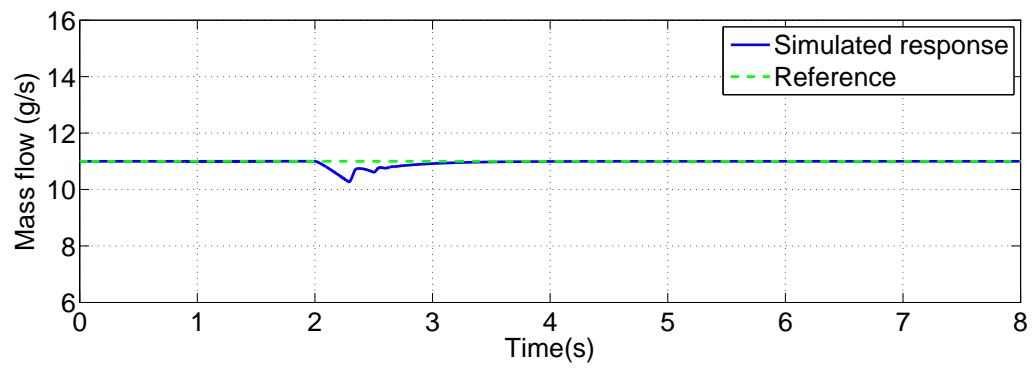

(b)

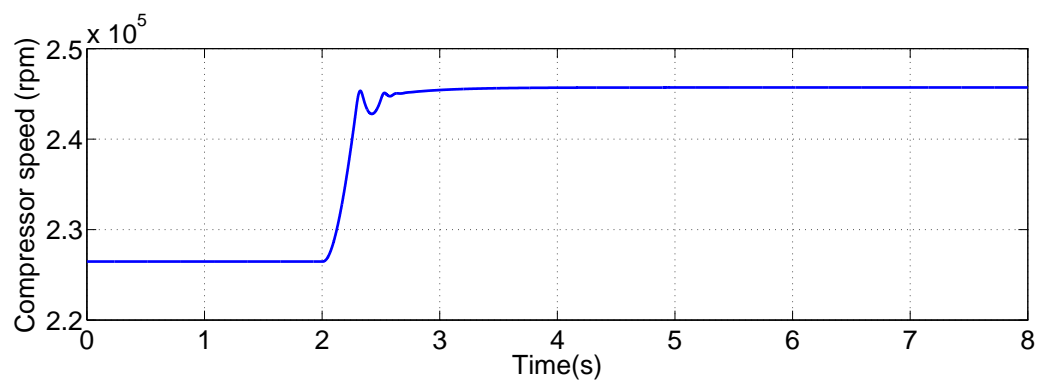

(c)

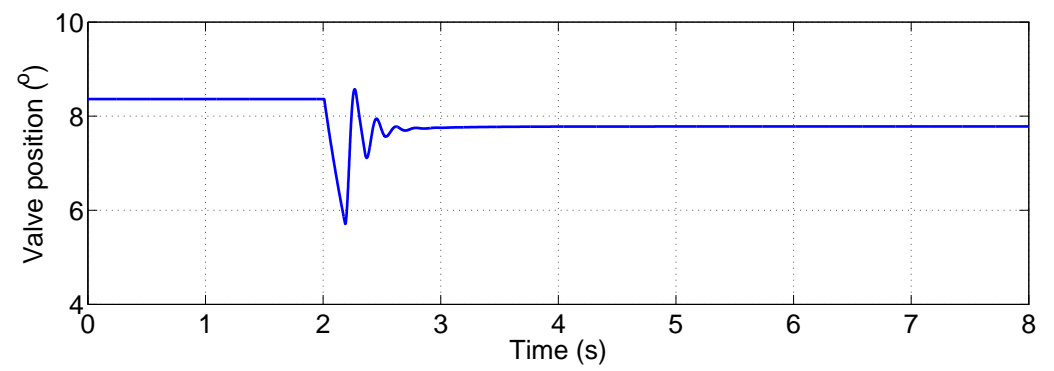

(d)

Fig. 44. Responses of the output variable under a pressure step command. 
by the DDC. There are mainly two reasons. One is the delay of the DDC decoupling because it is based on the measurement of the input/output data. How fast it can cancel the disturbance (coupling) depends on the convergence rate of the ESO. The other is the approximation of the control variable $b_{i}$. Because of the nonlinear characteristic of the system, $b_{i}$ are not constants. The approximation of their values in the desired operation range also leads to the incomplete decoupling. In spite of this, compared with model based decoupling controller the good robustness of DDC makes it more suitable for complex system, especially with unmodeled dynamics. Moreover its implementation process is much simple because very few parameters need to be designed, making the method attractive to the industry.

In order to demonstrate the performance of the proposed DDC method, in the next section a decentralized sliding mode controller is developed for comparison purpose. The latter one does not take the interaction of the system into account. The mass flow controller and the pressure controller are developed individually.

\subsection{Sliding mode control}

Sliding mode control, also known as variable structure control (VSC), has been widely studied for industry applications because of its of good robustness, fast tracking, etc. It also have been investigated for the air management of fuel cell systems [43] [27] [41]. In the above literature, second order sliding mode controllers have been used to control the oxygen excess ratio by the motor voltage. However, the pressure control is not addressed, which is challenging for a centrifugal compressor control. Through the coupling analysis, a discharge valve can be used to control the pressure. In this section, two decentralized sliding mode controllers based on twisting and super twisting algorithms are developed to control pressure and mass flow, individually. Both of the two control methods belong to second order sliding model control, which can effectively deal with the chatting problem. The basic idea of sliding mode control is to drive the system states onto a prespecified surface, called sliding surface, by high-speed switched feedback control algorithm.

Considering the convergence and stability of the system, the twisting control algorithm is used for pressure control, and the super twisting algorithm is employed for mass flow control. The derivation of $\theta$ is bounded as the result of the twisting control algorithm, 
which provides a condition for the convergency of the mass flow control based on the super twisting algorithm. In this case, the stability and convergency of the system can be guaranteed by appropriately selecting the control parameters.

\subsubsection{Pressure control}

The dynamic of the air management system can be expressed as:

$$
\begin{aligned}
\dot{x_{1}} & =f_{1}(x)+b_{1}(x) u_{1} \\
\dot{x_{2}} & =-\frac{1}{T_{m}} x_{2}+\frac{1}{T_{m}} u_{2}
\end{aligned}
$$

where $x=\left[x_{1}, x_{2}\right]=[p, \omega$,$] . Twisting sliding mode is used to control the pressure, p$. The sliding surface is defines as follows:

$$
s_{1}=p^{*}-p
$$

where $p^{*}$ is the reference of the pressure, which is kept constant $1.4 \mathrm{bar}$, on the basis of the fuel cell stack requirement.

Differentials of the sliding variables $s_{1}$ :

$$
\begin{aligned}
\dot{s}_{1} & =\dot{p}^{*}-\dot{p} \\
& =-f_{1}(x)-b_{1}(x) \cdot u_{1}
\end{aligned}
$$

As the control variable appears in $\dot{s}_{1}$, the system relative degree is one. The 2 nd order differential of the sliding variable $s_{1}$ is expressed as follows:

$$
\begin{aligned}
\ddot{s}_{1} & =\frac{\partial \dot{s}_{1}}{\partial p} \dot{p}+\frac{\partial \dot{s}_{1}}{\partial \omega} \dot{\omega}+\frac{\partial \dot{s}_{1}}{\partial u_{1}} \dot{u}_{1} \\
& =\varphi_{1}\left(p, \theta, \omega, i_{q}\right)-b_{1}(p, \omega) \dot{\theta}
\end{aligned}
$$

Depending on the bounds of the state variables and control variables, the following conservative ranges are determined: 


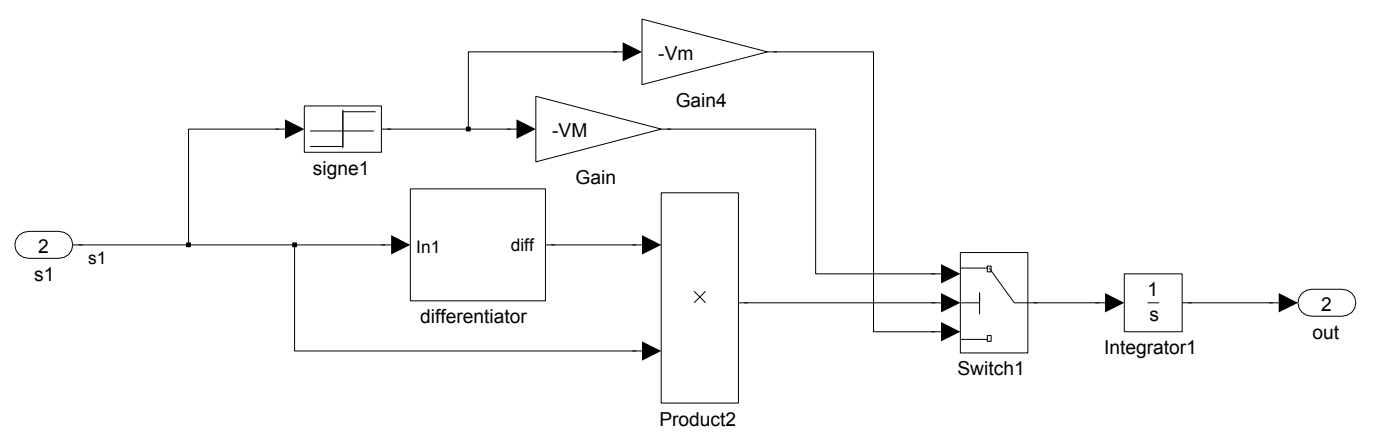

Fig. 45. Simulink model of the twisting algorithm.

$$
\left|\varphi_{1}(\cdot)\right| \leq \Phi, 0<\Gamma_{m} \leq-b_{1}(\cdot) \leq \Gamma_{M}
$$

The twisting control algorithm is expressed as follows [88]:

$$
\dot{\theta}= \begin{cases}-V_{m} \operatorname{sign}\left(s_{1}\right), & \text { if } s_{1} \dot{s}_{1} \leq 0 \\ -V_{M} \operatorname{sign}\left(s_{1}\right), & \text { if } \quad s_{1} \dot{s}_{1}>0\end{cases}
$$

The corresponding sufficient conditions for the finite time convergence to the sliding manifold are [88]:

$$
\begin{aligned}
& V_{M}>V_{m} \\
& V_{m}>\frac{4 \Gamma_{M}}{r_{0}} \\
& V_{m}>\frac{\Phi}{\Gamma_{m}} \\
& \Gamma_{m} V_{M}-\Phi>\Gamma_{M} V_{m}+\Phi
\end{aligned}
$$

where $r_{0}$ is a positive constant, which defines the convergence domain of the twisting control. Based on these conditions, the control parameters are selected as follows: $V_{M}=10, V_{m}=3$. The following differentiator [89] [90] is used to obtain the derivation of $s_{1}$.

$$
\begin{aligned}
& \dot{z}_{0}=-\sigma_{1} L^{\frac{1}{2}}\left|z_{0}-s_{1}\right|^{\frac{1}{2}} \operatorname{sign}\left(z_{0}-s_{1}\right)+z_{1} \\
& \dot{z}_{1}=-\sigma_{2} L \operatorname{sign}\left(z_{1}-\dot{z}_{0}\right)
\end{aligned}
$$




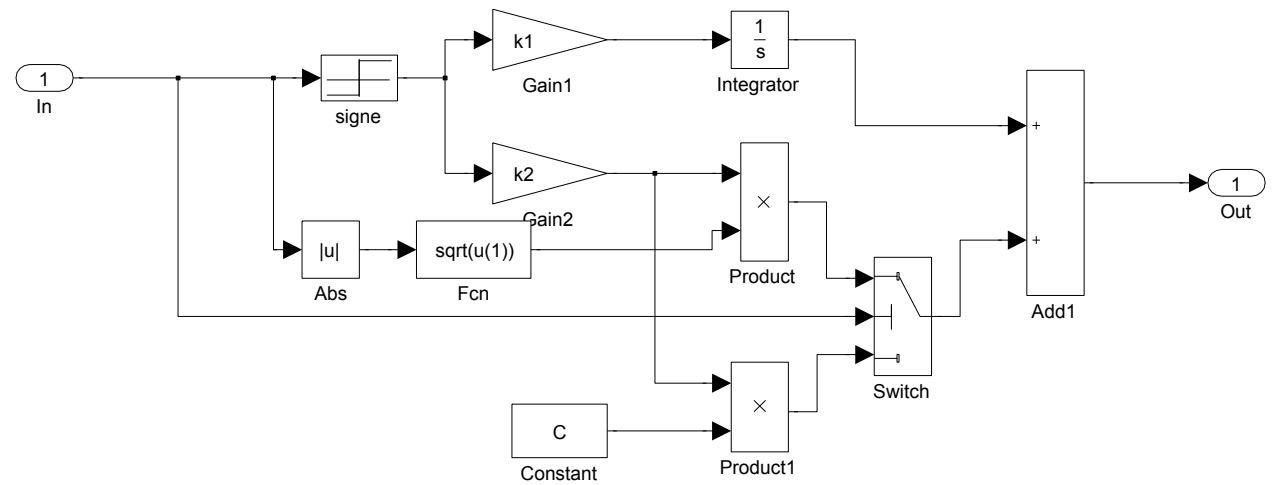

Fig. 46. Simulink model of the super-twisting algorithm.

where $z_{0}$ and $z_{1}$ are the online estimations of $s_{1}$ and $\dot{s}_{1}$ respectively. The parameters of the differentiator are chosen empirically as follows: $\sigma_{1}=1.1, \sigma_{2}=1.5, L=4$. The block diagram of the twisting control in Simulink is shown in Figure 45.

\subsubsection{Mass flow control}

Define the sliding surface as follows:

$$
s_{2}=q-q^{*}
$$

$q^{*}$ is the references of mass flow which is calculated online according to the power demand, supposing $\lambda_{o_{2}, \text { ref }}=2$.

Differentials of the sliding variables $s_{2}$ :

$$
\begin{aligned}
\dot{s}_{2} & =\dot{q}-\dot{q}^{*} \\
& =H_{p}(x)\left(f_{1}(x)+g_{1}(x) \cdot u_{1}\right)+H_{\omega}(x)\left(-\frac{1}{T_{m}} \omega+\frac{1}{T_{m}} \cdot u_{2}\right)-\dot{q}^{*}
\end{aligned}
$$

where $H_{\omega}(x)=\frac{\partial h}{\partial \omega}$ and $H_{p}(x)=\frac{\partial h}{\partial p}$.

The 2 nd order differential of the sliding variable $s_{2}$ can be expressed as follows:

$$
\begin{aligned}
\ddot{s}_{2} & =\frac{\partial \dot{s}_{2}}{\partial p} \dot{p}+\frac{\partial \dot{s}_{2}}{\partial \theta} \dot{\theta}+\frac{\partial \dot{s}_{2}}{\partial \omega} \dot{\omega}+\frac{\partial \dot{s}_{2}}{\partial u_{2}} \dot{u}_{2}-\ddot{q}^{*} \\
& =\varphi_{2}\left(p, \theta, \omega, i_{q}, \dot{\theta}, \ddot{q}^{*}\right)+\gamma_{2} \dot{u}_{2}
\end{aligned}
$$


Equation (3.48) shows that the boundary of $\varphi_{2}$ not only depends on the state variables and control variables but also correlates with the derivation of $\theta$. Thus, it is necessary to limit the value of $\dot{\theta}$. From (3.39), the twisting control algorithm results in $|\dot{\theta}| \leq V_{M}$. Under such circumstances, the following inequalities will hold:

$$
\begin{aligned}
& \left|\varphi_{2}(\cdot)\right| \leq C \\
& 0<L_{m} \leq \gamma_{2} \leq L_{M}
\end{aligned}
$$

According to super twisting control algorithm [88] [41], the control variable $u_{2}$ can be expressed as follows:

$$
\begin{aligned}
& u_{2}=v_{1}+v_{2} \\
& \dot{v}_{1}=-\eta \operatorname{sign}\left(s_{2}\right) \\
& v_{2}=\left\{\begin{array}{l}
-\lambda\left|s_{0}\right|^{\frac{1}{2}} \operatorname{sign}\left(s_{2}\right), \text { if }\left|s_{2}\right|>\left|s_{0}\right| \\
-\lambda\left|s_{2}\right|^{\frac{1}{2}} \operatorname{sign}\left(s_{2}\right), \text { if }\left|s_{2}\right| \leq\left|s_{0}\right|
\end{array}\right.
\end{aligned}
$$

The conditions for the convergence are given by the following inequalities:

$$
\begin{aligned}
& \eta>\frac{C}{L_{m}} \\
& \lambda^{2} \geq \frac{4 C L_{M}(\eta+C)}{L_{m}^{3}(\eta-C)}
\end{aligned}
$$

The block diagram of the super twisting algorithm is shown in Figure 46. During the parameter determination, it should be noted that the expression of $\varphi_{2}(\cdot)$ is too complicated to be calculated because of the complexity of the compressor neural network model. And the value of $C$ cannot be actually obtained. In fact, for complex systems the control parameters are never assigned based on the inequalities as the system model is hardly exactly known. Therefore, the control parameters $\eta$ and $\lambda$ are identified and optimized empirically in the simulation. Faster response could be achieved by increasing the controller parameters. At the same time, larger parameters makes the controller more sensitive to the disturbance.

\subsection{Comparison by Simulations}

The performances of the proposed DDC is evaluated by the comparison with the decentralized sliding mode controller. Denote the valve-position/pressure being the loop-1 
and the speed/mass flow being the loop-2. DDC aims to eliminates/weaken the interaction between the two loops. Therefore, the mass flow and pressure can be controlled independently without much influence of each other.

Two aspects are tested by simulation to evaluate the system coupling: One is to change the mass flow while keeping the pressure at the nominal value 1.4 bar. We expect the pressure is not changed by the variations of the mass flow. The other is to change the pressure while keeping the mass flow constant. In the same way that the mass flow is expected to keep constant no matter how the pressure varies.

\subsubsection{Test with mass flow variations}

For fuel cell applications, the mass flow has to be varied rapidly according to the stack current. The pressure is typically kept at an optimized constant value. Figure 47(a) shows the mass flow responses under the control of DDC and sliding mode controller. It shows that those two controllers have almost the same response time, around $2 \mathrm{~s}$. The pressure is almost not changed under the control of DDC. Whereas, under the sliding mode control, the pressure fluctuates as the mass flow varies, with small fluctuations up to 0.01 bar shown in Figure 47 (b). The faster response of the valve the smaller deviations of the pressure during the transient. The adoption of a fast response valve results in the robustness of the pressure control.

The mass flow is controled by the compressor speed whose dynamic is shown in Figure 48 (a). In order to maintain the pressure at 1.4 bar, the valve position varies, shown in Figure 48(b), with the mass flow changes.

It should be noted that, in spit of the pressure fluctuations is very small in the simulation, in practical applications it may be enlarged because of the external disturbances and parameter uncertainties. Moreover, unlike in the simulation, in actual applications the valve position cannot get the to desired point immediately. Therefore, the results also imply the DDC can perform better than sliding mode control, especially when being toward to the real applications. 


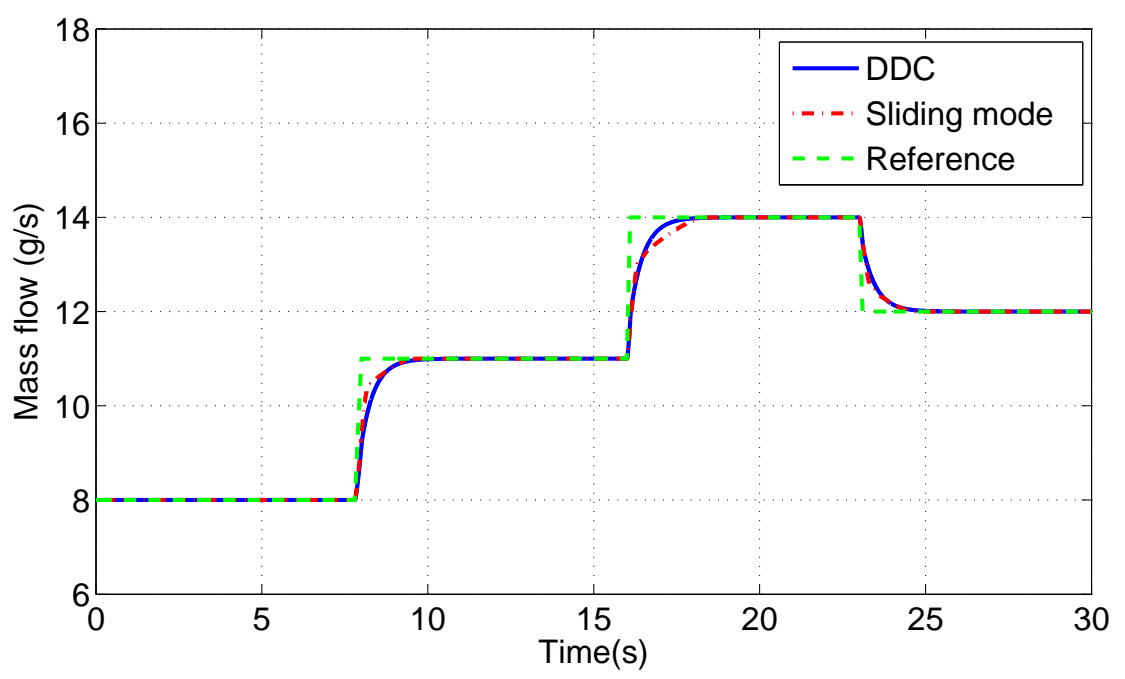

(a) Mass flow reponses

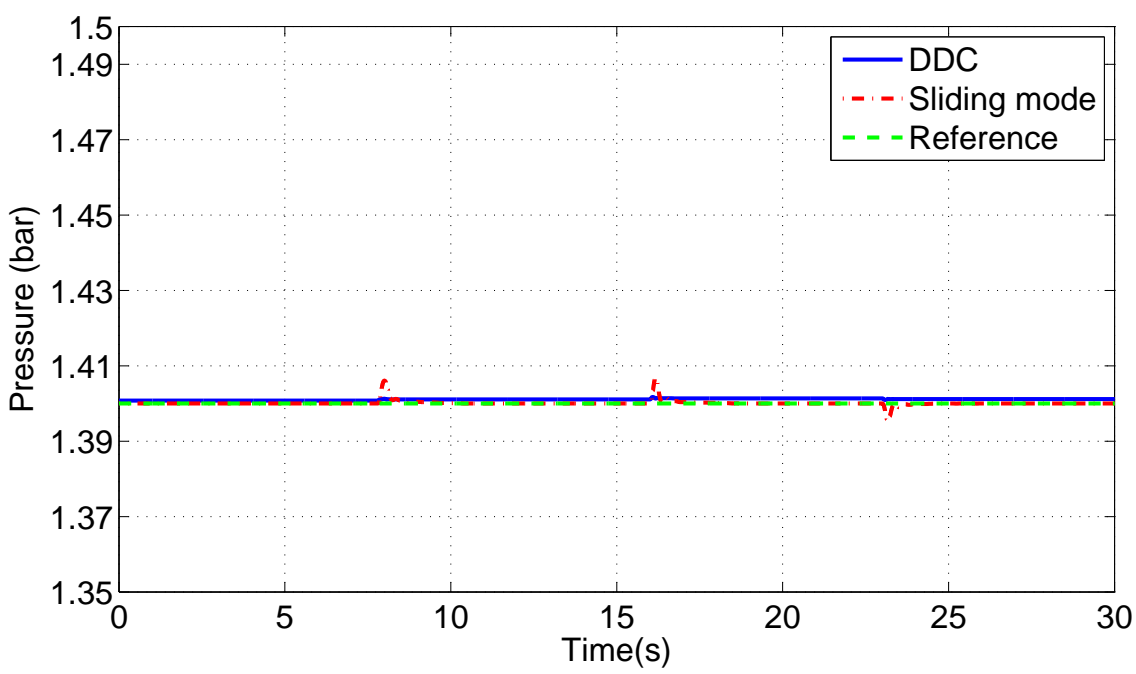

(b) Pressure responses

Fig. 47. Comparison of the DDC with the sliding mode controller with the mass flow variations. 


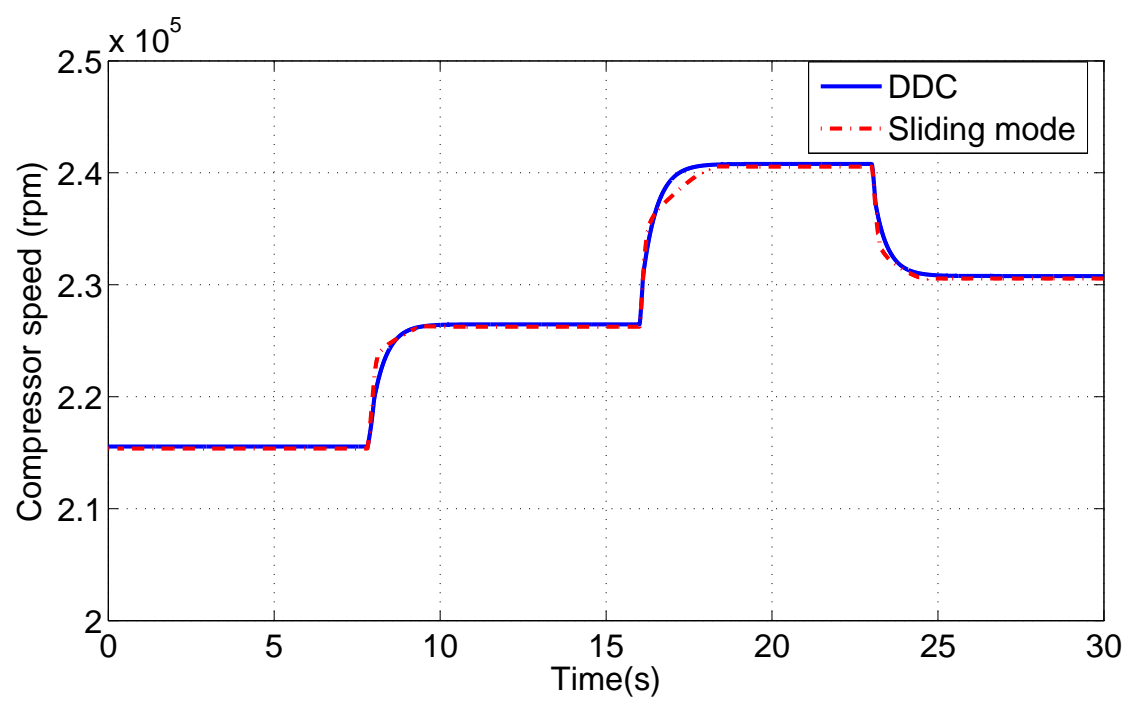

(a)

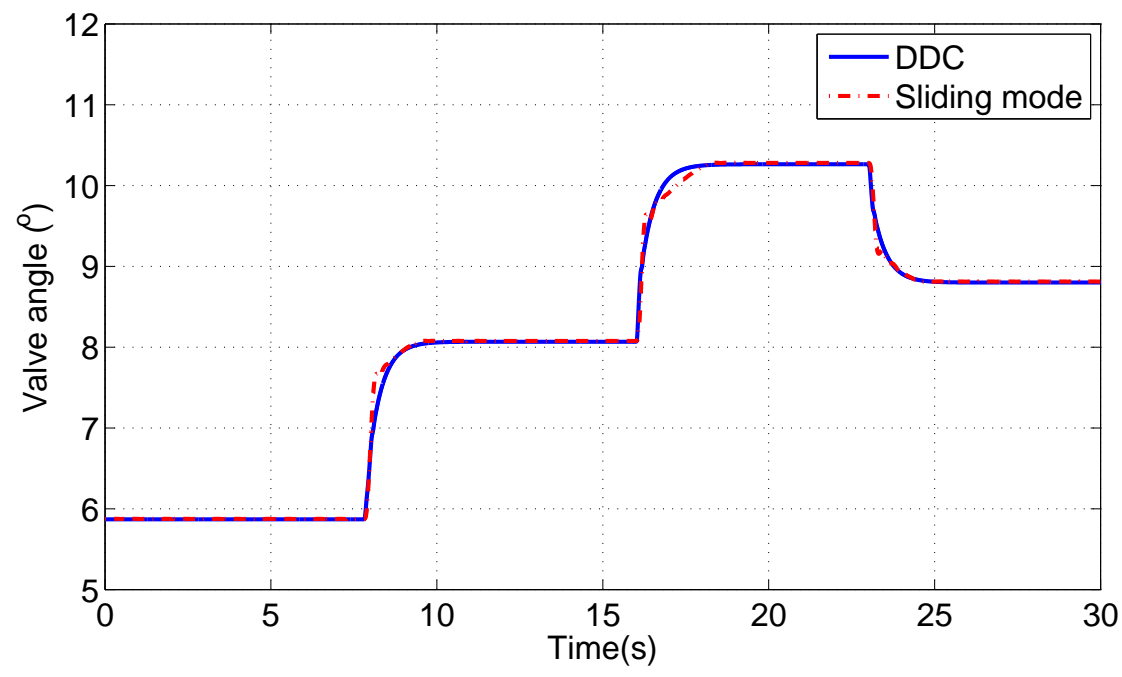

(b)

Fig. 48. Responses of the actuator under the mass flow variations. 


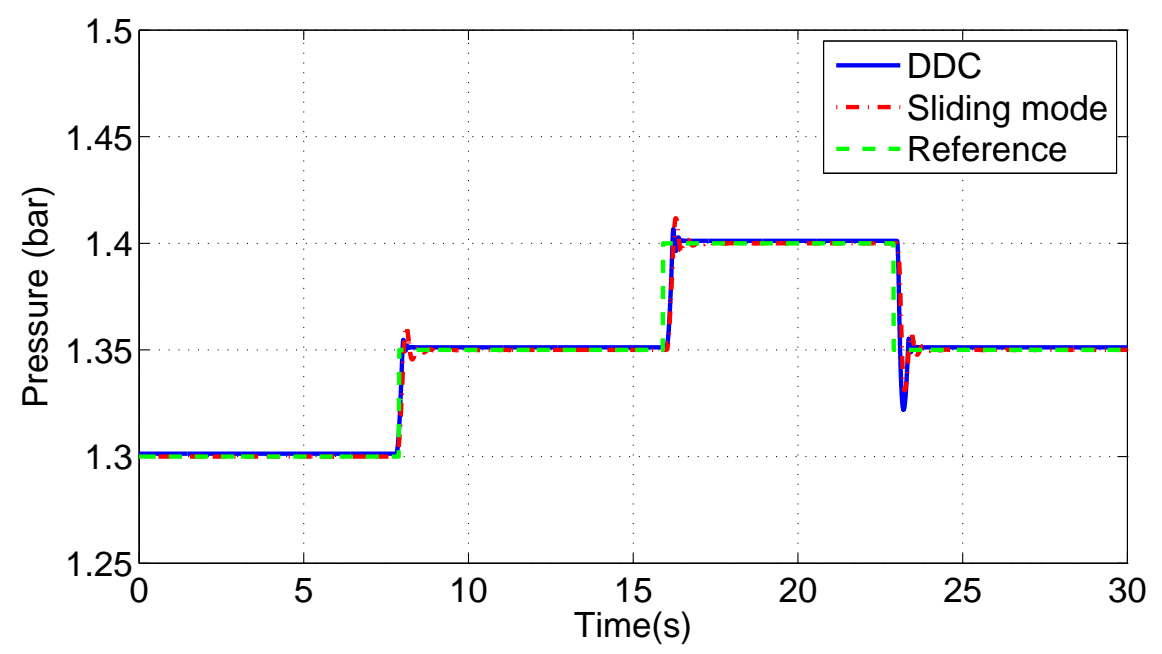

(a)

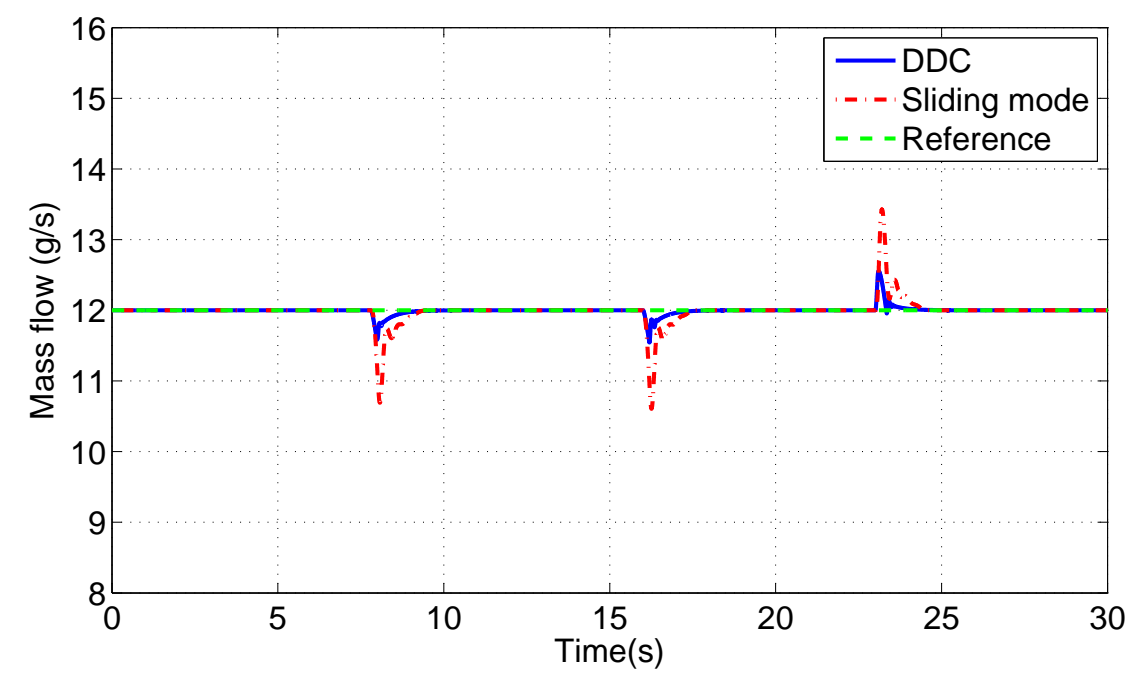

(b)

Fig. 49. Comparison of the DDC with the sliding mode controller with the pressure variations.

\subsubsection{Test with pressure variations}

To test the influence of the pressure variations to the mass flow, the pressure is changed while keeping the mass flow constant. Figure 49(a) gives the variations of the pressure, from 1.3 to 1.4 bar. The mass flow reference is kept at $12 \mathrm{~g} / \mathrm{s}$. Figure 49 (b) demonstrates the mass flow deviations are larger than $1 \mathrm{~g} / \mathrm{s}$ by the sliding mode control. Whereas the mass flow is much smaller influenced, under the control of DDC, 


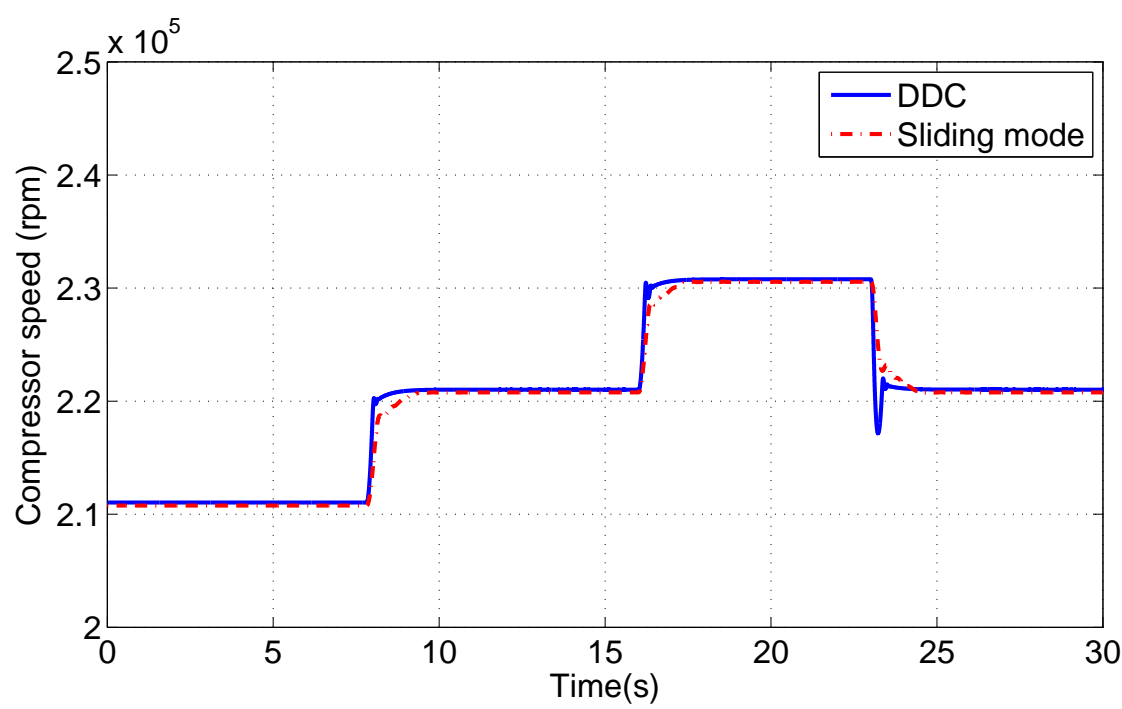

(a)

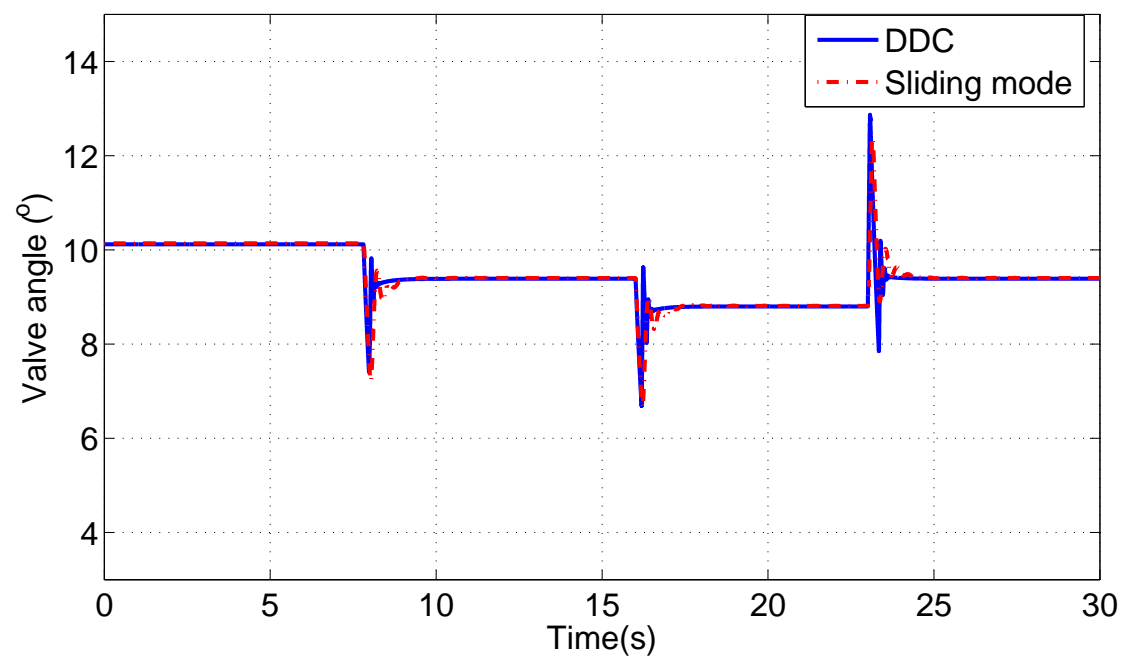

(b)

Fig. 50. Responses of the compressor and valve.

by the variations of the pressure. It means the interaction between the mass flow and pressure has been much rejected. Figure 50 shows the dynamics of the compressor speed and valve position. Following the pressure increases, the compressor speed goes up and the valve position turns down.

From this test we can see that the interaction between the two control loops is much weakened by the DDC. Although large variations of the pressure is forbidden in the 
fuel cell system some deviations of the pressure are inevitable in practical applications. The influence of the pressure deviations to the mass flow also should be minimized.

\subsubsection{Simulation with the parameter deviations}

Both internal interaction and external disturbances exist in practical applications. For the air management system, the internal interaction means the coupling between the mass flow and pressure. The external disturbances include the parametric deviations and the errors of the measurement. In this simulation, the deviations of the parameters and the uncertainty are taken into account to test the robustness of the developed controller. Table 5 gives the deviations of the parameters.

Table 4. Parameter deviation range.

\begin{tabular}{l|l}
\hline Parameters & Variations \\
Compressor inlet air pressure & $-10 \%$ \\
Air temperature & $+10 \%$ \\
Manifold volume & $-10 \%$ \\
Motor time constant & $+10 \%$ \\
\hline
\end{tabular}

Following varied commands, the dynamics of mass flow and pressure are shown in Figure 51 and Figure 52, respectively. The mass flow has abrupt drops at $31 \mathrm{~s}$ and $38 \mathrm{~s}$, respective, because of the step-up of the pressure. Figure 51(b) describes the zoom-in of the deviation at $38 \mathrm{~s}$. It shows that, as the pressure increases from 1.4 to $1.45 \mathrm{bar}$, the mass flow deviates from $12 \mathrm{~g} / \mathrm{s}$ to $11.5 \mathrm{~g} / \mathrm{s}$ and $10.5 \mathrm{~g} / \mathrm{s}$ (Figure 51(b)), respectively, for DDC and sliding mode control. Meanwhile, the DDC has a faster recover response.

For the pressure control, the DDC is capable of keeping the pressure at the reference with little variations as the mass flow changes. However, pressure variations exist in the sliding mode control. Figure 52(b) is the zoom-in of the pressure variations between $30 \mathrm{~s}$ and $35 \mathrm{~s}$, from which two conclusions can be obtained. On the one hand, DDC has a faster pressure response than the sliding mode control. On the other hand, for DDC the pressure is much less independent of the mass flow changes.

The compressor speed and the valve position increase (decrease) while the mass flow increases (decrease), shown in Figure 53 and Figure 54, respectively. As the pressure 
increases (decreases), the compressor speed increase (decreases) and the valve position decreases (increases).

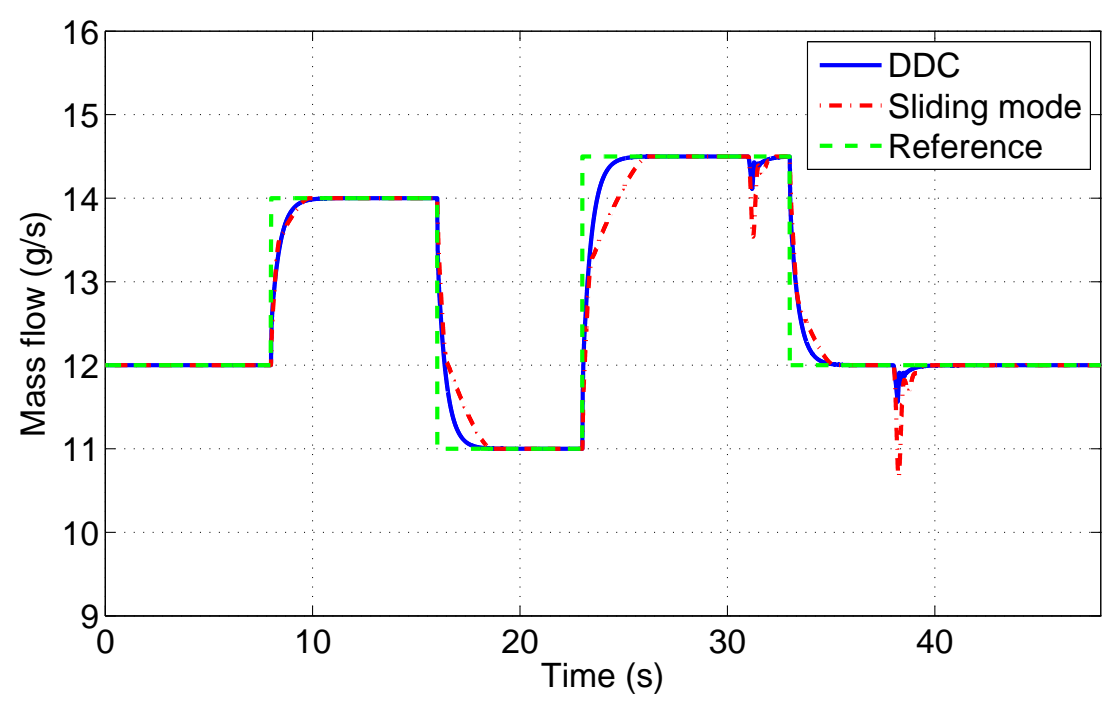

(a)

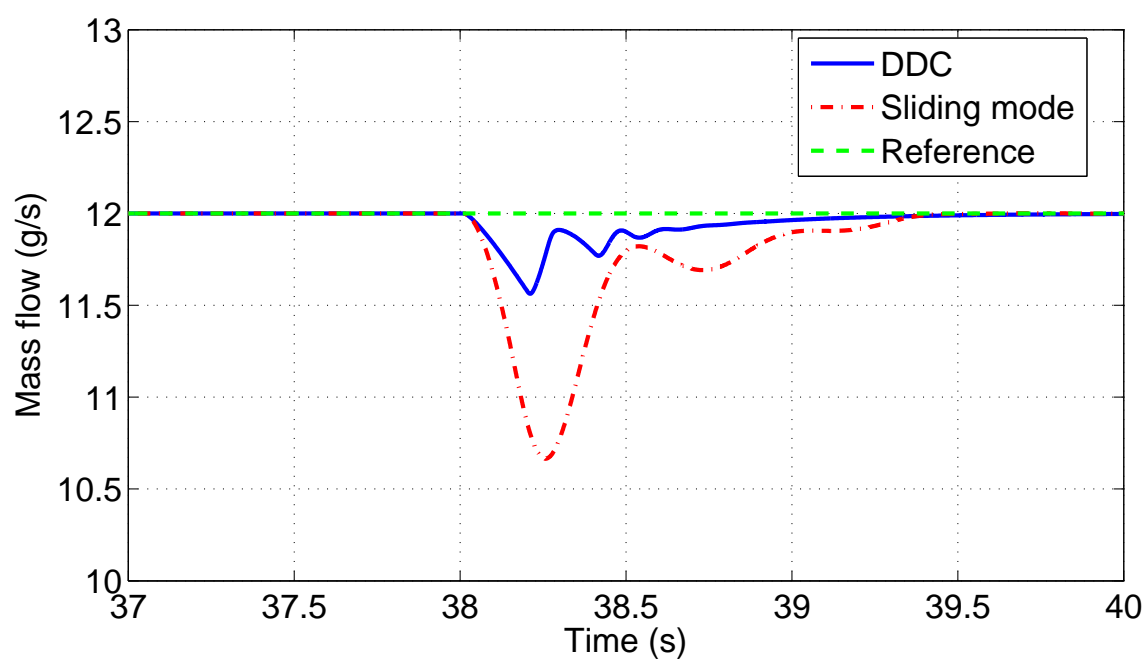

(b)

Fig. 51. Mass flow variations. (a) Mass flow dynamics (b) Zoom in of the mass flow deviation at 38 s. 


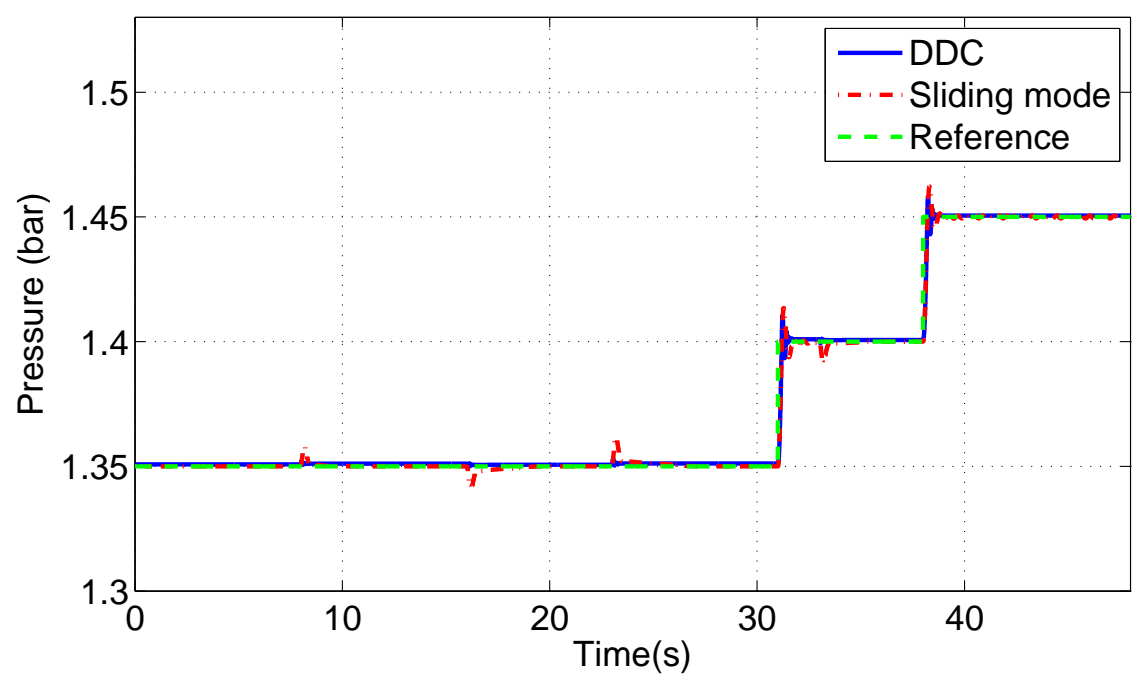

(a)

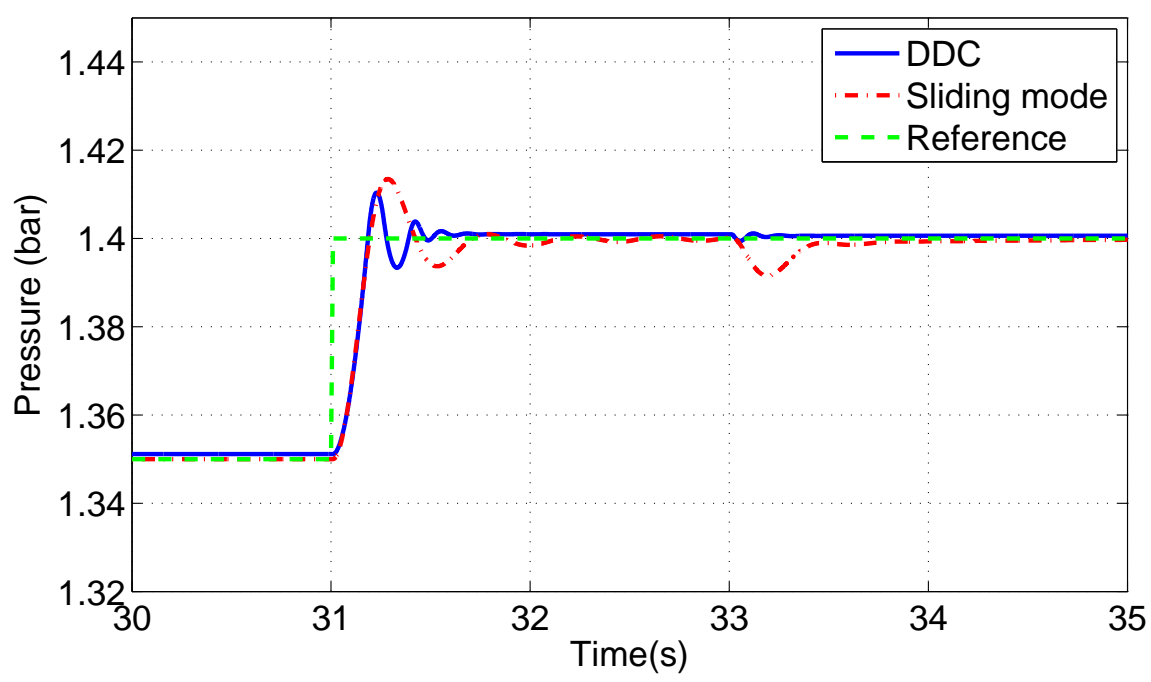

(b)

Fig. 52. Pressure variations. (a) pressure dynamics (b) Zoom in of the pressure deviations at 31 and $33 s$. 


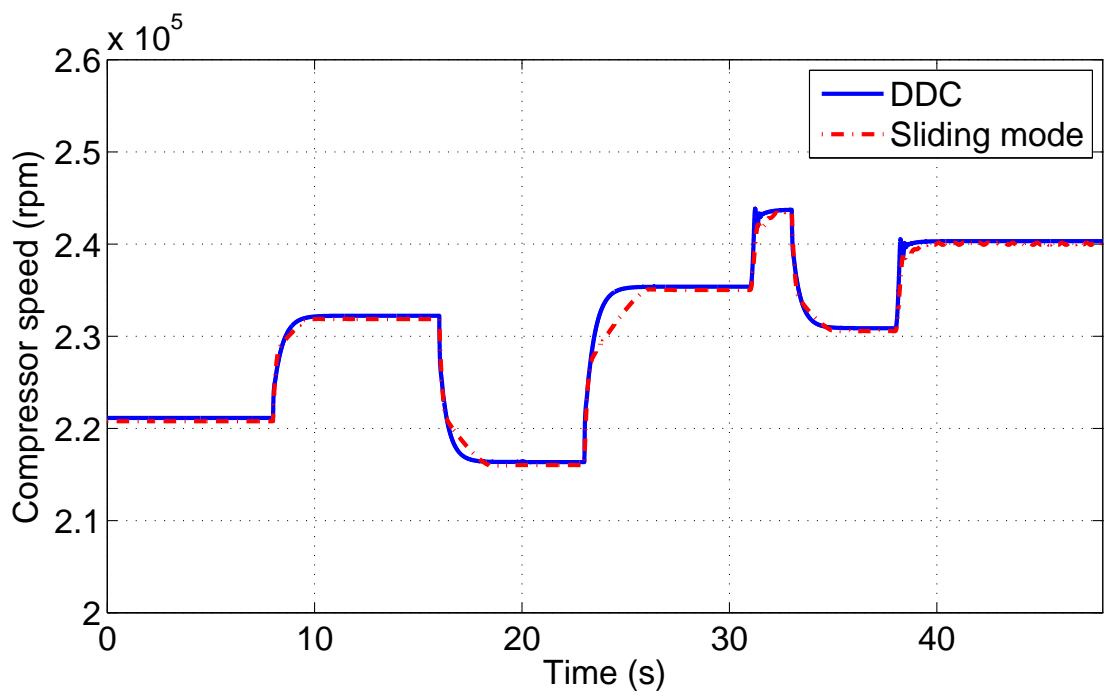

Fig. 53. Speed variations.

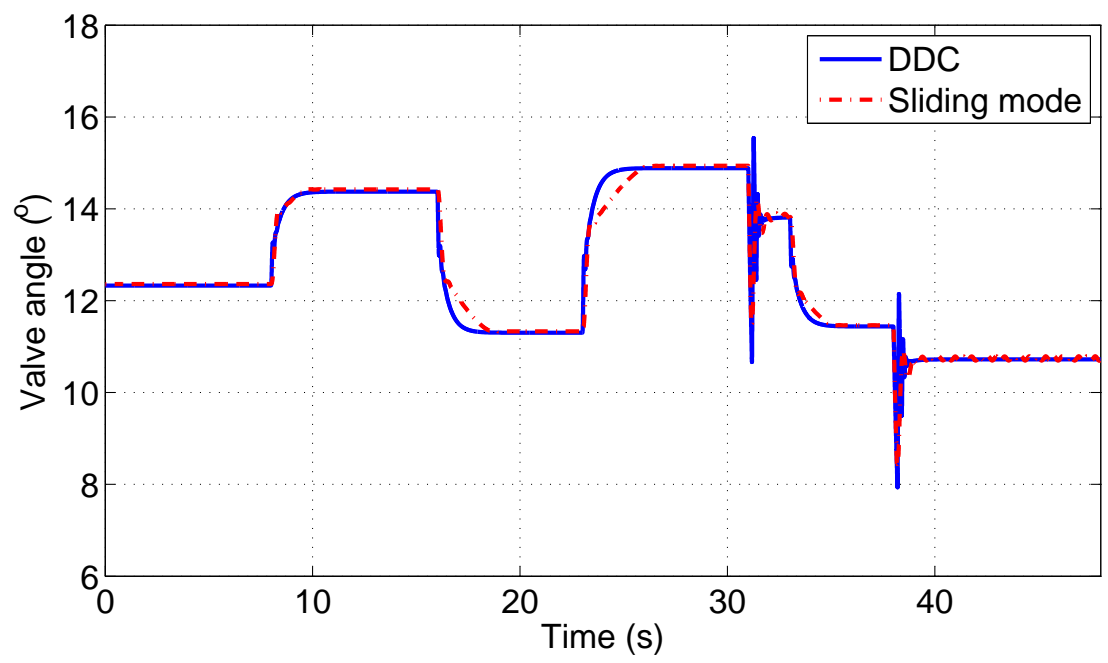

Fig. 54. Valve position variations. 


\subsection{Simulation for a $10 \mathrm{~kW}$ fuel cell model}

The proposed DDC algorithm is validated on a $10 \mathrm{~kW}$ fuel cell model by simulation. The fuel cell model has been described in Chapter 2. The block diagram of the simulation is given in Figure 56. The fuel cell is composed of 90 cells which are assumed having the same conditions. The current-voltage property is shown in Figure 55. The mass flow reference is calculated online according to the load demand, equation (2.17). The pressure reference is maintained at 1.4 bar for the fuel cell stack. The informations of the mass flow, pressure, temperature, etc., from the air management system are used for the fuel cell simulation.

The fuel cell current is shown in Figure 57, which varies from 80 to 140 A. Followed by the current drawn from the stack, the supplied mass flow is described in Figure 58. The oxygen excess ratio is controlled at $\lambda_{O_{2}}=2$, with deviations during the transient, as shown in Figure 59. The recover time of $\lambda_{\mathrm{O}_{2}}$ is about $2 \mathrm{~s}$. Figure 60 shows that pressure is control at 1.4 bar having very small fluctuations during the transient. The compressor speed and valve position are shown in Figure 61 and Figure 62, respectively. The output voltage is described as Figure 63, which is from 50 to $75 \mathrm{~V}$. The voltage decreases as the current increases.

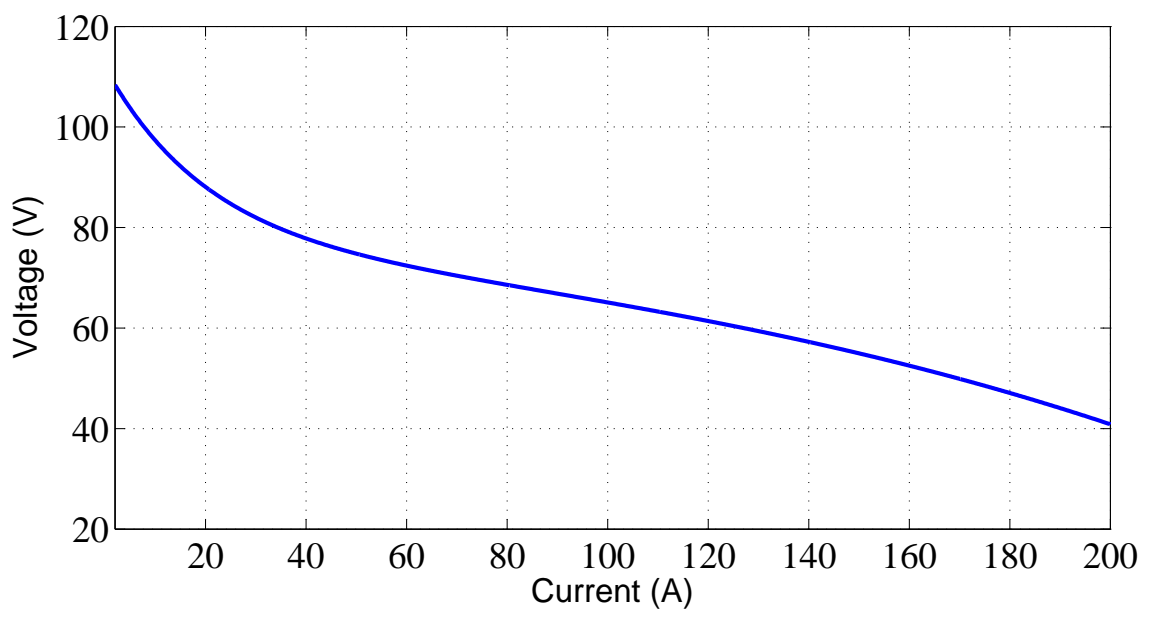

Fig. 55. Fuel cell polarization curve (U-I) property. 


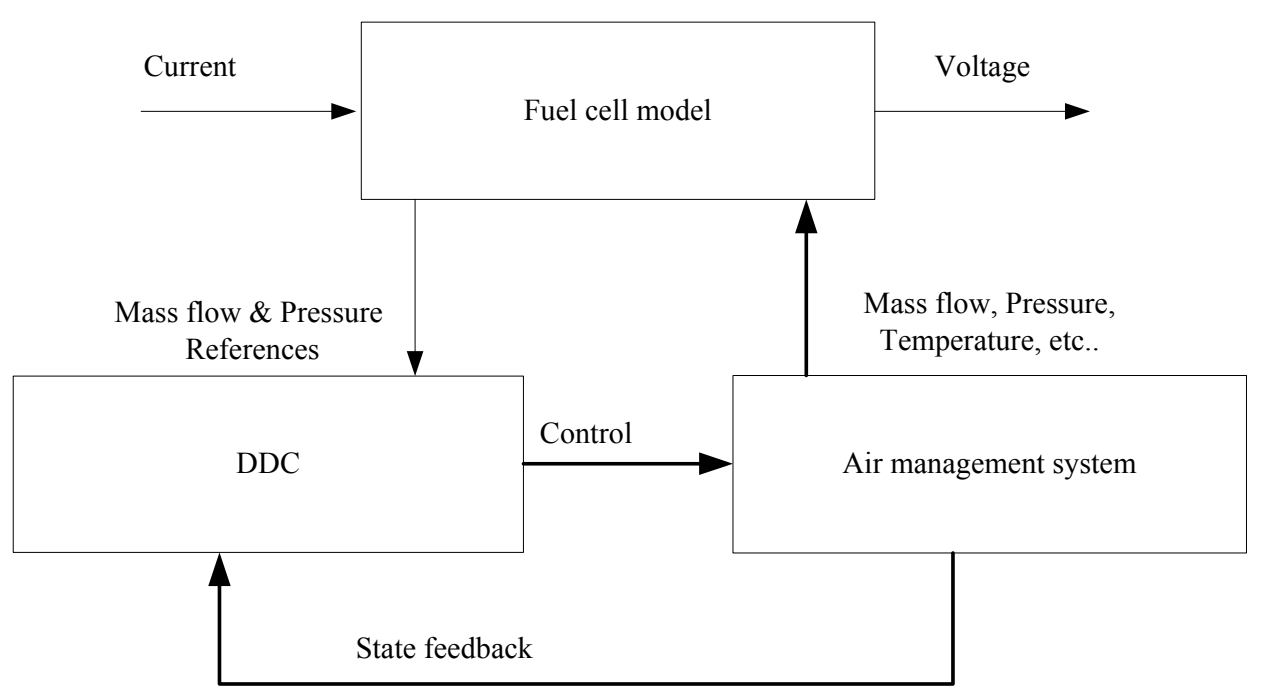

Fig. 56. Block diagram of the simulation.

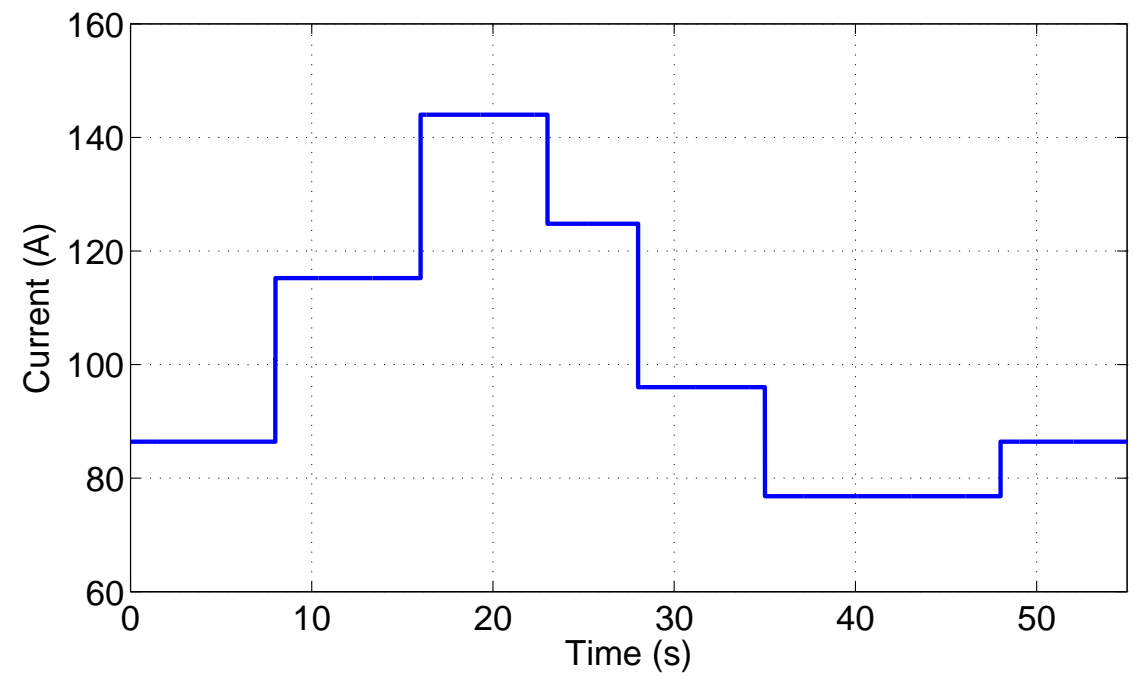

Fig. 57. Fuel cell current. 


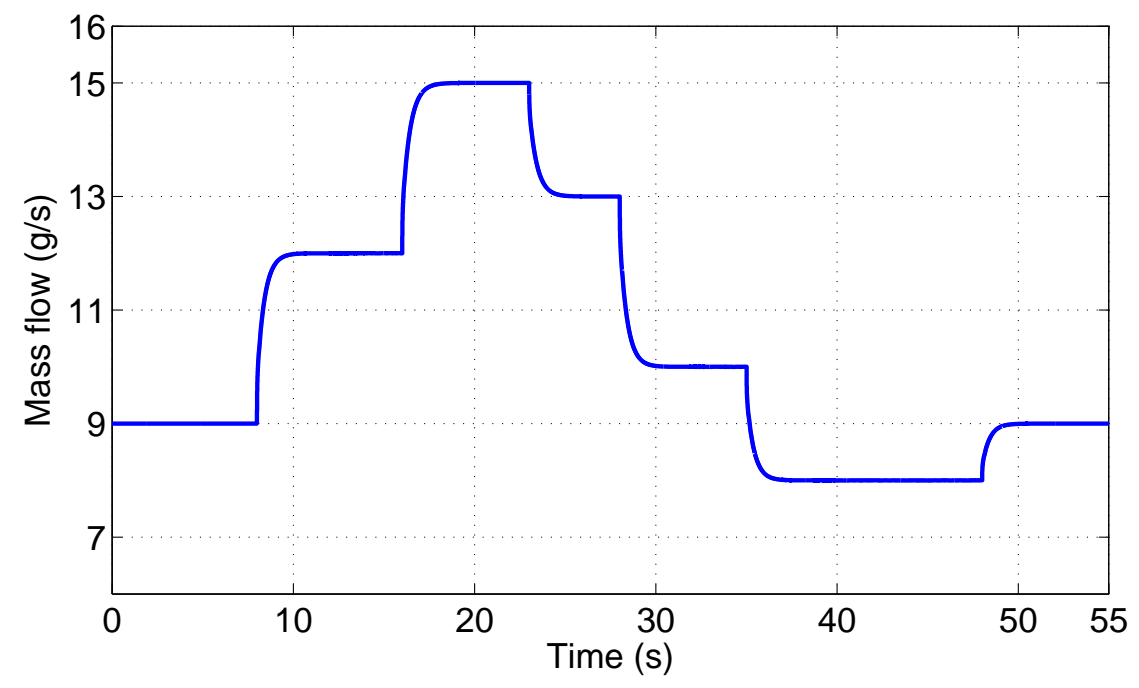

Fig. 58. Mass flow.

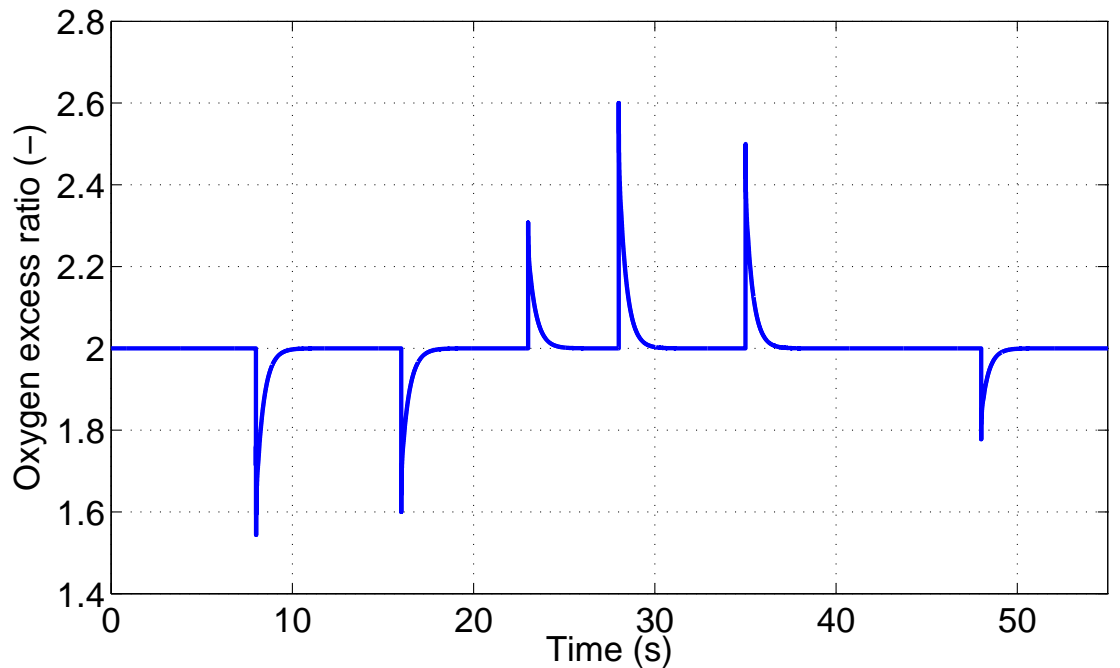

Fig. 59. Oxygen excess ratio. 


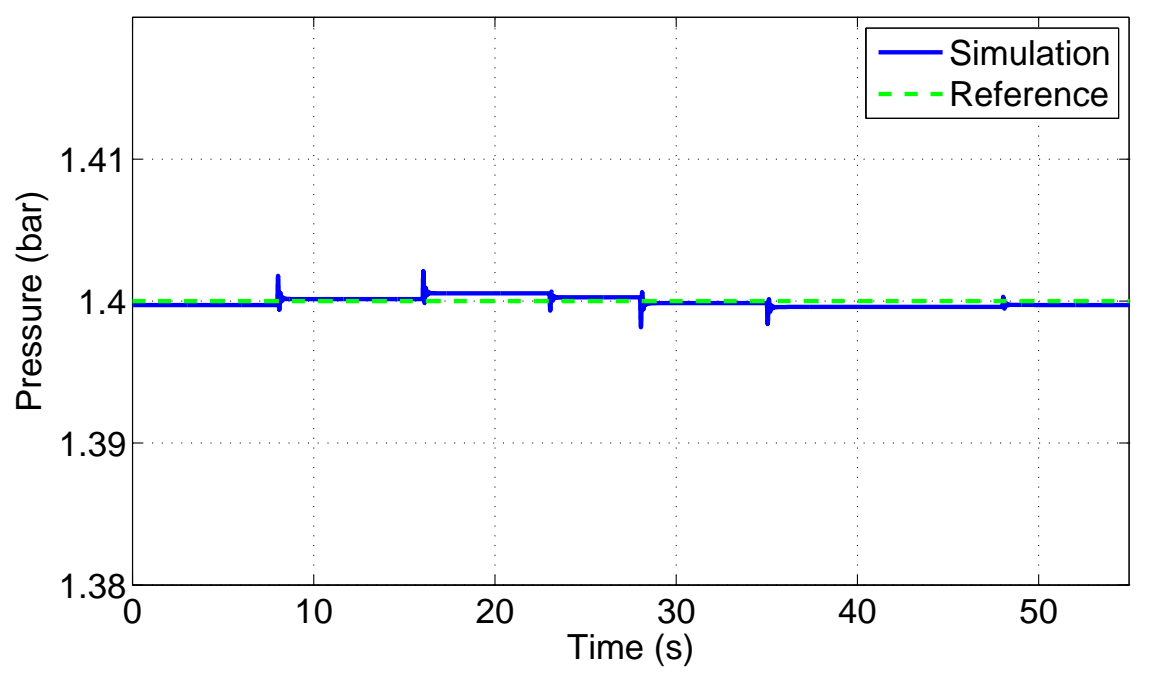

Fig. 60. Pressure.

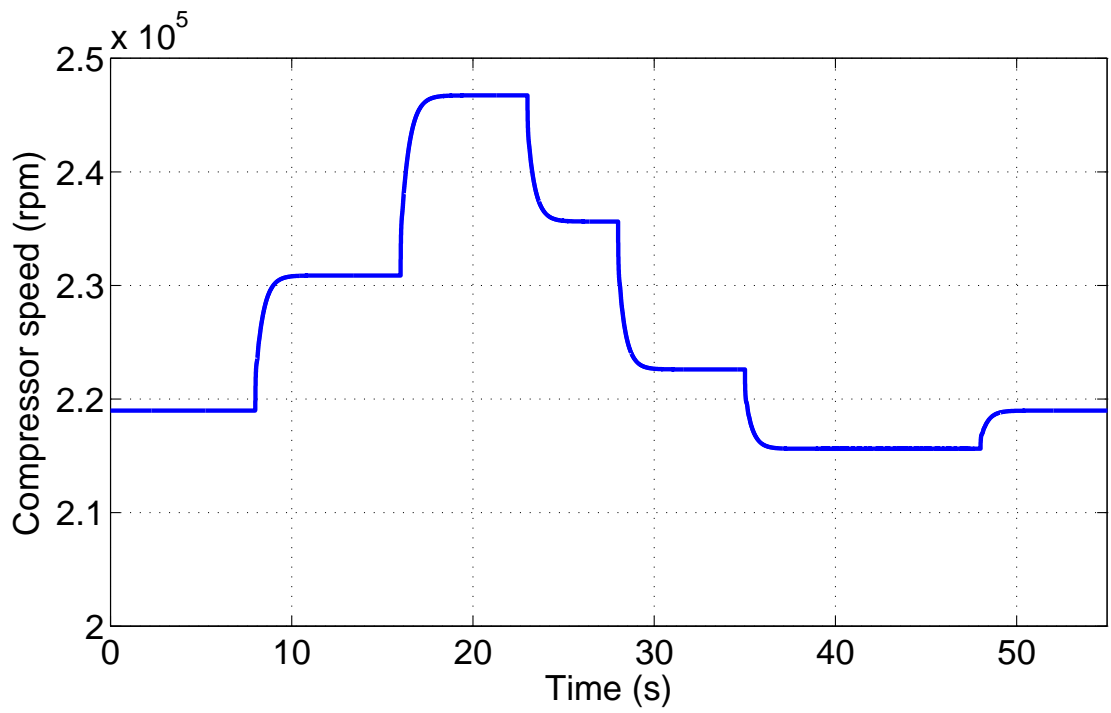

Fig. 61. Compressor speed. 


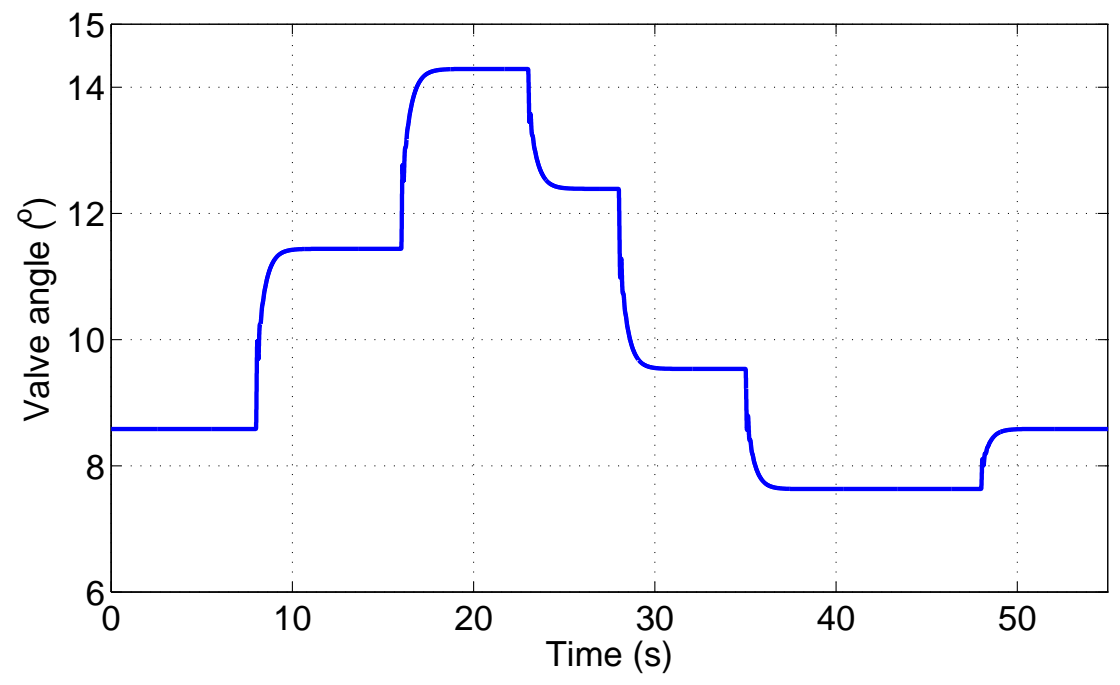

Fig. 62. Valve position.

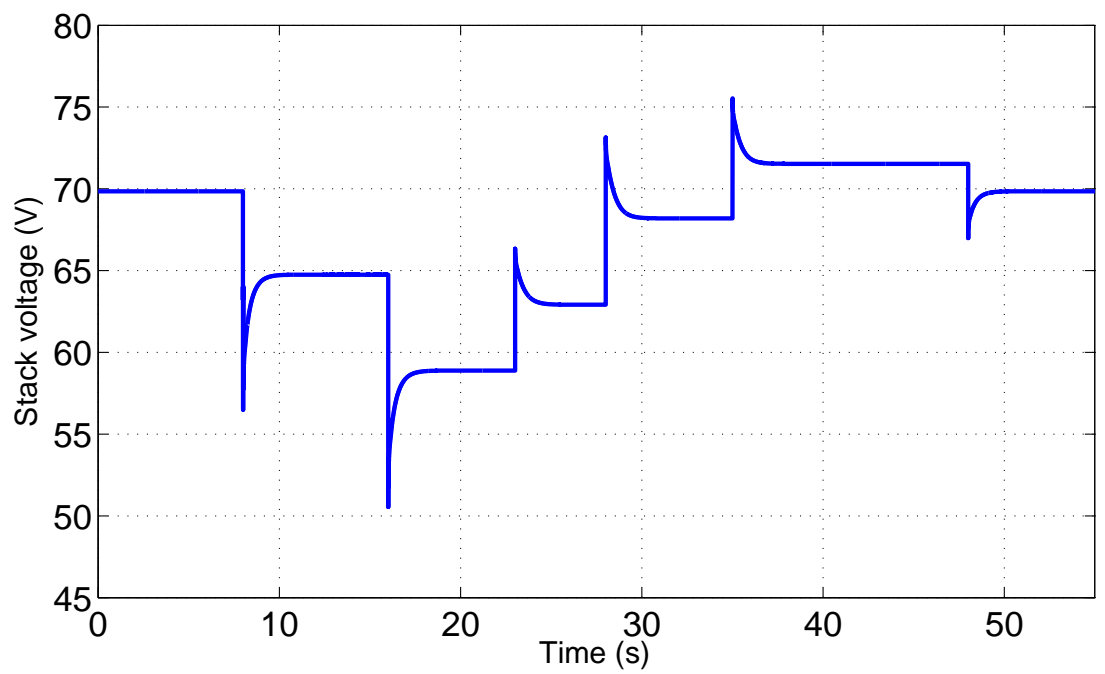

Fig. 63. Stack voltage. 


\subsection{Conclusions}

In this chapter, the coupling of the centrifugal compression system has been analyzed using relative gain array method. After the analysis, this chapter focuses on the development of a disturbance decoupling controller (DDC) to deal with the coupling problem between the mass flow control and pressure control. Simulation results show that under the control of DDC both the mass flow and pressure can quickly follow their varied references. But a small interaction between the two control loops still exists, resulting from the incompletely decoupling of the controller. In order to demonstrate the superiority of the proposed dynamic decoupling controller, a decentralized controller, which does not consider the coupling problem, is developed based on the sliding mode strategy. The performances of those two controllers are compared by simulations. The results have shown that the DDC performs better than sliding mode control in both the steady state and transient dynamics. Then, the proposed DDC is implemented on a $10 \mathrm{~kW}$ fuel cell system by simulation. Performances of the compressor as well as the fuel cell stack are discussed. 


\section{EXPERIMENTAL RESULTS}

\subsection{Experimental setup}

In order to validate experimentally the proposed control method, an hardware-in-theloop (HIL) experimental setup (Figure 64) has been built. The experimental setup includes a centrifugal compressor, manifolds, valves, real time controllers, sensors, air filter, etc. The temperature, mass flow and pressure sensors are installed on the manifold. For the pressure control, a fast butterfly valve is set at the outlet point of the manifold. The air filter is used to remove solid particulates such as dust, pollen, mold, and bacteria from the air before entering the compressor.

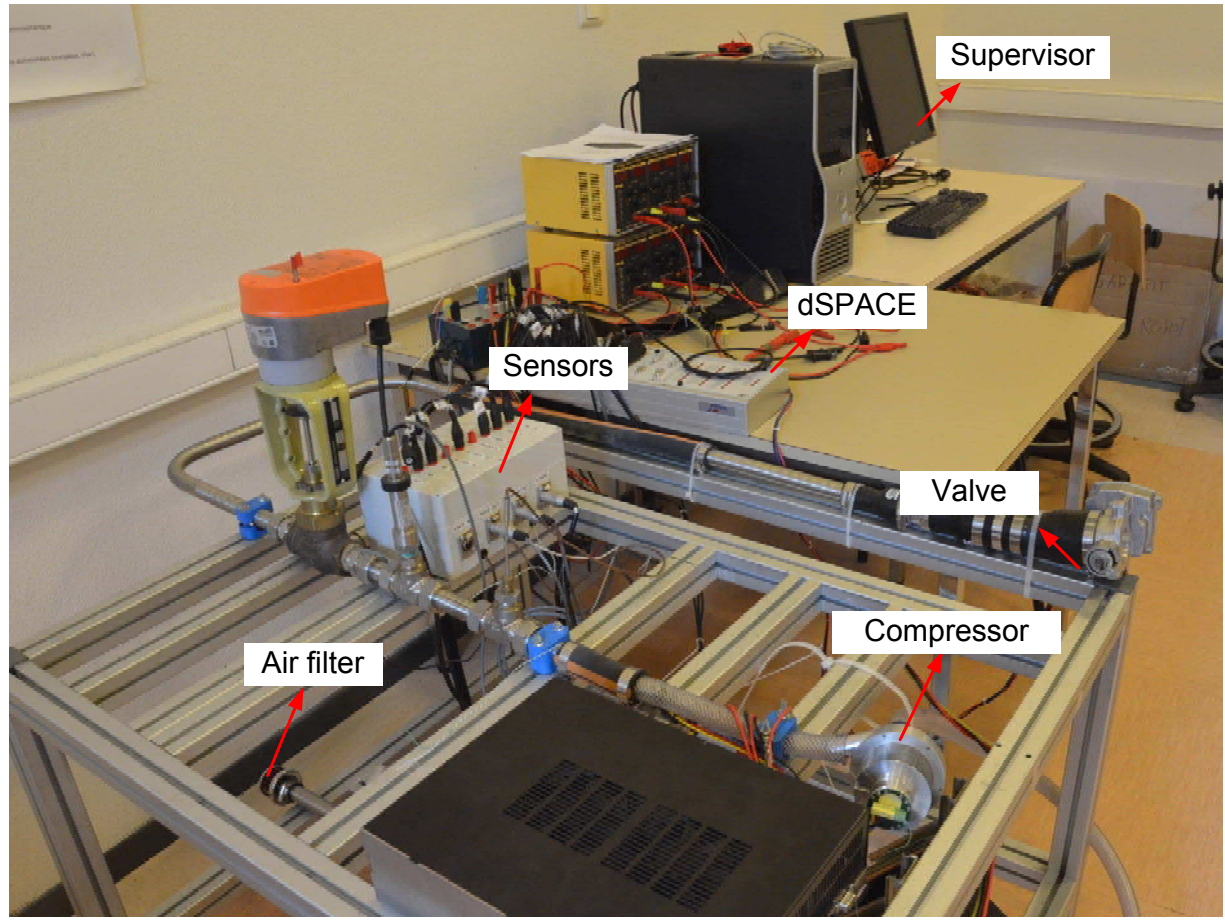

Fig. 64. Hardware-in-the-loop air management test bench. 
The high-performance compressor motor control algorithm is implemented by software on a DSP (TMS320F28334) at the current sampling frequency of $80 \mathrm{kHz}$ and speed sampling frequency of $15 \mathrm{kHz}$, respectively. The proposed mass flow and pressure controller, as well as a surge controller, is implemented in a dSPACE (DS1104) real-time controller.

\subsubsection{Signals measurement}

For the operation of the proposed controller, many signals such as mass flow, pressure, temperature, etc., need to be measured. And those information are then imported into dSPACE controller board by A/D converting.

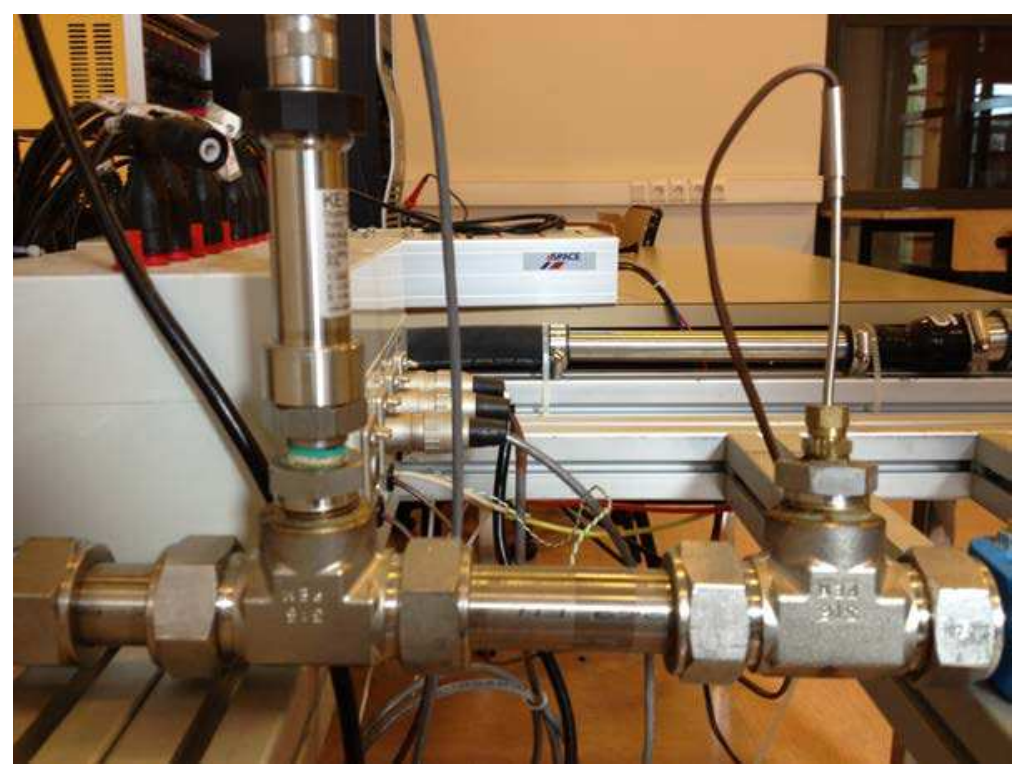

Fig. 65. Temperature sensor (right) and pressure sensor (left).

The pressure and temperature sensors (Figure 65) are settled at the outlet of the compressor. The thermocouple ( $\mathrm{T}$ type) sensor are used for the temperature measurement. As temperature goes up, the output voltage of the thermocouple rises but not necessarily linearly. The thermocouple is located inside a metal shield that protects it from exposure to a variety of environments. A pressure transmitters KELLERS Series 33X is used for pressure measurement with the output rate of $400 \mathrm{~Hz}$ and the accuracy of $0.05 \%$. 
The valve position $\theta$ is obtained by measuring the voltage $u$ on a variable resistance which gives the information of the position, i.e., $\theta=P(u)$ (Figure 66).

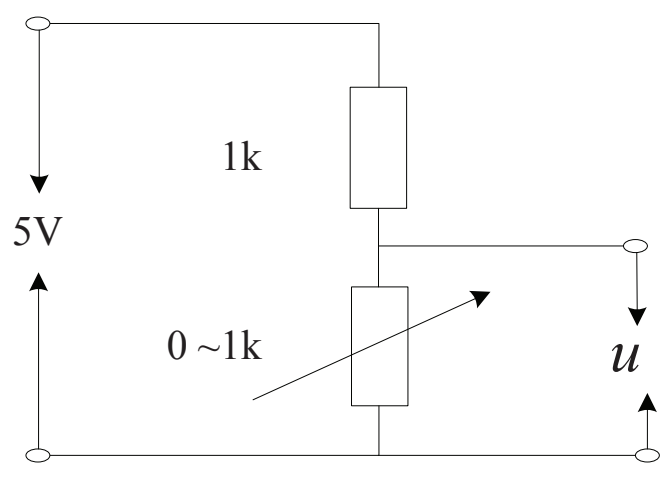

Fig. 66. Valve position measurement.

The mass flow meter (Figure 67) is settled at the inlet of the compressor, as the inlet flow is almost the same with the outlet. Thermal mass flowmeters use the principle of convective heat transfer to directly measure the mass flow. The mass flow meter has a linear signal output $0-5 \mathrm{VDC} \& 4-20 \mathrm{~mA}$, corresponding to the mass flow rate of $0-55 \mathrm{~g} / \mathrm{s}$

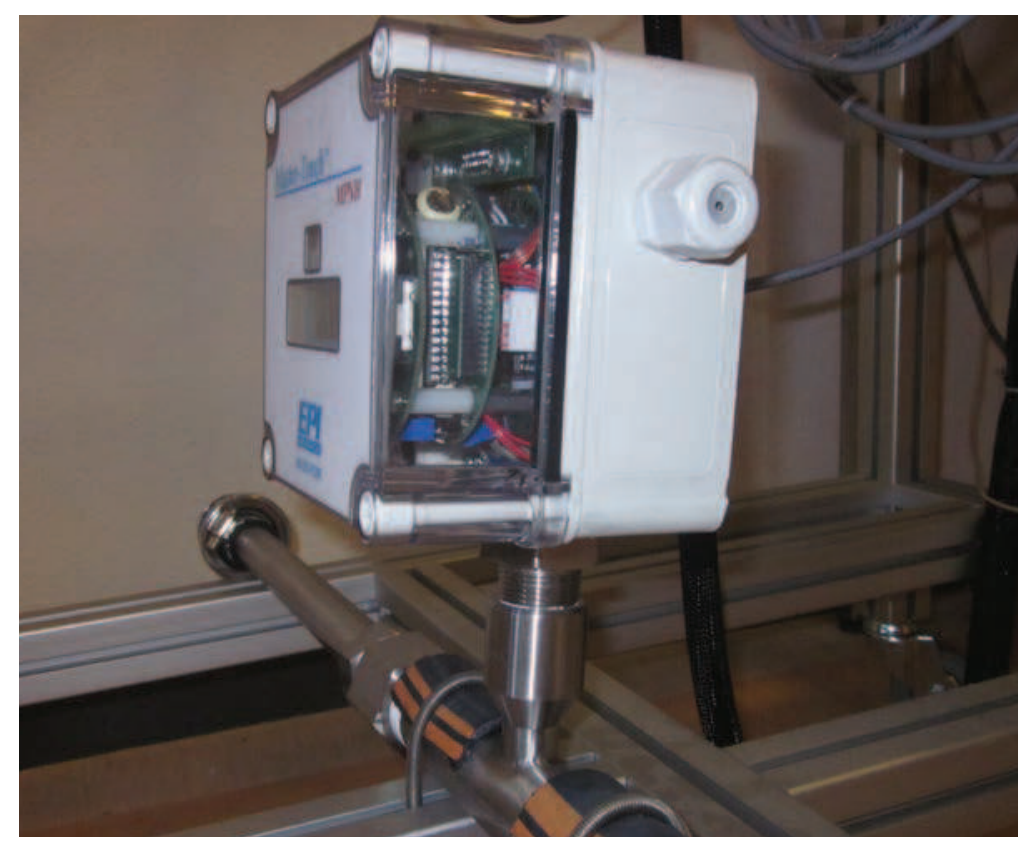

Fig. 67. Mass flow sensor. 
Table 5. Characters of the sensors.

\begin{tabular}{l|c}
\hline Sensor & Characters \\
\hline Temperature sensor & $\begin{array}{r}\text { Type T thermocouples, Measurement }-200 \text { to } 350^{\circ} \mathrm{C} . \\
\text { Input 8-30 VDC, Output 0-10 V }\end{array}$ \\
\hline Pressure sensor & Input 13-28 VDC, Measurement 0-3 bar. \\
Output 0-10 V, Accuracy $\pm 0.1 \%$
\end{tabular}

\subsubsection{Real-time controller}

A dSPACE DS1104 is used for the real-time validation of the proposed control approaches. The block diagram of DS1104 board is shown in Figure 68. The realtime hardware is based on the PowerPC 603e microprocessor. The interface provides Simulink blocks for configuration of A/D, D/A, digital I/O lines, and PWM generation, which makes it very convenient to connect with actual devices.

The measured data (mass flow, pressure, temperature, etc.) are obtained through ADC inputs with $12 / 16$ bit. The input voltage range of $\mathrm{ADC}$ is $\pm 10 \mathrm{~V}$. A D/A port is used to convert the desired speed to an analog output importing into the motor inverter. The 16 bit analog output range is $\pm 10 \mathrm{~V}$ with maximum settling time of $10 \mu \mathrm{s}$. The discharge valve position is controlled by the PWM switching output from the slave DSP subsystem on DS1104. The structure of the system is shown in Figure 69.

\subsection{Surge prevention}

Surge is defined as the operating point at which the compressor peak head capability and minimum flow limit are reached. The compressor loses the ability to maintain the peak head when surge occurs and the entire system becomes unstable [61]. Surge is an unstable state, which gives rise to oscillations of mass flow and pressure ratio, and severely reduces compressor efficiency. Moreover, it can possibly damage the compressor in the most severe cases [62]. An effective way to deal with the surge constraint is to make the compressor operate always at the right of the surge line. A reference limiter is designed and added to the compressor control loop to cope with 


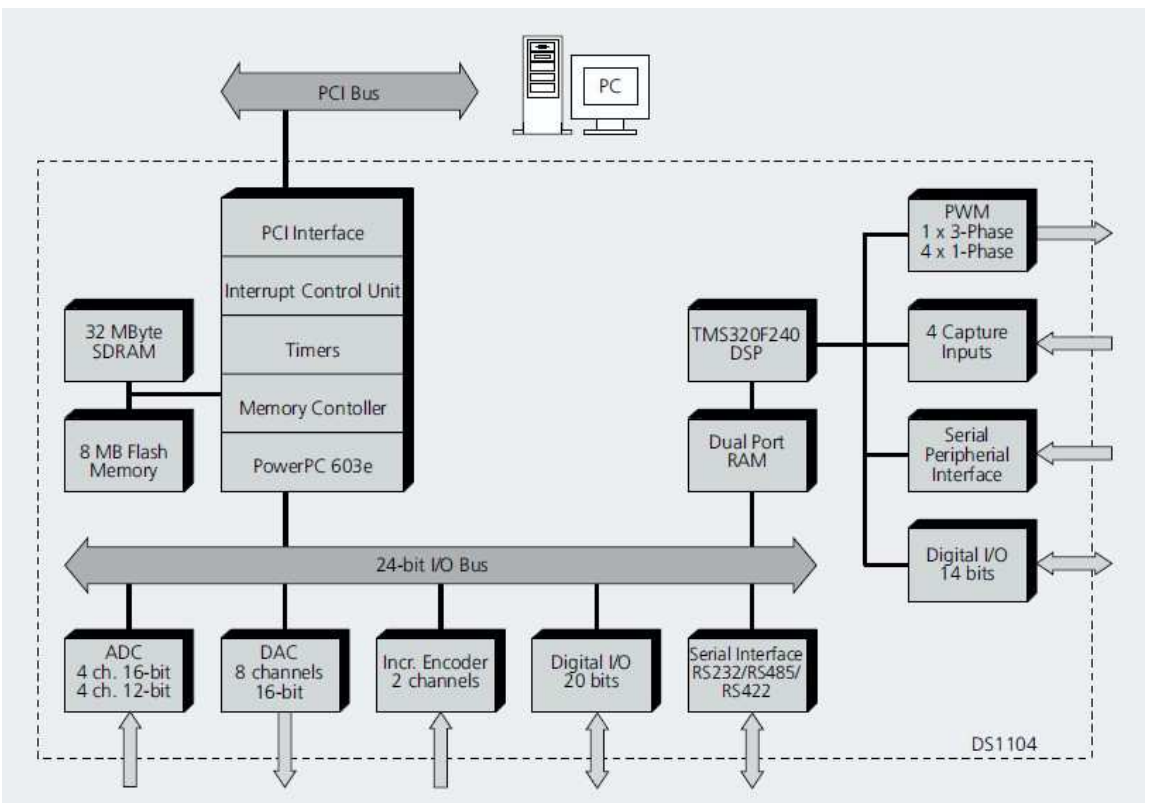

Fig. 68. DS1104 controller board layout.

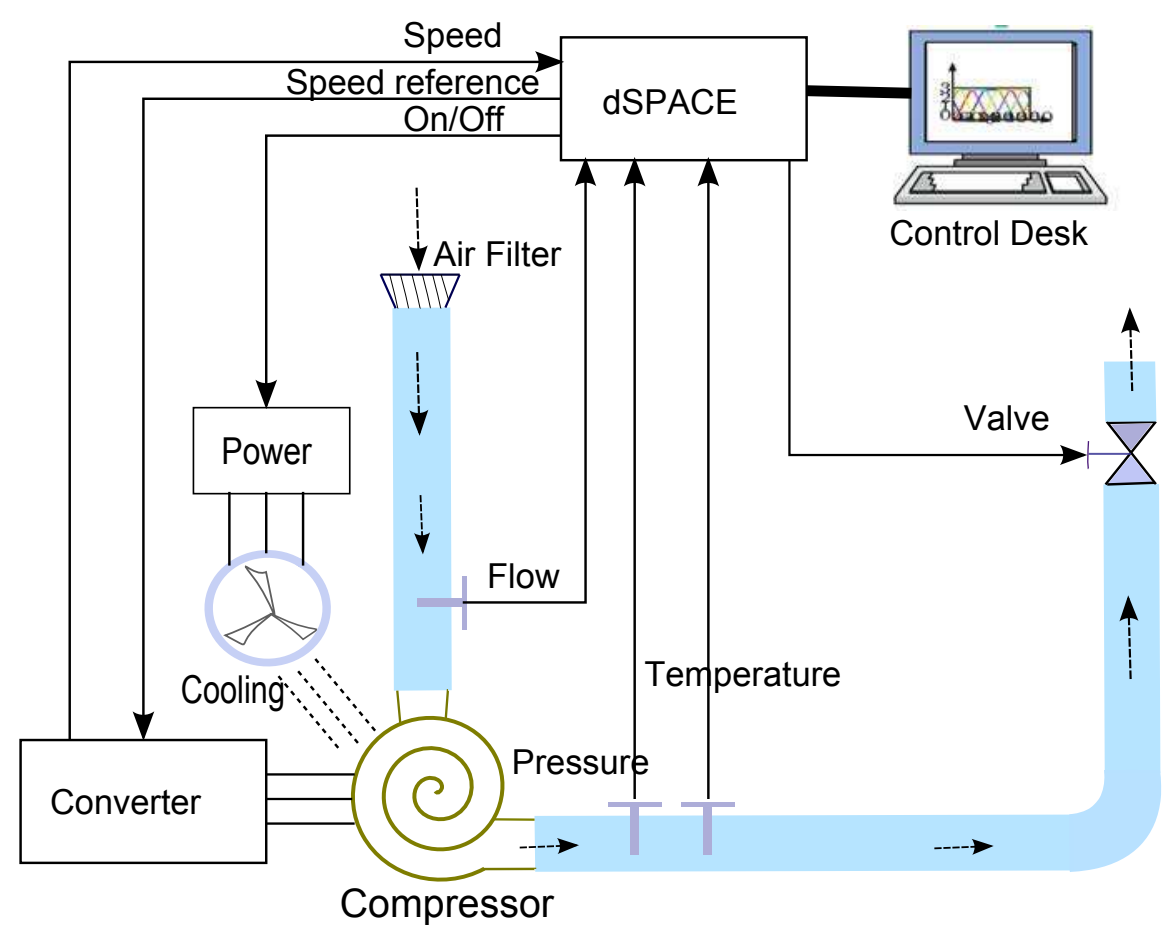

Fig. 69. Testbench block diagram and connections. 
the surge constraint.

In order to avoid compressor surge, a reference limiter is designed to prevent the trajectory crossing the surge line. A control surge line is defined, $p=\phi(q)$, which provides a safety margin for the surge control. The reference limiter is expressed as follows:

$$
\begin{aligned}
& p^{*}=\min \left\{\phi(q), p^{\mathrm{ref}}\right\} \\
& q^{*}=\max \left\{\phi^{-1}\left(p^{*}\right), q^{\mathrm{ref}}\right\}
\end{aligned}
$$

where $p^{\text {ref }}$ and $q^{\text {ref }}$ are the pressure and mass flow references respectively. $p^{*}$ and $q^{*}$ are the outputs of the reference limiter which redefines and optimizes the system references to avoid compressor surge. The characteristics of the trajectory during the operation are analyzed as follows.

For the closed loop system, the pressure is controlled by the discharge valve. As the valve position increases the pressure decreases, $\Delta p \propto \frac{1}{\Delta \theta}$. Whereas the mass flow is regulated by the compressor speed, and as the speed increases the mass flow also increases, $\Delta q \propto \Delta \omega$. where $\Delta$ denotes the increment of corresponding variable. Due to the faster response of the discharge valve than the motor-compressor, the pressure has a faster response than the mass flow. It makes that the trajectory of operation clockwise (see Figure 70)). Take the set points A and B for example.

1. Case 1: $p^{\mathrm{ref}}>p, q^{\mathrm{ref}}>q \cdot\left(A(q, p) \rightarrow B\left(q^{\mathrm{ref}}, p^{\mathrm{ref}}\right)\right)$

In this situation, the closed-loop controller results in the decrement of the valve angle $(\Delta \theta<0)$ and the increment of the compressor speed $(\Delta \omega>0)$, which exactly have an inverse impact on the mass flow and pressure ratio. $\Delta \theta<0$ reduces (increases) the mass flow (pressure), whereas $\Delta \omega>0$ increases (reduces) mass flow (pressure). The faster response of the valve makes the pressure reach the set point in the first place. The mass flow decreases at first and then increases to the set point, which is a clockwise trajectory as shown in Figure 70(a).

2. Case 2: $p^{\mathrm{ref}}<p, q^{\mathrm{ref}}<q .\left(B(q, p) \rightarrow A\left(q^{\mathrm{ref}}, p^{\mathrm{ref}}\right)\right)$

In this situation, the increment of the valve angle $(\Delta \theta>0)$ makes the pressure decrease and mass flow increase. Then the slower speed $(\Delta \omega<0)$ makes the mass flow reduce to the setpoint. The trajectory is shown in Figure 70(a) which is also clockwise. 
The same conclusion can be obtained in the same way for the other two situations: $p^{\text {ref }}>p, q^{\text {ref }}<q$ (case 3) and $p^{\text {ref }}<p, q^{\text {ref }}>q$ (case 4) shown in Figure 70(b). During the startup stage, the operating trajectory goes along the control surge line, and it may also slightly cross the control surge line. But it is still away from the actual surge line provided the safety margin exists.

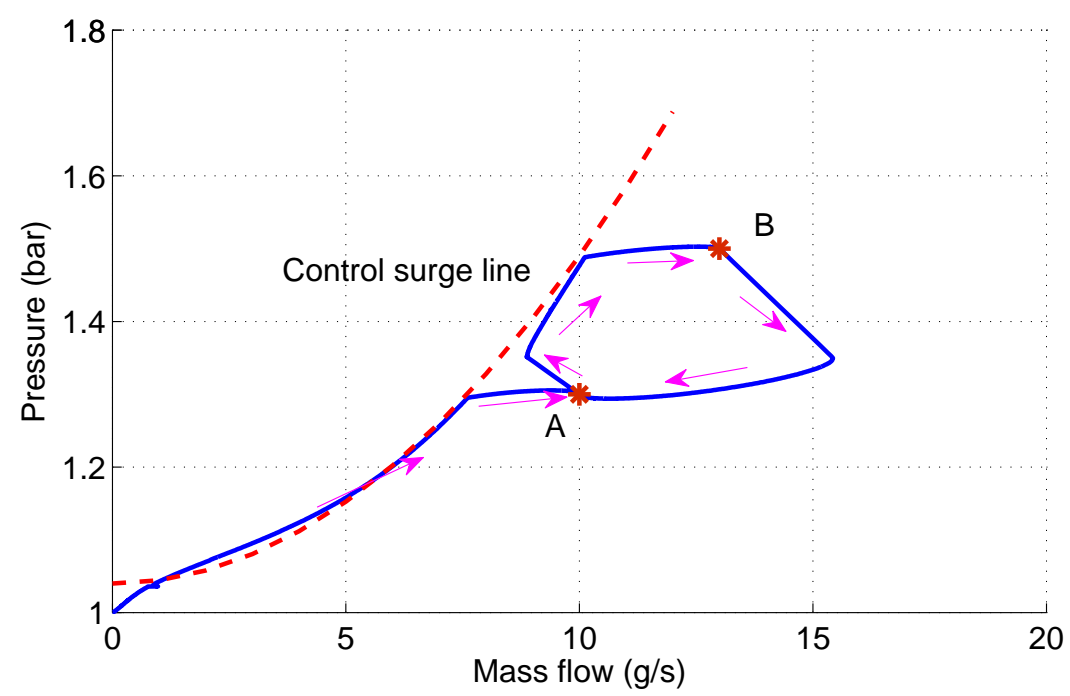

(a) Simulation trajectory $((0,1) \rightarrow A \rightarrow B \rightarrow A)$

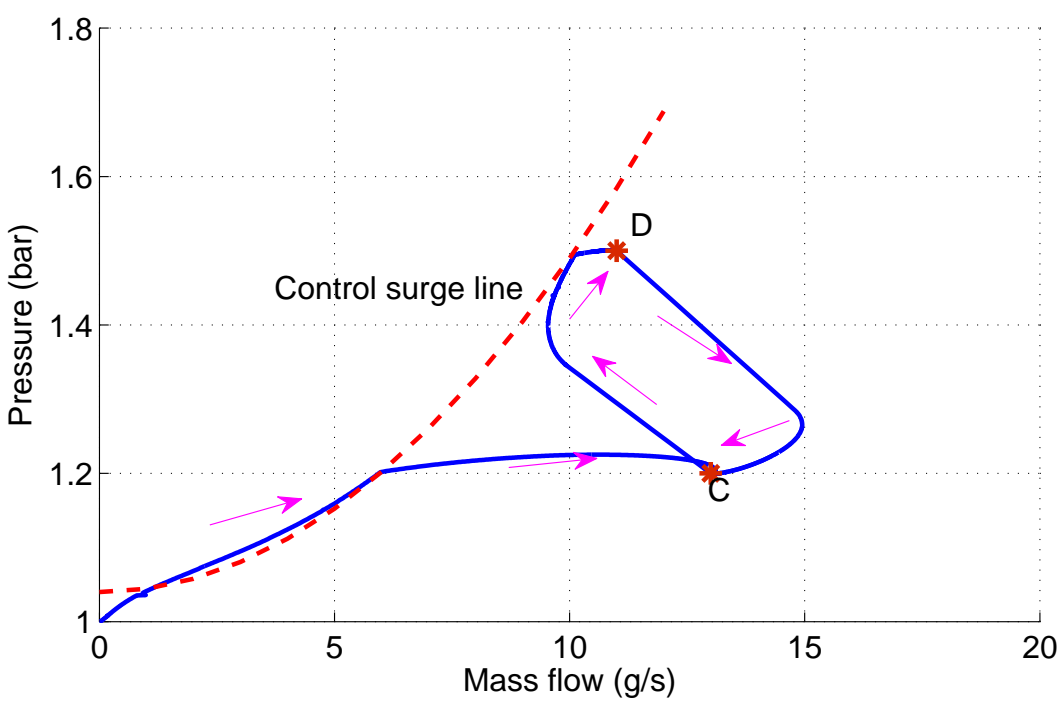

(b) Simulation trajectory $((0,1) \rightarrow C \rightarrow D \rightarrow C)$

Fig. 70. The trajectory of the compressor operation. 
Through the above analysises, only in the case 1 and case 3 there are possibilities that the trajectory cross the surge line. As the mass flow is small, equation (4.1) forces the set points to go along the control surge line to restrain the fast raise of pressure, so as to prevent the surge phenomenon. equation (4.2) makes sure that the set points are in the right hand side of the control surge line. The effectiveness of the limiter is shown by simulation shown in Figure 70(a) and Figure 70(b). The trajectory is controlled to the right of the surge line. It should be noticed that, in practical applications, because of the disturbances from the internal and external it is inevitable that it operates to left of the control surge line during the startup stage. The mass flow is declined by the increase of the pressure, leading to the backward motion of the pressure reference $p^{*}$. Therefore, it results in the oscillations of the trajectory along the control surge line as shown in Figure 71. Those oscillations degrades the fuel cell performance. The pressure oscillations lead to the vibrations of the output voltage of the fuel cell stack. Moreover, in severe cases it may damage the stack membrane. The mass flow oscillations may cause the fuel cell oxygen starvation, which can shorten the life time of fuel cell stack.

In order to avoid the oscillation, an improved reference limiter is developed as follows:

$$
\begin{aligned}
& p^{*}(k)= \begin{cases}\min \left\{\phi(q(k)), p^{\mathrm{ref}}\right\}, & p(k)<\phi(q(k)) ; \\
p^{*}(k-1), & p(k) \geq \phi(q(k)) ;\end{cases} \\
& q^{*}(k)=\max \left\{\phi^{-1}\left(p^{*}(k)\right), q^{\mathrm{ref}}\right\}
\end{aligned}
$$

where $p(k)$ and $q(k)$ represent the discrete form of the measured mass flow and pressure respectively. In the case of $p^{\text {ref }}>p$, equation (4.3) assures that $p^{*}$ is monotone nondecreasing until $p^{*}=p^{r e f}$, to avoid pressure oscillation. Figure 72 shows that with the improved reference limiter the oscillations along the control surge line are eliminated. A,B,C,D are the setpoints. The trajectory goes along the control surge line to the point A during the startup stage and then clockwise goes to B, C, D in turn. During this process, the small reciprocating movement of the mass flow or pressure are caused by the overshoot or ripples of the control at their references. During this operation, the dynamics of the pressure and mass flow are shown in Figure 72(b) and Figure 72(c), respectively. Because of the interaction between the mass flow and pressure cannot is not completely decoupled, the sudden changes of the pressure vary the mass flow. 


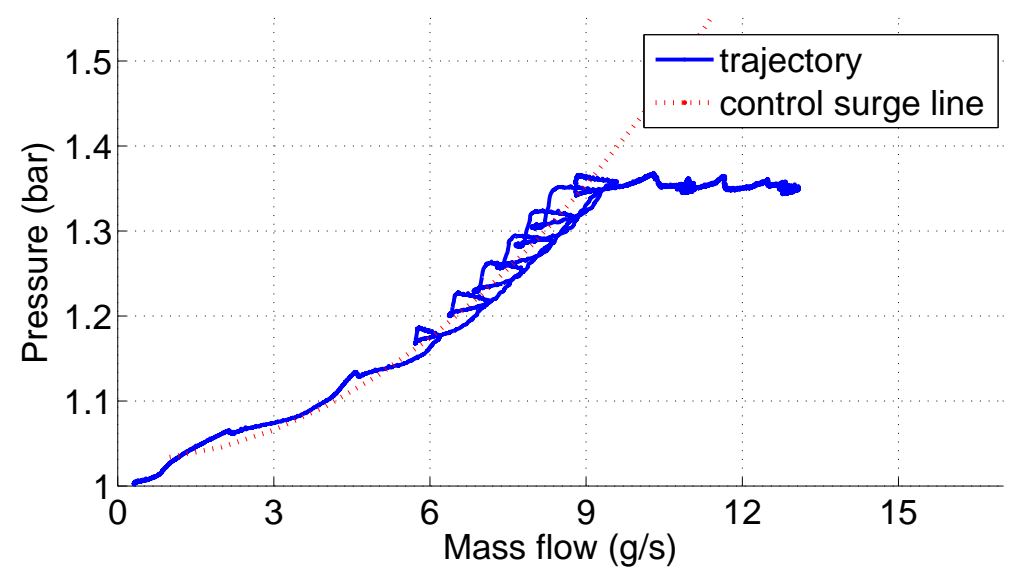

(a) Compressor operating trajectory

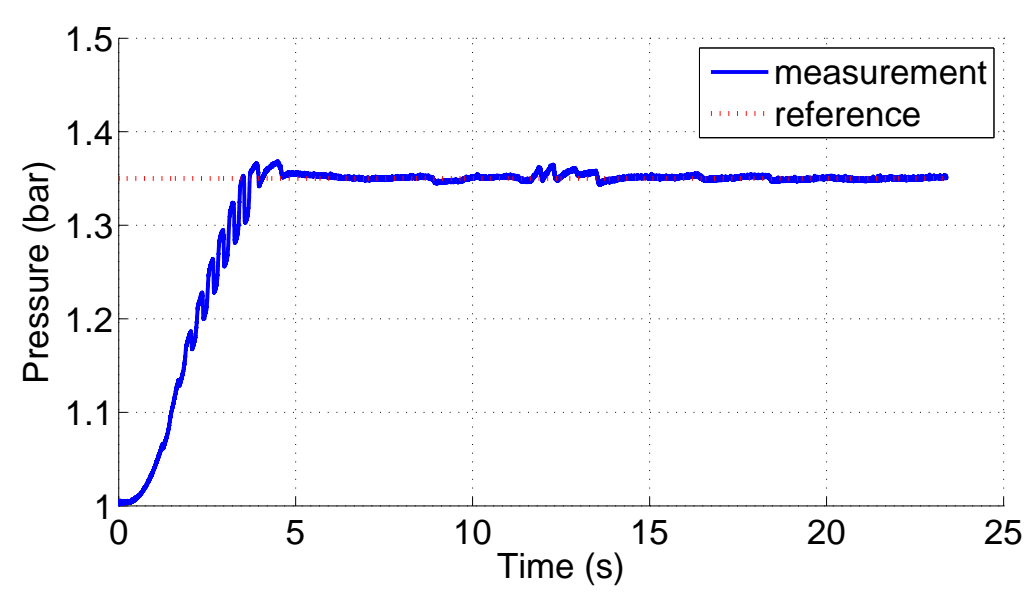

(b) pressure response

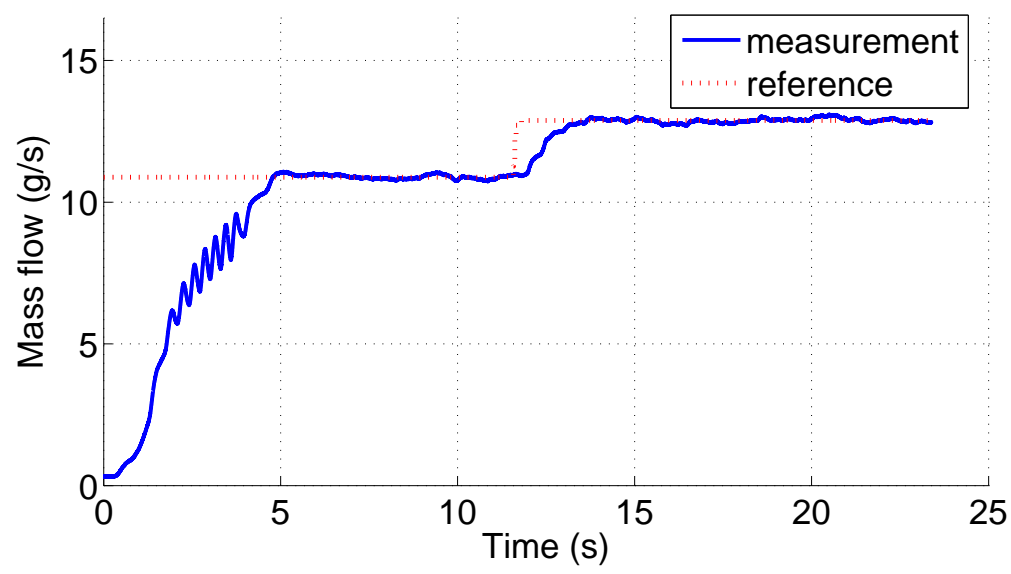

(c) mass flow response

Fig. 71. Oscillations caused by the reference limiter in terms of equation (4.1) and (4.2). 


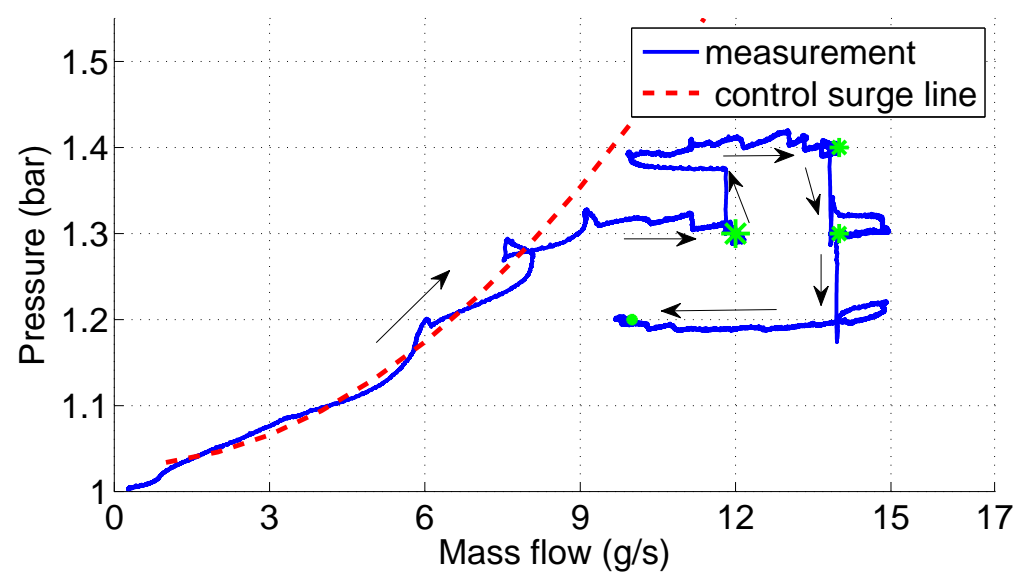

(a) Operating trajetory $(*$ represents the set-points)

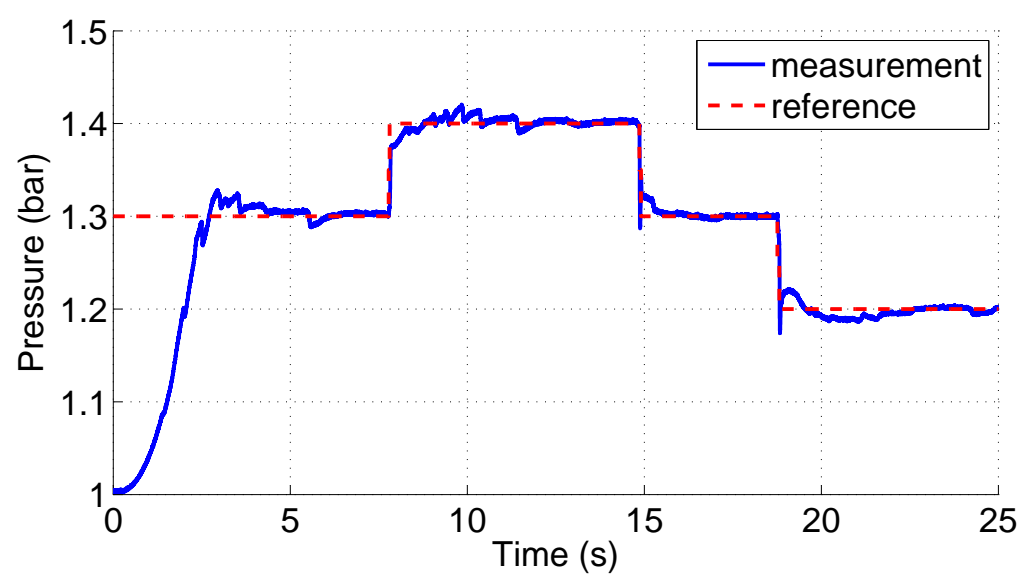

(b)

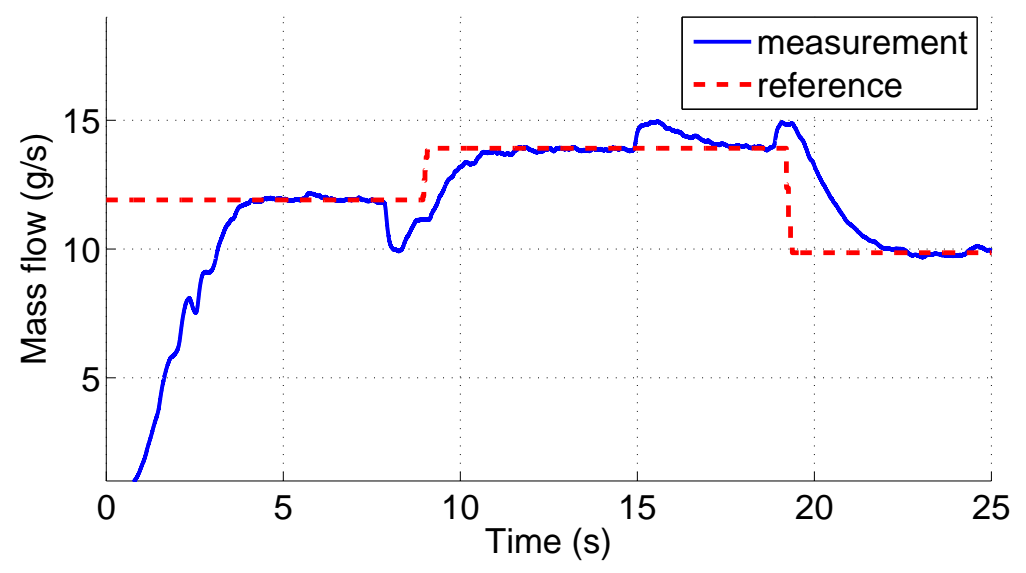

(c)

Fig. 72. Surge prevention as the results of the improved reference limiter. 


\subsection{Disturbance decoupling control vs Sliding mode control}

Two controllers were developed in the last chapter, i.e.,DDC and sliding mode controller. Sliding mode controller used two independent control loops, based on twisting and super twisting, to regulate the mass flow and pressure respectively. This two control loops influence each other. For the highly coupling centrifugal compression system, a decoupling controller which can weaken or eliminate the interaction among multiloops is more suitable. DDC based on ADRC is a decoupling controller which takes the interaction as the internal disturbance. The disturbance is estimated by a ESO and then removed in the control algorithm.

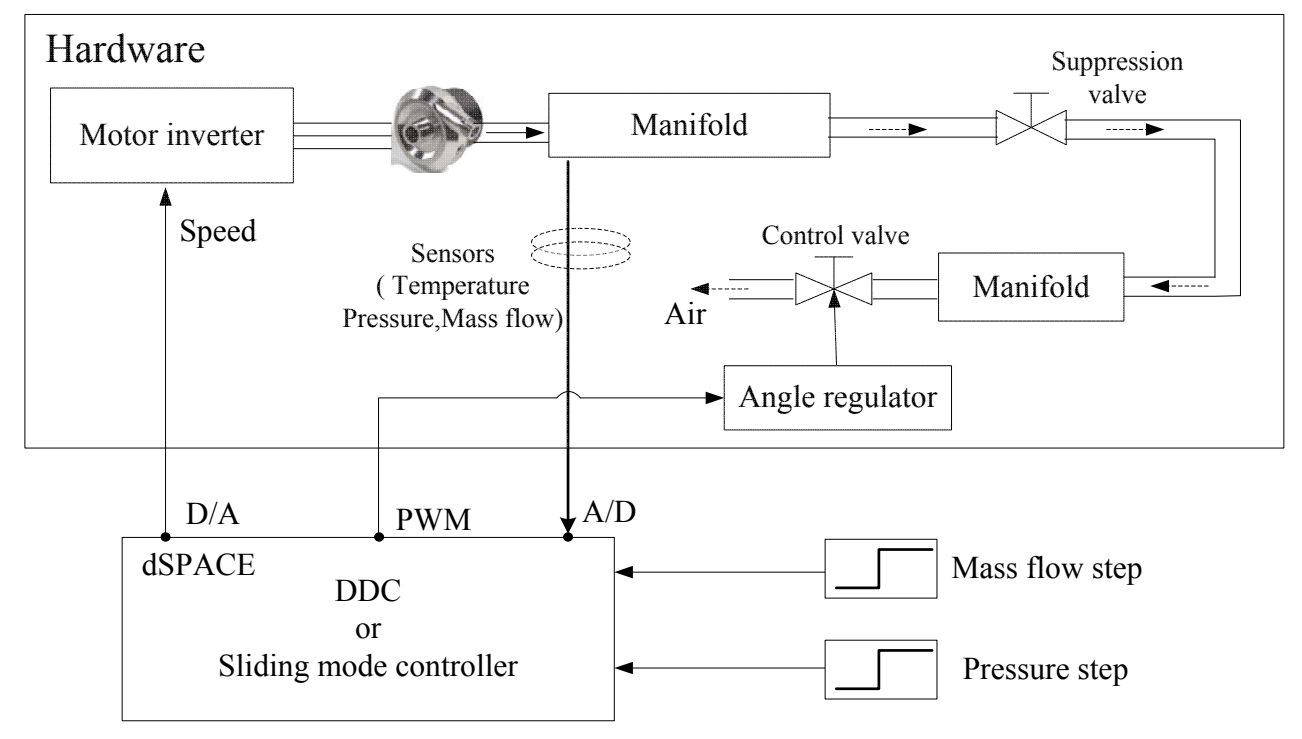

Fig. 73. Comparison by hard-ware-in-the-loop test.

The interaction between the two control loops can be evaluated by the responses of the step command change. The diagram of the HIL is shown in Figure 73. Both the dynamic and steady-state are compared between the two controllers.

In Figure 74(a), a mass flow step command (from 12 to $14 \mathrm{~g} / \mathrm{s}$ ) was imposed at $2 \mathrm{~s}$ on the two controllers. Figure 74(b) shows the pressure dynamics in this operation. The pressure is much smaller influenced through the control of DDC, compared with sliding mode controller. Moreover, both the mass flow and pressure are more smoother for DDC in steady-state as shown in Figure 75. Figure 76(a) shows the compressor speed dynamics with the variation between $220 \mathrm{krpm}$ and $250 \mathrm{krpm}$ in this process. 
Figure 76(b) gives the regulating process of the valve position.

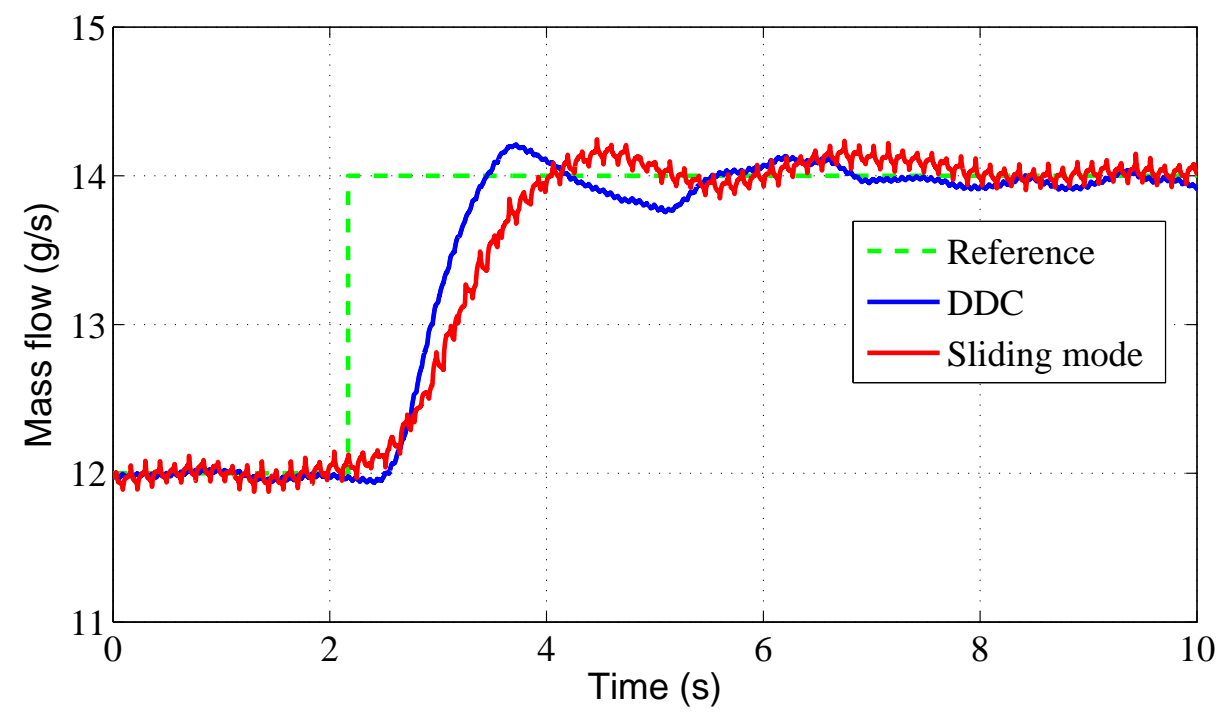

(a)

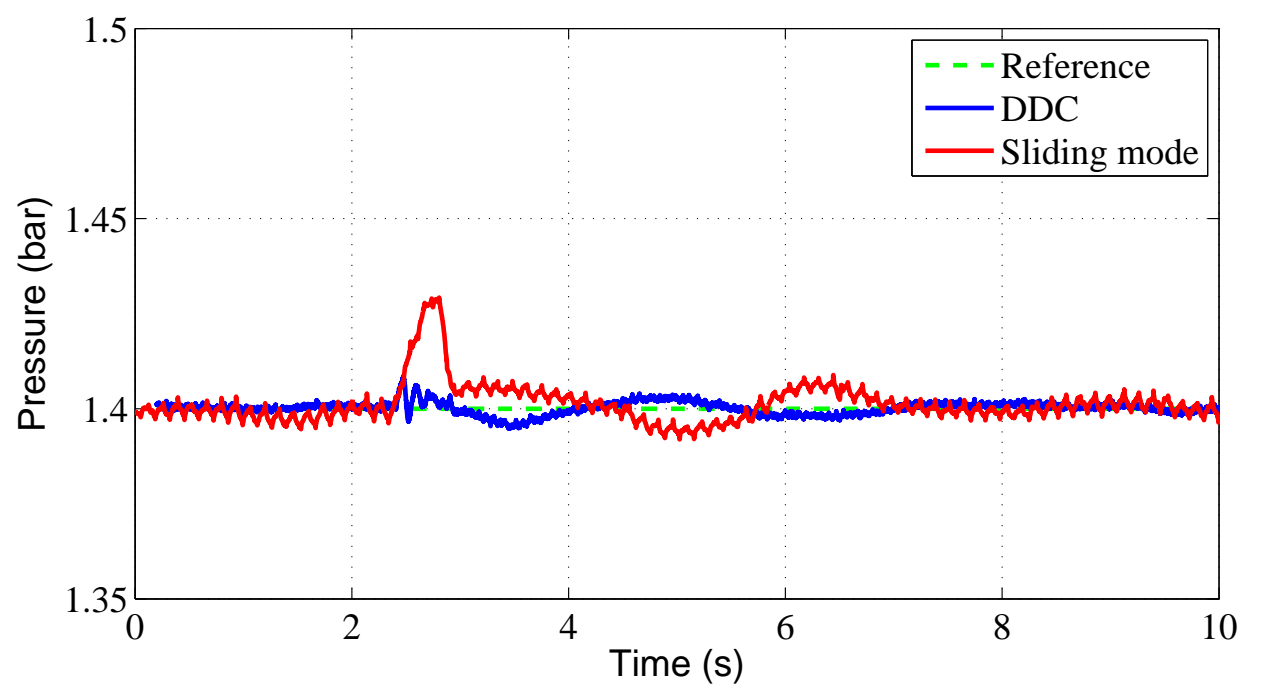

(b)

Fig. 74. The responses of the mass flow and pressure under a mass flow step command. 

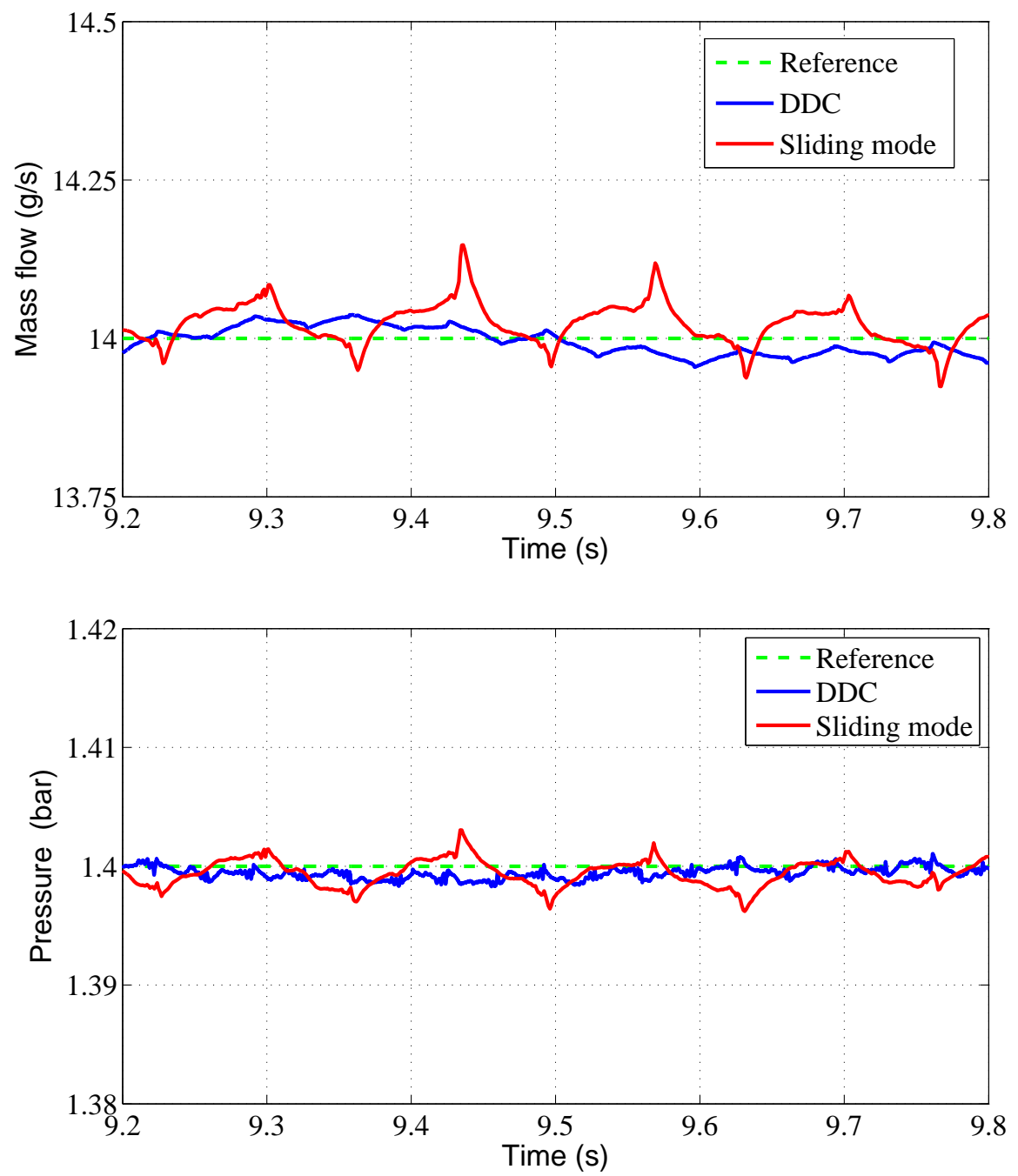

(b)

Fig. 75. Measurement at steady state (zoom-in of Figure 74). 


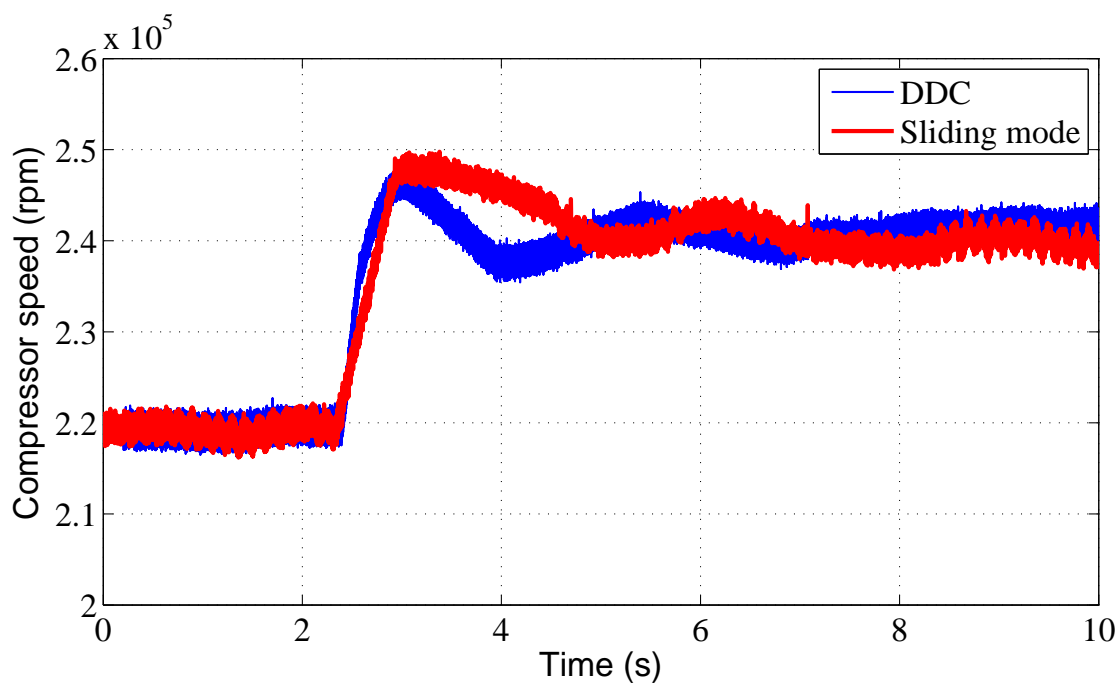

(a)

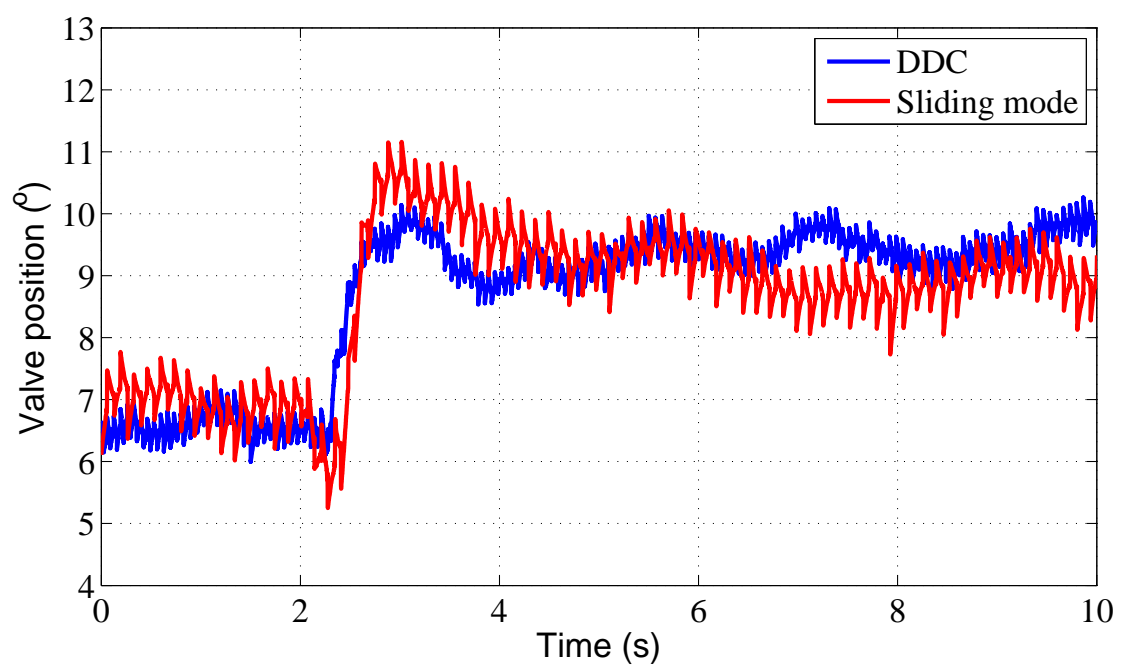

(b)

Fig. 76. The actuator responses under a mass flow step-up.

In the same way, a step change (from 1.4 to 1.45 bar) of pressure command is tested. And Figure 77 and Figure 79 show dynamics of the system during this process. Figure 77(a) shows that DDC has a faster pressure response. At the time of the pressure step-up, the mass flow was decreased from 14 to $13.5 \mathrm{~g} / \mathrm{s}$ (Figure 77(b)). For the mass flow deviation, compared with sliding mode controller, DDC has a faster recover time. Figure 78 exhibits performances in the steady state. The corresponding variations of the compressor speed and valve position are shown in Figure 79(a) and Figure 79(b) 
respectively.

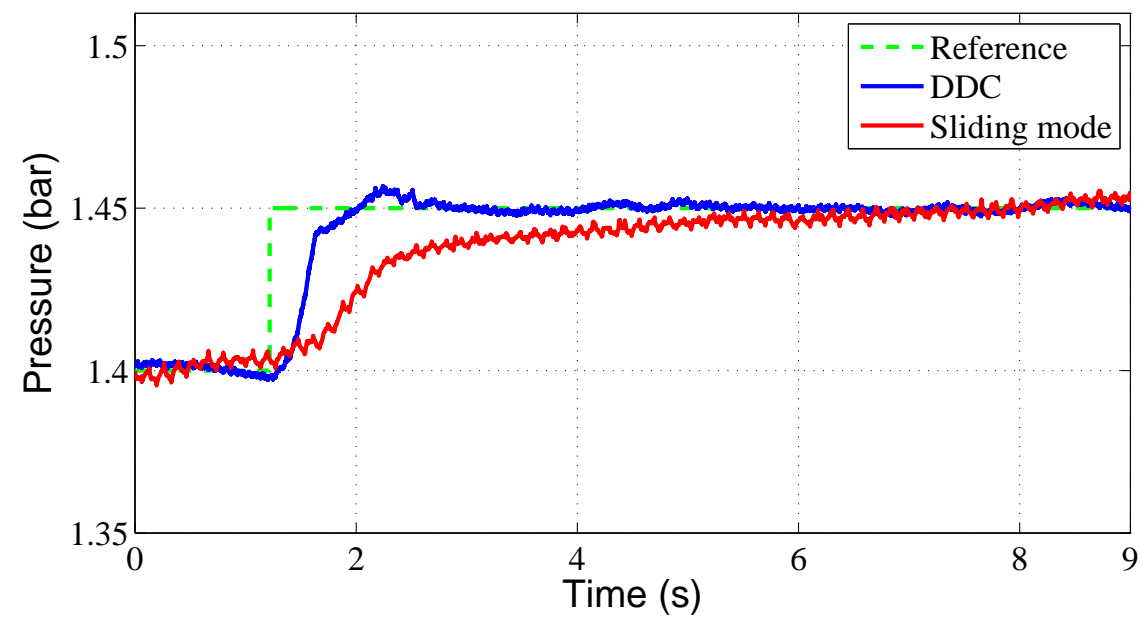

(a)

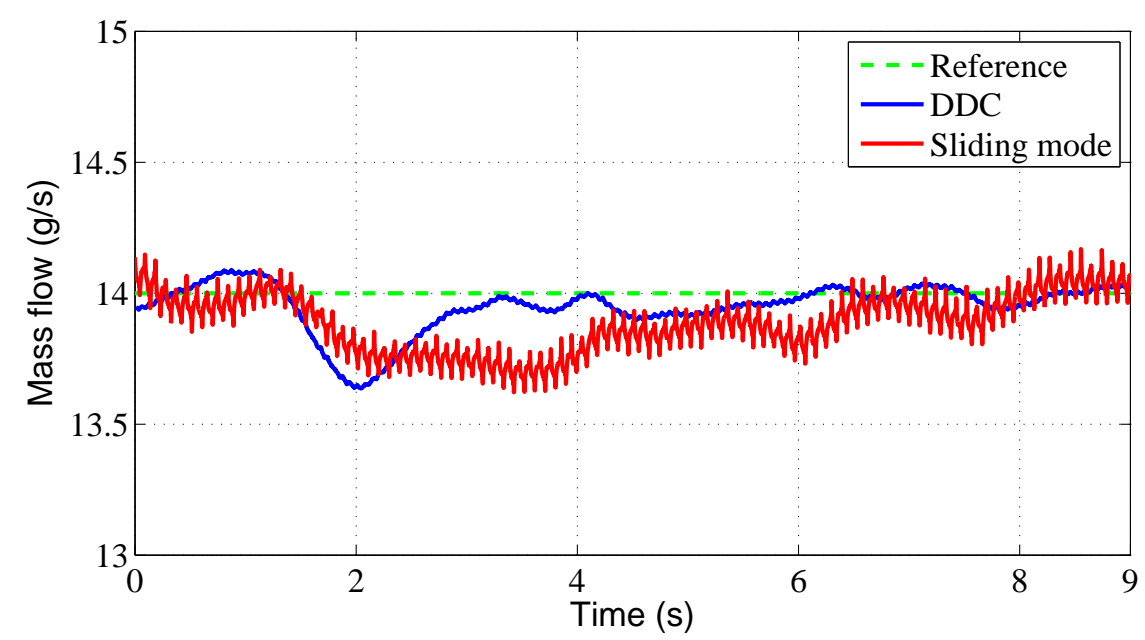

(b)

Fig. 77. The responses of the mass flow and pressure under a pressure step command.

The experiments results show that the DDC has a better performance both in the dynamic and the steady states because the coupling between the mass flow and pressure control has been much weakened. The abrupt pressure change which varies the mass flow has to be reduced to minimum for fuel cell applications. The inlet air pressure of the fuel cell is normally kept at constant which is determined by practical applications. 


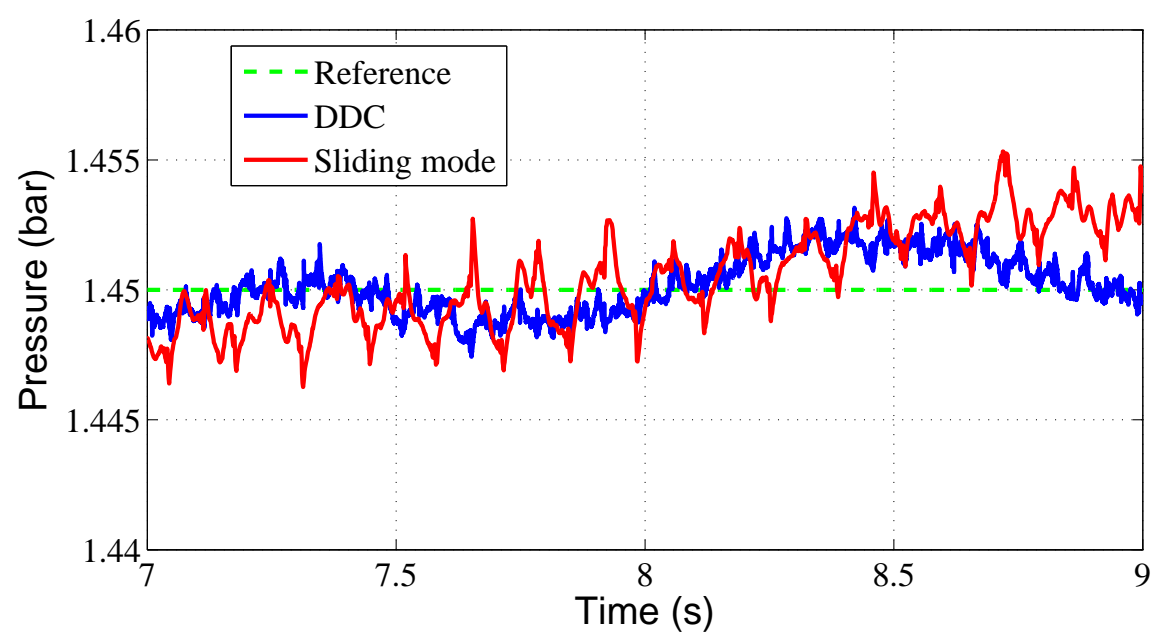

(a)

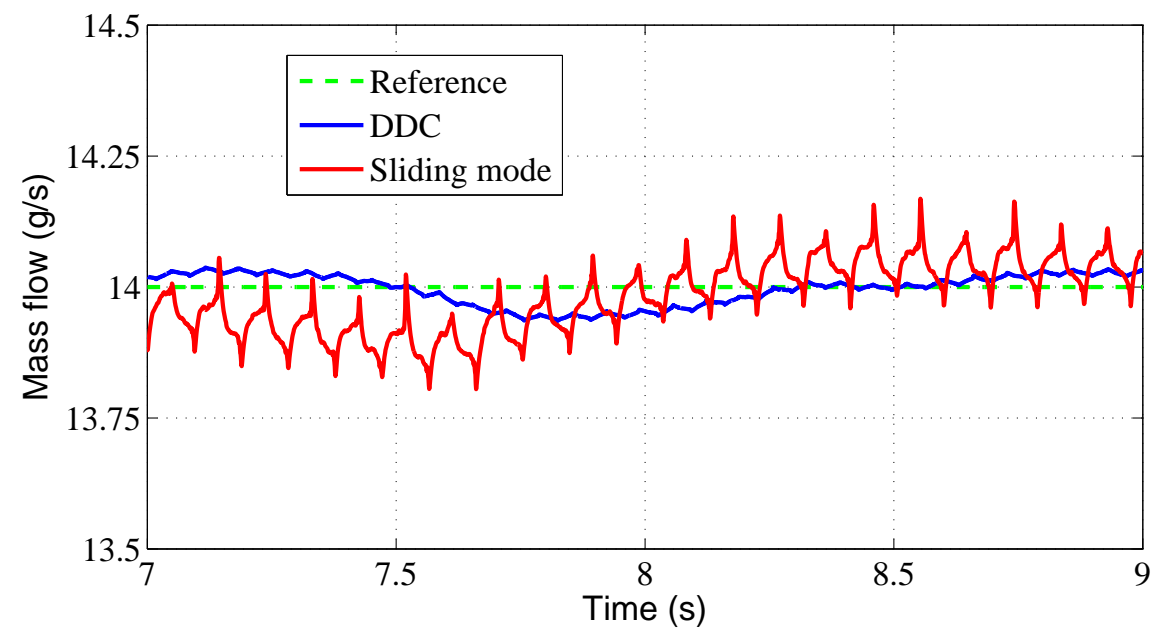

(b)

Fig. 78. Zoom in of Figure 77. 


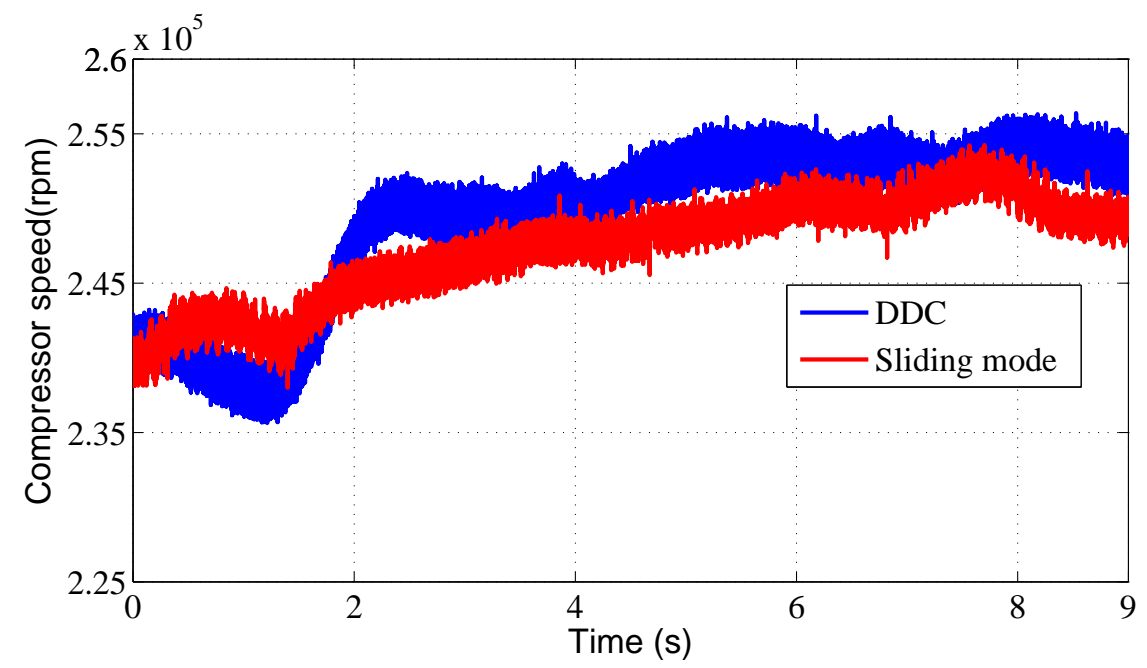

(a)

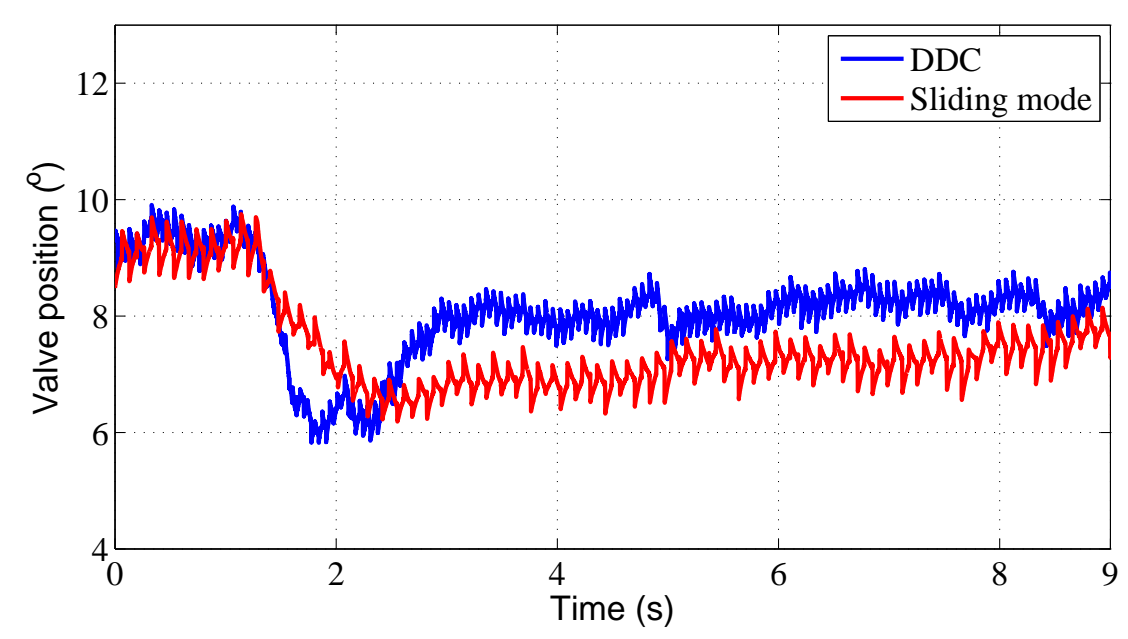

(b)

Fig. 79. The actuator responses. 


\subsection{Applied to a $10 \mathrm{~kW}$ fuel cell model}

In this section, the proposed DDC approach is tested with a $10 \mathrm{~kW}$ fuel cell model in the HIL application. The fuel cell stack model is based on a single-cell static characteristic $[25,69]$. The output voltage $V_{\text {stack }}$ is calculated as following.

$$
V_{\text {stack }}=\left(E_{o c}-V_{\text {ohmic }}-V_{\text {act }}-V_{\text {trans }}\right) \times N_{\text {cell }}
$$

where $N_{\text {cell }}$ is the number of cells, and $E_{o c}$ is the open circuit voltage which relates to the partial pressures of hydrogen and oxygen inside the stack. The ohmic losses $V_{\text {ohmic }}$, activation losses $V_{\text {act }}$ and transport losses $V_{\text {trans }}$ have a strong link to the current density $[91,92]$. In this model, we assume that cooling system, fuel supply system are appropriately controlled. Therefore, the fuel cell stack temperature, hydrogen pressure can be kept at constant. And the fuel cell stack is ideally conditioned by a humidifier to certain humidity [33]. The operating conditions of the fuel cell system are shown in Table 7.

Table 6. Operating conditions of the PEM fuel cell stack.

\begin{tabular}{ll}
\hline Fuel cell number & 90 \\
Cell active surface & $200 \mathrm{~cm}^{2}$ \\
Fuel cell stack temperature & $350 \mathrm{~K}$ \\
Membrane water content & 14 \\
Hydrogen pressure & $1.4 \mathrm{bar}$ \\
\hline
\end{tabular}

The model is modeled by dSPACE assuming that the stack temperature is at $350 \mathrm{~K}$ and the hydrogen pressure is supplied at 1.4 bar. The block diagram of the fuel cell stack model is shown in Figure 80.

In practical applications, current is instantaneously drawn from the fuel cell stack. In our study, a dynamic current profile varying between $100 \mathrm{~A}$ and $145 \mathrm{~A}$ as shown in Figure 81 is imposed on the fuel cell.

Based on the stack current, to avoid the oxygen starvation the air compressor needs to provide sufficiency air to the cathode. The supplied air pressure and oxygen excess ratio are important performance variables. 


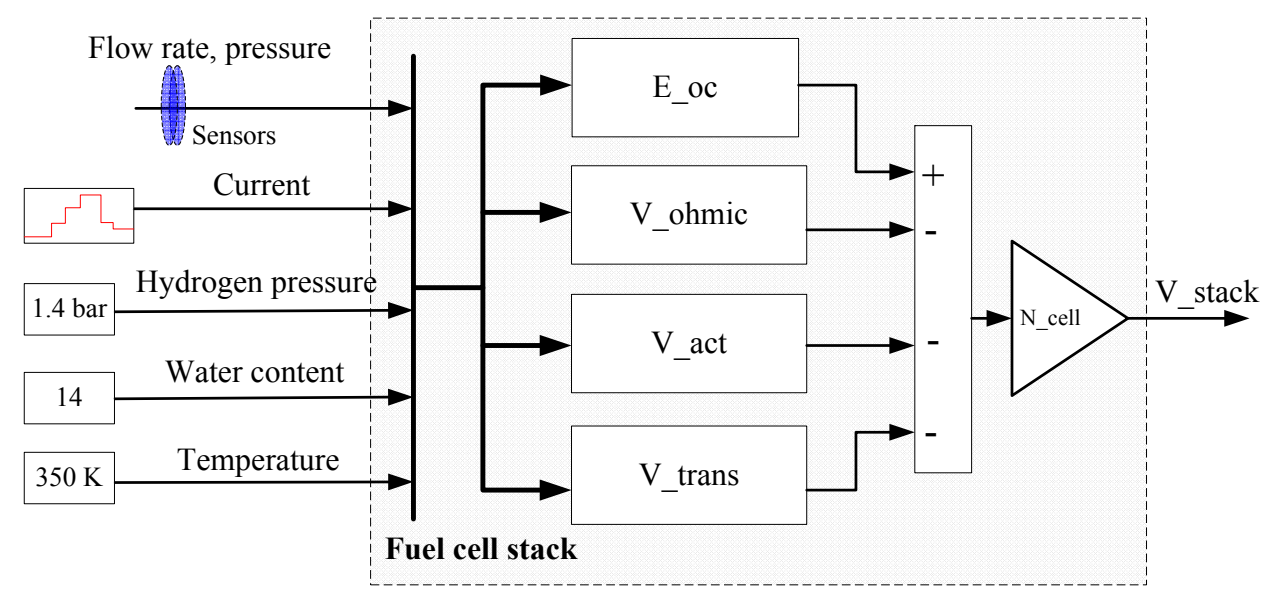

Fig. 80. Block diagram of the fuel cell stack model.

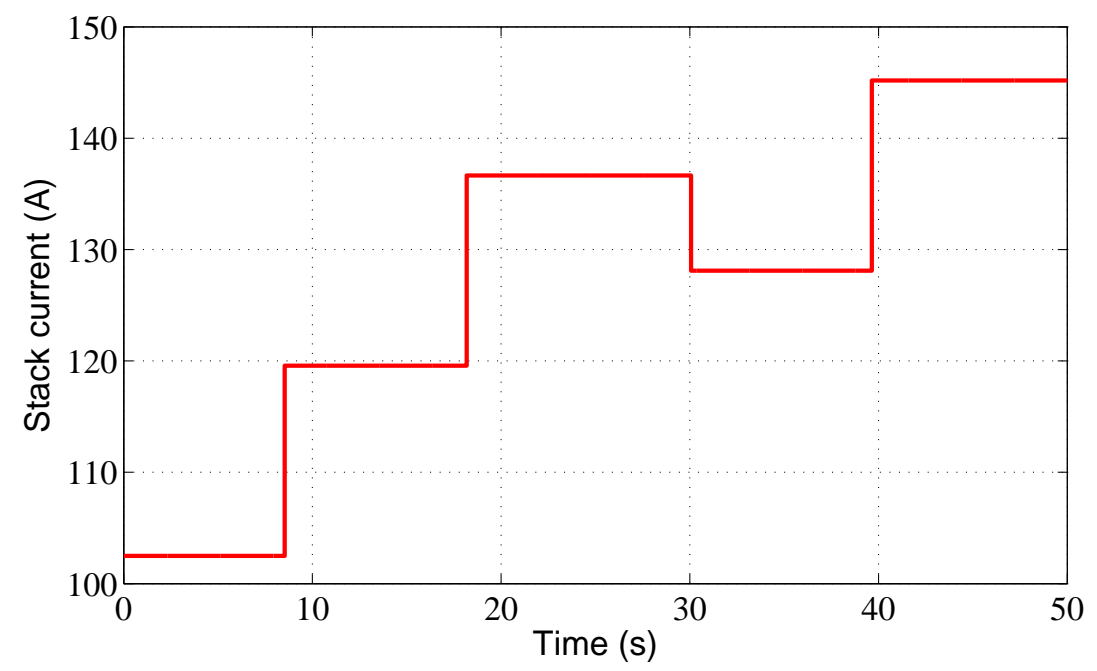

Fig. 81. Current drawn from the fuel cell stack. 


\subsubsection{Oxygen excess ratio}

Oxygen excess ratio $\lambda_{O_{2}}$ is defined as the ratio between the oxygen $q_{o_{2} \text {, in }}$ entering the cathode and the oxygen $q_{o_{2}}$,reacted consumed due to the electrochemical reaction [36, 39]:

$$
\lambda_{o_{2}}=\frac{q_{o_{2}, \text { in }}}{q_{o_{2}, \text { reacted }}}
$$

$\lambda_{o_{2}}$ is considered as a performance variable of the system and its control is an important factor since it ensures the safety of the fuel cell [36]. Oxygen starvation is a significant problem that could lead to irreversible damages to the polymeric membranes if $\lambda_{o_{2}}<1$ persists for a long time $[32,41]$. It degrades the fuel cell performance and shortens the life time of the stack. A large value of $\lambda_{o_{2}}$ results in excessive parasitic power consumption, and therefore, a lower efficiency. The optimal value of $\lambda_{o_{2}}$ depends heavily on the fuel cell operating conditions (current, temperature, water content, etc.) [93] [94]. However, this paper does not focus on the determination of this value. In this paper, $\lambda_{o_{2}}=2$, which contains some security margin and also provides a good performance [95], [51], [32], is adopted for the validation of the developed controller.

$\lambda_{O_{2}}$ is regulated by controlling the air flow going into the cathode. The required air flow can be calculated according to the current drawn from the fuel cell. Figure 82 shows the supplied air flow which varies from about 10 to $15 \mathrm{~g} / \mathrm{s}$. With the air flow varying the dynamics of $\lambda_{o_{2}}$ is given in Figure 83. It shows that in steady state $\lambda_{o_{2}}=2$ is guarantee no matter what the mass flow is. Moreover, $\lambda_{o_{2}}$ has very small ripples in steady state. During the transient, the decline of the $\lambda_{o_{2}}$ always happens as the current abruptly increases. With the first step-up of the current at $9 \mathrm{~s}, \lambda_{o_{2}}$ decreases to 1.7. Under the control of mass flow, the recover time of $\lambda_{o_{2}}$ is as fast as $1 \mathrm{~s}$, from 8.5 to $9.5 \mathrm{~s}$. The quick recovery time of $\lambda_{o_{2}}$ depends on the fast response of the mass flow, therefore, avoid the oxygen starvation caused by the abrupt current increase drawn from the stack.

Figure 84 gives the compressor rotational speed during the operation, varying from 220 to $250 \mathrm{krpm}$. At a fixed pressure, the higher speed implies a higher air flow rate. Meanwhile, the valve position is regulated accordingly, shown in Figure 85, to stabilize the pressure at 1.4 bar. 


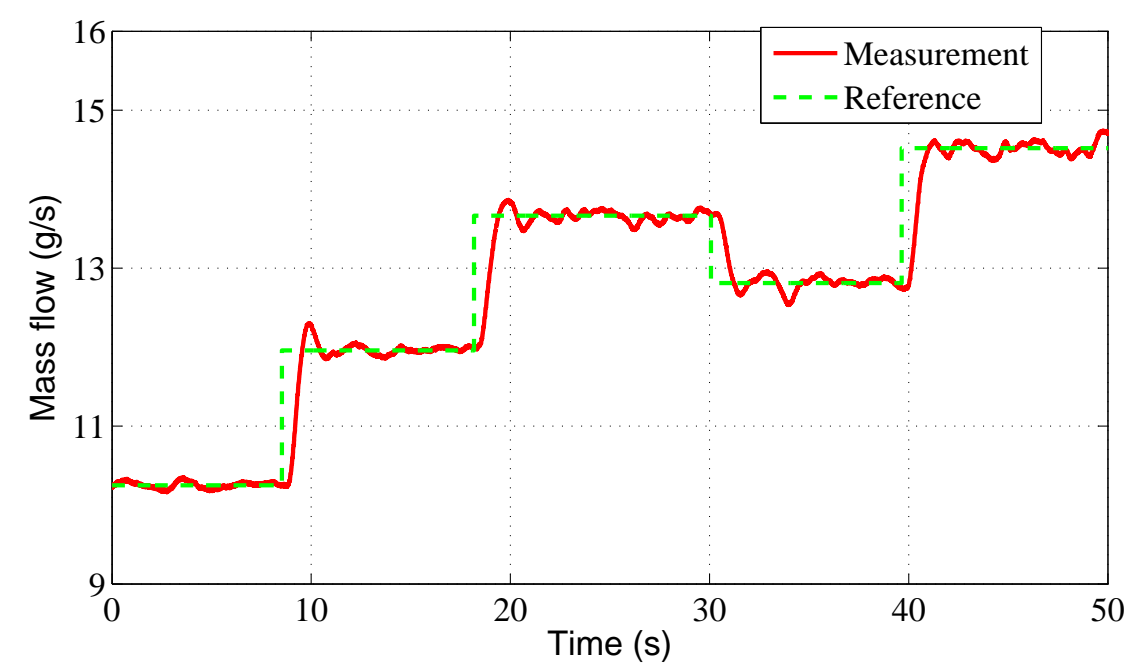

Fig. 82. Calculated mass flow reference and the measurement in real time.

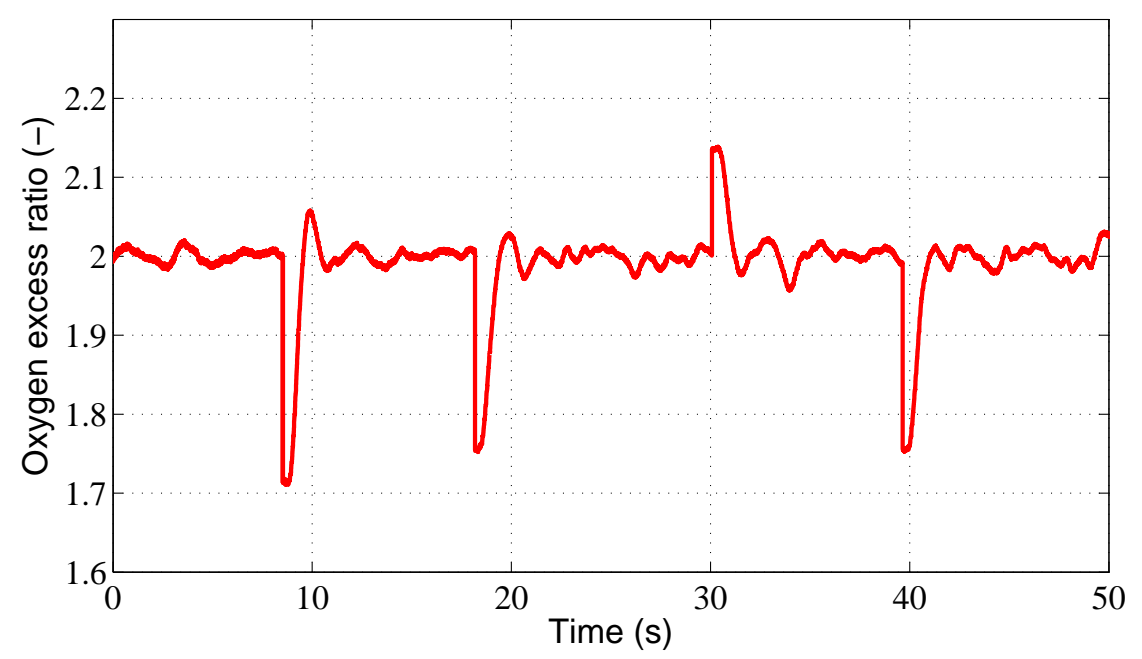

Fig. 83. Oxygen excess ratio. 


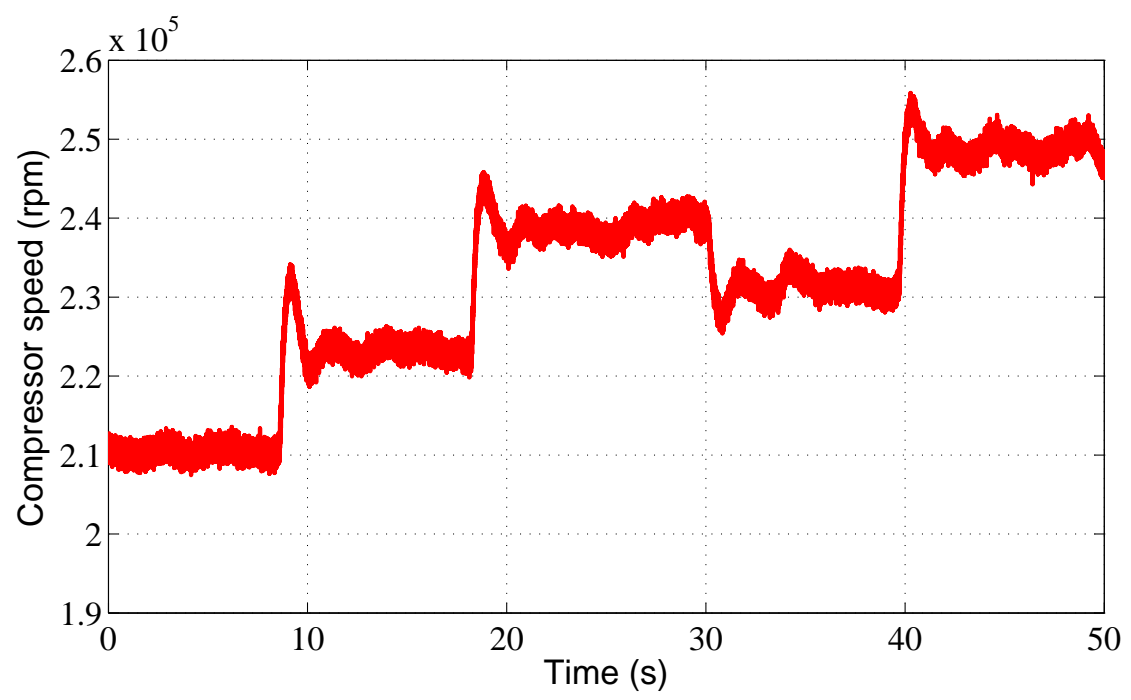

Fig. 84. Compressor speed dynamics during the operation.

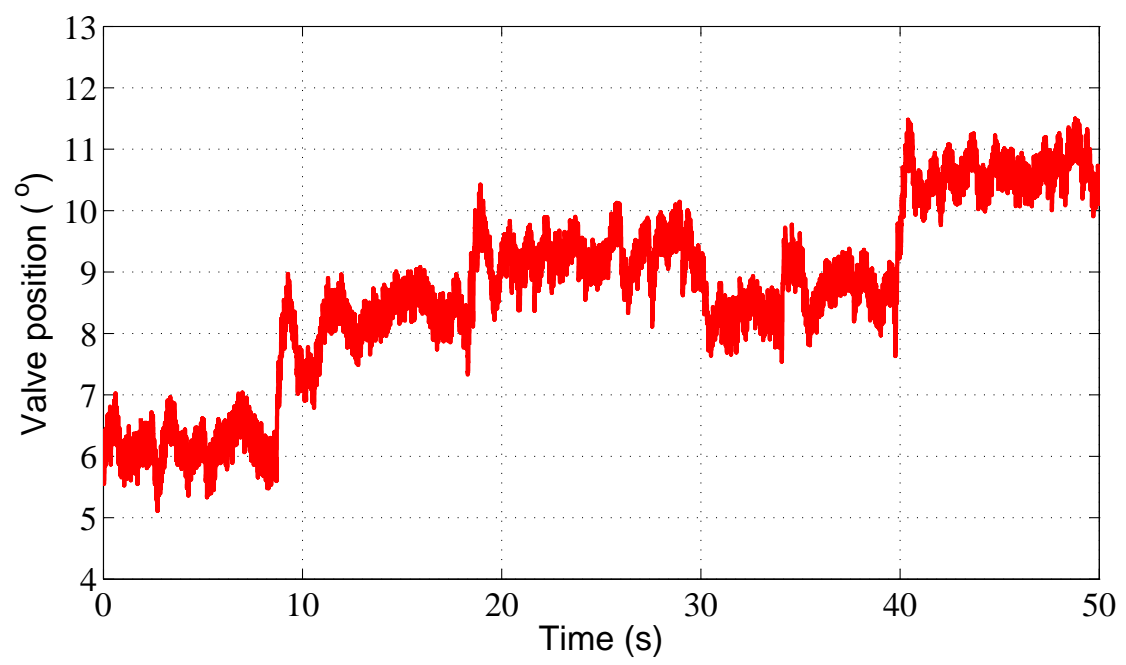

Fig. 85. Valve position dynamics during the operation. 


\subsubsection{Pressure}

In the fuel cell, higher pressure can lead to higher stack output voltage. Moreover, stacks designed for high working pressures are smaller and consequently less expensive. However, higher pressure also implies higher power consumption on the compressor. The nominal compression ratio, on which maximum efficiency is produced, is determined depending on the fuel cell stack and practical cases. It should be noticed that a greater pressure ripple would damage (perforate) the membrane. In automotive applications, no pressure ripple greater than 100-200 mbars is allowed [16].

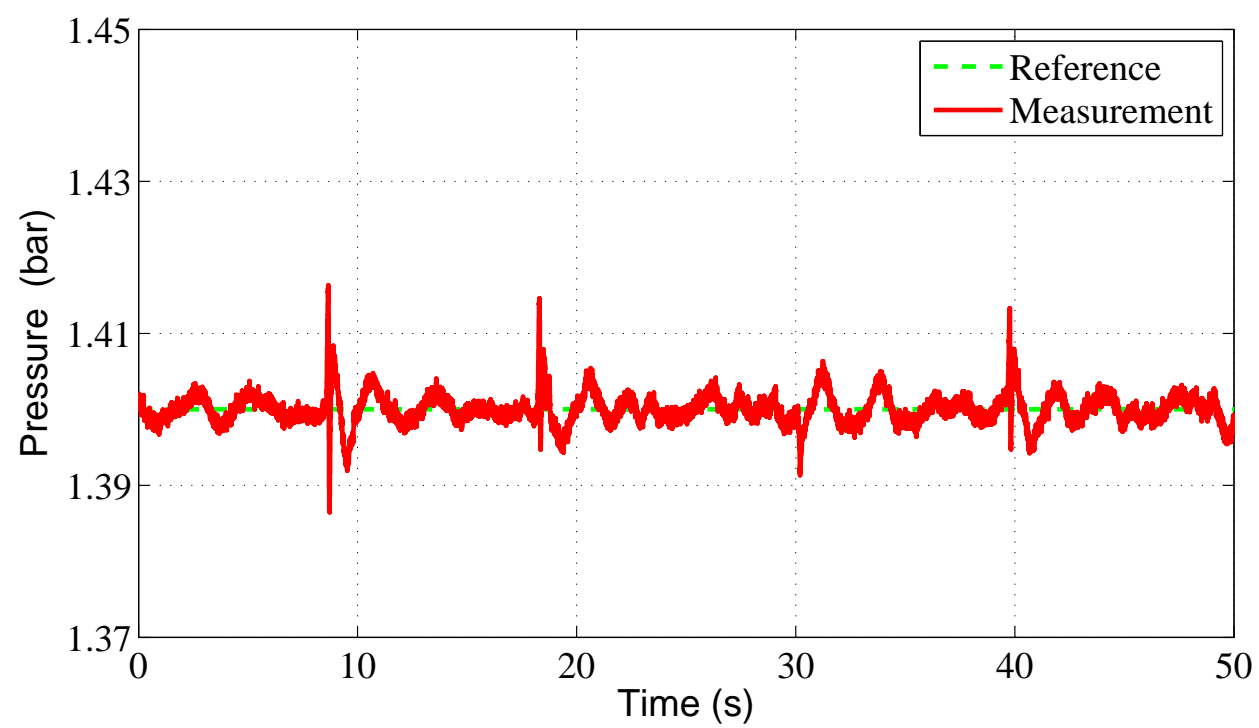

Fig. 86. Supplied air pressure.

Under the imposed current, dynamics of the air pressure is shown in Figure 86. The pressure is maintained at 1.4 bar with small pressure ripples at steady state. The pressure ripples are less than 20 mbars in steady state. Whereas, no deviations greater than 40 mbar happened during the dynamic responses. Meanwhile, it also has a quick recover time for those deviations resulting from the mass flow variations.

The abrupt changes of mass flow give rise to the pressure deviations, which directly influence the stack voltage. Pressure ripples and deviations result in the voltage variations, shown in Figure 87. The voltage varies from 67 to $57 \mathrm{~V}$ as the current changes from 102 to $145 \mathrm{~A}$. 
Figure 88 exhibits the dynamic behavior of the generated net power, which is from 6.8 to $8.4 \mathrm{~kW}$ varying with the load demand.

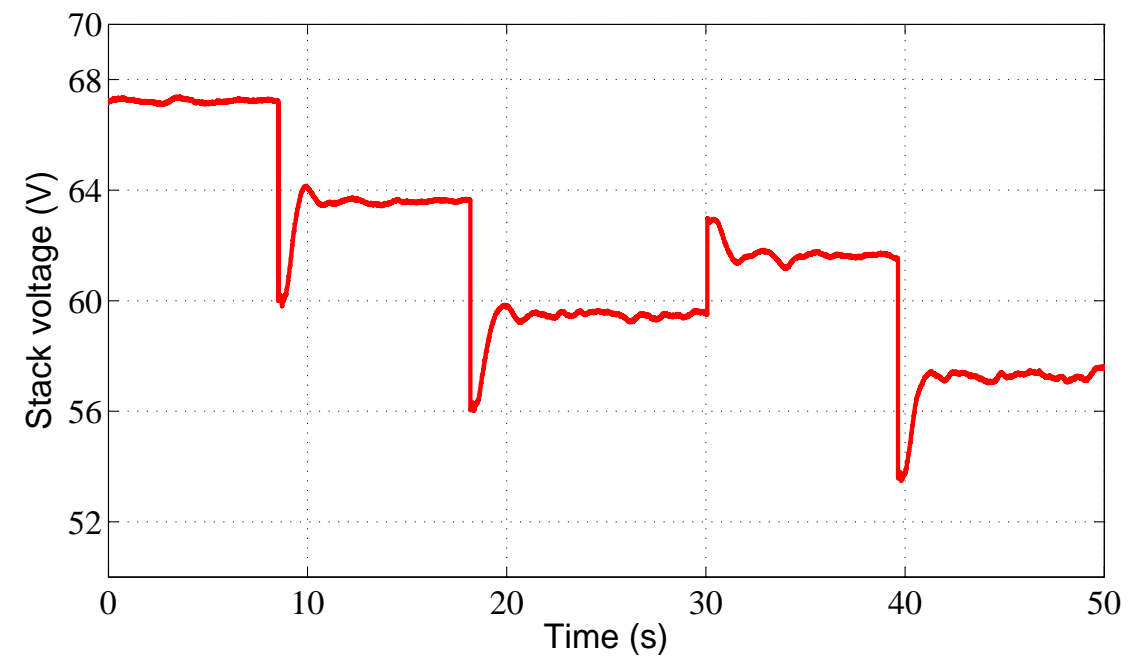

Fig. 87. Realtime simulated fuel cell stack output voltage.

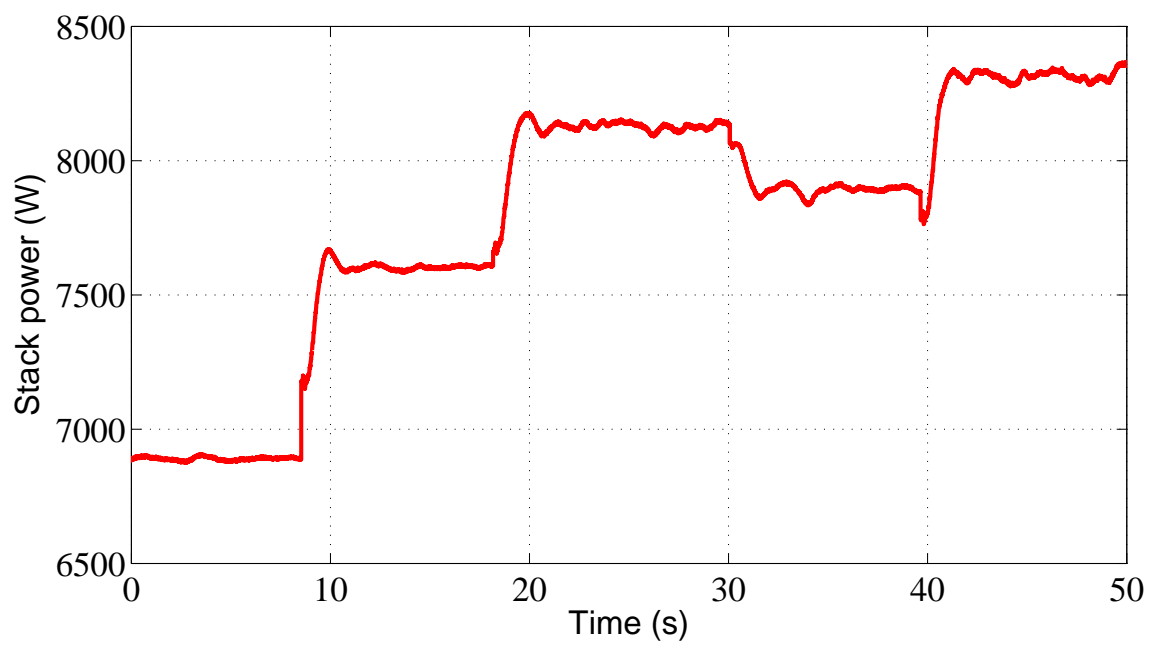

Fig. 88. Realtime simulated fuel cell stack output power. 


\subsection{Conclusions}

In this chapter, a hardware-in-the-loop (HIL) testbench is built for the validation of the proposed controller. The proposed control approach is implemented on a dSPACE1104. In the avoid compressor surge in the operation, a reference limiter is developed to constraint the compressor to work in the right region of the surge line. The performance of the developed reference limiter is validated experimentally. Then the proposed DDC controller is compared with the sliding mode controller. The interactions between the two control loops of the system are analyzed. The experimental results show that the DDC which can weaken the system coupling performs better in both the steady state and the transient dynamics. At last, the DDC is validated on a $10 \mathrm{~kW}$ fuel cell model. The results show that the oxygen excess ratio is maintained at the value of 2 to avoid the fuel cell oxygen starvation. Meanwhile the pressure is kept at 1.4 bar with very small ripples to protect the fuel cell membrane. Successfully implementing the proposed DDC for the centrifugal compressor system has a practical significance. It means that, the centrifugal compressor can be well adapted to the fuel cell system for automotive applications. 


\section{CONCLUSIONS AND FUTURE WORK}

\subsection{Conclusions}

\subsubsection{Compressor selection}

The compressor is a crucial component in the fuel cell system. It is used to provide constant compressed-air flow to the fuel cell cathode. Compressor types can be divided generally into positive displacement compressors and dynamic compressors based on their working principles. Currently several kinds of compressor have been studied for the fuel cell applications. In this dissertation, the comparison of those compressors has been summarized based on literature. Moreover, the requirements for fuel cell applications have been given. The choice of the compressor is directly related to practical applications. Automotive fuel cell vehicles need a compact, oil free and high efficiency air compressor for the air management. In this point of view, centrifugal compressor is a superior choice compared with positive displacement compressors. Additionally, the centrifugal compressor can supply continuously the air flow. Whereas the working principle of positive displacement compressors is a discrete process, which is also a disadvantage for fuel cell applications. Limited air flow range resulting from the surge constraint is the main drawbacks of centrifugal compressor. However the compressor surge only occurs at the very low mass flow rate which rarely happens in the hybrid fuel cell vehicles. Combined with the energy storage, the fuel cell usually operates around an optimized point to keep a high efficiency. Therefore, the drawbacks of the centrifugal compressor can be minimized. Based on the requirements of the automotive fuel cell applications, an ultra-high speed, resulting in the ultra-compactness, centrifugal compressor is adopted. It fits the automotive fuel cell demands of oil free, high efficiency and low noise. Based on the fuel cell applications, this compressor is designed for a rated mass flow of $12 \mathrm{~s}$ and a rated pressure of $1.4 \mathrm{bar}$. 


\subsubsection{Proposed control approaches}

A crucial process of fuel cell operation if the air management, including the air flow and pressure control. However, the existing compressor control technologies do not always fit the fuel cell demands. In order to make the fuel cell work ideally, new control technologies need to be developed to manage the supplied air. Two requirements to the compressor have to be fulfilled in the fuel cell operation. On the one hand is appropriate amount of air flow has to be provided to avoid the fuel cell oxygen starvation. On the other hand the air pressure has to be controlled properly for achieving the optimal operating point of the fuel cell. Unlike positive displacement compressors, the mass flow and pressure are coupled which leads to the difficulty in the controller development. For the system analysis, a neural network model of the compressor is developed using back-propagation algorithm. Then the coupling degree is analyzed and the control pairs are determined through the relative gain array method. The compressor speed is used to control the mass flow and an additional valve is used to control the air pressure.

Based on the coupling characteristic, a dynamic decoupling controller (DDC) is proposed for the compressor control. This controller aims to cancel the interaction between the mass flow control and pressure control. Compared with model based controllers, the DDC can achieve decoupling without the explicit model of the system. The idea of DDC is taking the coupling as an internal disturbance and using extended state observer (ESO) to estimate it based on the input-output data. Once the disturbance (coupling) is estimated online, it can then be deleted in the control algorithm to cancel the coupling between different control loops. In order to demonstrate the developed DDC, a decentralized sliding mode controller is developed for comparison purpose. Two control algorithms are proposed in the sliding mode controller. One is the twisting algorithm for the pressure control. The other is the super twisting algorithm for the air flow control. The twisting algorithm is capable of bounding the differential of the valve position, which make it possible to implement the super twisting algorithm for the mass flow control. However, decentralized sliding mode control strategy does not take the coupling problem into consideration. It means the two control loops influence each other because of the interaction. However, for fuel cell applications, the pressure is normally need to be kept constant no matter how the mass flow changes. In this point of view, DDC which is capable of cancel/weaken the coupling is more suitable 
for the centrifugal compressor control.

\subsubsection{Applications}

The proposed control strategies are validated on a hardware-in-the-loop testbench. It consists of an ultra-high speed compressors, sensors, a dSPACE real time controller, power source, etc. In the practical applications, compressor surge is a very dangerous phenomenon which may damage the compressor in severe cases. It also results in a large drop in performance and efficiency. Especially in the start-up stage, the pressure increases faster than the mass flow drawing the operation trajectory cross the surge line and then inducing the compressor surge. A simple reference limiter is develop to prevent the compressor operating to the surge region. The idea of the reference limiter is to restrict the fast increase of the pressure.

The proposed controllers have been implemented and then compared by the hardwarein-the-loop simulation. It shows that the DDC can effectively decline the interaction between the mass flow control and pressure control. In the end, a $10 \mathrm{~kW}$ fuel cell model is developed for further validation of the controller. According to the load the variations, the compressor is able to supply varied mass flow while maintaining the pressure constant. The oxygen excess ratio, output voltage are observed. The oxygen excess ratio is controlled at an optimized value, $\lambda_{O_{2}}=2$, which can maintain a high efficiency of the fuel cell. Moreover, during the transient, the value of $\lambda_{O_{2}}=2$ is still larger than 1.5, which means the oxygen starvation of the fuel cell is avoided.

\subsection{Future work}

\subsubsection{Active surge control}

Surge avoidance is the idea restricting the operation of the compressor to the right of the surge line, which dominants in the industry applications because of its easy implementation. In this work, a simple reference limiter is developed to prevent the compressor from surge. A limited operating range is the disadvantage of the surge avoidance. Active surge control is conceptually different idea using feedback control to suppress surge, which can operate the compressor to the left of the surge line, enlarging 
the working range as shown in Figure 89. Then, it can improve the fuel cell efficiency when working at small load situations.

Active surge control was first proposed by Epstein et al [96], and since then a number of results have been published. Different actuators have been employed, and examples include recycle, bleed and throttle valves, gas injection, variable guide vanes and a number of others [67]. The inlet guide vanes (IGV) and variable area throttle were studied for the active surge suppression in $[97,98]$. They show that, using appropriate feedback approach it is possible to stabilize the compressor beyond the natural surge line. In [99], Weigl et al used a high-speed valves to control the air rate injected to the compressor.

Before developing a feedback based active surge controller the dynamic behavior of the system including in the surge region has to be known. Giving the dynamic characteristics, Greitzer model [100] is a classical result in the field of compressor surge modeling.

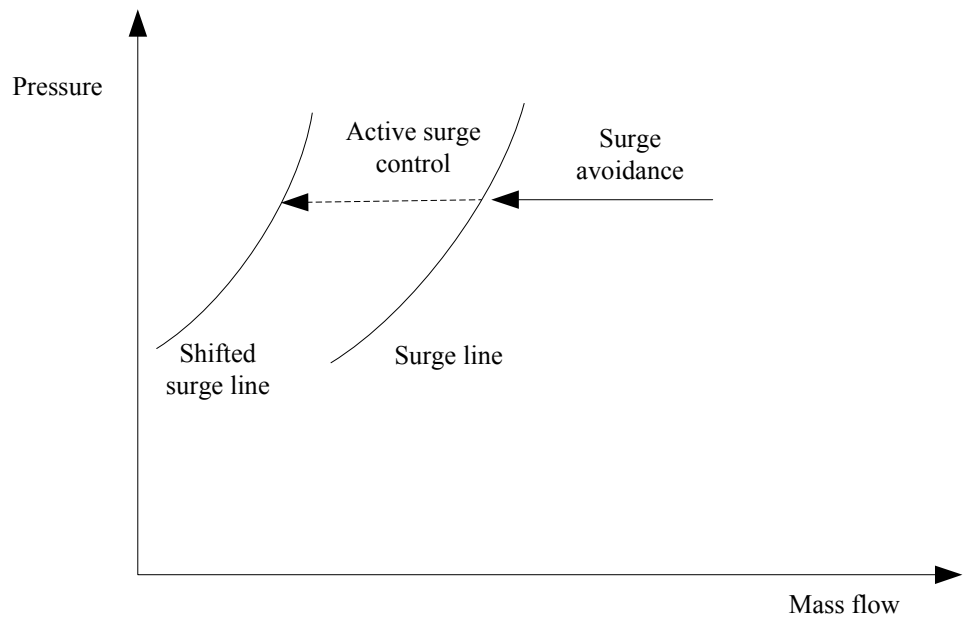

Fig. 89. Operating range of surge avoidance and active control.

\subsubsection{Applied to an actual $10 \mathrm{~kW}$ fuel cell system}

A $10 \mathrm{~kW}$ fuel cell system has been be built for the validation of the proposed air management system as well as the control approach. The hydrogen is supplied from a high-pressure tank, and the flow is controlled by a throttle. The air will be provided 
by the proposed centrifugal compressor. A humidifier is used to maintain the appropriate quantity of vapor in the air and hydrogen. The picture of the system is shown in Figure 90.

In addition to air flow control, the humidification control and partial pressure observation are also very important in the operation of an actual fuel cell system.

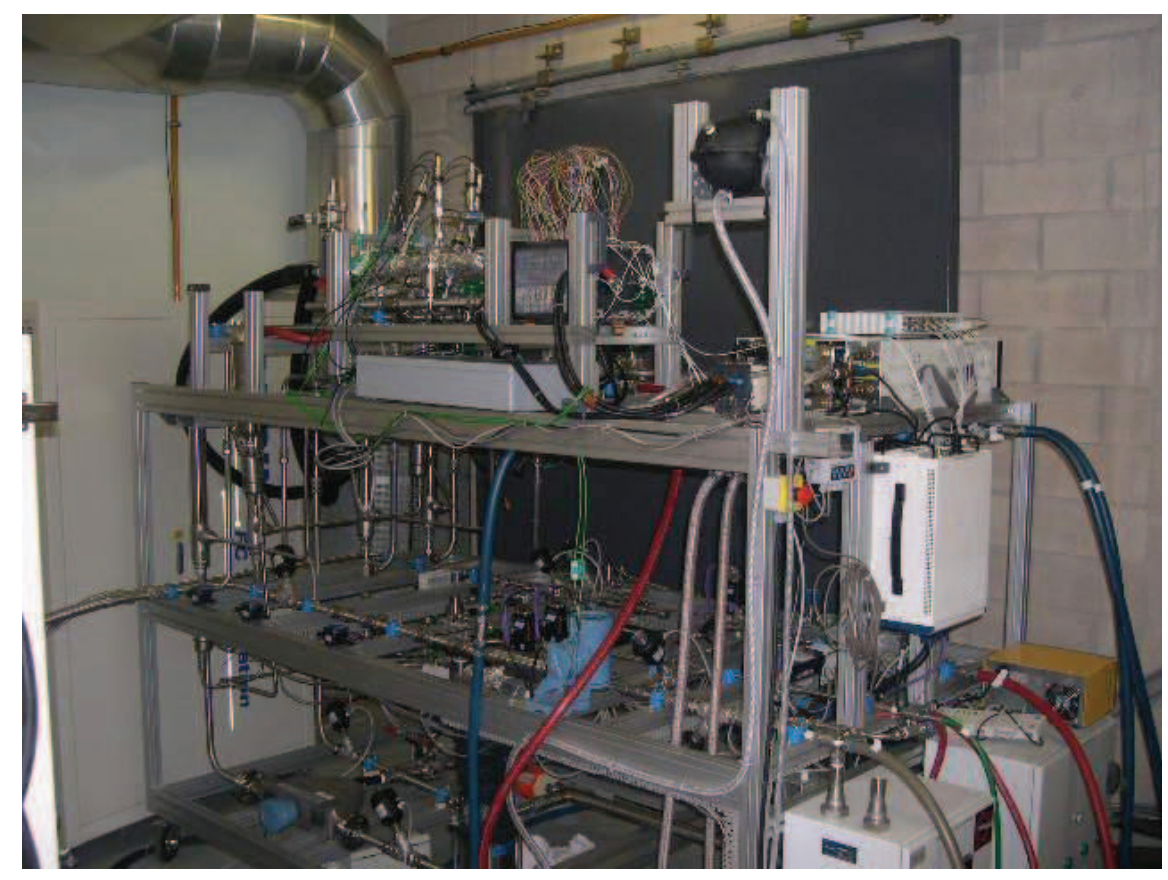

Fig. 90. A $10 \mathrm{~kW}$ fuel cell system testbench.

\subsubsection{Humidification control}

The membrane water content $\lambda$ which affects directly the membrane resistance is an important parameter of the fuel cell system. Figure 91 shows that the membrane resistance increases as the $\lambda$ decreases. $\lambda=14$ is a state that the membrane is totally humidified. Dehydration, i.e., $\lambda$ has a relative small value, declines the fuel cell performance due to increasing membrane resistance.

The humidification is usually controlled by the inlet air humidity. Less water included in the inlet air, more water is taken away from the cell. The cell can avoid dehydration by increasing the inlet air humidity. The water saturation of the inlet air is directly relates to the temperature and pressure as shown in Figure 92. 


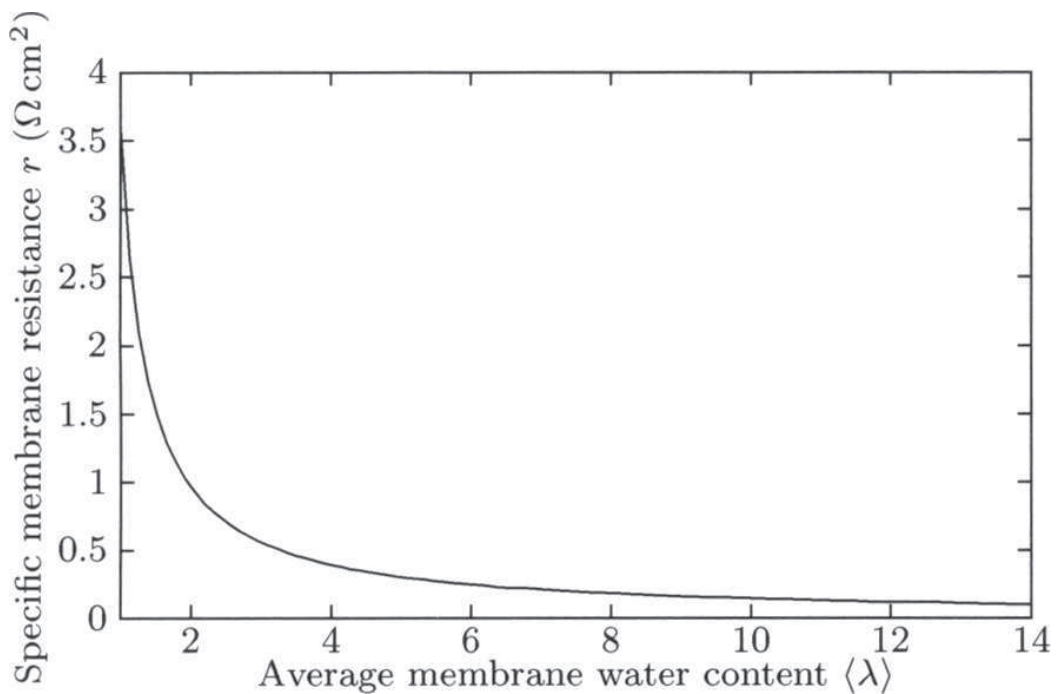

Fig. 91. Membrane specific resistance vs. average water content at $80^{\circ} \mathrm{C}$ and with the same water activity at the anode and cathode side [10].

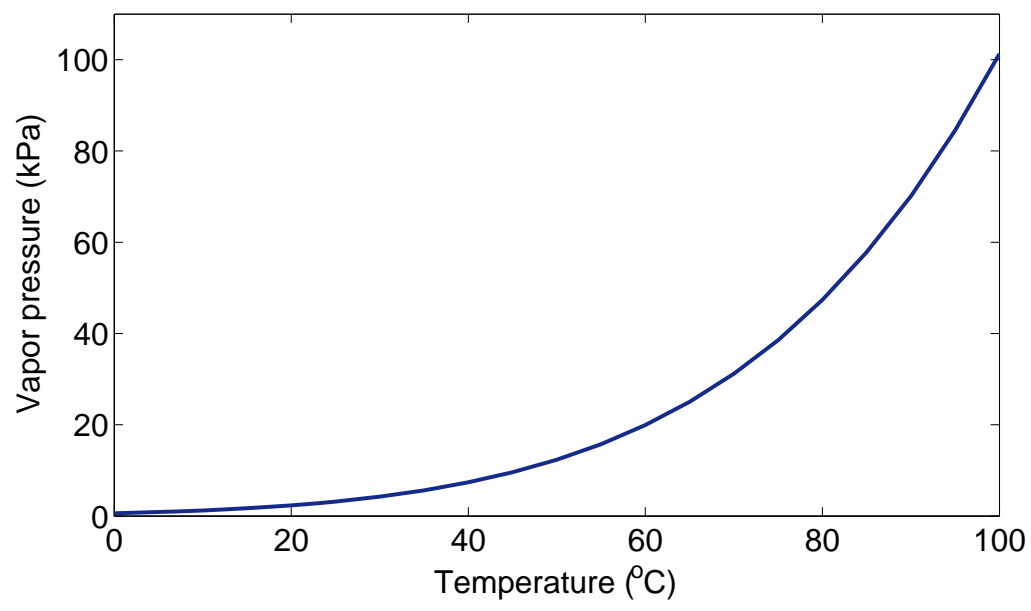

Fig. 92. Saturated vapor pressure at different temperature. 
For the humidification control, the inlet air temperature also needs to be taken into consideration. If the entrance temperature is lower than the stack temperature, the air stream in the stack is not saturated and the water removed rate from the stack is thus increased. On the contrary, if the air at the entrance has a higher temperature than the stack, the water condenses and may flood the gas diffusion electrodes.

The humidifier is usually stalled after the compressor. The vapor is injected to the fuel cell with the air flow from the compressor. The relative humidity of the air is related to the air flow rate and pressure. Hence, further investigations about the air humidity are needed when controling the compressor.

\subsubsection{Cathode partial pressure observation}

The amount of oxygen in the fuel cell is an important variable. Insufficient oxygen, called oxygen starvation, results in a decreased performance and even the paralysis of the fuel cell system. However, it is difficult to measure directly the amount of oxygen in the cathode. Therefore, we propose using an observer to estimate the an partial pressure (oxygen) of oxygen in the cathode. Then, we can directly control the oxygen partial pressure to avoid the oxygen starvation.

According to the analysis, dynamics of the pressure in the fuel cell system are summarized by state space equations. Denote $\left[x_{1}, x_{2}, x_{3}\right]=\left[p_{O_{2}}, p_{N_{2}}, p_{s m}\right]$, which are the oxygen pressure, nitrogen pressure and supply manifold pressure respectively. A three order fuel cell air dynamic model was develop by [27].

$$
\begin{aligned}
& \dot{x}_{1}=c_{1}\left(x_{3}-x_{1}-x_{2}-c_{2}\right)-\frac{c_{3} x_{1}}{c_{4} x_{1}+c_{5} x_{2}+c_{6}} f\left(x_{1}, x_{2}\right) \theta-c_{7} I_{s t} \\
& \dot{x}_{2}=c_{8}\left(x_{3}-x_{1}-x_{2}-c_{2}\right)-\frac{c_{3} x_{2}}{c_{4} x_{1}+c_{5} x_{2}+c_{6}} f\left(x_{1}, x_{2}\right) \theta \\
& \dot{x}_{3}=c_{9}\left[1+c_{10}\left[\left(\frac{x_{3}}{c_{11}}\right)^{c_{12}}-1\right]\right]\left[q_{c p}-c_{13}\left(x_{3}-x_{1}-x_{2}-c_{2}\right)\right] \\
& y_{m}=x_{3} \\
& y_{c}=x_{1}+x_{2}+c_{2}
\end{aligned}
$$

where

$$
f\left(x_{1}, x_{2}\right)=c_{14} \cdot \sqrt{\left(\frac{c_{15}}{x_{1}+x_{2}+c_{2}}\right)^{\frac{2}{\gamma}}-\left(\frac{c_{15}}{x_{1}+x_{2}+c_{2}}\right)^{\frac{\gamma+1}{\gamma}}}
$$


where $x=\left[x_{1}, x_{2}, x_{3}\right]$ is the system state, $y_{m}$ the measurable output, $y_{c}$ the output need to be controlled, $u=\theta$ the control variable . $c_{i}, i=1,2, \cdots, 15$ are constant coefficients which have been given in [27]. $\xi=\left[I_{s t}, q_{c p}\right]$ is the measurable disturbance.

A ESO is proposed for the partial pressure observation. Since our target is to observe and control $y_{c}=x_{1}+x_{2}+c_{2}$ we can deem it as another state, i.e. $x_{4}=x_{1}+x_{2}+c_{2}$.

$$
\dot{x}_{4}=\dot{x}_{1}+\dot{x}_{2}=\left(c_{1}+c_{8}\right)\left(x_{3}-x_{4}\right)-\frac{c_{3}\left(x_{4}-c_{2}\right)}{c_{4} x_{1}+c_{5} x_{2}+c_{6}} f\left(x_{1}, x_{2}\right) \theta-c_{7} I_{s t}
$$

According to the analysis the value of $c_{4} x_{1}+c_{5} x_{2}+c_{6}$ can be approximated as $\kappa \cdot x_{4}$. Therefore, eliminating $x_{1}$ and $x_{2}$, the system can be represented as follows, a second order system:

$$
\begin{aligned}
& \dot{x}_{3}=c_{9}\left[1+c_{10}\left[\left(\frac{x_{3}}{c_{11}}\right)^{c_{12}}-1\right]\right]\left[q_{c p}-c_{13}\left(x_{3}-x_{4}\right)\right] \\
& \dot{x}_{4}=\left(c_{1}+c_{8}\right)\left(x_{3}-x_{4}\right)-\frac{c_{3}\left(x_{4}-c_{2}\right)}{\kappa x_{4}} f\left(x_{4}\right) \theta-c_{7} I_{s t} \\
& y_{m}=x_{3} \\
& y_{c}=x_{4}
\end{aligned}
$$

where $y_{m}$ is the measurable output. $y_{c}$ is the output need to be controlled. Both the disturbances $q_{c p}$ and $I_{s t}$ are measurable. $\theta$ is the control input. Therefore, the model is reduced to a two order system.

For this reduced model, we need to observe and control $y_{c}$ given that $y_{m}$ can be measured.

The temperature of the air output from the compressor is measurable, i.e.

$$
c_{9}\left[1+c_{10}\left[\left(\frac{x_{3}}{c_{11}}\right)^{c_{12}}-1\right]\right]=\lambda(t)
$$

Assume that $-\frac{c_{3}\left(x_{4}-c_{2}\right)}{\kappa x_{4}} f\left(x_{4}\right) \theta=w\left(x_{3}, x_{4}, \theta, t\right)$ is the disturbance which will be observed. Then, the system can be reformed as follows:

$$
\begin{aligned}
& \dot{x}_{3}=\lambda\left[q_{c p}-c_{13}\left(x_{3}-x_{4}\right)\right] \\
& \dot{x}_{4}=\left(c_{1}+c_{8}\right)\left(x_{3}-x_{4}\right)-c_{7} I_{s t}+w\left(x_{3}, x_{4}, \theta, t\right) \\
& \dot{w}\left(x_{3}, x_{4}, t\right)=h(t)
\end{aligned}
$$


where, $w\left(x_{3}, x_{4}, t\right)$ is the lumped disturbance including the internal uncertainty and external disturbance. Observer is designed as follows

$$
\begin{aligned}
& \dot{\hat{x}}_{3}=\lambda\left[q_{c p}-c_{13}\left(\hat{x}_{3}-\hat{x}_{4}\right)\right]+k_{1}\left(x_{3}-\hat{x}_{3}\right) \\
& \dot{\hat{x}}_{4}=\left(c_{1}+c_{8}\right)\left(\hat{x}_{3}-\hat{x}_{4}\right)-c_{7} I_{s t}+\hat{w}+k_{2}\left(x_{3}-\hat{x}_{3}\right) \\
& \dot{\hat{w}}=k_{3}\left(x_{3}-\hat{x}_{3}\right)
\end{aligned}
$$

$e=x-\hat{x}$. Stability analysis:

$$
\left[\begin{array}{c}
\dot{e}_{3} \\
\dot{e}_{4} \\
\dot{e}_{w}
\end{array}\right]=\left[\begin{array}{ccc}
-c_{13} \lambda-k_{1} & c_{13} \lambda & 0 \\
\left(c_{1}+c_{8}\right)-k_{2} & -\left(c_{1}+c_{8}\right) & 1 \\
-k_{3} & 0 & 0
\end{array}\right]\left[\begin{array}{c}
e_{3} \\
e_{4} \\
e_{w}
\end{array}\right]+\left[\begin{array}{l}
0 \\
0 \\
1
\end{array}\right] h(t)
$$

Assuming that $\left.h(t)\right|_{t \rightarrow \infty}=0$.

Sufficient convergency conditions are

$$
\left\{\begin{array}{l}
k_{1}>-c_{13} \lambda \\
k_{2}>\left(c_{1}+c_{8}\right) \\
k_{3}<0
\end{array}\right.
$$

Estimated mass flow going out of the fuel cell, $\hat{q}_{\text {out }}=f\left(\hat{x}_{4}\right) \theta$, then can be calculated by

$$
\begin{gathered}
\hat{q}_{\text {out }}=-\hat{w} \times \frac{\kappa \hat{x}_{4}}{c_{3}\left(\hat{x}_{4}-c_{2}\right)} \\
{\left[\begin{array}{c}
\dot{\hat{x}}_{1} \\
\dot{\hat{x}}_{2}
\end{array}\right]=\left[\begin{array}{cc}
-c_{1}-\frac{\hat{q}_{\text {out }}}{\lambda_{1}} & -c_{1} \\
-c_{8} & -c_{8}-\frac{\hat{q}_{\text {out }}}{\lambda_{1}}
\end{array}\right]\left[\begin{array}{l}
\hat{x}_{1} \\
\hat{x}_{2}
\end{array}\right]+\left[\begin{array}{c}
c_{1} \\
c_{8}
\end{array}\right] x_{3}+\left[\begin{array}{c}
-c_{7} \\
0
\end{array}\right] I_{s t}}
\end{gathered}
$$

where $\hat{q}_{\text {out }}$ is the estimated outlet mass flow. Denote $e_{q_{\text {out }}}=q_{\text {out }}-\hat{q}_{\text {out }}$. Then the estimation error is

$$
\left[\begin{array}{c}
\dot{e}_{1} \\
\dot{e}_{2}
\end{array}\right]=\left[\begin{array}{cc}
-c_{1}-\frac{q_{\text {out }}}{\lambda_{1}} & -c_{1} \\
-c_{8} & -c_{8}-\frac{q_{\text {out }}}{\lambda_{1}}
\end{array}\right]\left[\begin{array}{c}
e_{1} \\
e_{2}
\end{array}\right]+\left[\begin{array}{cc}
\frac{e_{q_{\text {out }}}}{\lambda_{1}} & 0 \\
0 & \frac{e_{q_{o} \text { ut }}}{\lambda_{1}}
\end{array}\right]\left[\begin{array}{l}
\hat{x}_{1} \\
\hat{x}_{2}
\end{array}\right]
$$

The matrix $Q=\left[\begin{array}{cc}-c_{1}-\frac{q_{\text {out }}}{\lambda_{1}} & -c_{1} \\ -c_{8} & -c_{8}-\frac{q_{\text {out }}}{\lambda_{1}}\end{array}\right]$ is Hurwitz matrix. In the previous section, it is proved that $\lim _{t \rightarrow \infty} e_{q_{\text {out }}}=0, \hat{x}_{1} \doteq x_{1}, \hat{x}_{2} \doteq x_{2}$. Therefore, $\lim _{t \rightarrow \infty} e(t)=0$. 
Following the current variations shown in Figure 93, the supplied mass flow is shown in Figure 94. With the parameters $k 1=10.0, k 2=5000.0, k 3=-10.0$, the simulation results of the partial pressure observation are shown in Figure 95, Figure 96, Figure 97(a), Figure 97(b), which are the cathode pressure, supply manifold pressure, oxygen partial pressure, nitrogen partial pressure respectively. Further research will work on the experimental validation of the proposed observer.

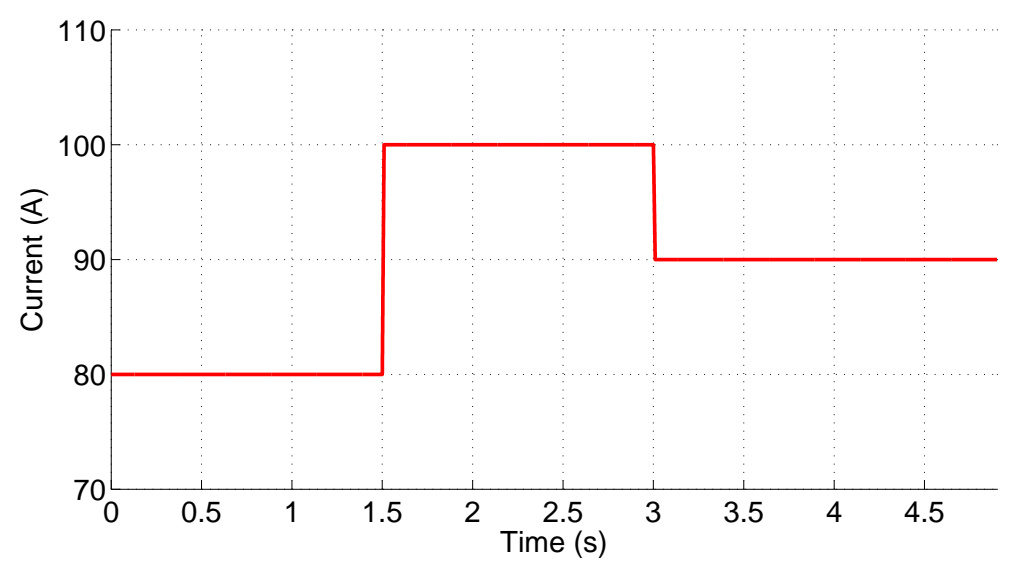

Fig. 93. Fuel cell current variations.

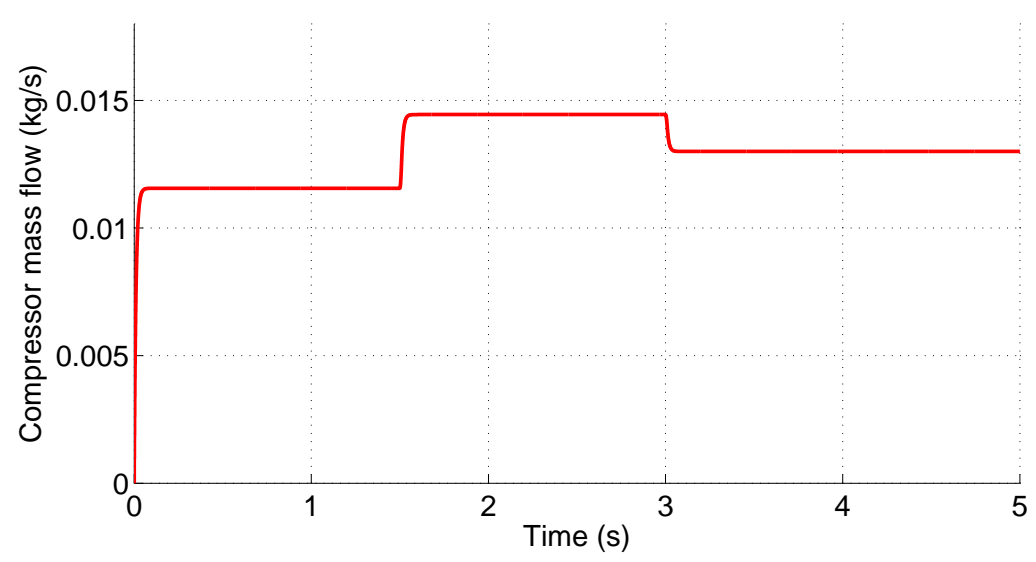

Fig. 94. Compressor mass flow variations. 


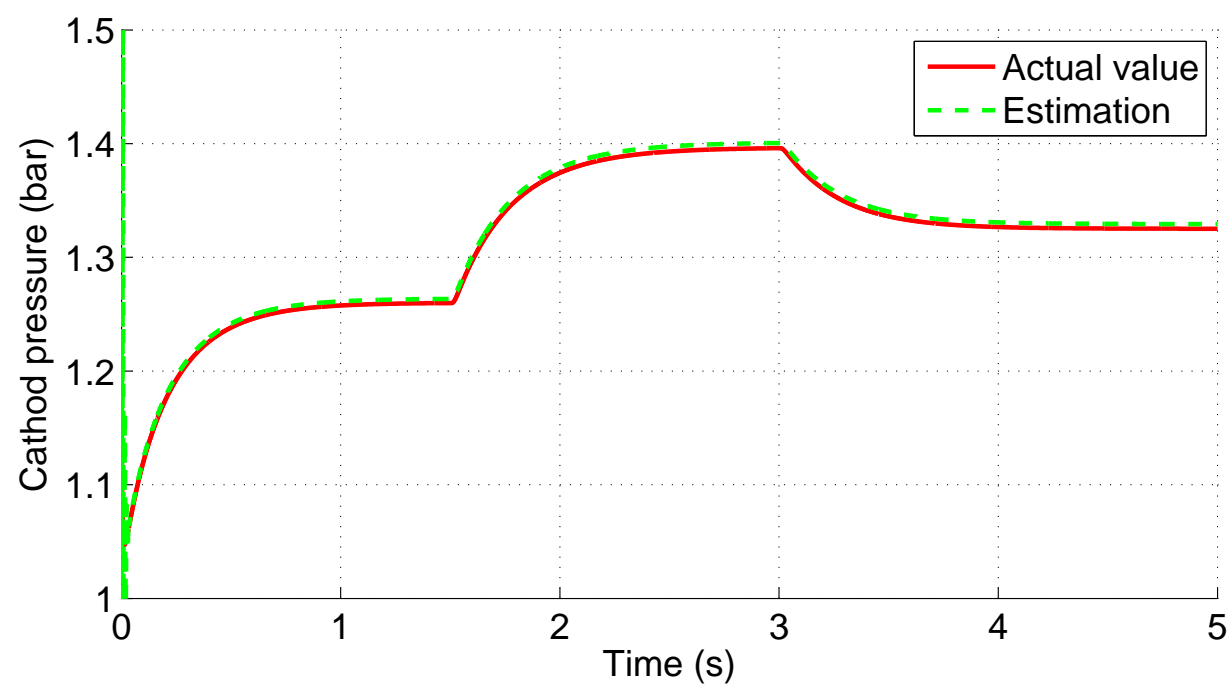

(a)

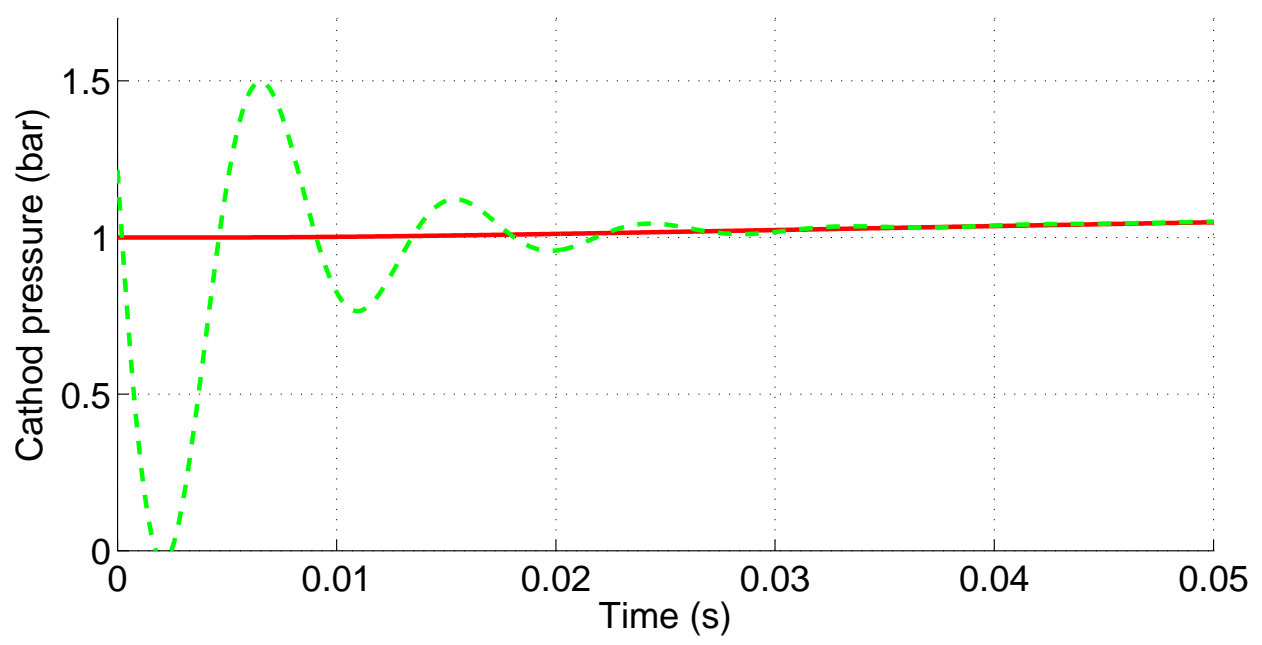

(b)

Fig. 95. (a) Cathode pressure estimation, (b) Zoom of the startup. 


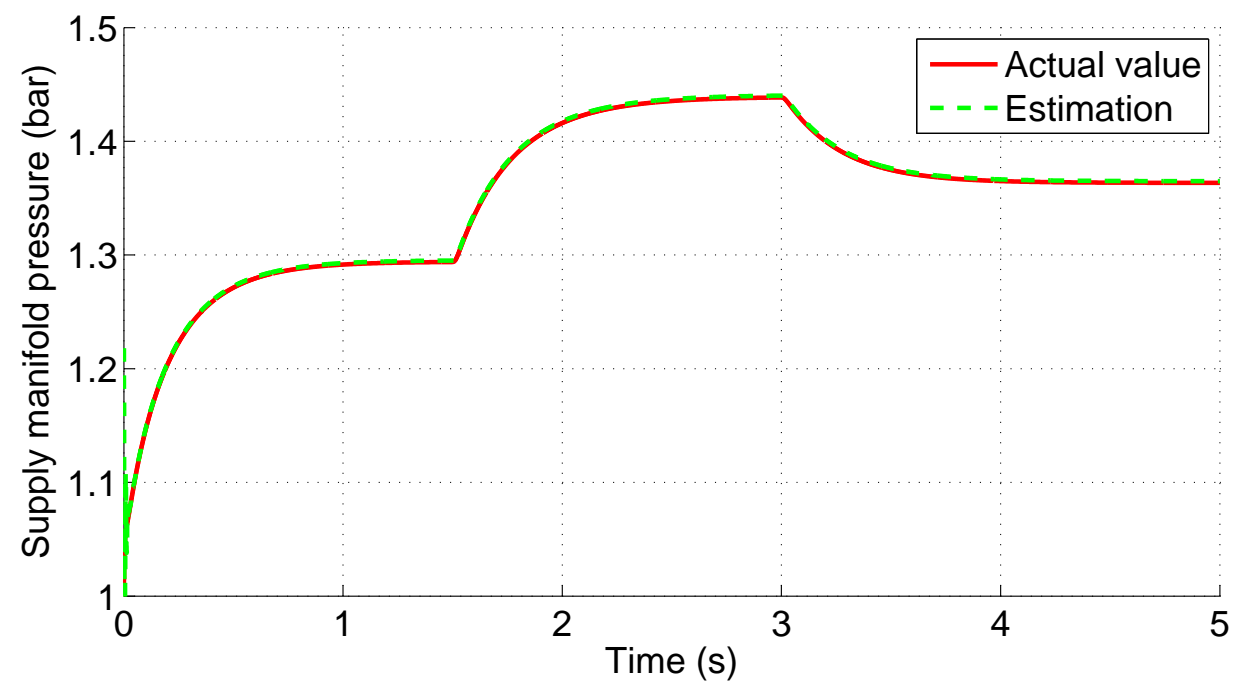

(a)

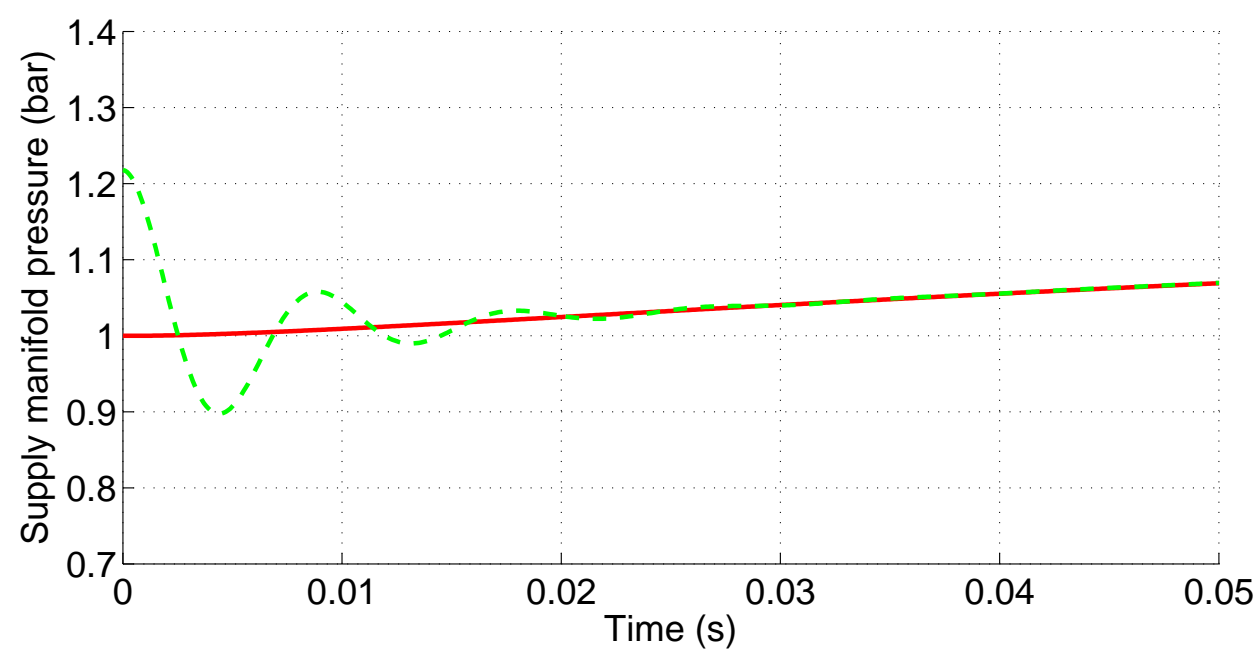

(b)

Fig. 96. (a) Supply manifold pressure estimation, (b) Zoom of the startup. 


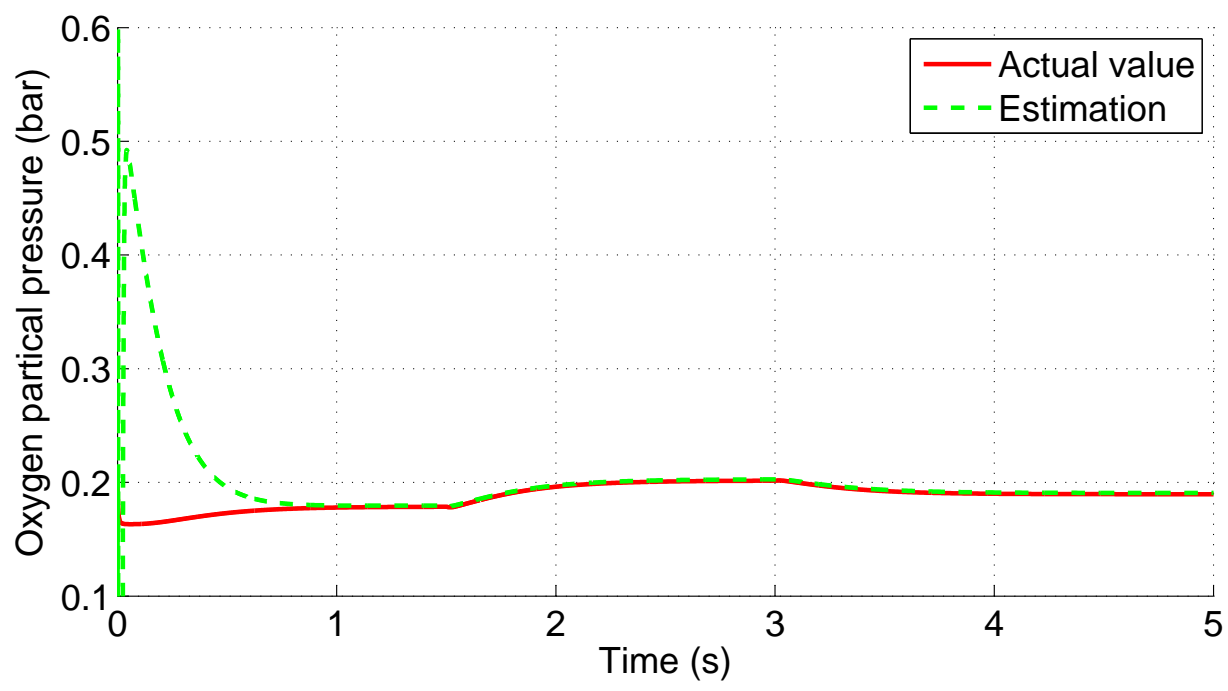

(a)

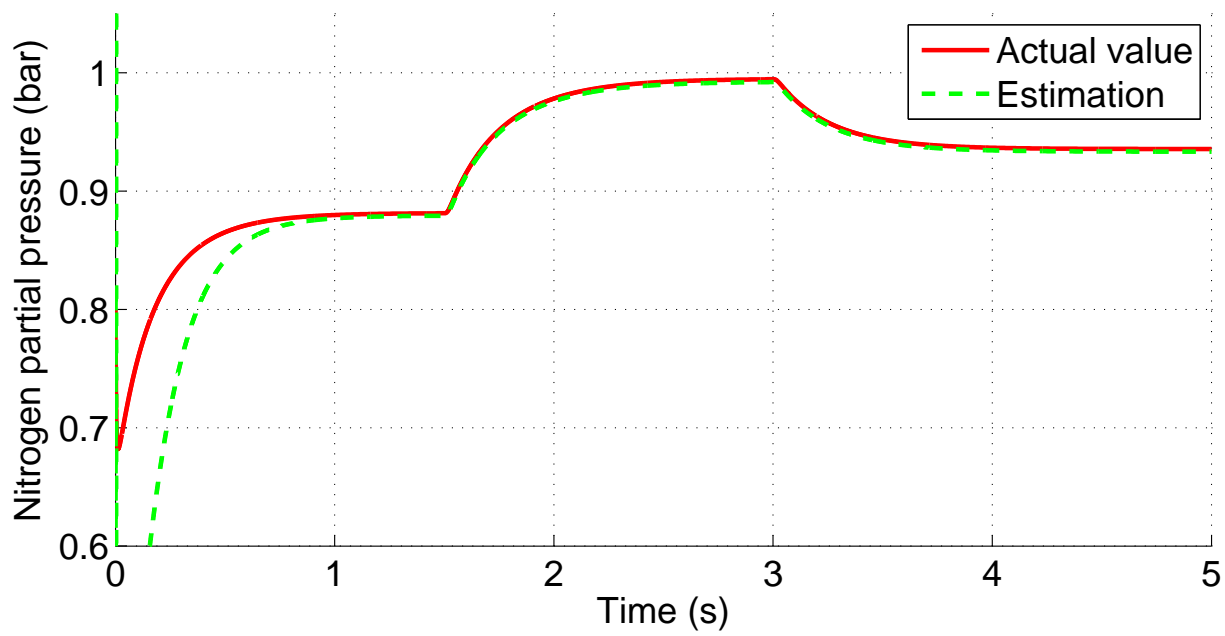

(b)

Fig. 97. (a) Oxygen partial pressure estimation, (b) Nitrogen partial pressure estimation. 


\section{BIBLIOGRAPHY}

[1] Yun Wang, Ken S. Chen, Jeffrey Mishler, Sung Chan Cho, and Xavier Cordobes Adroher. A review of polymer electrolyte membrane fuel cells: Technology, applications, and needs on fundamental research. Applied Energy, 88(4):9811007, 2011.

[2] a. Kirubakaran, Shailendra Jain, and R.K. Nema. A review on fuel cell technologies and power electronic interface. Renewable and Sustainable Energy Reviews, 13(9):2430-2440, 2009.

[3] Jay Pukrushpan, Anna Stefanopoulou, Subbarao Varigonda, Jonas Eborn, and Christoph Haugstetter. Control-oriented model of fuel processor for hydrogen generation in fuel cell applications. Control engineering practice, 14(3):277293, 2006.

[4] Alan S Feitelberg and Donald F Rohr. Operating line analysis of fuel processors for pem fuel cell systems. International journal of hydrogen energy, 30(11):1251-1257, 2005.

[5] Anca Faur Ghenciu. Review of fuel processing catalysts for hydrogen production in pem fuel cell systems. Current opinion in solid state and materials science, 6(5):389-399, 2002.

[6] P Sridhar, Ramkumar Perumal, N Rajalakshmi, M Raja, and KS Dhathathreyan. Humidification studies on polymer electrolyte membrane fuel cell. Journal of Power Sources, 101(1):72-78, 2001.

[7] KH Choi, DJ Park, YW Rho, YT Kho, and TH Lee. A study of the internal humidification of an integrated pemfc stack. Journal of power sources, 74(1):146$150,1998$. 
[8] K Ramya, J Sreenivas, and KS Dhathathreyan. Study of a porous membrane humidification method in polymer electrolyte fuel cells. International Journal of Hydrogen Energy, 36(22):14866-14872, 2011.

[9] Duksu Hyun and Junbom Kim. Study of external humidification method in proton exchange membrane fuel cell. Journal of Power Sources, 126(1):98103, 2004.

[10] Guangsheng Zhang and Satish G Kandlikar. A critical review of cooling techniques in proton exchange membrane fuel cell stacks. International Journal of Hydrogen Energy, 37(3):2412-2429, 2012.

[11] Xiangjun Li, Liangfei Xu, Jianfeng Hua, Xinfan Lin, Jianqiu Li, and Minggao Ouyang. Power management strategy for vehicular-applied hybrid fuel cell/battery power system. Journal of Power Sources, 191(2):542-549, 2009.

[12] Min-Joong Kim and Huei Peng. Power management and design optimization of fuel cell/battery hybrid vehicles. Journal of Power Sources, 165(2):819-832, 2007.

[13] Ke Jin, Xinbo Ruan, Mengxiong Yang, and Min Xu. A hybrid fuel cell power system. Industrial Electronics, IEEE Transactions on, 56(4):1212-1222, 2009.

[14] Kwi-Seong Jeong, Won-Yong Lee, and Chang-Soo Kim. Energy management strategies of a fuel cell/battery hybrid system using fuzzy logics. Journal of Power Sources, 145(2):319-326, 2005.

[15] Ali Emadi, Kaushik Rajashekara, Sheldon S Williamson, and Srdjan M Lukic. Topological overview of hybrid electric and fuel cell vehicular power system architectures and configurations. Vehicular Technology, IEEE Transactions on, 54(3):763-770, 2005.

[16] B. Blunier and A. Miraoui. Proton exchange membrane fuel cell air management in automotive applications. Journal of Fuel Cell Science and Technology, 7(041007), 2010.

[17] www.grc.nasa.gov. 
[18] Jan van Helvoirt. Centrifugal compressor surge, modeling and identification for control. PhD dissertation, Technische Universiteit Eindhoven, 2007.

[19] Zoltán Sándor Spakovszky. Applications of axial and radial compressor dynamic system modeling. PhD thesis, Massachusetts Institute of Technology, 2000 .

[20] Wei Jiang, Jamil Khan, and Roger A Dougal. Dynamic centrifugal compressor model for system simulation. Journal of power sources, 158(2):1333-1343, 2006.

[21] J Galindo, JR Serrano, H Climent, and A Tiseira. Experiments and modelling of surge in small centrifugal compressor for automotive engines. Experimental Thermal and Fluid Science, 32(3):818-826, 2008.

[22] Jean-Marie Mérigoux. Ventilateurs. compresseurs notions fondamentales. dimensionnement. Techniques de l’ingénieur. Génie mécanique, 1999.

[23] Konstantin Boynov. Efficiency and time-optimal control of fuel cellcompressor-electrical drive systems. PhD dissertation, Technische Universiteit Eindhoven, 2008.

[24] http://airsquared.com.

[25] B. Blunier, M. Pucci, G. Cirrincione, M. Cirrincione, and A. Miraoui. A scroll compressor with a high-performance sensorless induction motor drive for the air management of a PEMFC system for automotive applications. IEEE Trans. Vehicular Technology, 57(6):3413-3427, 2008.

[26] Jeremie M'Boua, Benjamin Blunier, Abdellatif Miraoui, and Marcelo Simoes Godoy. Modeling and control of a high speed three-lobe compressor for fuel cell system. 2010.

[27] R.J. Talj, D. Hissel, R. Ortega, M. Becherif, and M. Hilairet. Experimental validation of a PEM fuel-cell reduced-order model and a moto-compressor higher order sliding-mode control. IEEE Trans.Industrial Electronics, 57(6):19061913, 2010. 
[28] Mestan Tekin, Daniel Hissel, Marie-Cécile Pera, and Jean-Marie Kauffmann. Energy consumption reduction of a PEM fuel cell motor-compressor group thanks to efficient control laws. Journal of Power Sources, 156(1):57-63, 2006.

[29] Rajesh K Ahluwalia and Xiaohua Wang. Fuel cell systems for transportation: Status and trends. Journal of power sources, 177(1):167-176, 2008.

[30] www.miti.cc.

[31] D. Krähenbühl, C. Zwyssig, H. Weser, and J.W. Kolar. A miniature 500 000r/min electrically driven turbocompressor. IEEE Trans.Industry Applications, 46(6):2459-2466, 2010.

[32] J.T. Pukrushpan, A.G. Stefanopoulou, and H. Peng. Control of fuel cell breathing. IEEE Control Systems Magazine, 24(2):30-46, 2004.

[33] Yuehong Zhao and Efstratios Pistikopoulos. Dynamic modelling and parametric control for the polymer electrolyte membrane fuel cell system. Journal of Power Sources, 232:270-278, 2013.

[34] Michael A Danzer, Jörg Wilhelm, Harald Aschemann, and Eberhard P Hofer. Model-based control of cathode pressure and oxygen excess ratio of a pem fuel cell system. Journal of Power Sources, 176(2):515-522, 2008.

[35] Michael A Danzer, Simon J Wittmann, and Eberhard P Hofer. Prevention of fuel cell starvation by model predictive control of pressure, excess ratio, and current. Journal of Power Sources, 190(1):86-91, 2009.

[36] J.K. Gruber, C. Bordons, and A. Oliva. Nonlinear MPC for the airflow in a PEM fuel cell using a volterra series model. Control Engineering Practice, 20(2):205 $-217,2012$.

[37] JK Gruber, M Doll, and C Bordons. Design and experimental validation of a constrained mpc for the air feed of a fuel cell. Control Engineering Practice, 17(8):874-885, 2009.

[38] JK Gruber, C Bordons, and A Oliva. Nonlinear mpc for the airflow in a pem fuel cell using a volterra series model. Control Engineering Practice, 20(2):205$217,2012$. 
[39] Alicia Arce, Alejandro J del Real, Carlos Bordons, and Daniel R Ramírez. Realtime implementation of a constrained mpc for efficient airflow control in a pem fuel cell. IEEE Transactions on Industrial Electronics, 57(6):1892-1905, 2010.

[40] Winston Garcia-Gabin, Fernando Dorado, and Carlos Bordons. Real-time implementation of a sliding mode controller for air supply on a pem fuel cell. Journal of process control, 20(3):325-336, 2010.

[41] C. Kunusch, P.F. Puleston, M.A. Mayosky, and J. Riera. Sliding mode strategy for PEM fuel cells stacks breathing control using a super-twisting algorithm. IEEE Trans.Control Systems Technology, 17(1):167-174, 2009.

[42] Imad Matraji, Salah Laghrouche, and Maxime Wack. Pressure control in a PEM fuel cell via second order sliding mode. International Journal of Hydrogen Energy, 37(21):16104-16116, November 2012.

[43] Imad Matraji, Salah Laghrouche, Samir Jemei, and Maxime Wack. Robust control of the PEM fuel cell air-feed system via sub-optimal second order sliding mode. Applied Energy, 104:945-957, April 2013.

[44] Jérémie M'Boua. Contribution à la modélisation et au contrôle de compresseurs. Application à la gestion de l'air dans les systèmes piles à combustible de type PEM. PhD thesis, Université de Technologie de Belfort-Montbeliard, 2010.

[45] Cheng Bao, Minggao Ouyang, and Baolian Yi. Modeling and control of air stream and hydrogen flow with recirculation in a pem fuel cell systemłii. linear and adaptive nonlinear control. International journal of hydrogen energy, 31(13):1897-1913, 2006.

[46] Reine Talj, Romeo Ortega, and Alessandro Astolfi. Passivity and robust pi control of the air supply system of a pem fuel cell model. Automatica, 47(12):2554$2561,2011$.

[47] A. Vahidi, I. Kolmanovsky, and A. Stefanopoulou. Constraint management in fuel cells: A fast reference governor approach. In Proceedings of American Control Conference, pages 3865-3870, 2005. 
[48] A. Vahidi, I. Kolmanovsky, and A. Stefanopoulou. Constraint handling in a fuel cell system: A fast reference governor approach. IEEE Trans. Control Systems Technology, 15(1):86-98, 2007.

[49] D. Zhao, M. Dou, B. Blunier, and A. Miraoui. Control of an ultra high speed centrifugal compressor for the air management of fuel cell systems. In Proc.IEEE Industry Applications Society Annual Meeting (IAS), pages 1-8, 2012.

[50] D. Zhao, F Gao, D Bouquain, M. Dou, and A. Miraoui. Sliding mode control of an ultra high speed centrifugal compressor for the air management of fuel cell systems for automotive applications. In IEEE Trans.Vehicular Technology (in press), pages 1-8, 2013.

[51] A. Vahidi, A. Stefanopoulou, and Huei Peng. Current management in a hybrid fuel cell power system: A model-predictive control approach. IEEE Trans. Control Systems Technology, 14(6):1047-1057, 2006.

[52] J. Sun and I.V. Kolmanovsky. Load governor for fuel cell oxygen starvation protection: A robust nonlinear reference governor approach. IEEE Transactions Control Systems Technology, 13(6):911-920, 2005.

[53] J. Han. Nonlinear design methods for control systems. In Proc. of the 14th IFAC World Congress, pages 521-526, 1999.

[54] Z. Gao. Scaling and bandwidth-parameterization based controller tuning. In Proc.American Control Conference, volume 6, pages 4989-4996, 2006.

[55] Z. Gao. Active disturbance rejection control: a paradigm shift in feedback control system design. In Proc.American Control Conference, pages 7-pp, 2006.

[56] L. Dong, Y. Zhang, and Z. Gao. A robust decentralized load frequency controller for interconnected power systems. ISA transactions (2012), 2012.

[57] F.J. Goforth, Q. Zheng, and Z. Gao. A novel practical control approach for rate independent hysteretic systems. ISA transactions (2012), 2012.

[58] J. Vincent, D. Morris, N. Usher, Z. Gao, S. Zhao, A. Nicoletti, and Q. Zheng. On active disturbance rejection based control design for superconducting rf cavities. 
Nuclear Instruments and Methods in Physics Research Section A: Accelerators, Spectrometers, Detectors and Associated Equipment, 643(1):11-16, 2011.

[59] Q. Zheng, Z. Chen, and Z. Gao. A practical approach to disturbance decoupling control. Control Engineering Practice, 17(9):1016-1025, 2009.

[60] Q. Zheng, L. Dong, DH. Lee, and Z. Gao. Active disturbance rejection control for MEMS gyroscopes. IEEE Transactions on Control Systems Technology, 17(6):1432-1438, 2009.

[61] M.G. Nored, K. Brun, and R. Kurz. Development of a guideline for the design of surge control systems. ASME Turbo Expo, Berlin, June, pages 9-13, 2008.

[62] J.T. Gravdahl and O. Egeland. Compressor surge control using a close-coupled valve and backstepping. In Proceedings of American Control Conference, volume 2, pages 982-986, 1997.

[63] MV Casey and CJ Robinson. A guide to turbocharger compressor characteristics. In Dieselmotorentechnik, 10th Symposium (Ed. M. Bargende), pages 3031, 2006.

[64] MV Casey and Robinson. A new streamline curvature throughflow method for radial turbomachinery. Journal of Turbomachinery, 132:031021, 2010.

[65] M. V. Casey and C. J. Robinson. A method to estimate the performance map of a centrifugal compressor stage. In Proc. of the ASME Turbo Expo 2011, Vancouver, Canada.

[66] J. Luomi, C. Zwyssig, A. Looser, and J.W. Kolar. Efficiency optimization of a 100-w 500 000-r/min permanent-magnet machine including air-friction losses. IEEE Transactions on Industry Applications, 45(4):1368-1377, 2009.

[67] Jan Tommy Gravdahl, A Egeland, and Svein Ove Vatland. Active surge control of centrifugal compressors using drive torque. In Decision and Control, 2001. Proceedings of the 40th IEEE Conference on, volume 2, pages 12861291. IEEE, 2001. 
[68] Joachim Kurzke and Claus Riegler. A new compressor map scaling procedure for preliminary conceptional design of gas turbines. ASME TURBO EXPO 2000, Munich, Germany, 2000.

[69] J.T. Pukrushpan. Modeling and control of fuel cell systems and fuel processors. PhD dissertation, The University of Michigan, 2003.

[70] R Tirnovan, S Giurgea, A Miraoui, and M Cirrincione. Surrogate modelling of compressor characteristics for fuel-cell applications. Applied Energy, 85(5):394-403, 2008.

[71] Youhong Yu, Lingen Chen, Fengrui Sun, and Chih Wu. Neural-network based analysis and prediction of a compressors characteristic performance map. Applied energy, 84(1):48-55, 2007.

[72] Andrea Lazzaretto and Andrea Toffolo. Analytical and neural network models for gas turbine design and off-design simulation. International Journal of Thermodynamics, 4(4):173-182, 2010.

[73] M Gholamrezaei and K Ghorbanian. Compressor map generation using a feedforward neural network and rig data. Proceedings of the Institution of Mechanical Engineers, Part A: Journal of Power and Energy, 224(1):97-108, 2010.

[74] HIH Saravanamuttoo and BD Maclsaac. Thermodynamic models for pipeline gas turbine diagnostics. Journal of engineering for power, 105(4):875-884, 1983.

[75] M. Grujicic, KM Chittajallu, EH Law, and JT Pukrushpan. Model-based control strategies in the dynamic interaction of air supply and fuel cell. Proceedings of the Institution of Mechanical Engineers, Part A: Journal of Power and Energy, 218(7):487-499, 2004.

[76] Lukas Schwager, Arda Tuysuz, Christof Zwyssig, and Johann W Kolar. Modeling and comparison of machine and converter losses for PWM and PAM in high-speed drives. In IEEE International Conference on Electrical Machines (ICEM), pages 2441-2447, 2012. 
[77] C. Zwyssig, M. Duerr, D. Hassler, and JW Kolar. An ultra-high-speed, 500000 rpm, $1 \mathrm{kw}$ electrical drive system. In Power Conversion Conference-Nagoya, 2007, pages 1577-1583. IEEE.

[78] C. Zwyssig, S.D. Round, and J.W. Kolar. An ultrahigh-speed, low power electrical drive system. IEEE Transactions on Industrial Electronics, 55(2):577-585, 2008 .

[79] D Krähenbühl, C Zwyssig, and J.W. Kolar. Half-controlled boost rectifier for low-power high-speed permanent-magnet generators. IEEE Transactions on Industrial Electronics, 58 , Issue: 11:5066- 5075, 2011.

[80] F. Gao, B. Blunier, A. Miraoui, and A. El-Moudni. Cell layer level generalized dynamic modeling of a pemfc stack using vhdl-ams language. International Journal of Hydrogen Energy, 34(13):5498-5521, 2009.

[81] F. Gao, D. Chrenko, B. Blunier, D. Bouquain, and A. Miraoui. Multi-rates fuel cell emulation with spatial reduced real-time fuel cell modelling. In IEEE Transactions on Industry Applications, pages 1-8. IEEE, 2012.

[82] T.V. Nguyen and R.E. White. A water and heat management model for proton-exchange-membrane fuel cells. Journal of the Electrochemical Society, 140(8):2178-2186, 1993.

[83] Polynomial Control Systems practical solutions for multivariable control. Wolfram Research, 2006.

[84] Yi Tang and Runhua Wang. Decoupling control for nonlinear coupling systems based on cmac and pid. In 8th IEEE International Conference on Cognitive Informatics, 2009., pages 302-305, 2009.

[85] D. Zhao, F Gao, D Bouquain, M. Dou, and A. Miraoui. Sliding mode control of an ultrahigh-speed centrifugal compressor for the air management of fuel cell systems for automotive applications. IEEE transactions on vehicular technology, 99:1-11, 2013.

[86] Jingqing Han. From pid to active disturbance rejection control. IEEE transactions on Industrial Electronics, 56(3):900-906, 2009. 
[87] Dong Sun. Comments on active disturbance rejection control. IEEE Transactions on Industrial Electronics, 54(6):3428-3429, 2007.

[88] L. Fridman and A. Levant. Higher order sliding modes. Sliding mode control in engineering, 11:53-102, 2002.

[89] I. Matraji, S. Laghrouche, and M. Wack. Cascade control of the motocompressor of a PEM fuel cell via second order sliding mode. In Proc. Decision and Control and European Control Conf., pages 633-638, 2011.

[90] A. Levent. Robust exact differentiation via sliding mode technique. Automatica, 34(3):379-384, 1998.

[91] F. Gao, B. Blunier, A. Miraoui, and A. El-Moudni. Proton exchange membrane fuel cell multi-physical dynamics and stack spatial non-homogeneity analyses. Journal of Power Sources, 195(22):7609-7626, 2010.

[92] F. Gao, B. Blunier, M.G. Simoes, and A. Miraoui. Pem fuel cell stack modeling for real-time emulation in hardware-in-the-loop applications. Energy Conversion, IEEE Transactions on, (99):1-11, 2011.

[93] Y.A. Chang and S.J. Moura. Air flow control in fuel cell systems: An extremum seeking approach. In American Control Conference, 2009. ACC'09., pages 1052-1059. IEEE, 2009.

[94] A. Arce, DR Ramirez, AJ del Real, and C. Bordons. Constrained explicit predictive control strategies for pem fuel cell systems. In Decision and Control, 2007 46th IEEE Conference on, pages 6088-6093. IEEE, 2007.

[95] A. Vahidi, A. Stefanopoulou, and Huei Peng. Model predictive control for starvation prevention in a hybrid fuel cell system. In Proc. American Control Conf the 2004, volume 1, pages 834-839.

[96] AH Epstein, JE Ffowcs Williams, and EM Greitzer. Active suppression of aerodynamic instabilities in turbomachines. Journal of Propulsion and Power, 5(2):204-211, 1989. 
[97] JE Pinsley, GR Guenette, AH Epstein, and EM Greitzer. Active stabilization of centrifugal compressor surge. Journal of turbomachinery, 113(4):723-732, 1991.

[98] JD Paduano, AH Epstein, L Valavani, JP Longley, E Greitzer, and GR Guenette. Active control of rotating stall in a low-speed axial compressor. Journal of Turbomachinery;(United States), 115(1), 1993.

[99] Harald Jürgen Weigl, JD Paduano, LG Frechette, AH Epstein, EM Greitzer, MM Bright, and AJ Strazisar. Active stabilization of rotating stall and surge in a transonic single stage axial compressor. $\mathrm{PhD}$ thesis, Massachusetts Institute of Technology, Dept. of Aeronautics and Astronautics, 1997.

[100] Edward M Greitzer. Surge and rotating stall in axial flow compressorsłpart i: Theoretical compression system model. Journal of Engineering for Power, 98:190, 1976. 